CELIO FONTÃO CARRIL JÚNIOR

\title{
ANÁLISE NUMÉRICA E EXPERIMENTAL DO EFEITO DINÂMICO DO VENTO EM TORRES METÁLICAS TRELIÇADAS PARA TELECOMUNICAÇÕES
}

Tese apresentada à Escola

Politécnica da Universidade de São Paulo para obtenção do título de Doutor em Engenharia Civil 


\section{CELIO FONTÃO CARRIL JÚNIOR}

\section{ANÁLISE NUMÉRICA E EXPERIMENTAL DO EFEITO DINÂMICO DO VENTO EM TORRES METÁLICAS TRELIÇADAS PARA TELECOMUNICAÇÕES}

Tese apresentada à Escola Politécnica da Universidade de São Paulo para obtenção do título de Doutor em Engenharia Civil

Área de Concentração: Engenharia de Estruturas e Fundações

Orientador:

Reyolando M. L. R. da Fonseca Brasil 


\section{Carril Jr, Célio Fontão}

Análise numérica e experimental do efeito dinâmico do vento em torres metálicas treliçadas para telecomunicações. São Paulo, 2000.

$143 \mathrm{p}$.

Tese (Doutorado) - Escola Politécnica da Universidade de São Paulo. Departamento de Engenharia de Estruturas e Fundações.

1. Engenharia do vento. 2. Estruturas metálicas. 3. Torres para telecomunicações. I. Universidade de São Paulo. Escola Politécnica. Departamento de Engenharia de Estruturas e Fundações. II. $\mathrm{t}$ 


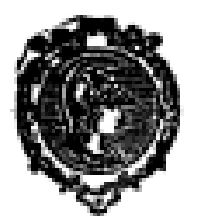

\title{
UNIVERSIDADE DE SÃO PAULO ESCOLA POLITÉCNICA
}

\author{
TERMO DE JULGAMENTO \\ DE
}

DEFESA DE TESE DE DOUTORAMENTO

Aos 21 dias do mês de agosto de 2000, às 09:00 horas, no Edifício Paula Souza da Escola Politécnica da Universidade de São Paulo, presente a Comissão Julgadora, integrada pelos Senhores Professores Doutores Reyolando Manoel Lopes R. da Fonseca Brasil, orientador do candidato, Mário Franco, Acir Mercio Loredo Souza, Jorge Daniel Riera e João Luís Pascal Roehl iniciou-se a Defesa de Tese de Doutoramento do Senhor CELIO FONTÃO CARRIL JÚNIOR.

Título da Tese: "ANÁLISE NUMÉRICA E EXPERIMENTAL DO EFEITO DINÂMICO DO VENTO EM TORRES METÁLICAS TRELIÇADAS PARA TELECOMUNICAÇÕES".

Concluída a argüição, procedeu-se ao julgamento na forma regulamentar, tendo a Comissão Julgadora considerado o candidato:

Prof. Dr. Reyolando Manoel Lopes.R. da F. Brasil......( a puova do-)

Prof. Dr. Mário Franco. (aptiones )

Prof. Dr. Acir Mercio Loredo Souza. (aprovado )

Prof.Dr. Jorge Daniel Riera.

Prof.Dr. João Luís Pascal Roehl. (Gporad )

Para constar, é lavrado o presente termo, que var assinado pela Comissão Julgadora e pela Secretária da Seção de Pós-Graduação.

A Comissão Julgadora:

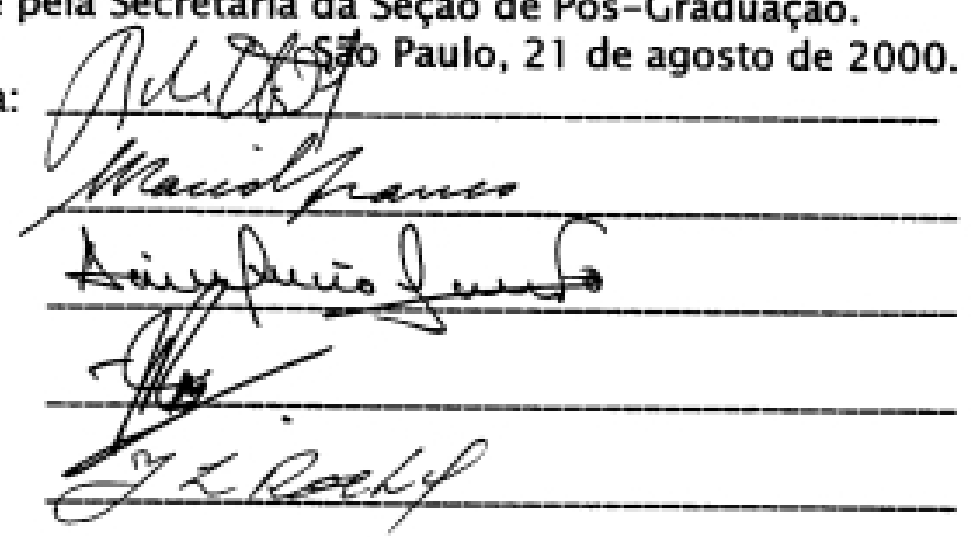

Secretária: Elisabete Ap ${ }^{a}$ F.S.Ramos

Obs: Resolução 4476, de 17-9-1997 Altera dispositivos do Regimento Geral da USP Art.109 - Imediatamente após o encerramento da argūição da dissertação ou da tese cada examinador expressará seu julgamento em sessão secreta, considerando o candidato aprovado ou reprovado.

Homologado pela C.P.G. em reunião realizada a 
A todos os meus familiares pelo amor e compreensão durante minha ausência, em especial a meu pai Dr. Célio Fontão Carril que me incentivou a seguir seus passos na jornada acadêmica. 


\section{AGRADECIMENTOS}

Ao Prof. Dr. Reyolando M. L. R. F. Brasil pela orientação e incentivo constantes durante a realização desse trabalho;

Ao Prof. Dr. Nicholas Isyumov pela orientação durante o estágio no Boundary Layer Wind Tunnel Laboratory da University of Western Ontario, London, Ontario, Canadá;

À Fundação Coordenação de Aperfeiçoamento de Pessoal de Nível Superior CAPES que tornou possível este trabalho com o auxilio dado durante o estágio no exterior;

A todos os amigos do LEM que direta ou indiretamente contribuíram para elaboração deste trabalho;

Aos colegas do Departamento de Engenharia de Estruturas e Fundações pelo incentivo para a conclusão desta tese;

Aos amigos e técnicos do BLWTL pelo apoio dado para a realização da parte experimental da pesquisa, em especial pela dedicação do Sr. Stan Norman que auxiliou nos experimentos durante algumas madrugadas;

Aos amigos do "Machine Shop" da "University of Western Ontario" pela dedicação e precisão na construção dos modelos utilizados; 
Lista de Figuras

Lista de Tabelas

Lista de abreviaturas ou siglas

Lista de Símbolos

Resumo

"Abstract”

1 INTRODUÇÃ

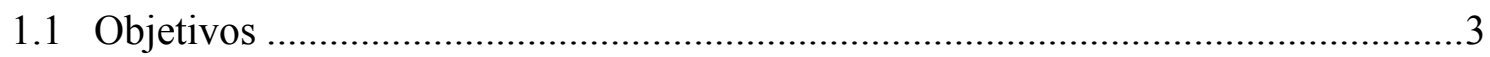

2 EFEITO DO VENTO EM TORRES TRELIÇADAS .........................................4

2.1 Ações principais em torres de telecomunicações ..................................................4

2.2 Torres metálicas treliçadas existentes no Brasil..................................................

2.3 Uma revisão sobre os efeitos do vento em estruturas reticuladas ............................

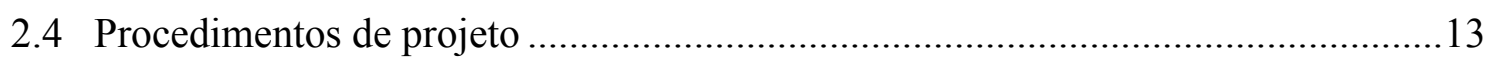

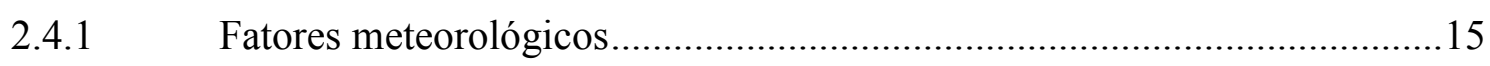

2.4.2 Determinação dos coeficientes de arrasto de torres treliçadas .....................16

2.4.3 Torres simétricas com estruturas adicionais ............................................21

3 MÉTODOS ANALÍTICOS E NUMÉRICOS ...................................................23

3.1 Fundamentos para o cálculo de estruturas esbeltas submetidas ao efeito

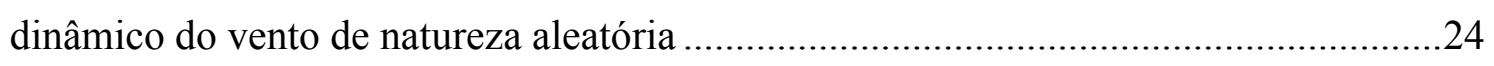

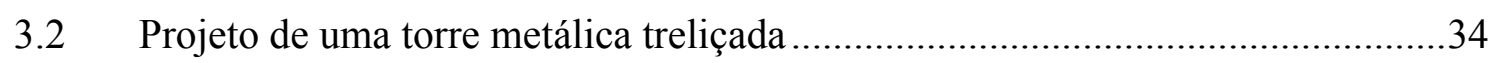

3.3 Modelo de Davenport para torres de telecomunicações......................................36

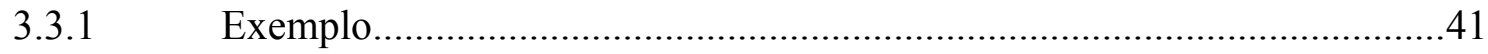

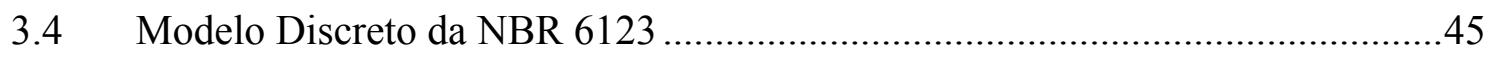

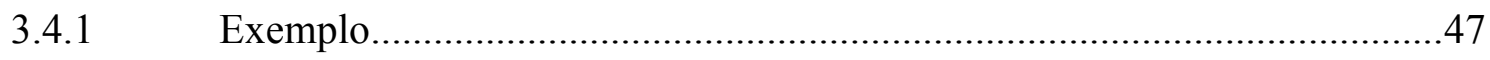

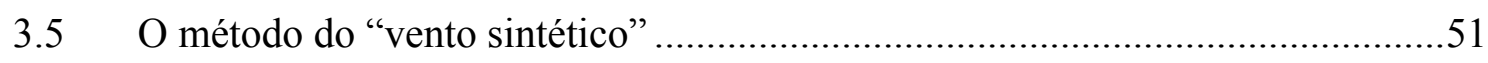

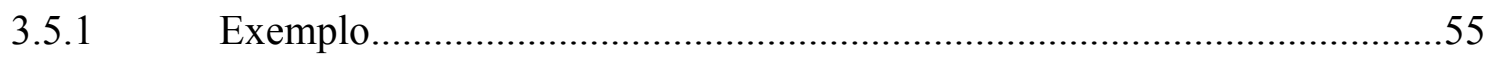




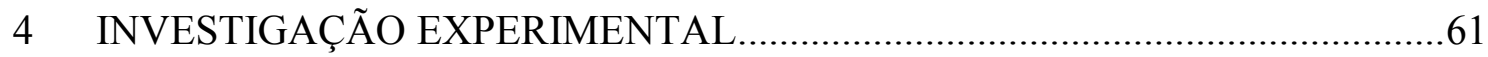

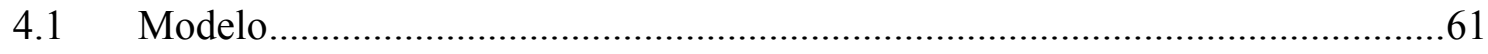

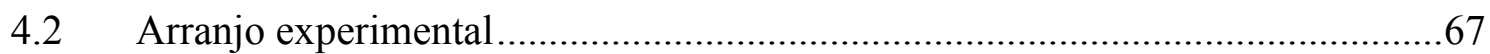

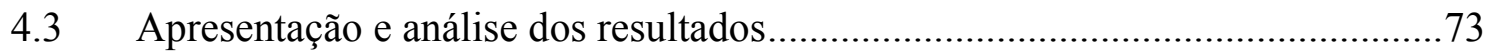

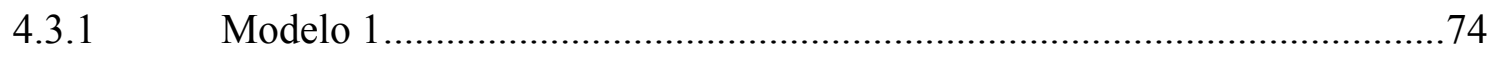

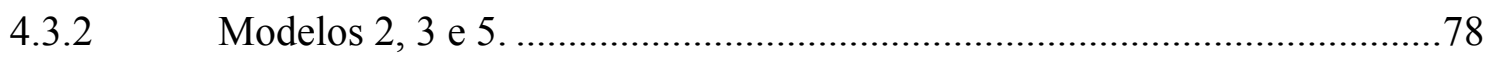

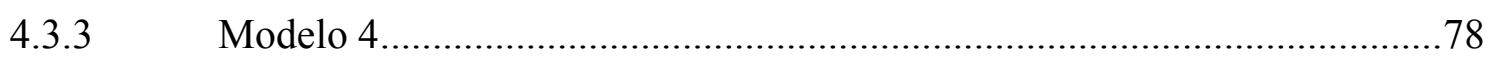

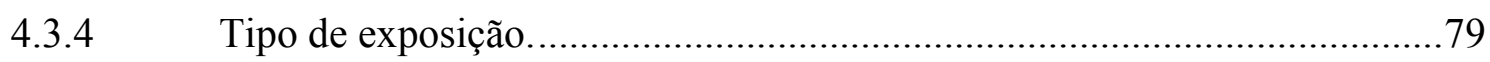

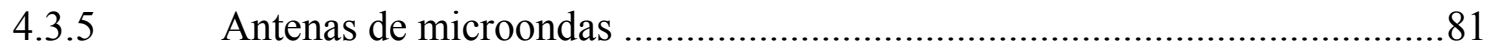

5 RESULTADOS EXPERIMENTAIS: COMPARAÇÕES E COMENTÁRIOS .....93

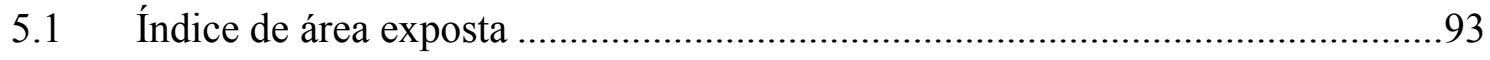

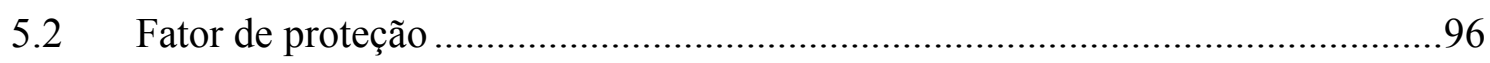

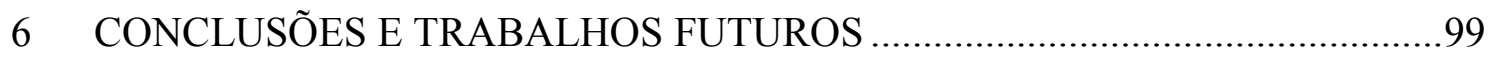

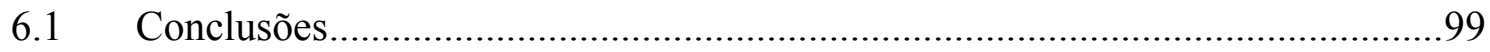

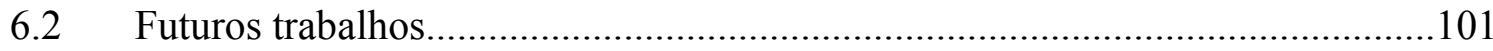

ANEXO A - DADOS SOBRE A CONSTRUÇÃO DE TORRES METÁLICAS PARA

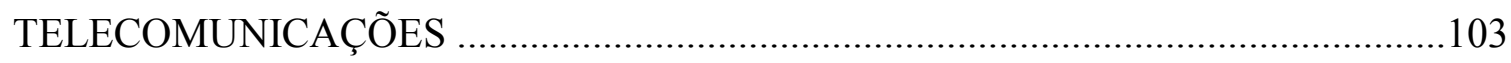

ANEXO B - TABELAS DE DIMENSIONAMENTO DOS PERFIS DA

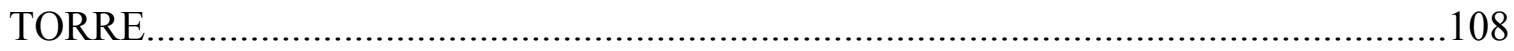

ANEXO C - RESPOSTA DINÂMICA DA TORRE AO LONGO DO VENTO,

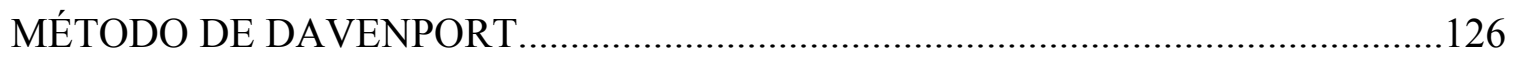

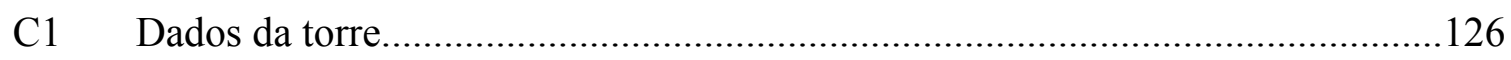

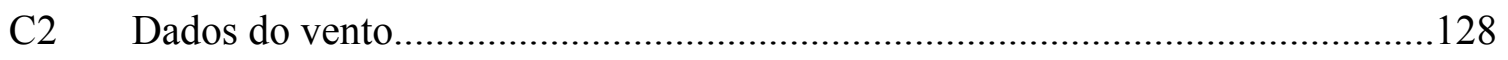

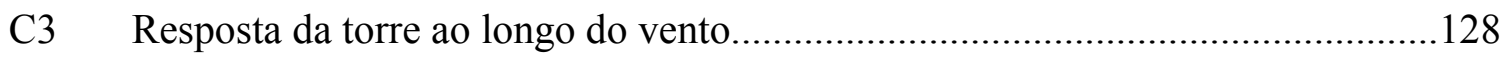




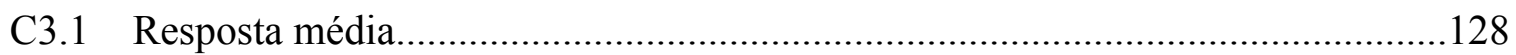

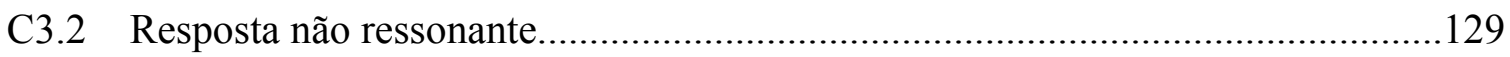

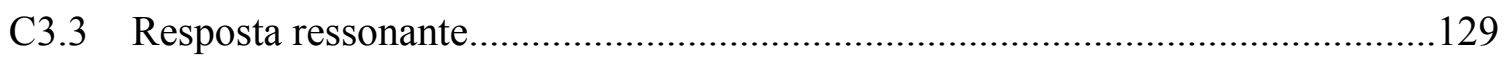

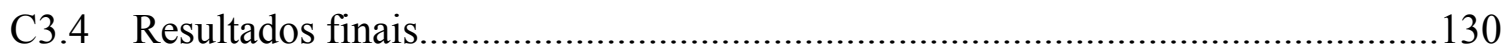

ANEXO D - VENTO SINTÉTICO MODIFICADO .................................................. 131

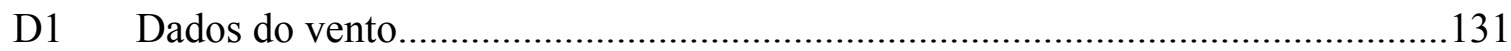

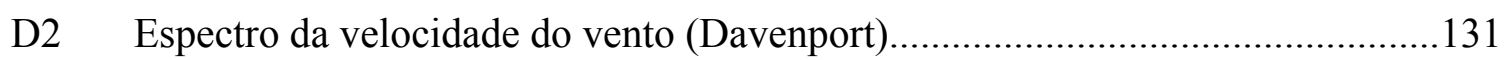

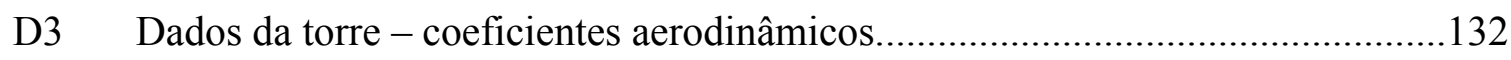

D4 Decomposição das pressões flutuantes...........................................................133

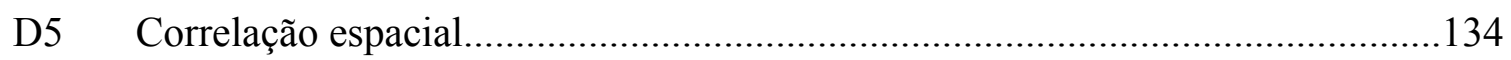

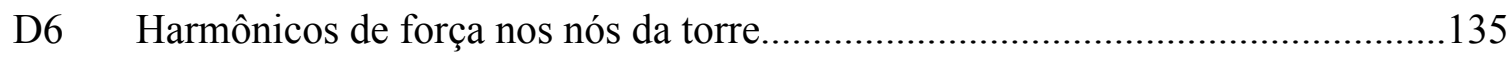

D7 Gravação das séries temporais para serem utilizadas pelo SAP2000..................137

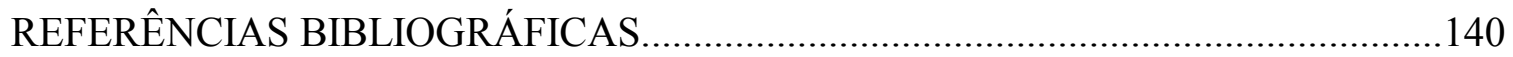




\section{LISTA DE FIGURAS}

Figura 2.1 - (a) Resposta da estrutura; (b) Espectro de potência dos esforços na estrutura oriundos das rajadas de vento.

Figura 2.2 - Resultados experimentais: G. EIFFEL (1911) ........................................ 12

Figura 2.3 - Isopletas da velocidade básica Vo (m/s) (NBR 6123/88) ..........................14

Figura 2.4 - Coeficiente de arrasto, $\mathrm{C}_{\mathrm{a}}$, para torres reticuladas de seção quadrada e triangular equilátera, formadas por barras prismáticas de cantos vivos ou levemente arredondados. NBR 6123 (1988)..................................... 16

Figura 2.5 - Coeficiente de arrasto para torres reticuladas de seção quadrada, formada por barras de seção circular. Vento incidindo perpendicularmente a duas faces paralelas. NBR6123 (1988).

Figura 2.6 - Coeficiente de arrasto, $\mathrm{C}_{\mathrm{a}}$, para torres reticuladas de seção quadrada, formada por barras de seção circular. Vento incidindo segundo uma diagonal. NBR6123 (1988).

Figura 2.7 - Coeficiente de arrasto, $\mathrm{C}_{\mathrm{a}}$, para torres reticuladas de seção triangular equilátera, formadas por barras de seção circular. Vento em qualquer direção. NBR6123 (1988)

Figura 2.8 - Fator de proteção, $\eta$, para dois ou mais reticulados paralelos igualmente

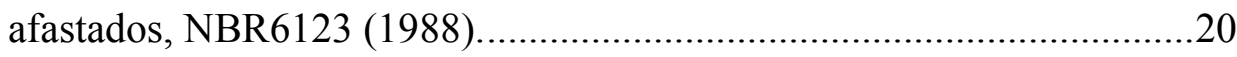

Figura 3.1 - Velocidade média do vento e suas flutuações..............................................26

Figura 3.2- Representação gráfica da autocovariância .................................................27

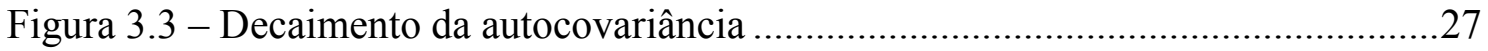

Figura 3.4 - Decaimento da autocorrelação ................................................................28

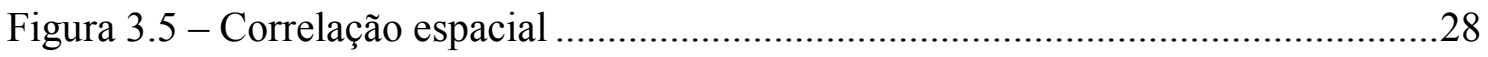

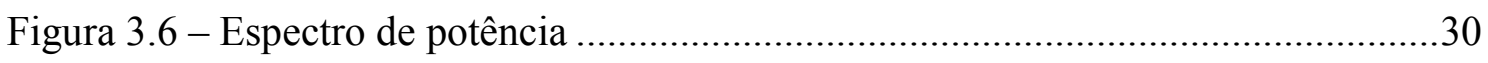

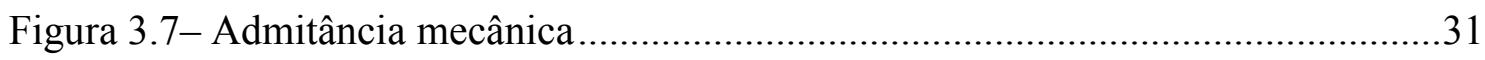

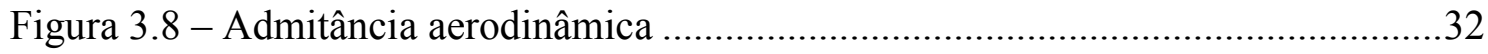


Figura 3.9 - Representação gráfica do procedimento estatístico de cálculo da resposta de estruturas esbeltas submetidas às forças das rajadas de vento

Figura 3.10 - Vista da face lateral da torre (medidas em metros).................................35

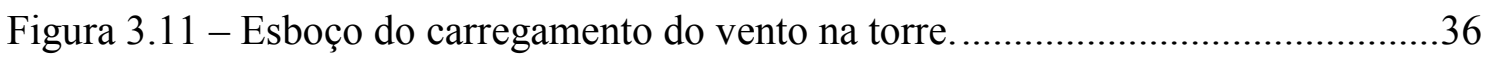

Figura 3.12 - Primeiro modo de vibração - f1=0,85 Hz.............................................43

Figura 3.13 - Resposta média, não ressonante e ressonante - força cortante..................44

Figura 3.14 - Resposta média, não ressonante e ressonante - momento fletor ..............44

Figura 3.15 - Coeficiente de amplificação dinâmica, $\xi$, para categoria III (NBR6123/1988) ..........................................................................47

Figura 3.16 - Resposta dos harmônicos separadamente .................................................57

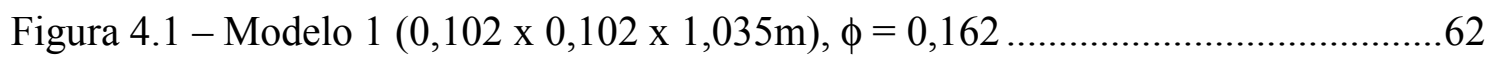

Figura 4.2 - Modelo 2 (0,102 x 0,204 x 1,035m), $\phi=0,162 \ldots \ldots \ldots \ldots \ldots \ldots \ldots \ldots \ldots \ldots \ldots \ldots \ldots . . .62$

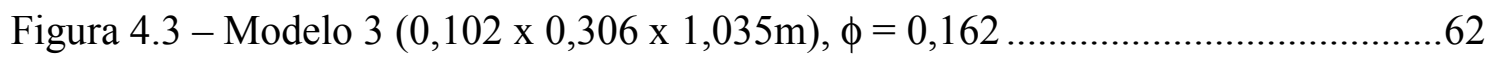

Figura 4.4 - Fabricação do modelo - Máquina de comando numérico ..........................63

Figura 4.5 - Fabricação do modelo - Detalhe da chapa de acrílico na máquina de

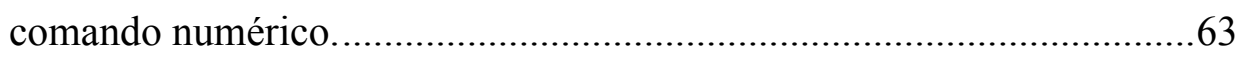

Figura 4.6 - Partes do modelo - faces laterais (acrílico) ...............................................64

Figura 4.7 - Partes do modelo - chapas de topo e seções transversais (poliestireno) .....64

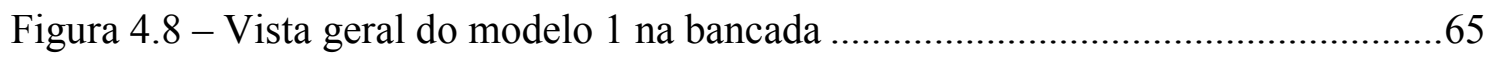

Figura 4.9 - Vista geral do modelo 1 no túnel de vento BLWT II................................65

Figura 4.10 - Coeficiente de arrasto de placas planas em função do número de Reynolds (FLASHBART, 1932 apud BLESSMANN, 1990) ................66

Figura 4.11 - Convenção de sinais para as forças de arrasto e lateral ...........................67

Figura 4.12 - Comparação do espectro de potência das rajadas geradas pela grelha e fornecido por ESDU 70431 (1975)...................................................69

Figura 4.13 - Arranjo experimental - suporte, grelha e modelo. .................................69

Figura 4.14 - Arranjo experimental - vista lateral do suporte........................................70

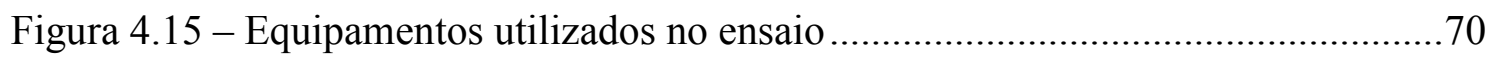

Figura 4.16 - Vista do modelo 1 - exposição 2 …...................................................... 71

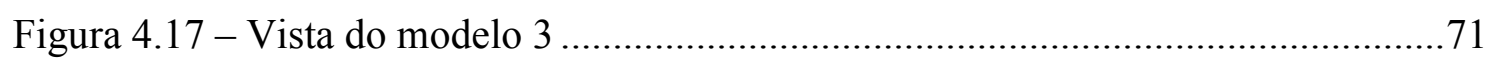

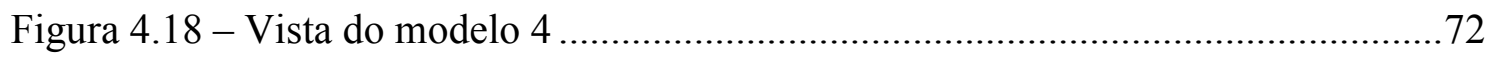




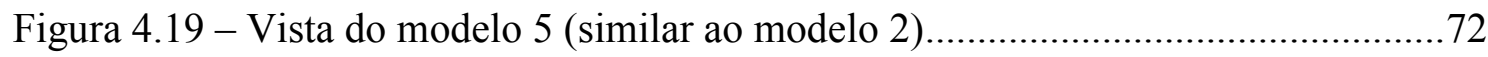

Figura 4.20 - Parâmetros B e s do modelo, seção transversal. ........................................73

Figura 4.21 - Modelo 1- Coeficientes de arrasto e de sustentação da seção da torre em fluxo suave. (definição de CL e Ca no item 4.1, figura 4.5)..............75

Figura 4.22 - Modelo 1 - Coeficientes de arrasto e de sustentação da seção da torre em fluxo suave (teste repetido) ...........................................................76

Figura 4.23 - Modelo 1 - Coeficientes de arrasto e de sustentação para fluxo turbulento

Figura 4.24 - Modelo 4 - Coeficientes de arrasto e de sustentação para fluxo turbulento

Figura 4.25 - Modelo 1 - Comparação entre os resultados obtidos com a exposição 1 e exposição $2-\operatorname{Re}=3864$

Figura 4.26 - Modelo 1 - Comparação entre os resultados obtidos com a exposição 1 e exposição $2 . \operatorname{Re}=6440$

Figura 4.27 - Detalhe do ângulo de incidência do vento e do ângulo da antena relativo à torre.

Figura 4.28 - Modelo de isopor da antena de microondas.......................................... 83

Figura 4.29 - Detalhe da posição das antenas de microondas no modelo .......................83

Figura 4.30 - Antenas na posição 2 do modelo no túnel de vento BLWT II..................85

Figura 4.31 - Detalhe da seção de ensaio do túnel de vento usado para o ensaio da antena separadamente.

Figura 4.32 - Detalhes do arranjo experimental no túnel de vento de 50 x 50 centímetros de seção de ensaio - Antena posicionada sem a conexão com a balança.

Figura 4.33 - Vista da grelha, do tubo de pitot e da antena conectada à balança. .86

Figura 4.34 - Espectro de potência do vento incidente (exposição 2) gerado para determinação das forças na antena separadamente. $\mathrm{I}_{\mathrm{V}}=9,7 \%$. .90

Figura 4.35 - Modelo 1 e modelo 4- Variação dos coeficientes de força $\Delta \mathrm{C}_{\mathrm{a}} \operatorname{com} \mathrm{o}$ número de antenas.

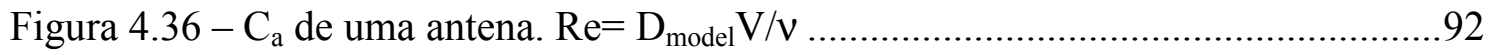

Figura 4.37 - Fator de interferência - dados experimentais e ESDU 81028 (1990) .......92 
Figura 5.1 - Coeficientes de arrasto em função do índice de área exposta - normas e

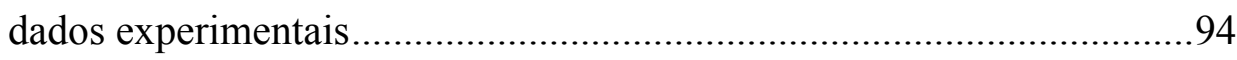

Figura 5.2 - Fator de proteção: normas e dados experimentais ...................................97

Figura B01 - Vista da face lateral da torre. Numeração das barras...............................118

Figura B02 - Vista da face lateral da torre. Perfis adotados.....................................121

Figura B03 - Travamento horizontal típico. Numeração das barras.............................124

Figura B04 - Travamento horizontal típico. Perfis adotados......................................125

Figura D01 - Espectro de potência do vento (Davenport)..........................................131

Figura D02 - Coeficientes de redução das pressões flutuantes.....................................136 


\section{LISTA DE TABELAS}

Tabela 2.1 - Dados estatístico sobre a construção de torres treliçadas de seção quadrada e triangular nos últimos quatro anos no Brasil. .8

Tabela 2.2 - Componentes da força de arrasto nas faces de torres reticuladas de seção quadrada ou triangular equilátera.

Tabela 3.1 - Perfis das barras principais da torre. .35

Tabela 3.2 - Dados utilizados para cálculo da resposta da torre .41

Tabela 3.3 - Resultados da análise. .42

Tabela 3.4 - Expoente p e parâmetro b (NBR6123, 1988) 45

Tabela 3.5 - Resultados da força cortante $\mathrm{F}$ ao longo da altura da torre e do deslocamento horizontal ux no topo.

Tabela 3.6 - Determinação das forças do vento na torre segundo a NBR6123

Tabela 3.7 - Decomposição espectral das pressões flutuantes. .57

Tabela 3.8 - Determinação da posição do centro de rajada .57

Tabela 3.9 - Valor característico do deslocamento no topo da estrutura .58

Tabela 3.10 - Resposta de pico dos harmônicos separadamente. .59

Tabela 3.11 - Comparação dos resultados .59

Tabela 4.1 - Propriedades dos modelos ensaiados. .73

Tabela 4.2- Modelo 1 - Coeficientes de arrasto e de sustentação da seção da torre. Exposição 1 . .76

Tabela 4.3 - Modelo 1 - Coeficientes de arrasto e de sustentação da seção da torre em fluxo suave (teste repetido)

Tabela 4.4 - Modelo 1 - Coeficientes de arrasto e de sustentação para fluxo turbulento.

Tabela 4.5 - Modelos 2 e 3- Coeficientes de arrasto e de sustentação para fluxo suave, (exp. 1) e fluxo turbulento (exp. 2).

Tabela 4.6 - Modelo 5 - Coeficientes de arrasto e de sustentação para fluxo turbulento (exposição 2).

Tabela 4.7 - Modelo 4 - Coeficientes de arrasto e de sustentação para fluxo turbulento 
Tabela 4.8 - Modelo 1 e antenas - Coeficientes de sustentação e arrasto. Acréscimo do coeficiente de arrasto, $\Delta \mathrm{C}_{\mathrm{a}}$, normalizado pela área efetiva da face do modelo sem as antenas. Exposição 1.

Tabela 4.9 - Modelo 1 e antenas - Coeficientes de sustentação e arrasto. Acréscimo do coeficiente de arrasto,$\Delta \mathrm{C}_{\mathrm{a}}$, normalizado pela área efetiva da face do modelo sem as antenas. Exposição 2 .

Tabela 4.10 - Modelo 4 e antenas - Coeficientes de sustentação e arrasto. Acréscimo do coeficiente de arrasto, $\Delta \mathrm{C}_{\mathrm{a}}$, normalizado pela área efetiva da face do modelo sem as antenas. Exposição 2 …............................................... 88

Tabela 4.11 - Resumo de $\Delta \mathrm{C}_{\mathrm{a}}$ apresentado nas tabelas 4.8, 4.9 e 4.10. .88

Tabela 4.12 - Coeficiente de arrasto da antena derivado do ensaio no túnel de vento pequeno. $\left(\mathrm{C}_{\mathrm{a}}=\mathrm{F}_{\mathrm{a} \_ \text {antena }} / \mathrm{qA}_{\text {antena }}\right)$.

Tabela 4.13 - Coeficiente de arrasto em um disco de antena $(\mathrm{d}=6 \mathrm{~cm})$ derivado dos resultados experimentais. $\left(\mathrm{C}_{\mathrm{a} \text { antena no modelo }}=\Delta \mathrm{F}_{\mathrm{a}} / \mathrm{A}_{\text {antena }}\right)$

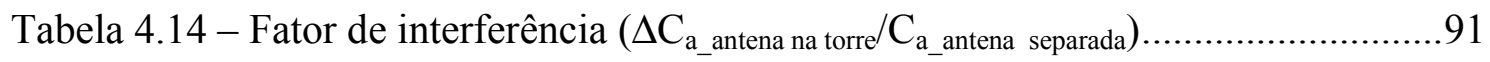

Tabela 5.1 - Coeficiente de arrasto, dados experimentais. ..........................................95

Tabela 5.2 - Diferenças entre os resultados dos dados experimentais -

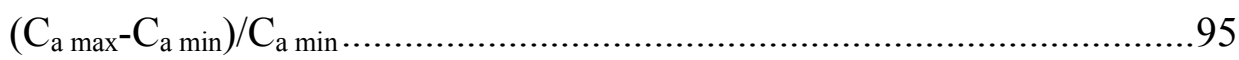

Tabela 5.3 - Coeficiente de arrasto das normas ........................................................95

Tabela 5.4 - Fator de proteção: normas e dados experimentais...................................97

Tabela A1 - Dados sobre a construção de torres metálicas para telecomunicações nos últimos 4 anos no Brasil.....................................................................103

Tabela B1 - Verificação das barras verticais da torre................................................109

Tabela B2 - Verificação das barras diagonais da torre ...............................................112

Tabela B3 - Verificação das barras horizontais da torre.............................................116 


$\begin{array}{ll}\text { ASCE } & \text { - American Society of Civil Engineers } \\ \text { BLWT } & \text { - Boundary Layer Wind Tunnel (Túnel de Vento de Camada Limite } \\ & \text { Atmosférica) } \\ \text { BLWTL } & \text { - Boundary Layer Wind Tunnel Laboratory (Laboratório do Túnel de } \\ & \text { Vento de Camada Limite Atmosférica) } \\ \text { BS } & \text { - British Standard } \\ \text { ESDU } & \text { - Engineering Science Data Unit. Associação situada em Londres, } \\ & \text { Inglaterra, que produz trabalhos científicos, com a cooperação de } \\ & \text { engenheiros e cientistas da indústria, órgãos de pesquisa e } \\ & \text { universidades. } \\ \text { NBR } & - \text { Norma Brasileira Registrada } \\ \text { UWO } & - \text { University of Western Ontario, Ontário, Canadá } \\ \text { rms } & - \text { Root Mean Square (raiz quadrada do valor quadrado médio, igual ao } \\ & \text { desvio padrão) } \\ \text { SAP } & - \text { Structural Analysis Program. Programa de análise estrutural em } \\ & \text { elementos finitos }\end{array}$




\section{a) Letras maiúsculas}

A

- Área efetiva da estrutura.

- Área delimitada pelos limites externos do painel da torre.

$\mathrm{A}_{\mathrm{o}} \quad$ - Área de referência.

$\mathrm{A}_{\mathrm{i}} \quad$ - Área efetiva de uma das faces da torre.

$\mathrm{A}_{\mathrm{Ti}} \quad$ - Área da torre delimitada pelas barras externas na coordenada $\mathrm{i}$.

A antena - Área frontal do disco de antena.

B - Largura do modelo.

C - Coeficiente de decaimento da correlação de banda estreita.

$\mathrm{C}_{\mathrm{a}} \quad-$ Coeficiente de arrasto.

$\mathrm{C}_{\mathrm{a} \alpha} \quad$ - Coeficiente de arrasto medido com ângulo $\alpha$ de incidência do vento.

$\mathrm{C}_{\text {antena_separada }}-$ Coeficiente de arrasto da antena isolada da torre.

$\mathrm{C}_{\mathrm{L}} \quad-$ Coeficiente de força lateral.

$\mathrm{C}_{\mathrm{p}} \quad-$ Coeficiente de pressão.

$\mathrm{C}_{\mathrm{r}}(\mathrm{j}, \mathrm{k}) \quad$ - Coeficiente de redução das pressões flutuantes.

$\mathrm{C}^{\mathrm{v}}(\tau) \quad$ - Autocovariância da velocidade do vento.

$\mathrm{D}_{0} \quad$ - Largura da parte onde há mudança na inclinação das barras principais da torre

$\mathrm{D}_{\mathrm{H}} \quad$ - Largura no topo da torre.

F - Força do vento.

- Força cortante.

$\overline{\mathrm{F}} \quad$ - Força média do vento.

- Força cortante média.

$\hat{\mathrm{F}} \quad$ - Força cortante de pico.

$\widetilde{\mathrm{F}}^{2}$ - Variância das forças do vento, $\sigma^{2}(\mathrm{~F})$.

$\mathrm{F}_{\mathrm{a}} \quad-$ Força de arrasto.

$\mathrm{F}_{\mathrm{L}} \quad$ - Força lateral.

G - Fator de rajada. 
Gc

$\mathrm{G}_{0}$

$\mathrm{G}_{\infty}$

$\mathrm{H}$

$\mathrm{H}_{0}$

$I_{V}$

$\mathrm{K}_{\alpha}$

$\mathrm{K}_{\mathrm{x}}$

$\mathrm{L}$

$\mathrm{L}_{\mathrm{F}}$

$\mathrm{L}_{\mathrm{V}}$

M

$\mathrm{R}$

Re

$\mathrm{R}_{\mathrm{F}}(\mathrm{z})$

$\mathrm{R}_{1,2}(\mathrm{f}, \Delta \mathrm{z})$

$\mathrm{S}_{\mathrm{F}}(\mathrm{f})$

$\mathrm{S}_{\mathrm{GFj}}(\mathrm{f})$

$\mathrm{S}_{\mathrm{p}}(\mathrm{f})$

$\mathrm{S}_{\mathrm{r}}(\mathrm{f})$

$S_{V}(f)$

- Posição do centro de rajada

- Fator relacionado à resposta da estrutura, quando as forças do vento estão correlacionadas ao longo da mesma.

- Fator relacionado à resposta da estrutura, quando as forças do vento estão correlacionadas apenas localmente.

- Altura da torre.

- Comprimento do modelo.

- Altura intermediária na torre onde há mudança na variação da largura da torre com a altitude.

- Intensidade de turbulência do vento.

- Coeficiente multiplicador de $\mathrm{C}_{\mathrm{a}}$.

- Fator de proteção.

- Dimensão característica de uma edificação.

- Escala da correlação de força.

- Escala de turbulência da velocidade do vento.

- Massa pontual da torre.

- Número do harmônico ressonante.

- Número de Reynolds.

- Coeficiente de correlação entre duas forças F separadas por uma altura $\Delta \mathrm{z}$.

$\mathrm{S}_{\mathrm{V}}(\mathrm{f}) / \sigma^{2}(\mathrm{v})$ - Função de densidade espectral ou espectro normalizado da velocidade do vento.

$\mathrm{S}_{1} \quad$ - Fator topográfico. 
- Fator que considera a influência da rugosidade do terreno, das dimensões da edificação ou parte da edificação em estudo, e de sua altura sobre o terreno.

$\mathrm{S}_{3} \quad$ - Fator baseado em conceitos estatísticos.

$\mathrm{S}_{\mathrm{P}}(\mathrm{f}) \quad$ - Espectro de potência das pressões do vento estrutura.

T - Tempo de amostragem.

$\mathrm{T}_{\mathrm{r}} \quad$ - Período do harmônico coincidente com o período fundamental da torre.

- Velocidade média do vento.

$\mathrm{V}_{0} \quad$ - Máxima velocidade média sobre $3 \mathrm{~s}$, que pode ser excedida em média uma vez em 50 anos, a 10m sobre o nível do terreno em lugar aberto e plano.

$\mathrm{V}_{\mathrm{H}} \quad-$ Velocidade média do vento no topo da torre.

$\mathrm{V}_{\mathrm{k}} \quad-$ Velocidade característica do vento.

$\mathrm{V}_{\mathrm{p}} \quad-$ Velocidade do vento de projeto (NBR6123/88).

Z - Altitude.

\section{b) Letras minúsculas}

b - Parâmetro de ajuste experimental do fator de interferência.

- Parâmetro meteorológico usado na determinação de S2 conforme a NBR6123/88.

cck - Coeficiente corrigido de redução das pressões flutuantes.

$c_{\mathrm{k}} \quad-$ Coeficiente de redução das pressões flutuantes.

d - Diâmetro da barra principal da torre.

- Largura das barras do modelo.

dW - Elemento de área do espectro de potência, energia ou variância associada a um elemento de freqüência df.

e - Espaçamento entre painéis reticulados.

f - Freqüência.

$\mathrm{f}_{\mathrm{a}} \quad$ - Fator de interferência.

g - Fator de pico. 
$\mathrm{m}_{\mathrm{o}}$

$\mathrm{m}_{\mathrm{H}}$

$\mathrm{n}$

$\mathrm{p}$

$\hat{\mathrm{r}}$

$\widetilde{\mathrm{r}}_{\mathrm{B}}$

$\widetilde{\mathrm{r}}_{\mathrm{B}}^{2}$

$\widetilde{\mathrm{r}}_{\mathrm{R}}$

$\widetilde{\mathrm{r}}_{\mathrm{R}}^{2}$

S

t

$\mathrm{U} *$

$\mathrm{v}(\mathrm{t})$

$\widetilde{\mathrm{V}}$

$\widetilde{\mathrm{V}}^{2}$

Z

- Altura do painel reticulado.

- Altura de uma placa plana

- Linha de influência da resposta da estrutura.

- Coeficiente de ajuste do fator de interferência.

- Largura: dimensão horizontal de uma edificação perpendicular à direção do vento.

- Massa de referência.

- Massa por unidade de comprimento no topo da torre.

- Componente da força normal à face da torre.

- Expoente da lei potencial de variação de $\mathrm{S}_{2}$ conforme a NBR6123/88.

- Pressão do vento.

- Pressão flutuante do vento.

- Pressão dinâmica do vento.

- Pressão dinâmica do vento no topo da torre.

- Freqüência natural da estrutura.

- Número do harmônico ressonante.

- Resposta média da estrutura.

- Resposta de pico da estrutura.

- Desvio padrão da resposta não ressonante da estrutura.

- Variância da resposta não ressonante.

- Desvio padrão da resposta ressonante da estrutura.

- Variância da resposta ressonante.

- Espaçamento entre as faces do modelo.

- Tempo.

- Componente da força tangencial à face da torre.

- Velocidade de cisalhamento do vento .

- Velocidade flutuante do vento.

- Desvio padrão da velocidade flutuante do vento.

- Variância da velocidade flutuante do vento.

- Altitude normalizada pela altura da torre. 


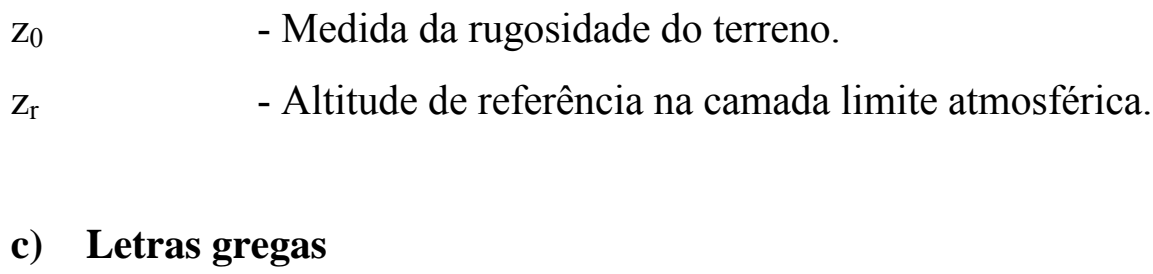

$\alpha \quad$ - Ângulo de incidência do vento.

- Expoente da lei potencial de variação da velocidade do vento na atmosfera.

- Dispersão.

$\alpha_{d} \quad-$ Angulo da normal ao disco de antena relativo à torre.

$\beta, \gamma \quad$ - Expoente da forma modal.

$\chi_{\mathrm{m}}(\mathrm{f}) \quad$ - Admitância mecânica.

$\Delta \mathrm{z}_{\mathrm{k}} \quad$ - Comprimento da rajada do harmônico k.

$\Delta \quad$ - Flexibilidade da estrutura.

$\Delta \mathrm{C}_{\text {antena_na_torre }}$ Acréscimo do coeficiente de arrasto da torre quando a antena está acoplada.

$\chi_{\mathrm{a}}(\mathrm{f}) \quad$ - Admitância aerodinâmica.

$\Phi_{\mathrm{D}} \quad$ - Função da variação da largura da torre com a altitude.

$\Phi_{\mathrm{V}} \quad$ - Função da variação da velocidade do vento com a altitude.

$\Phi_{\mathrm{m}} \quad$ - Função da variação da massa da estrutura ao longo da altitude.

$\phi, \delta(\mathrm{z}) \quad$ - Índice de área exposta.

- Viscosidade dinâmica.

- Modo de vibração.

- Média

$\mu_{1} \quad$ - Primeiro modo de vibração da estrutura.

- Viscosidade cinemática.

- Número de vezes que o valor médio é ultrapassado por unidade de tempo.

- Moda.

$\theta_{\mathrm{k}} \quad$ - Ângulo de fase do harmônico k.

$\rho \quad$ - Densidade do ar. 
$\rho^{\mathrm{v}}(\tau) \quad$ - Autocorrelação da velocidade do vento.

$\sigma \quad$ - Desvio padrão

$\sigma(\mathrm{v}) \quad$ - Desvio padrão da velocidade flutuante do vento.

$\sigma^{2}(\mathrm{v}) \quad$ - Variância da velocidade flutuante do vento.

$\tau \quad$ - Intervalo de tempo.

$\xi \quad$ - Coeficiente da amplificação dinâmica.

- Relação entre a massa na coordenada i e a massa de referência $\left(\mathrm{m}_{\mathrm{i}} / \mathrm{m}_{0}\right)$.

$\zeta \quad$ - Razão de amortecimento.

$\zeta_{\mathrm{a}} \quad$ - Coeficiente de amortecimento aerodinâmico.

$\zeta_{\mathrm{s}} \quad$ - Coeficiente de amortecimento estrutural. 
Torres metálicas treliçadas tem sido largamente utilizadas como suporte de antenas de microondas. Devido ao baixo peso e a inexistência de terremotos significativos no Brasil, a força de vento é o fator determinante do projeto destas estruturas.

Com o objetivo de determinar estas forças e seus efeitos em torres treliçadas foram realizadas investigações numéricas e experimentais. Uma torre de 100 metros foi dimensionada com base nos padrões existentes no Brasil. Examinou-se a resposta dinâmica da estrutura ao longo do vento. Investigaram-se a resposta ressonante, não ressonante e o fator resposta de rajada. Concluiu-se que a resposta ressonante não é significativa para este tipo de estrutura. Compararam-se os modelos de DAVENPORT (1993), da norma Brasileira NBR6123/88 e o processo do vento sintético de FRANCO (1993).

Uma investigação experimental foi realizada para analisar os coeficientes de força em uma seção da torre estudada. Os experimentos foram realizados no "Boundary Layer Wind Tunnel Laboratory" (BLWTL) da "University of Western Ontario" (UWO), Canadá. Foram analisados o ângulo de incidência do vento; o índice de área exposta; o efeito de proteção; o fator de interferência no coeficiente de arrasto de antenas de microondas, devido à proximidade da torre e a influência da turbulência do vento. Os resultados mostraram boa concordância com os valores obtidos em diferentes normas existentes. 
With today's expanding communication systems, a large number of lattice towers to support cellular and microwave antennas are being constructed in Brazil. Due to the lightweight of these structures, wind forces are the primary concern in the design.

With the objective of determining these forces and their effects upon latticed towers, a numerical and experimental investigation is accomplished. A 100-meter tower is designed based on existing patterns of latticed towers in Brazil. The along wind dynamic response is analysed. The resonant, background response and gust factor are examined. It is concluded that the resonant response is not significant for this type of structure. The DAVENPORT (1993) method, the Brazilian code NBR6123/88 and the process of the synthetic wind of FRANCO (1993) are compared.

An experimental investigation is accomplished to analyse the force coefficients on a section of the lattice tower studied. The tests were performed at the Boundary Layer Wind Tunnel Laboratory, University of Western Ontario (UWO), Canada. The wind incidence angle; the tower solidity; the shielding effect; the interference factor upon the drag coefficient of the microwave antennas, due to the tower proximity and the influence of the wind turbulence are analysed. The results are ii good agreement with the values obtained in different existent codes. 


\section{INTRODUÇÃO}

O desenvolvimento constante do sistema de telecomunicações e a necessidade de ampliação das linhas de transmissão de energia elétrica são responsáveis pela atual e intensa utilização de torres metálicas treliçadas. No entanto, observa-se a ocorrência de quedas de torres metálicas devido à ação do vento, como no caso do acidente ocorrido nas linhas de transmissão da usina de Itaipu entre Foz do Iguaçu e Ivaiporã no Paraná, em 02 de novembro de 1997, quando 10 torres ruíram sob o efeito de ventos de até 130 $\mathrm{km} / \mathrm{h}(36 \mathrm{~m} / \mathrm{s})$, conforme reportagem do jornal O Estado de São Paulo do dia 04 de novembro de 1997. Outros acidentes em torres de microondas são citados por BLESSMANN (1986).

Devido ao baixo peso próprio das torres treliçadas e à rara ocorrência de terremotos no Brasil, o vento é o fator determinante do projeto. É essencial, portanto, ter estimativas confiáveis do carregamento do vento e de seu efeito na estrutura.

Atualmente há uma crescente demanda de torres metálicas treliçadas devido à expansão do sistema de telefonia celular no Brasil. Dados sobre a construção de torres nos últimos quatro anos pela Telegoiás são apresentados no capítulo 2 e no anexo A.

Geralmente as torres para telecomunicações são esbeltas, podendo ser consideradas estruturas em que apenas uma dimensão é relevante. As freqüências naturais de vibração de estruturas treliçadas, em sua maioria, estão na faixa de $0,5 \mathrm{~Hz}$ e 5Hz conforme TAYLOR (1970). A resposta ressonante de estruturas esbeltas se torna importante apenas quando essas estruturas têm freqüências naturais de vibração menores que $1 \mathrm{~Hz}$ ou períodos fundamentais maiores que 1 segundo. É nessa faixa de freqüência que a energia das rajadas do vento é maior. Com isso a análise dinâmica da estrutura sob carregamento do vento é necessária para determinar a resposta ressonante que pode ser significativa comparada com a resposta de fundo ou não ressonante. Este estudo pretende colaborar com a sistematização de procedimentos específicos para o cálculo das forças do vento e seus efeitos em torres metálicas treliçadas para telecomunicações. 
O segundo capítulo desta tese retrata o efeito do vento em estruturas treliçadas e traz uma revisão bibliográfica do assunto. Descrevem-se quais os possíveis tipos de ações do vento nas estruturas de torres treliçadas para telecomunicações, o que é importante para uma melhor compreensão das principais ações a que essas estruturas estão sujeitas. Para avaliar o tipo de torre e de terreno onde ela é construída, há um estudo estatístico sobre o tipo e o local de torres de telecomunicações construídas no Brasil, particularmente para a Telegoiás, nos últimos 4 anos. O capítulo 2 é concluído com os procedimentos de projeto para o cálculo das forças pseudo-estáticas do vento em torres treliçadas baseado na norma brasileira NBR6123 (1988).

O capítulo 3 traz alguns modelos analíticos e numéricos para determinação do efeito do vento em torres treliçadas. Um deles é o modelo estatístico de DAVENPORT (1993). Outro é o modelo da norma NBR6123 (1988). Estuda-se também o processo do vento sintético de FRANCO (1993). Um projeto preliminar de uma torre treliçada é apresentado a partir de estruturas de torres existentes construídas no Brasil para suporte de antenas de microondas. A norma Brasileira NBR6123 não mostra um modelo específico para o cálculo da resposta dinâmica de torres treliçadas metálicas, mas indica o modelo discreto que pode ser utilizado. Apresenta-se, também, exemplos de cálculo da torre segundo o modelos aqui especificados. São comparados os resultados do fator de rajada obtidos por cada um dos métodos.

A parte experimental encontra-se no quarto capítulo. São apresentados os resultados da investigação experimental em uma seção da torre cujo projeto preliminar consta do capítulo 3. Foram projetados e fabricados três modelos. Os parâmetros estudados são o fator de proteção entre as faces de barlavento e de sotavento da torre, o índice de área exposta, a quantidade de antenas e o efeito da turbulência atmosférica. Verificou-se também uma possível influência do número de Reynolds dos modelos na determinação dos coeficientes de força dos mesmos.

O quinto capítulo traz comentários e um estudo comparativo dos resultados experimentais com algumas normas existentes. A comparação refere-se apenas aos resultados médios dos coeficientes de arrasto em torres de seção quadrada, objeto desta tese. 
As conclusões e propostas para futuros trabalhos estão apresentadas no sexto capítulo.

\subsection{Objetivos}

Em linhas gerais, o escopo desta tese é apresentar procedimentos de análise e realizar um estudo experimental das estruturas de torres metálicas treliçadas para suporte de antenas celulares. Os objetivos principais deste trabalho são, a seguir, listados.

- Fazer uma análise numérica sobre o efeito do vento em torres metálicas treliçadas identificando os tipos de resposta mais importantes da estrutura: resposta ressonante e resposta não ressonante.

- Fazer uma análise experimental dos coeficientes de força nessas estruturas e comparar com as normas existentes. As variáveis consideradas são o fator de proteção entre as faces de barlavento e sotavento da torre, o índice de área exposta e o ângulo de incidência do vento.

- Investigar o efeito de proteção ou efeito de interferência na determinação das forças do vento em antenas de microondas devido à sua proximidade com a torre.

- Comparar os resultados experimentais com as principais normas existentes no mundo sobre as forças e o efeito do vento em torres metálicas treliçadas.

- Apresentar procedimentos de projeto para o cálculo das forças do vento em torres treliçadas. 


\section{EFEITO DO VENTO EM TORRES TRELIÇADAS}

Quando se fala em efeito do vento em torres treliçadas deve-se perguntar a que tipos de ações essas estruturas estão sujeitas, ou melhor, qual as ações ou a ação principal que excitam esse tipo de estrutura. No item 2.1 há um resumo dos diversos tipos de ações do vento que podem excitar essas estruturas.

A velocidade média do vento em função da altitude e suas flutuações no tempo dependem do tipo de terreno em que a estrutura está localizada. Um estudo parcial sobre a localização de torres treliçadas para suporte de antenas de microondas no Brasil é apresentado no item 2.2 e anexo A. Este estudo não pretende ser definitivo tendo em vista que não engloba todas as torres existentes no Brasil e, além disso, a alteração física das regiões modifica a paisagem e conseqüentemente a camada limite atmosférica. É importante considerar essas mudanças nas verificações de cálculo de torres existentes.

O item 2.3 traz uma revisão da bibliografia sobre as forças do vento em estruturas treliçadas. No item 2.4 apresentam-se os procedimentos para elaboração de projeto para determinar as forças médias do vento em torres treliçadas baseados na NBR6123 (1988).

\subsection{Ações principais em torres de telecomunicações}

Devido ao baixo peso da estrutura e a pouca importância de terremotos no território nacional, o vento é o principal agente que determina o projeto de torres metálicas treliçadas para telecomunicações.

Separando-se o vento natural em uma parte média e outra flutuante, os possíveis esforços que podem estar atuando nesse tipo de estrutura são os esforços pseudo estáticos correspondentes à parte média do vento e os esforços dinâmicos decorrentes da parte flutuante do vento, fig. 2.1a. Os esforços dinâmicos podem ser predominantemente não ressonantes quando a maior parte da energia contida no espectro de resposta está abaixo da menor freqüência de vibração natural da estrutura, e podem ser predominantemente ressonantes quando a parcela maior dessa energia contiver as freqüências naturais de vibração da estrutura. Para uma melhor 
compreensão, a figura $2.1 \mathrm{~b}$ mostra o espectro de resposta da estrutura com a correspondente indicação do tipo de resposta. As áreas hachuradas sob o espectro de potência correspondem à variância da resposta correspondente. A resposta indicada genericamente pode ser um esforço solicitante na estrutura ou um deslocamento. No capítulo 3 esse assunto é aprofundado com a apresentação dos fundamentos estatísticos para o cálculo de estruturas submetidas ao efeito dinâmico do vento.

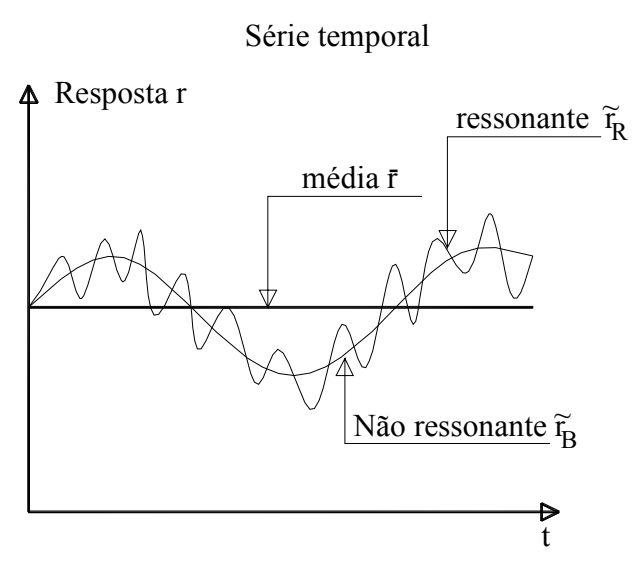

(a)

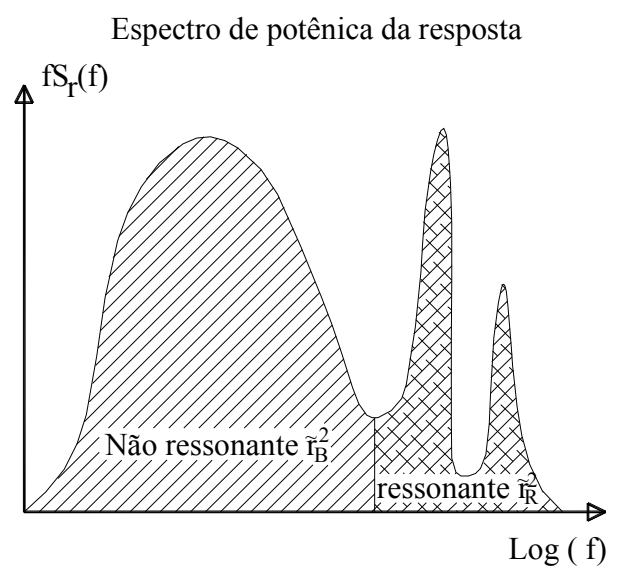

(b)

Figura 2.1 - (a) Resposta da estrutura; (b) Espectro de potência dos esforços na estrutura oriundos das rajadas de vento.

As possíveis forças devidas ao vento que podem estar excitando as torres de telecomunicações são:

a) Forças de martelamento devidas à turbulência atmosférica

O martelamento, segundo autores como SIMIU; SCANLAN (1996), é definido como a excitação da estrutura pela flutuação da velocidade do vento. Se o martelamento estiver associado à turbulência gerada pela presença de uma construção à frente da estrutura, o carregamento é chamado de martelamento de esteira. Nesse caso, a geração de turbilhões pelos obstáculos a barlavento em uma determinada freqüência gera efeitos dinâmicos que poderão ser de grande intensidade se a freqüência excitadora coincidir com uma das freqüências naturais de vibração da estrutura. BLESSMANN (1998) define o martelamento de esteira como sendo simplesmente martelamento, e o 
martelamento devido à turbulência atmosférica como sendo a excitação de uma estrutura pelas rajadas de vento.

As estruturas das torres usadas para telefonia celular estão predominantemente sujeitas a forças de martelamento devido à turbulência atmosférica. Caso haja obstáculos vizinhos, essas estruturas também estão sujeitas ao martelamento de esteira.

b) Desprendimento de vórtices

Em muitos corpos rombudos, para número de Reynolds maiores que, aproximadamente, 30, aparece um desprendimento alternado de vórtices com uma freqüência bem definida. São os chamados vórtices de Kármán que geram forças oblíquas em relação à direção do vento médio. A componente dessa força na direção da velocidade média excita a estrutura na freqüência individual do desprendimento dos vórtices, e a componente da força na direção transversal do vento médio excita a estrutura na freqüência do desprendimento de cada par de vórtices. Elas geram oscilações na estrutura na direção em que agem. No entanto, a componente na direção do vento é pequena em comparação à componente transversal ao vento. Na prática, as oscilações na direção do vento devidas ao desprendimento de vórtices raramente ocorrem. Por outro lado, as oscilações transversais à direção do vento podem ocorrer em estruturas de seções circulares, retangulares, quadradas, triangulares e com outras formas de cantos vivos.

Cada barra de uma estrutura treliçada, caso das torres em estudo, está sujeita ao desprendimento de vórtices isoladamente. No entanto, para o caso presente, a estrutura como um todo não se ressente desse fenômeno, já que os desprendimentos de vórtices pelas barras da treliça ocorrem de maneira desordenada, não havendo correlação entre eles.

c) Instabilidade aerodinâmica por galope e por drapejamento.

O fenômeno de instabilidade aerodinâmica por galope é caracterizado por grandes amplitudes de vibração em freqüências muito baixas. DEN HARTOG (1985) observou o fenômeno em cabos de linhas de transmissão de energia elétrica cuja seção transversal foi alterada pela formação de gelo. Embora esse fenômeno raramente ocorra, pois 
envolve estruturas muito esbeltas e uma faixa reduzida de número de Reynolds, na engenharia civil há um grande número de seções usuais que são em potencial suscetíveis a este fenômeno, como os prismas de seção quadrada, retangular, triangular, poligonal, semicircular e cantoneiras.

O surgimento da instabilidade por galope depende de uma determinada velocidade do vento chamada de velocidade de disparo. A amplitude de oscilação aumenta com a velocidade do vento. Durante a oscilação, o ângulo de incidência do vento está em constante modificação. Se durante essa oscilação for desenvolvida uma força na direção e sentido do movimento, energia será extraída do vento continuando o movimento oscilatório. Um detalhamento maior do fenômeno pode ser visto em LAWSON (1980) ou BLESSMANN (1998).

O fenômeno de drapejamento clássico é característico de pontes pênseis. É caracterizado por oscilações envolvendo dois graus de liberdade, rotação e deslocamento vertical, acoplados em oscilação instável.

As torres metálicas treliçadas, objeto deste estudo, possuem freqüências naturais, em geral, acima de $0,5 \mathrm{~Hz}$, não sendo suscetíveis, portanto, a fenômenos de instabilidade aerodinâmica que ocorrem em estruturas com freqüências naturais de vibração mais baixas. Além disso, a geometria da torre é conhecida como não suscetível ao drapejamento clássico.

Portanto a excitação da estrutura por rajadas de vento, ou seja, o martelamento devido à turbulência atmosférica, é o principal carregamento a que está sujeito esse tipo de estrutura. 


\subsection{Torres metálicas treliçadas existentes no Brasil.}

Há diversos tipos de torres metálicas treliçadas construídas para suporte de antenas celulares e de microondas. As mais comuns são as torres de seção quadrada e triangular de arestas levemente inclinadas. Raramente encontram-se torres de seção retangular. Diversos são os tipos de barras utilizadas na construção das torres. Existem torres de barras circulares e de barras de cantos afilados ou levemente arredondados, por exemplo, cantoneiras. A força do vento na torre depende do tipo de barra adotada.

Dados sobre o tipo, a localização e a altura de torres construídas no Brasil nos últimos quatro anos pela Telegoiás são apresentados no anexo A. Um estudo estatístico sobre esses dados está na tabela 2.1. Para cada tipo de terreno a tabela traz a altura média e o desvio padrão. Analisando essa tabela verifica-se que a altura média das torres é de $47.9 \mathrm{~m}$ com desvio padrão de 21. As torres estudadas possuem altura máxima de 100 metros. Embora a maioria das torres esteja localizada em áreas onde se concentram muitas casas, ou em pequenas cidades (categoria IV de rugosidade da NBR6123) as torres maiores se concentram em áreas de subúrbios com casas espaçadas ou em área rural, o que significa categoria III da NBR6123. Neste trabalho, maior ênfase se dará às torres maiores e de seção quadrada com barras de cantos vivos ou levemente arredondadas, por possuírem freqüências naturais de vibração na faixa das freqüências do vento natural em que há maior energia. Observa-se, também, que 10\% dessas torres estão localizadas em morros o que torna o fator topográfico importante para o efeito do vento.

Tabela 2.1 - Dados estatístico sobre a construção de torres treliçadas de seção quadrada e triangular nos últimos quatro anos no Brasil

\begin{tabular}{|l|l|l|l|l|l|}
\hline & Categoria & Quantidade & $\%$ & Alt. Média & Desvio padrão \\
\hline $\begin{array}{l}\text { Área cheia de casas e } \\
\text { pequenas cidades }\end{array}$ & CAT IV & 107 & 63.3 & 46.2 & 19.0 \\
\hline Centro de grandes cidades & CAT V & 20 & 11.8 & 36.5 & 13.3 \\
\hline $\begin{array}{l}\text { Subúrbios-casas espaçadas, } \\
\text { área rural. }\end{array}$ & CAT III & 42 & 24.9 & 57.0 & 25.3 \\
\hline Morros & & 19 & 11.2 & 52.6 & 20.1 \\
\hline
\end{tabular}




\subsection{Uma revisão sobre os efeitos do vento em estruturas reticuladas}

Os fatores principais que governam o carregamento do vento em estruturas reticuladas são, a seguir, apresentados.

- A razão de aspecto, ou seja, a relação entre o comprimento e a largura da estrutura.

- O índice de área exposta, que é a relação entre a área efetiva da treliça e a área total correspondente à área limitada pelas bordas da treliça.

- Efeito de proteção causado pela treliça de barlavento na treliça ou treliças de sotavento.

- A forma das barras da treliça: na barra arredondada, as forças do vento dependem do número de Reynolds e da rugosidade da superfície desses elementos; na treliça constituída de barras prismáticas de cantos vivos, os efeitos do número de Reynolds e da rugosidade da superfície são mínimos, podendo ser desconsiderados no cálculo.

- A turbulência do vento. Segundo SIMIU, SCANLAN (1996), o efeito da turbulência na força de arrasto em estruturas constituídas de barras prismáticas de cantos vivos é relativamente pequeno em quase todos os casos práticos. Uma conclusão similar pode ser aplicada a estruturas feitas de barras circulares com o número de Reynolds na faixa subcrítica. Por essa razão, e pelas dificuldades de obter a escala correta de teste, os ensaios em túneis de vento são geralmente conduzidos em fluxo suave, ou seja, com baixa intensidade e baixa escala de turbulência.

- A orientação da estrutura treliçada em relação à direção média do vento.

- A inclinação das barras principais da torre ainda hoje é uma incerteza. É o caso da maioria das torres utilizadas para telecomunicações e linhas de transmissão. Ainda não há estudos mostrando sua interferência no carregamento do vento. A inclinação das barras principais modifica a razão de aspecto das torres treliçadas.

As estruturas reticuladas têm sido utilizadas por mais de um século. Os primeiros estudos sobre a força do vento em estruturas parecem ser de EIFFEL (1911) com suas experiências no Laboratório do Campo de Marte. Ele estudou os coeficientes de força em placa plana retangular em relação à razão de aspecto e ângulo de ataque. Estudou também o efeito de proteção de duas treliças considerando diferentes distâncias entre as treliças. Nestes estudos, EIFFEL (1911) não levou em consideração a variação do 
ângulo de ataque, a razão de aspecto e o índice de área exposta, figura 2.1, mas foi o precursor dos atuais estudos.

Um importante estudo sobre o efeito do vento em treliças planas de barras de seção com cantos afilados é de FLACHBART (1932). Até hoje, os resultados obtidos em seus ensaios servem de referência para diversos autores. FLACHBART estudou o efeito do vento em treliças planas levando em consideração o espaçamento entre duas treliças, o índice de área exposta e a razão de aspecto. Foram investigados diferentes modelos de treliças.

GOULD; HAYMER (1972) estudaram os coeficientes de força do vento em estruturas tubulares reticuladas. Foram investigados modelos de estruturas planas de torres de seção triangular e de seção quadrada. Os ensaios foram realizados em túnel de vento de ar comprimido. Estudou-se o efeito do índice de área exposta e o número de Reynolds. Este trabalho é importante para estruturas compostas de perfis arredondados em que o número de Reynolds é um parâmetro importante para se determinar o carregamento do vento.

Outro trabalho importante é o de WHITBREAD (1981) que investigou a influência do efeito de proteção nas forças do vento em estruturas reticuladas levando em consideração o índice de área exposta, o espaçamento entre treliças, o número de treliças e o tipo da barra do reticulado. WHITBREAD propôs um modelo empírico para determinação do efeito de proteção em relação ao espaçamento entre reticulados e ao índice de área exposta, atualizando o modelo proposto anteriormente por FLACHBART.

GEORGIOU; VICKERY (1979), apresentaram um trabalho mais profundo sobre o efeito do vento em reticulados planos, tema da dissertação de mestrado de GEORGIOU (1979). Em relação ao efeito de proteção entre reticulados foram investigadas as influências do ângulo de incidência do vento, do índice de área expostas, do espaçamento entre reticulados, da razão de aspecto e do número de reticulados.

GEORGIOU (1979) mostrou também que a influência da turbulência atmosférica nos resultados médios é mínima e pode ser desconsiderada. Nessa investigação experimental foram mostradas as divergências entre as diversas normas existentes na 
época e os resultados experimentais. Atualmente algumas normas sobre o efeito do vento em reticulados baseiam-se nesse trabalho.

Mais recentemente, SIMIU; SCANLAN (1996), em seu livro sobre o efeito do vento em estruturas apresentou os estudos já desenvolvidos sobre estruturas reticuladas, incluindo torres treliçadas de seção triangular e quadrada compostas por elementos circulares ou de pontas afiladas.

No estudo de torres treliçadas merecem referência a norma britânica BS 8100 (1986) e os dados fornecidos pelo Engineering Science Data Unit ESDU 81027 (1982).

Atualmente algumas normas estão em preparação para serem publicadas: a norma americana "ASCE Guide for the Dynamic Response of Lattice Towers" e a parte 3 da norma britânica "BS 8100 - Lattice Towers and Masts", conforme os comentários de SMITH, (1999). 


\section{LA RESISTANCE DE LAIR ET LAVIATION}

Poussées sup des treillis parallèles de $20.2 \times 403$

Vue d'un treiflis Ech. $1 / 20$

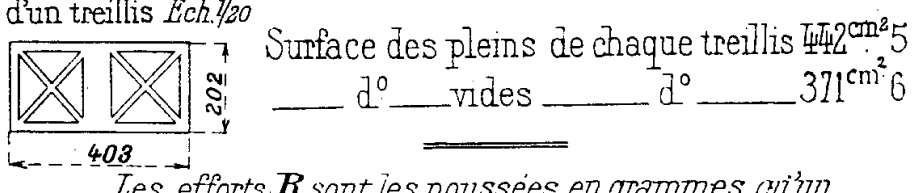

Les efforts $R$ sont les poussées en grammes quizun

vent de $10^{\mathrm{m}} \mathrm{s}$ exercerait sur les treillis expérimentés

Ies coefficients $K_{\text {sont }}$ calculés en comptant pour surface $4 \Psi 2 \mathrm{~cm}^{2} 5$ surface des plems d'un serzl trenllis

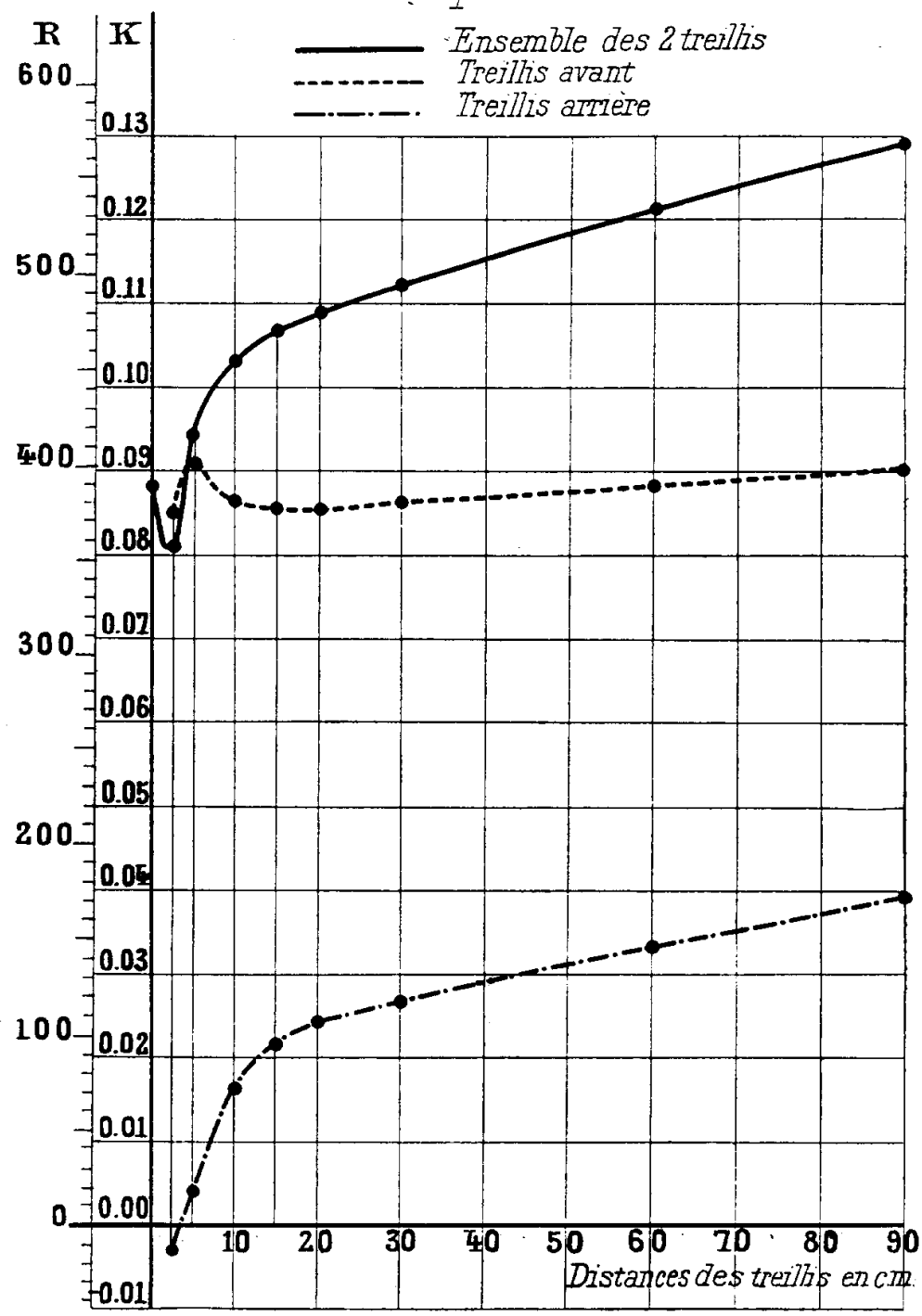

Figura 2.2 - Resultados experimentais: G. EIFFEL (1911) 


\subsection{Procedimentos de projeto}

No Brasil, não há uma norma específica para se determinar as forças e o efeito do vento em torres de telecomunicações. A norma NBR6123 (1988) fornece diretrizes para se determinar as forças do vento em torres treliçadas dentro de um contexto mais geral. Pretende-se, portanto, discriminar os principais pontos relacionados a torres treliçadas fornecidos pela norma brasileira, completando com as sugestões deste trabalho. Não se

pretende esgotar o assunto dada a sua complexidade, mas fornecer subsídios para trabalhos futuros na área.

Esta seção traz um procedimento de projeto para o cálculo das forças do vento e seus efeitos em estruturas de torres para telecomunicações. A seção é separada em duas partes: a primeira parte refere-se aos parâmetros meteorológicos como a velocidade do vento, rugosidade do terreno e topografia; a segunda parte refere-se à determinação dos coeficientes de arrasto médio em torres simétricas considerando a presença de antenas, cabos e escadas marinheiro. O cálculo da resposta dinâmica da torre devido à turbulência do vento atmosférico é estudado no capítulo 3 deste trabalho.

Para isso, seguem-se as conclusões da investigação numérica e experimental e as recomendações da norma NBR6123. Não é objetivo estudar o mérito de todos os coeficientes das normas referenciadas, apenas são usados no procedimento de cálculo, admitindo-se sua validade. 


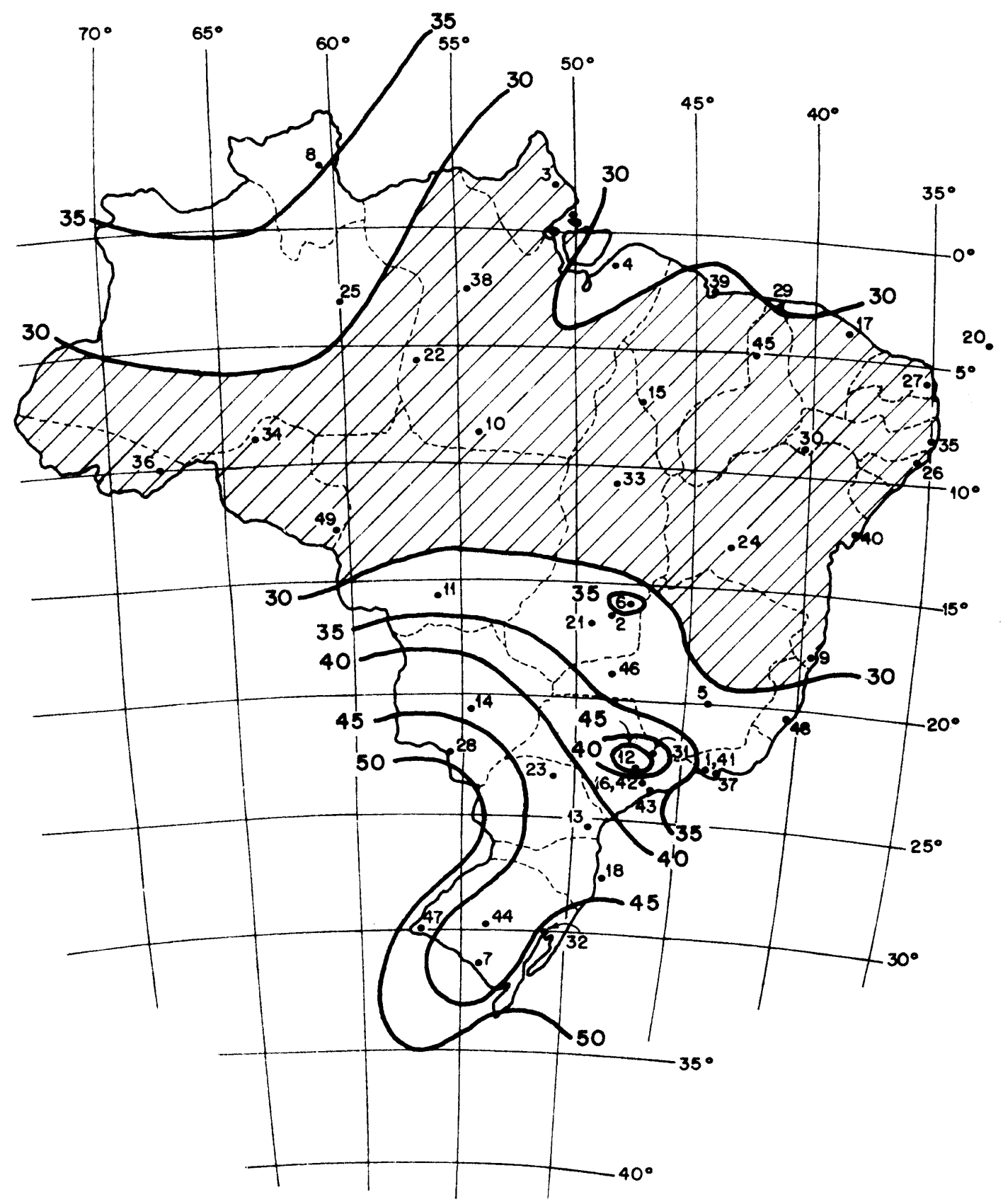

Figura 2.3 - Isopletas da velocidade básica Vo (m/s) (NBR 6123/88)

$\mathrm{V}_{\mathrm{o}}$ : máxima velocidade média sobre $3 \mathrm{~s}$, que pode ser excedida em média uma vez em 50 anos, a $10 \mathrm{~m}$ sobre o nível do terreno em lugar aberto e plano. 


\subsubsection{Fatores meteorológicos}

Os fatores meteorológicos são determinados a partir da norma NBR6123/1988. Nesse assunto, muito há ainda por fazer para aprimorar os dados existentes, como uma atualização das medidas da velocidade básica do vento no território nacional. Ela é definida como a velocidade de uma rajada de 3 segundos, excedida em média uma vez em 50 anos, a 10 metros acima do solo em campo aberto e plano. As isopletas de velocidade básica, figura 2.3, retirada da NBR6123/88, permitem sua determinação.

A velocidade característica é determinada por:

$\mathrm{V}_{\mathrm{k}}=\mathrm{V}_{0} \mathrm{~S}_{1} \mathrm{~S}_{2} \mathrm{~S}_{3}$

onde $S_{1}$ é o fator topográfico; $S_{2}$ depende da rugosidade do terreno, dimensões da edificação e altura sobre o terreno; e $\mathrm{S}_{3}$ é o fator estatístico que, para o caso de torres de telecomunicações, é considerado de valor 1,1. Os fatores $S_{1}$ e $S_{2}$ são determinados a partir das recomendações da NBR6123/1988.

$\mathrm{O}$ fator $\mathrm{S}_{2}$ leva em consideração o perfil de velocidade do vento na atmosfera conforme o tipo de terreno. A norma brasileira separa rugosidade do terreno em 4 categorias: categoria I, superfícies lisas de grandes dimensões; categoria II, terrenos abertos com poucos obstáculos; categoria III, terrenos planos ou ondulados com obstáculos, tais como sebes e muros; categoria IV, terrenos cobertos por obstáculos numerosos e pouco espaçados; e categoria $\mathrm{V}$, terrenos cobertos por obstáculos numerosos, grandes, altos e pouco espaçados. $\mathrm{O}$ fator $\mathrm{S}_{2}$ também considera a duração da rajada para que o vento englobe toda a estrutura. Nesse caso a norma brasileira fornece três tipos de edificações: classe A - edificações menores que 20 metros, ou unidades de vedação (duração da rajada de 3 segundos); classe B - edificações entre 20 e 50 metros (duração da rajada de 5 segundos); e classe C - Dimensões da edificação maiores que 50 metros (rajadas de 10 segundos).

O fator topográfico $S_{1}$ leva em consideração o aumento da velocidade do vento na presença de morros e taludes, mas não considera a diminuição da turbulência com o aumento da velocidade do vento. A turbulência é importante para a determinação da 
resposta dinâmica de estruturas esbeltas, como o caso de algumas torres de telecomunicações. São necessários novos estudos experimentais e numéricos para determinar essa diminuição da intensidade de turbulência causada pela presença de aclives.

\subsubsection{Determinação dos coeficientes de arrasto de torres treliçadas}

O cálculo segue as recomendações da NBR6123 (1988) que determina quais os coeficientes de arrasto longitudinal para as torres treliçadas. A norma apresenta um gráfico do coeficiente de arrasto $\mathrm{C}_{\mathrm{a}}$ com o índice de área exposta $\phi$ para diversos tipos de torre. As figuras 2.4 a 2.8 e a tabela 2.2 retiradas da NBR6123 fornecem os dados necessários para determinar o coeficiente de arrasto nas torres usuais.

Nas figuras apresentadas a seguir, o coeficiente de arrasto $\mathrm{C}_{\mathrm{a}}$ é obtido experimentalmente, dividindo-se a força do vento na direção da velocidade média, pela força obtida com o produto da pressão dinâmica do vento e a área frontal efetiva de um reticulado. A equação 2.2, página 20, exemplifica a definição. O índice de área exposta $\phi$ é obtido dividindo-se a área frontal efetiva de um reticulado $\mathrm{A}_{e}$, pela área frontal $\mathrm{A}$ da superfície limitada pelo contorno do reticulado.
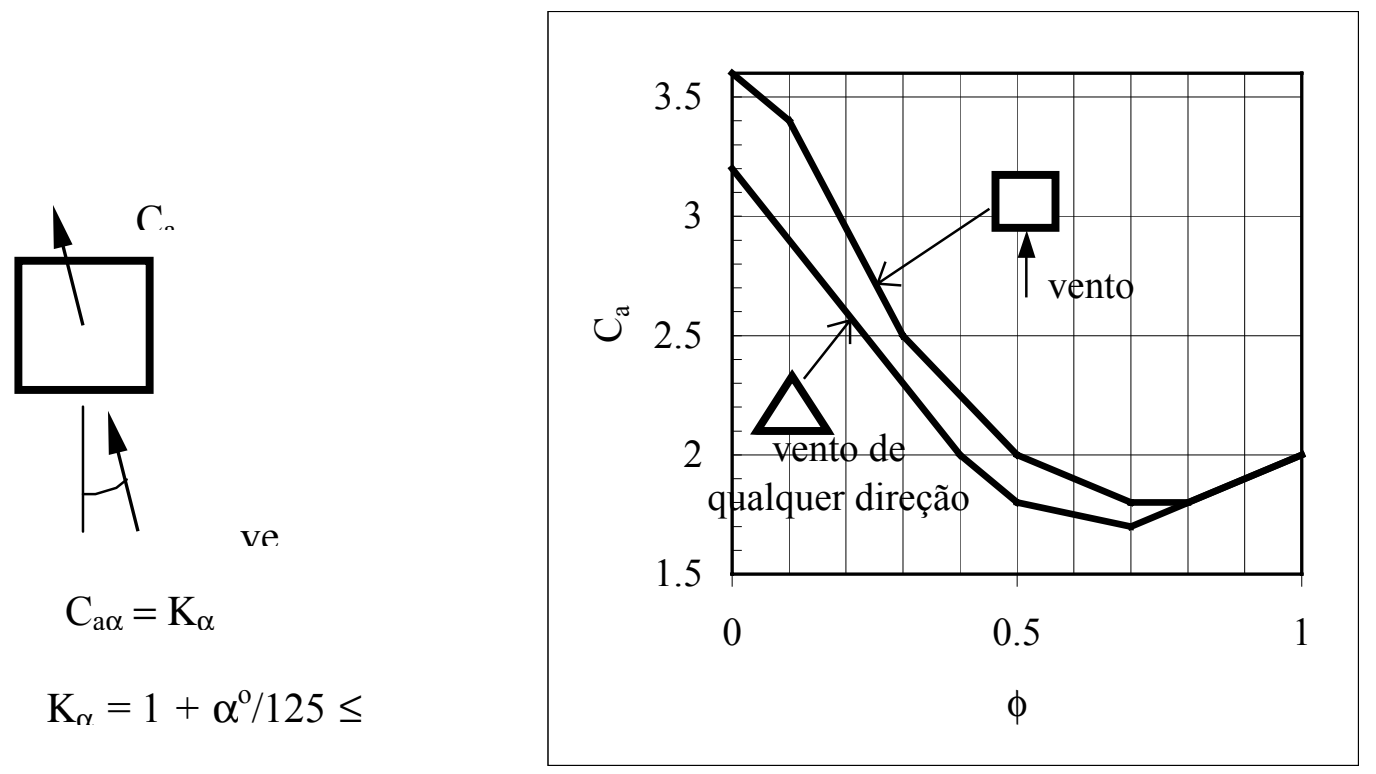

Figura 2.4 - Coeficiente de arrasto, $\mathrm{C}_{\mathrm{a}}$, para torres reticuladas de seção quadrada e triangular equilátera, formadas por barras prismáticas de cantos vivos ou levemente arredondados. NBR 6123 (1988) 


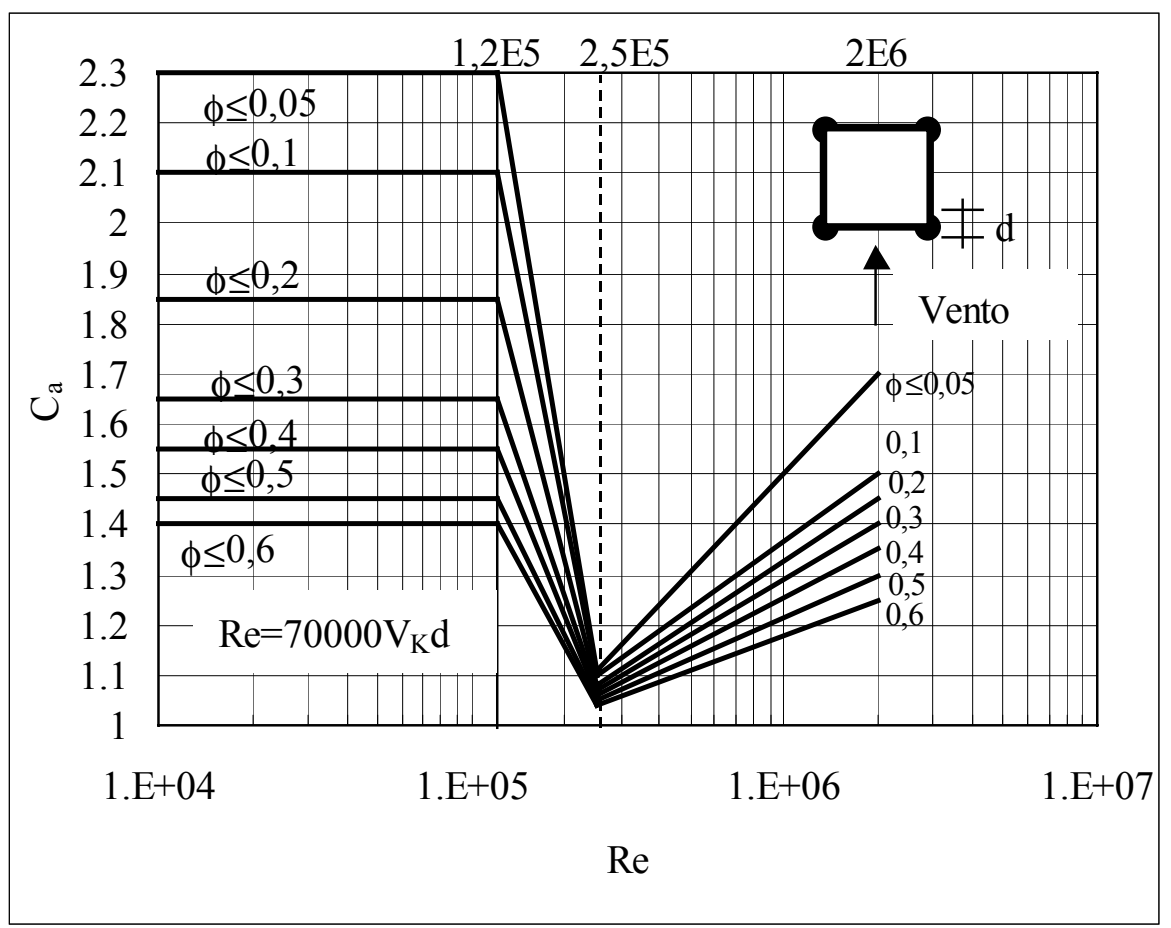

Figura 2.5 - Coeficiente de arrasto para torres reticuladas de seção quadrada, formada por barras de seção circular. Vento incidindo perpendicularmente a duas faces paralelas. NBR6123 (1988).

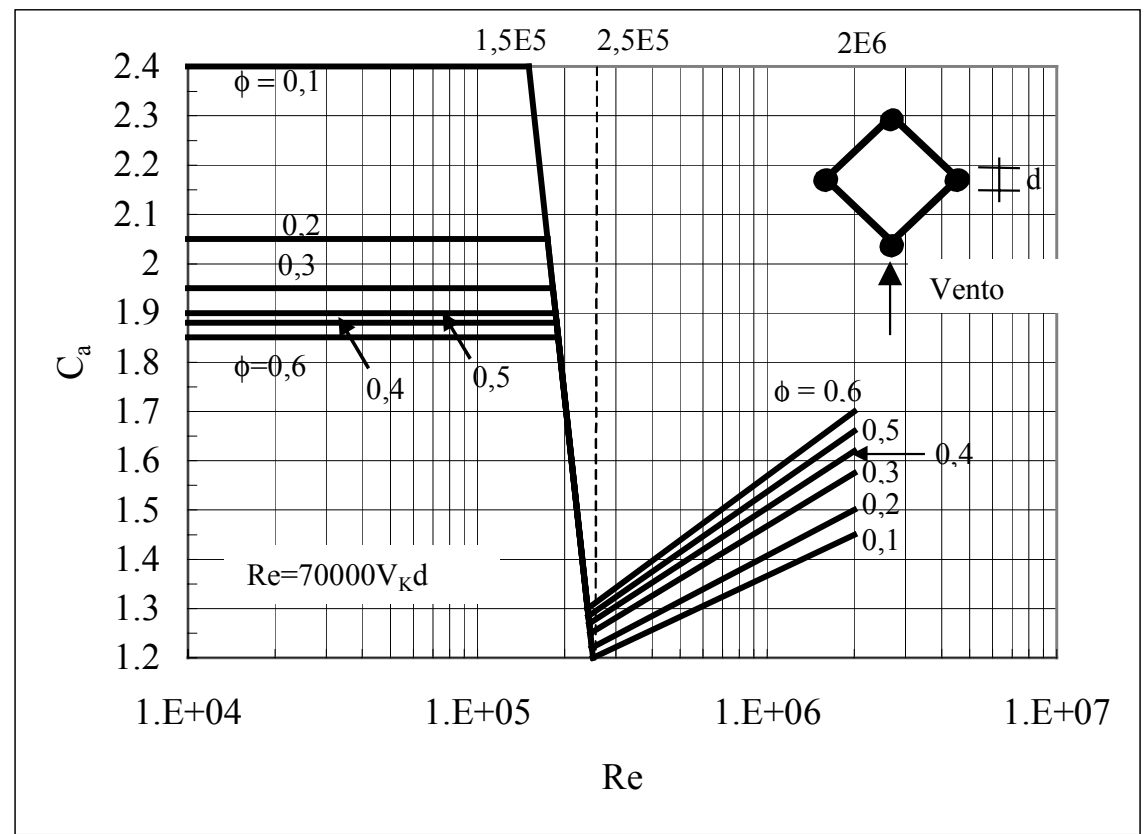

Figura 2.6 - Coeficiente de arrasto, $\mathrm{C}_{\mathrm{a}}$, para torres reticuladas de seção quadrada, formada por barras de seção circular. Vento incidindo segundo uma diagonal. NBR6123 (1988). 


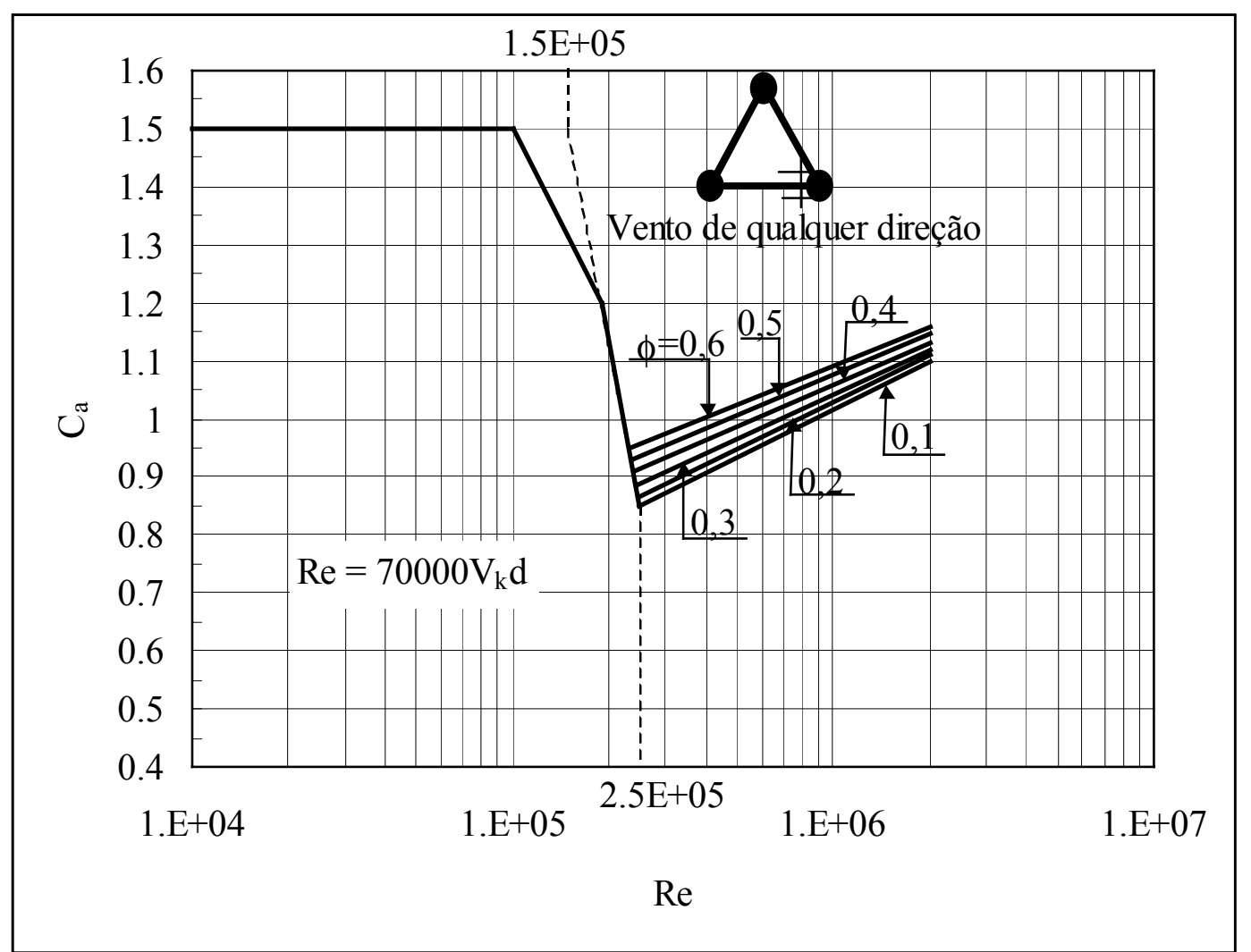

Figura 2.7 - Coeficiente de arrasto, $\mathrm{C}_{\mathrm{a}}$, para torres reticuladas de seção triangular equilátera, formadas por barras de seção circular. Vento em qualquer direção.

$$
\text { NBR6123 (1988). }
$$

A tabela 2.2 fornece valores que multiplicados pela força de arrasto, $\mathrm{F}_{\mathrm{a}}$, fornecem as componentes da mesma nas faces da torre. Nessa tabela, $\eta$ é o fator de proteção de um reticulado em relação a outro, e é determinado conforme o gráfico da figura 2.8 .

Os valores experimentais encontrados nesse trabalho referentes a torres de seção quadrada e perfis com seção transversal de pontas afiladas indicam que, dentro da faixa do índice de área exposta estudada, a norma NBR6123 pode ser utilizada com segurança (ver item 5.1). 
Tabela 2.2 - Componentes da força de arrasto nas faces de torres reticuladas de seção quadrada ou triangular equilátera.

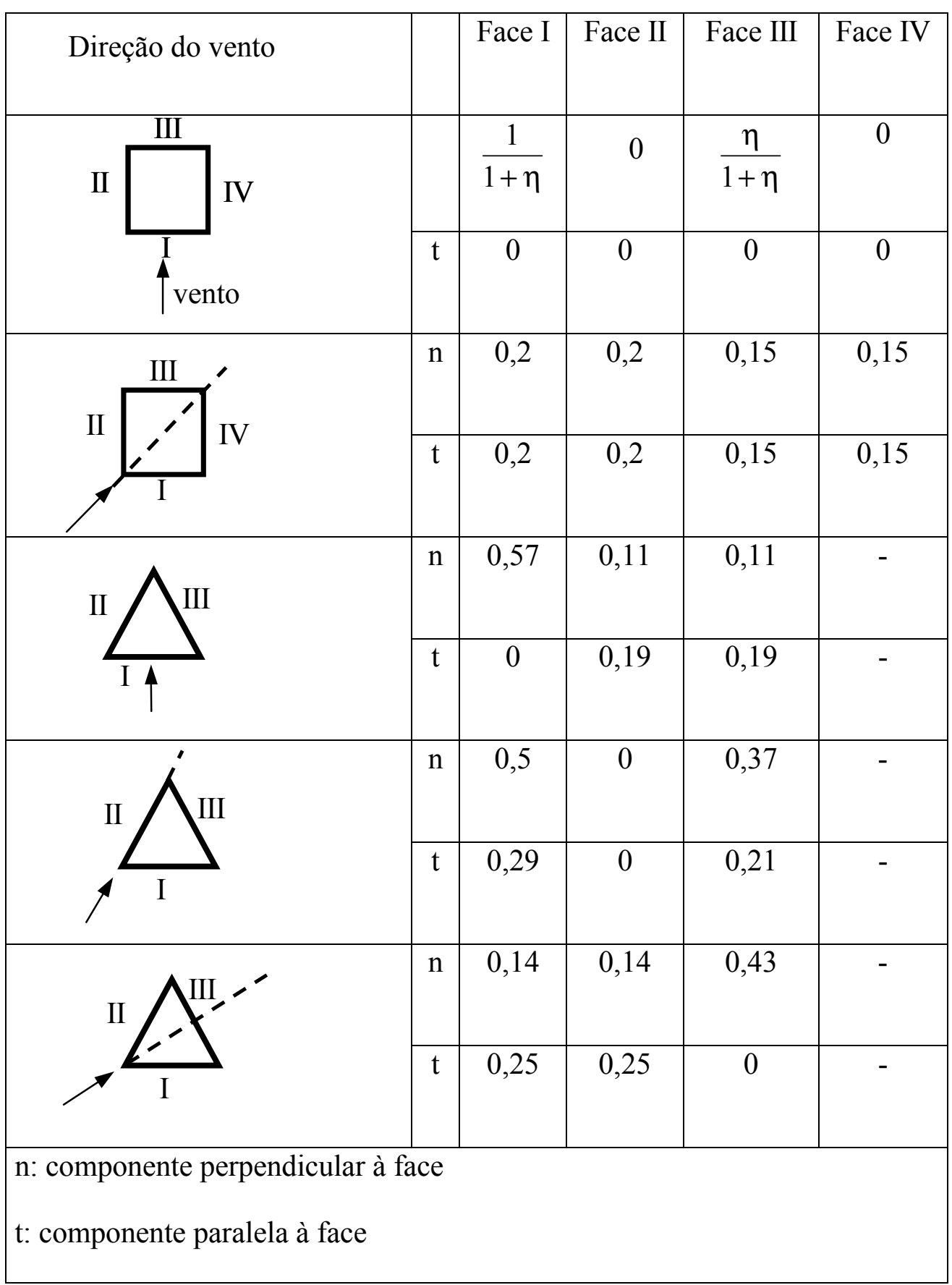




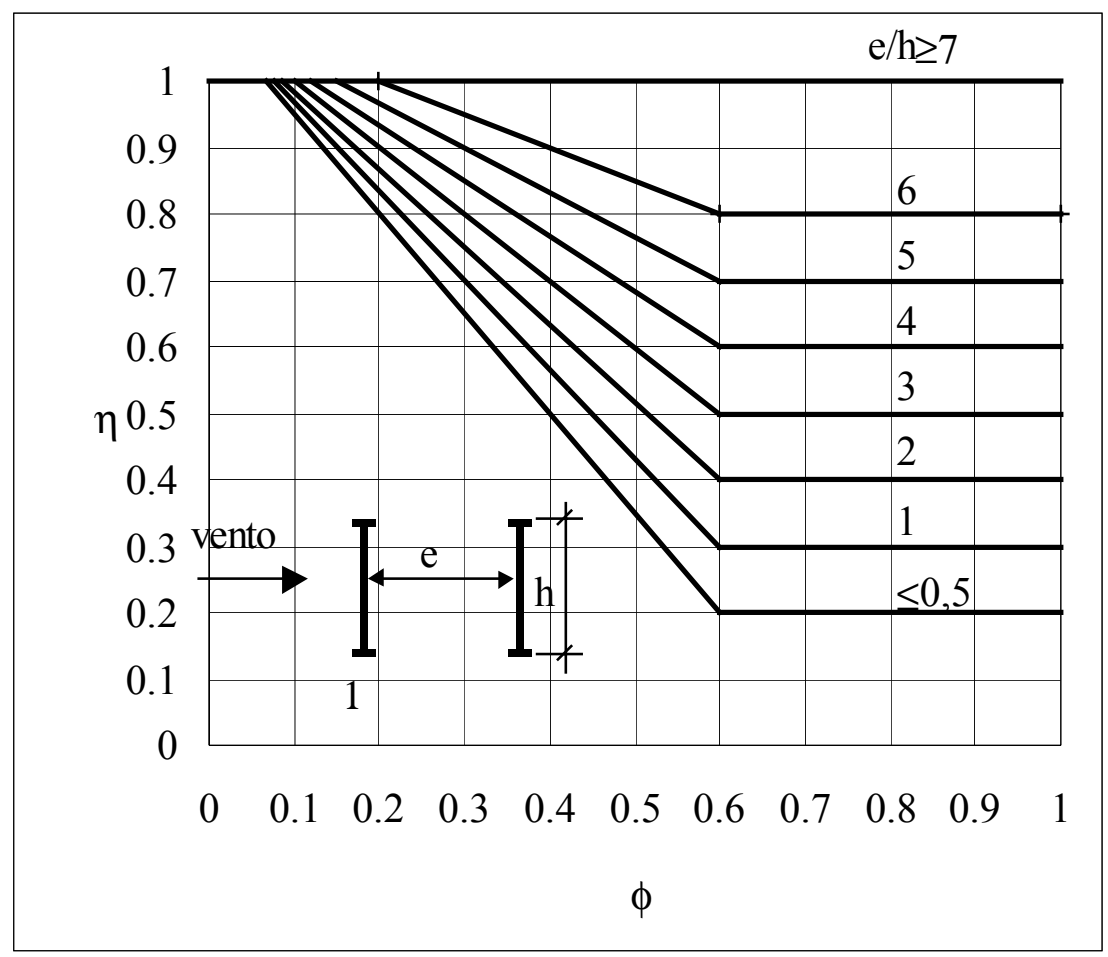

Figura 2.8 - Fator de proteção, $\eta$, para dois ou mais reticulados paralelos igualmente afastados, NBR6123 (1988).

A torre deve ser separada em painéis com diferentes índices de área exposta, e o coeficiente de arrasto deve ser determinado para cada painel de torre. A força no trecho considerado é determinada por:

$\mathrm{F}_{\mathrm{a}}=\mathrm{C}_{\mathrm{a}} \phi \mathrm{Aq}$

onde q é a pressão dinâmica do vento dada por:

$\mathrm{q}=0,613 \mathrm{~V}_{\mathrm{k}}^{2}$

A é a área delimitada pelos limites externos do painel de barlavento da torre e $\phi$ é o índice de área exposta. Observa-se que $\mathrm{q}$ e $\mathrm{V}_{\mathrm{k}}$ variam com a altitude.

Devem ser consideradas também as forças do vento em estruturas adicionais como: escadas marinheiro; plataformas; tubulações; estruturas de antenas celulares e de microondas. A norma Brasileira não especifica como determinar essas forças do vento adicionais, apenas fornece o coeficiente de arrasto para perfis e tubos de comprimento 
infinito. As forças do vento são simplesmente adicionadas sem considerar a proteção de um elemento sobre o outro. Embora a investigação experimental realizada seja restrita a determinado tipo de antena de microondas, pretende-se, a partir de normas estrangeiras, apresentar um procedimento de cálculo para a determinação dessas forças adicionais.

\subsubsection{Torres simétricas com estruturas adicionais}

Sugeriu-se nesse trabalho que, para torres cujo índice de área exposta é menor que 0,2 , as forças de arrasto na torre e nas estruturas adicionais podem ser determinadas como se fossem estruturas independentes e, para torres com índice de área exposta maior, um fator de interferência deve ser considerado. No entanto, HOLMES et al. (1993), fornecem dados experimentais de antenas de microondas fixadas no painel da torre, indicando fatores de interferência maiores que 1, da ordem de 1,3, para determinada posição relativa da antena na torre e do ângulo de incidência do vento. Portanto, as sugestões que aqui são feitas com base nos estudos experimentais apresentados no item 4.3.5 devem ser utilizadas com cautela, sendo ainda necessário novos ensaios experimentais para comprovação dos valores especificados do fator de interferência fornecidos por HOLMES et al (1993).

$\mathrm{Na}$ falta de dados sobre o efeito de proteção do painel da torre em escadas marinheiro, tubulações elétricas, ou outra estrutura adicional qualquer, as forças de arrasto da torre e dos objetos adicionais podem ser simplesmente adicionadas. Considerando-se apenas antenas de microondas posicionadas na face de barlavento da torre com vento perpendicular a ela, pode-se adotar o mesmo procedimento quando o índice de área exposta do painel da torre não ultrapassar 0,2. Para valores do índice de área exposta maiores que 0,2 , pode-se usar o fator de interferência $f_{a}$, equação 2.5 , para determinar os coeficientes de arrasto adicionais. Este fator é aplicado no segundo termo da equação 2.4. No caso deste trabalho, sugere-se que se use a expressão empírica da equação 4.5, página 81, indicada pelo ESDU 81028 (1990).

Portanto, o resultado da força de arrasto final em cada painel de torre será:

$\mathrm{F}_{\mathrm{a}}=\mathrm{C}_{\mathrm{a}} \phi \mathrm{Aq}+\sum_{\mathrm{i}} \mathrm{f}_{\mathrm{ai}} \mathrm{C}_{\mathrm{ai}} \mathrm{q}_{\mathrm{i}}$

onde $\mathrm{f}_{\mathrm{ai}}$ é o fator de interferência de cada antena adicional dada por 
$\mathrm{f}_{\mathrm{ai}}=\frac{\Delta \mathrm{C}_{\mathrm{a}_{-} \text {antenana_na_torre }}}{\mathrm{C}_{\text {_antena_separada }}}$

ESDU81021 (1990) propôs uma fórmula empírica para $\mathrm{f}_{\mathrm{a}}$ dada por:

$\mathrm{f}_{\mathrm{a}}=\exp \left[-\mathrm{k}\left(\mathrm{C}_{\mathrm{a}} \phi\right)^{2}\right]$

onde k é 1,2 para torres de seção quadrada.

Para os casos mais genéricos da posição relativa da antena de microonda na torre com direções de vento variáveis, pode-se determinar o fator de interferência com a fórmula empírica 2.6, modificada por HOLMES et al. (1993), na forma:

$f_{a}=\exp \left[-k\left(C_{a} \phi\right)^{2} \llbracket\left[(1+b)+b \cos 2\left(\alpha-\alpha_{d}-90\right)\right]\right.$

onde $\mathrm{b}$ é um parâmetro de ajuste, $\alpha_{\mathrm{d}}$ é o ângulo normal à antena em relação à torre, $\alpha$ é o ângulo de incidência do vento em relação à torre (figura 4.27), k é 1,2 para torres de seção quadrada e 1,8 para torres de seção triangular. No entanto, a aplicação prática da equação 2.7 depende do parâmetro $b$ que depende de ajustes experimentais. HOLMES et al. (1993) sugerem o valor de 0,5 para b, conforme os ajustes dos dados experimentais por ele obtidos. São necessários, portanto, novos estudos experimentais para avaliar o parâmetro b, considerando outros tipos de antenas de microondas e torres com índice de esbeltez diferentes dos testados por HOLMES et al (1993). No capítulo 4 este assunto é novamente abordado e nele aparecem os resultados experimentais dos fatores de interferência obtidos apenas para $\alpha_{d}$ e $\alpha$ iguais a zero e para antenas de microondas com capas de proteção. Neste caso conclui-se que o valor de b pode ser nulo e a equação 2.7 iguala-se à equação 2.6. Observa-se, ainda, que os valores encontrados para índices de esbeltez de 0,162 foram maiores que os fornecidos pela equação 2.6, mas menores que a unidade, sugerindo-se que não se aplique o fator de interferência nesse caso. 


\section{MÉTODOS ANALÍTICOS E NUMÉRICOS}

Neste capítulo, são apresentados os fundamentos para o cálculo da resposta dinâmica de estruturas submetidas à ação do vento turbulento e apresentada uma aplicação a um exemplo, utilizando vários procedimentos analíticos e numéricos. Os procedimentos adotados pelas normas existentes para determinar a resposta dinâmica de estruturas esbeltas seguem as bases fornecidas por Davenport, que caracterizam estatisticamente as propriedades da turbulência do vento na atmosfera. Os primeiros estudos começaram na década de 1960 com os trabalhos de DAVENPORT (1961, 1966, 1967). VICKERY (1972) colaborou com trabalhos experimentais no desenvolvimento do método. Atualmente, algumas normas empregam os mesmos procedimentos introduzidos por Davenport e outras o fazem de modo ligeiramente diferente, mas com os mesmos fundamentos. É o caso das normas Canadense NBCC (1995), Americana ASCE 7-95 9 (1995), Britânica BS8100 (1986), Australiana AS 1179.2 (1989) e Européia EUROCODE 1 (1991). A norma Brasileira também segue os fundamentos introduzidos por DAVENPORT com algumas modificações ao calcular a resposta flutuante da estrutura conforme RIERA; BLESSMANN (1979), RIERA; GALINDEZ (1979) e BLESSMANN (1998).

Estudos ainda mais atuais envolvem o cálculo de estruturas esbeltas como chaminés e torres incluindo a resposta transversal da estrutura, como os de VICKERY (1997) e DAVENPORT $(1992,1993,1995)$. Nesses trabalhos, aparece o conceito de linhas de influência que relacionam a carga do vento com a resposta da estrutura. HOLMES (1994) desenvolveu o método estatístico de Davenport para torres treliçadas esbeltas com inclinação constante, permitindo o cálculo da resposta da estrutura na direção do vento médio, com o auxílio de planilhas eletrônicas usuais. 


\subsection{Fundamentos para o cálculo de estruturas esbeltas submetidas ao efeito dinâmico do vento de natureza aleatória}

O cálculo do efeito dinâmico do vento de natureza aleatória, sobre estruturas esbeltas incluindo as torres de telecomunicações é composto de três estágios básicos: a descrição do vento, a descrição das propriedades físicas e aerodinâmicas da estrutura e a combinação desses fatores na determinação da resposta da estrutura.

A variação da velocidade do vento ao longo do tempo é composta de uma parte média e uma parte flutuante (figura 3.1).

$\mathrm{V}(\mathrm{t})=\overline{\mathrm{V}}+\mathrm{v}(\mathrm{t})$

A determinação da velocidade média do vento depende dos dados meteorológicos existentes. A maioria das estações meteorológicas fornecem dados sobre a velocidade média do vento em uma hora de observação (velocidade média horária). Utilizando-se um conjunto de dados sobre o valor máximo anual dessa velocidade fornecido por determinada estação de observação, a velocidade do vento associada a qualquer probabilidade pode ser determinada com uma análise estatística de valores extremos. Se utilizarmos vários locais de observações espalhados pelo país, pode-se desenhar as curvas das velocidades do vento associada a uma determinada probabilidade (isopletas). Definindo-se a probabilidade de determinada velocidade do vento ser alcançada ou ultrapassada como $\mathrm{P}(>\mathrm{V})$, a norma brasileira NBR6123 (1988), por exemplo, fornece as curvas da velocidade de rajada de 3 s associada a uma probabilidade anual de $\mathrm{P}(>\mathrm{V})=$ 0,02 (figura 2.3). Esse valor indica que a máxima velocidade média anual medida sobre 3s pode ser ultrapassada em média uma vez a cada 50 anos. Esse número de anos equivale ao período de retorno ou intervalo de recorrência definido como o inverso dessa probabilidade anual $\mathrm{R}=1 / \mathrm{P}(>\mathrm{V})$.

As medidas da velocidade do vento especificadas nas normas são realizadas a 10 metros de altura do solo. Para transformar a velocidade de rajada medida em 3 segundos de observação na velocidade média horária, a norma brasileira fornece os fatores que multiplicados pela velocidade de rajada permitem obter esta última. A norma brasileira define esse multiplicador como sendo um fator de rajada, diferentemente de outras normas que definem o fator de rajada como um multiplicador da resposta média da 
estrutura para obter o valor de pico da mesma. Maiores detalhes sobre a determinação da velocidade média do vento podem ser vistos em ANTONY (1970).

A parte flutuante da velocidade do vento pode ser definida pela distribuição de probabilidade, pelo espectro de potência e pelas funções de correlação cruzada. Para melhor compreender o significado desses termos, que são utilizados no procedimento de cálculo de estruturas sujeitas à ação das rajadas, é necessário fazer algumas considerações sobre o vento e definir alguns parâmetros estatísticos.

A figura 3.1 e equação 3.1 mostram uma possível série temporal da velocidade do vento caracterizada por uma média e uma velocidade flutuante. Para caracterização da parte flutuante da velocidade utiliza-se a teoria das probabilidades e a estatística.

Para a engenharia civil, admite-se que as rajadas de vento constituem um processo aleatório estacionário, em que as propriedades estatísticas são invariantes para qualquer mudança da origem do tempo da série temporal. Admite-se, também, que as rajadas do vento constituem um processo estacionário e ergódico, em que as propriedades estatísticas calculadas sobre uma única amostra são as mesmas que os valores calculados sobre um conjunto de amostras.

O engenheiro estrutural não necessita determinar os parâmetros estatísticos da rajada para projetar uma estrutura, mas para se entender os conceitos e a terminologia usada no processo de cálculo, apresentam-se a seguir, generalidades sobre alguns parâmetros estatísticos de um processo aleatório.

A estimativa da variância $\sigma^{2}(\mathrm{v})$ pode ser determinada a partir de uma série temporal de velocidades do vento (figura 3.1) pela soma dos quadrados da velocidade flutuante $\mathrm{v}(\mathrm{t})$ dividida pelo número de valores da amostra. O resultado é chamado de valor quadrado médio $\widetilde{\mathrm{v}}^{2}$ da velocidade de rajada. 


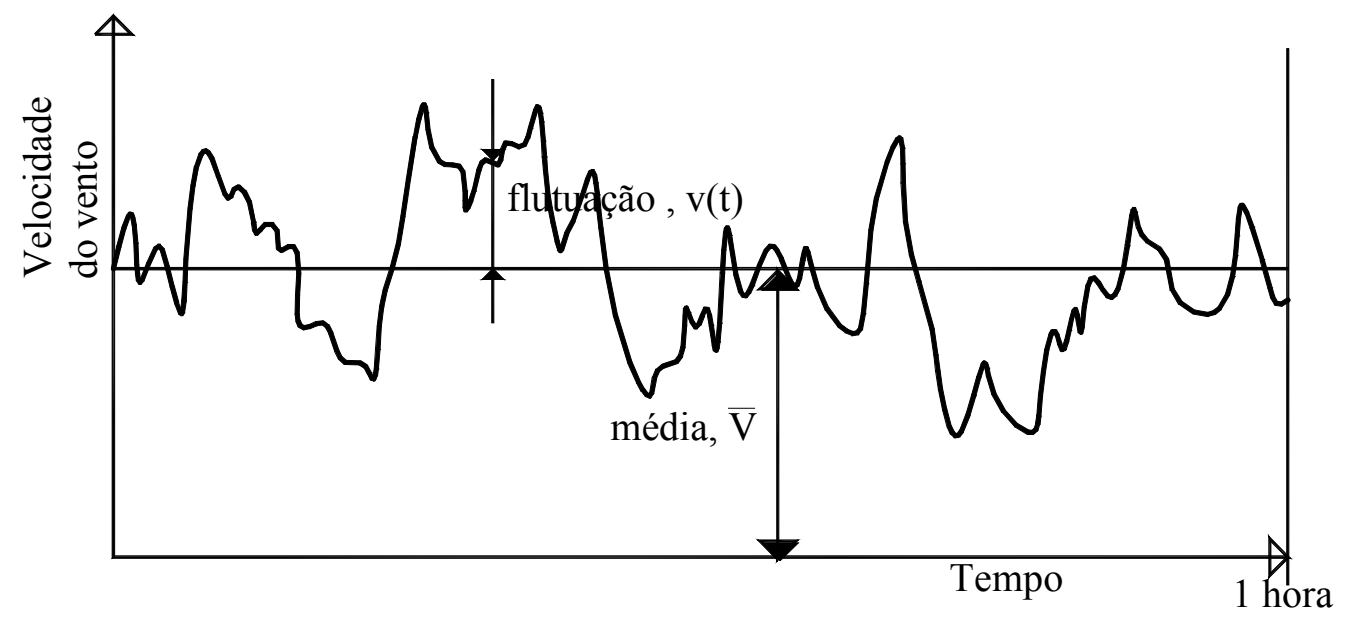

Figura 3.1- Velocidade média do vento e suas flutuações

O desvio padrão é o valor da raiz quadrada da variância e representa a medida da dispersão das velocidades de rajada em torno da média. O desvio padrão é referido neste trabalho como sendo a raiz quadrada do valor quadrado médio ("root mean square" em inglês ou valor rms), $\sigma(\mathrm{v})$ ou $\widetilde{\mathrm{v}}$, das flutuações da velocidade do vento. As rajadas do vento são representadas pela intensidade de turbulência, que é determinada pela razão entre o desvio padrão e o valor médio da velocidade do vento.

$I_{v}=\frac{\sigma(v)}{\bar{V}}=\frac{\widetilde{v}}{\bar{V}}$

A função de autocovariância, $C^{\mathrm{v}}(\tau)$, é umas das mais importantes funções na análise de séries aleatórias contínuas, já que leva diretamente ao espectro de potência e à medida da escala temporal do processo aleatório. A equação 3.3 define a autocovariância como sendo a média do produto das velocidades no tempo t e no tempo $\mathrm{t}+\tau$, ilustrada pela figura 3.2. Multiplicando-se, para cada tempo $t$, as velocidades $v(t) e$ $\mathrm{v}(\mathrm{t}+\tau)$, obtém-se o gráfico inferior da figura 3.2, cuja média é uma estimativa da autocovariância para o intervalo $\tau$, representada pela reta indicada. A estimativa será tanto melhor quanto maior for o tempo $t$ considerado.

$\mathrm{C}^{\mathrm{V}}(\tau)=\overline{\mathrm{v}(\mathrm{t}) \cdot \mathrm{v}(\mathrm{t}+\tau)}$ 

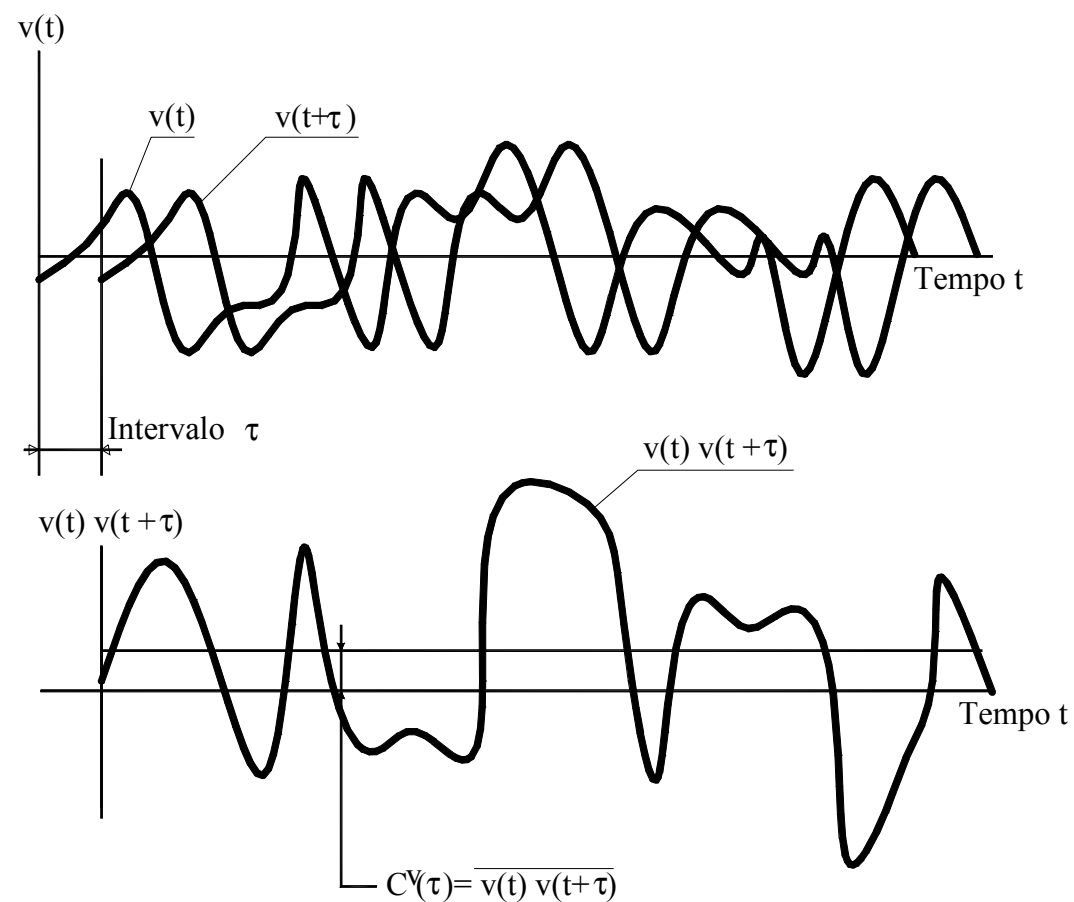

Figura 3.2- Representação gráfica da autocovariância

Supondo-se que as rajadas do vento constituam um processo estacionário, o valor da autocovariância é independente do tempo e é função somente do intervalo de tempo $\tau$. Calculando-se o valor da autocovariância para diferentes intervalos de tempo obtém-se um gráfico como o da figura 3.3. Observa-se que, para o intervalo de tempo nulo, a autocovariância é igual à variância.

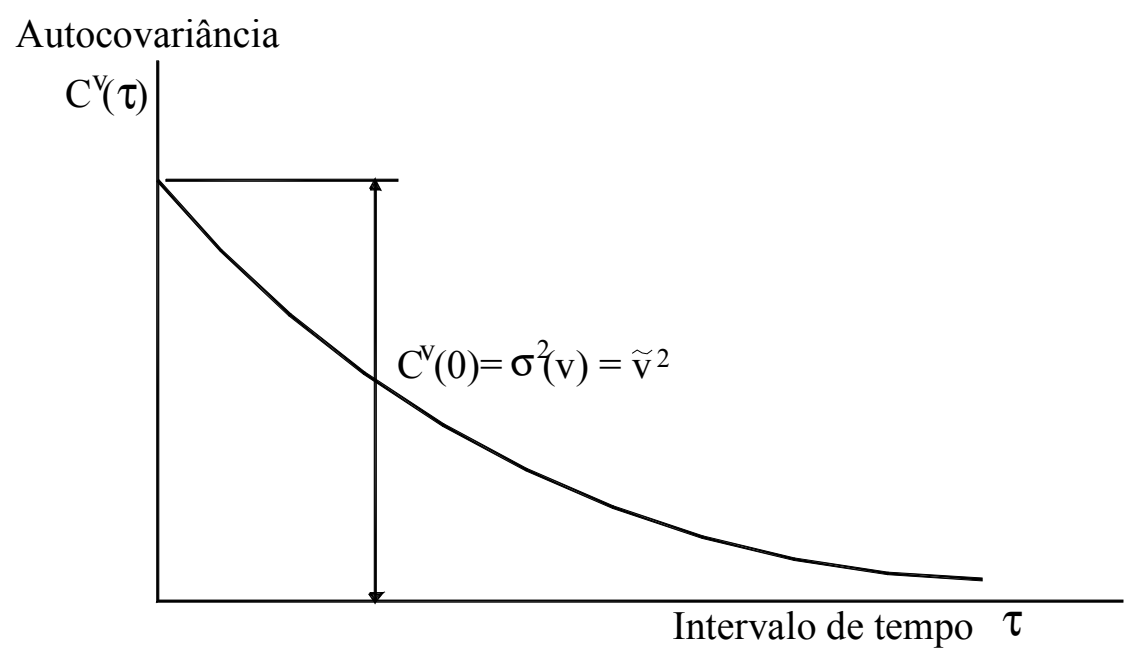

Figura 3.3 - Decaimento da autocovariância 
A autocorrelação $\rho^{\mathrm{v}}(\tau)$ é obtida dividindo-se a autocovariância pela variância. É utilizada para comparar séries temporais com diferentes escalas de medidas. $\mathrm{O}$ gráfico da autocorrelação tem a mesma forma que o da autocovariância, com a diferença que para o intervalo de tempo nulo, a autocorrelação tem valor unitário, como o ilustrado na figura 3.4.

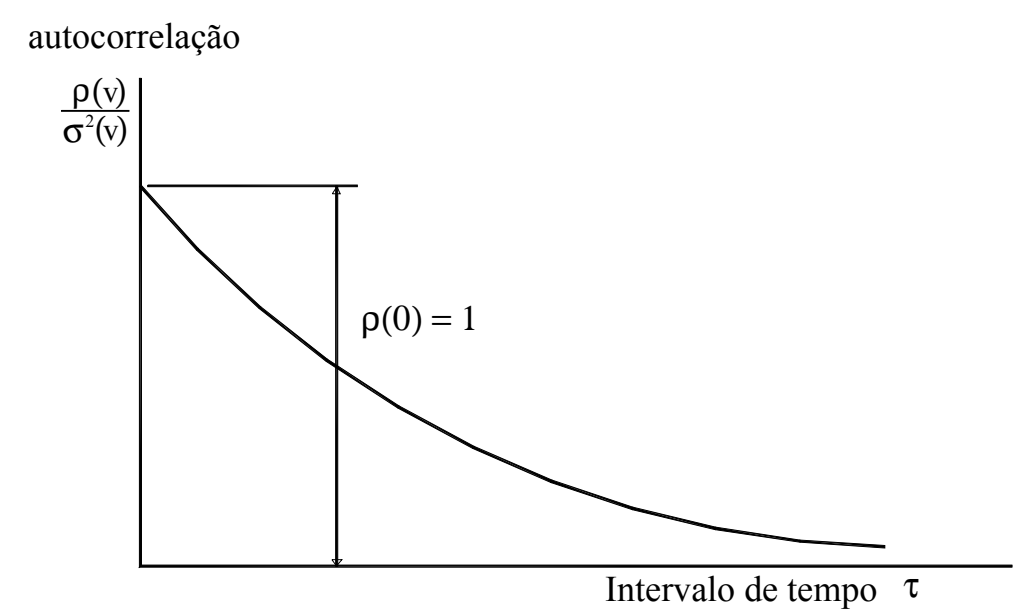

Figura 3.4 - Decaimento da autocorrelação

A área sob a curva de autocorrelação constitui uma medida da escala temporal do processo aleatório, ou seja, da distância de tempo sobre a qual há dependência entre os valores médios das flutuações.

Em vez de considerar a correlação temporal da componente longitudinal da velocidade do vento, considerando-se o intervalo de tempo (autocorrelação), pode-se determinar a correlação entre as mesmas componentes em dois pontos diferentes do espaço, considerando-se a distância entre os mesmos. É a chamada correlação espacial, que constitui uma medida da escala de turbulência, ou seja, do tamanho dos vórtices ou das rajadas do vento, conforme ilustrado na figura 3.5.

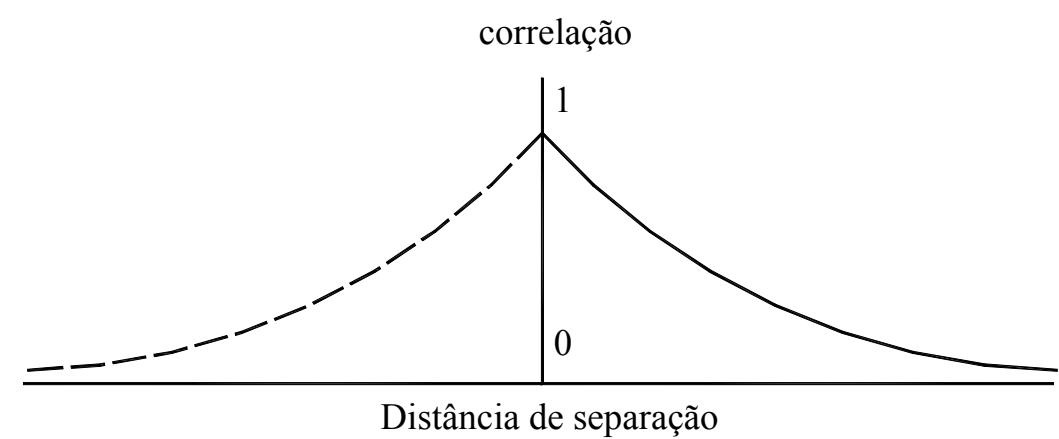

Figura 3.5 - Correlação espacial 
Para visualizar a prática da determinação da correlação espacial da velocidade do vento, imagina-se o uso de um anemômetro fixo e outro móvel. Se os dois anemômetros são colocados na mesma altura e as medidas simultâneas de velocidade longitudinal são feitas para várias distâncias transversais ao vento, obtém-se a correlação transversal da velocidade longitudinal do vento. Se o anemômetro móvel é colocado ao longo da altura, obtém-se a correlação vertical da velocidade longitudinal do vento. Se colocarmos o anemômetro móvel ao longo da direção do vento, obtém-se a correlação ao longo do vento da componente longitudinal da velocidade do vento. Essa correlação pode ser obtida a partir da autocorrelação, pois o espaço percorrido pela rajada está relacionado com o intervalo de tempo. Para uma velocidade média de $20 \mathrm{~m} / \mathrm{s}$, a distância de separação de 20 metros equivale ao intervalo de tempo de 1 segundo. Portanto a série temporal é levada para um ponto mais adiante do fluxo através da velocidade média do vento (Hipótese de Taylor). Esta hipótese não se aplica à correlação vertical da velocidade longitudinal do vento, pois a velocidade média varia com a altura.

O engenheiro estrutural deve analisar qual a correlação espacial indicada para o cálculo da estrutura em questão. Se for um prédio alto ou uma torre, deve-se usar a correlação vertical da componente longitudinal e transversal da velocidade do vento, visto que, em geral, há interesse na resposta da estrutura na direção do vento médio e transversal ao vento. Por outro lado, se a estrutura for uma ponte pênsil, deve-se usar a correlação horizontal da componente longitudinal e vertical da velocidade do vento.

Para se calcular uma estrutura seguindo os fundamentos aqui apresentados, utilizam-se as correlações cruzadas com o espectro de potência das rajadas do vento. A autocovariância e o espectro de potência formam um par de Transformadas de Fourier. Conhecendo-se a autocovariância, determina-se o espectro de potência.

O espectro de potência do vento define a energia contida nas rajadas em função da freqüência. A variância é o valor da autocovariância para o intervalo de tempo nulo, e representa a área sob a curva do espectro de potência. Conforme ilustrado na figura 3.6, dW é a energia ou variância associada a um elemento de freqüência df. Portanto a variância é dada por: 
$\sigma^{2}(\mathrm{v})=\int_{0}^{\infty} \mathrm{dW}=\int_{0}^{\infty} \mathrm{S}_{\mathrm{V}}(\mathrm{f}) \mathrm{df}$

Uma analogia com um conjunto de diapasões arranjados em ordem crescente de freqüência natural é bem propícia para o entendimento do espectro de potência. Cada diapasão vibra na sua freqüência natural emitindo um som característico. Sob o efeito de uma energia de caráter aleatório, a energia absorvida por cada diapasão é uma medida de sua contribuição para a energia total absorvida. Se o valor da energia particular de cada diapasão é colocado graficamente com relação à freqüência, obtém-se um gráfico de como a energia está distribuída ao longo da freqüência. A diferença entre esta ilustração e o espectro de potência é que as energias dos diapasões estão distribuídas discretamente ao longo da freqüência, e o espectro de potência é uma função contínua na faixa de freqüências estudadas.

Como no caso da autocovariância, é conveniente dividir o espectro de potência pela variância para comparar espectros de séries com diferentes escalas. A expressão resultante $S_{V}(f) / \sigma^{2}(v)$ é denominada função de densidade espectral ou espectro normalizado que, com a autocorrelação, formam um par de Transformadas de Fourier.

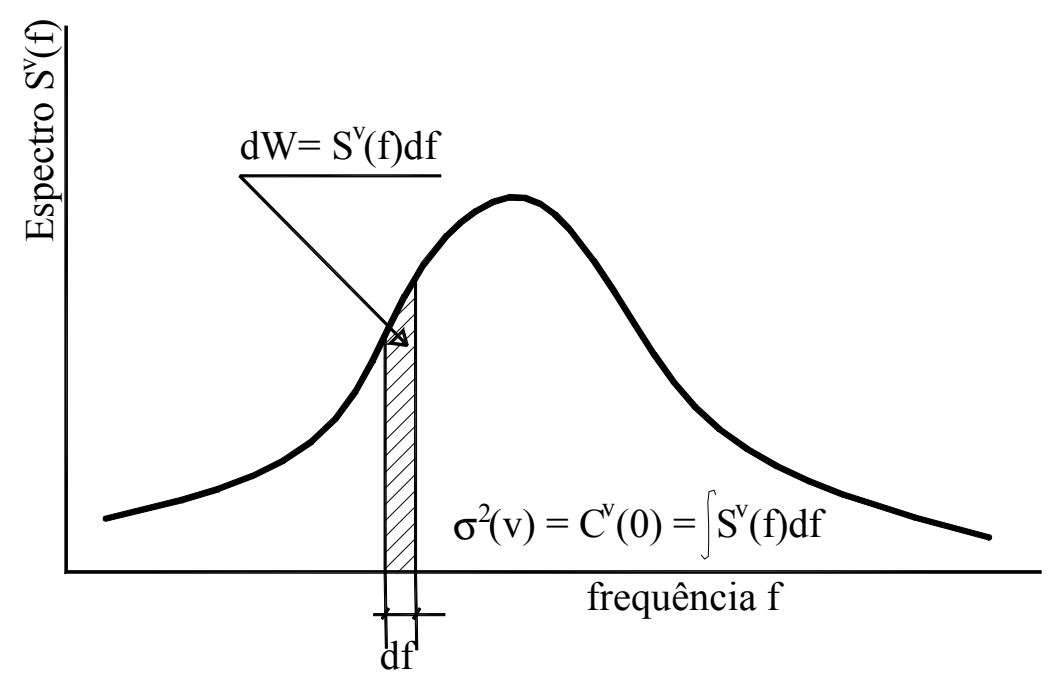

Figura 3.6 - Espectro de potência

De forma resumida, o vento médio é definido pela distribuição de probabilidades de valores extremos anuais. As rajadas são definidas pela distribuição de probabilidade, correlação cruzada e o espectro de potência das flutuações da velocidade do vento. Falta, portanto, definir a resposta da estrutura. Esta é, também, definida pela média, 
distribuição de probabilidade, correlação cruzada e espectro de potência das flutuações. A média da resposta é obtida a partir da média da velocidade do vento. A distribuição de probabilidades é definida pela média e pelo desvio padrão.

Para se obter o espectro de potência da resposta da estrutura é necessário definir duas funções: admitância mecânica e admitância aerodinâmica. Idealizando uma certa estrutura como uma mola sujeita a um carregamento harmônico senoidal, a variância do carregamento e a variância dos deslocamentos podem ser determinadas. A razão entre a variância do carregamento e a variância da resposta da estrutura é a admitância mecânica para uma determinada freqüência. Se calcularmos a mesma relação para diversas freqüências excitadoras, obtém-se um gráfico da admitância mecânica como o da figura 3.7. Para se obter o espectro de potência da resposta da estrutura, multiplica-se o espectro de potência do carregamento pela admitância mecânica:

$$
\frac{\mathrm{S}_{\mathrm{r}}(\mathrm{f})}{\widetilde{\mathrm{r}}^{2}}=\left|\chi_{\mathrm{m}}(\mathrm{f})\right|^{2} \frac{\mathrm{S}_{\mathrm{F}}(\mathrm{f})}{\widetilde{\mathrm{F}}^{2}}
$$

em que $\mathrm{r}$ representa a resposta da estrutura e $\mathrm{F}$ o carregamento. Os termos no denominador são as variâncias da resposta e do carregamento da estrutura. f é a freqüência e $\chi_{m}(f)$ é a admitância mecânica.

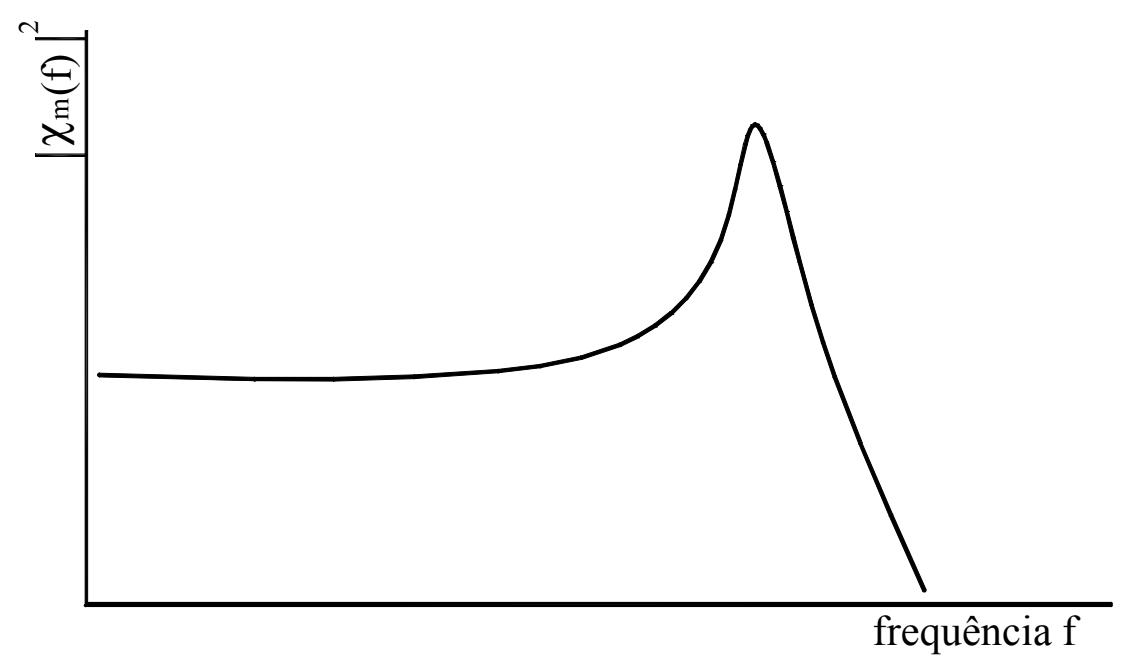

Figura 3.7- Admitância mecânica

A admitância aerodinâmica estabelece a relação entre o espectro da velocidade do vento e o espectro do carregamento do vento na estrutura. A função reflete a maneira 
como as forças aplicadas variam espacialmente sobre a estrutura e o efeito nos coeficientes de força devido às flutuações naturais do vento aplicado.

A admitância aerodinâmica depende da forma da estrutura (uma torre treliçada possui uma admitância aerodinâmica diferente de um edifício, por exemplo). Depende, também, da escala de turbulência do vento, ou seja, do tamanho das rajadas. Para freqüências baixas, a velocidade do vento pode ser considerada totalmente correlacionada ao longo da estrutura e, portanto a estrutura responderá a essas freqüências. Por outro lado, as freqüências altas das rajadas levam a correlações baixas ou nulas e a estrutura responde fracamente a essas freqüências, diminuindo o valor da admitância aerodinâmica.

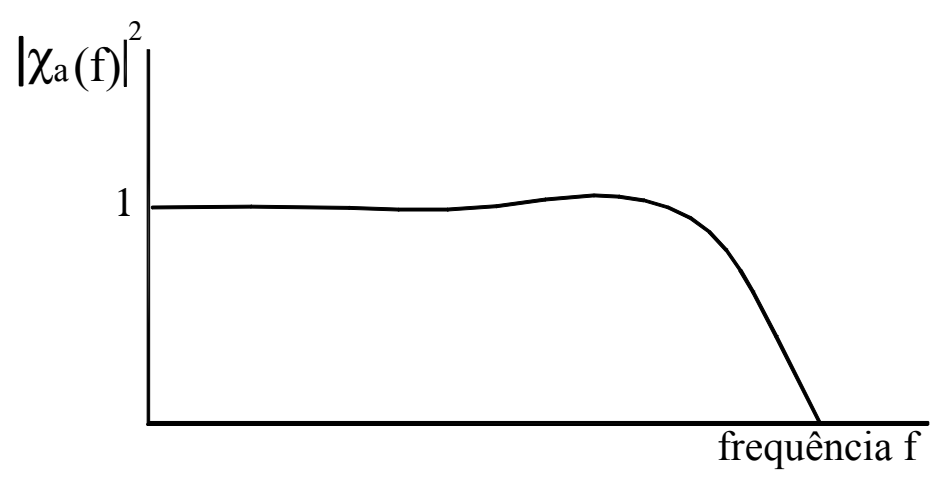

Figura 3.8 - Admitância aerodinâmica

Se considerarmos a relação entre o espectro de velocidade e o espectro de força em um ponto do fluxo turbulento, pode-se mostrar, ANTHONY (1970), que:

$\frac{\mathrm{S}_{\mathrm{F}}(\mathrm{f})}{\widetilde{\mathrm{F}}^{2}}=4 \frac{\mathrm{S}_{\mathrm{V}}(\mathrm{f})}{\widetilde{\mathrm{V}}^{2}}$

Para toda a estrutura:

$\frac{\mathrm{S}_{\mathrm{F}}(\mathrm{f})}{\widetilde{\mathrm{F}}^{2}}=4\left|\chi_{\mathrm{a}}(\mathrm{f})\right|^{2} \frac{\mathrm{S}_{\mathrm{V}}(\mathrm{f})}{\widetilde{\mathrm{V}}^{2}}$

Combinando todos os fundamentos descritos para obter a resposta da estrutura, tem-se: 
$\frac{\mathrm{S}_{\mathrm{r}}(\mathrm{f})}{\widetilde{\mathrm{r}}^{2}}=4\left|\chi_{\mathrm{a}}(\mathrm{f})\right|^{2}\left|\chi_{\mathrm{m}}(\mathrm{f})\right|^{2} \frac{\mathrm{S}_{\mathrm{V}}(\mathrm{f})}{\widetilde{\mathrm{V}}^{2}}$

A representação gráfica do procedimento estatístico está ilustrada na figura 3.9. O método leva naturalmente ao uso de programas para o cálculo da resposta da estrutura. O valor de pico da resposta da estrutura é então determinado por:

$\hat{\mathrm{r}}=\overline{\mathrm{r}}+\mathrm{g} \cdot \sigma(\mathrm{r})$

em que $\hat{\mathrm{r}}$ é a resposta máxima (de pico), $\overline{\mathrm{r}}$ é a resposta média e g é o fator de pico, relação entre o valor da resposta flutuante máxima e o desvio padrão $\sigma(\mathrm{r})$, equação 3.28. Segundo DAVENPORT (1993), na maioria dos casos, g varia entre 3 e 4.
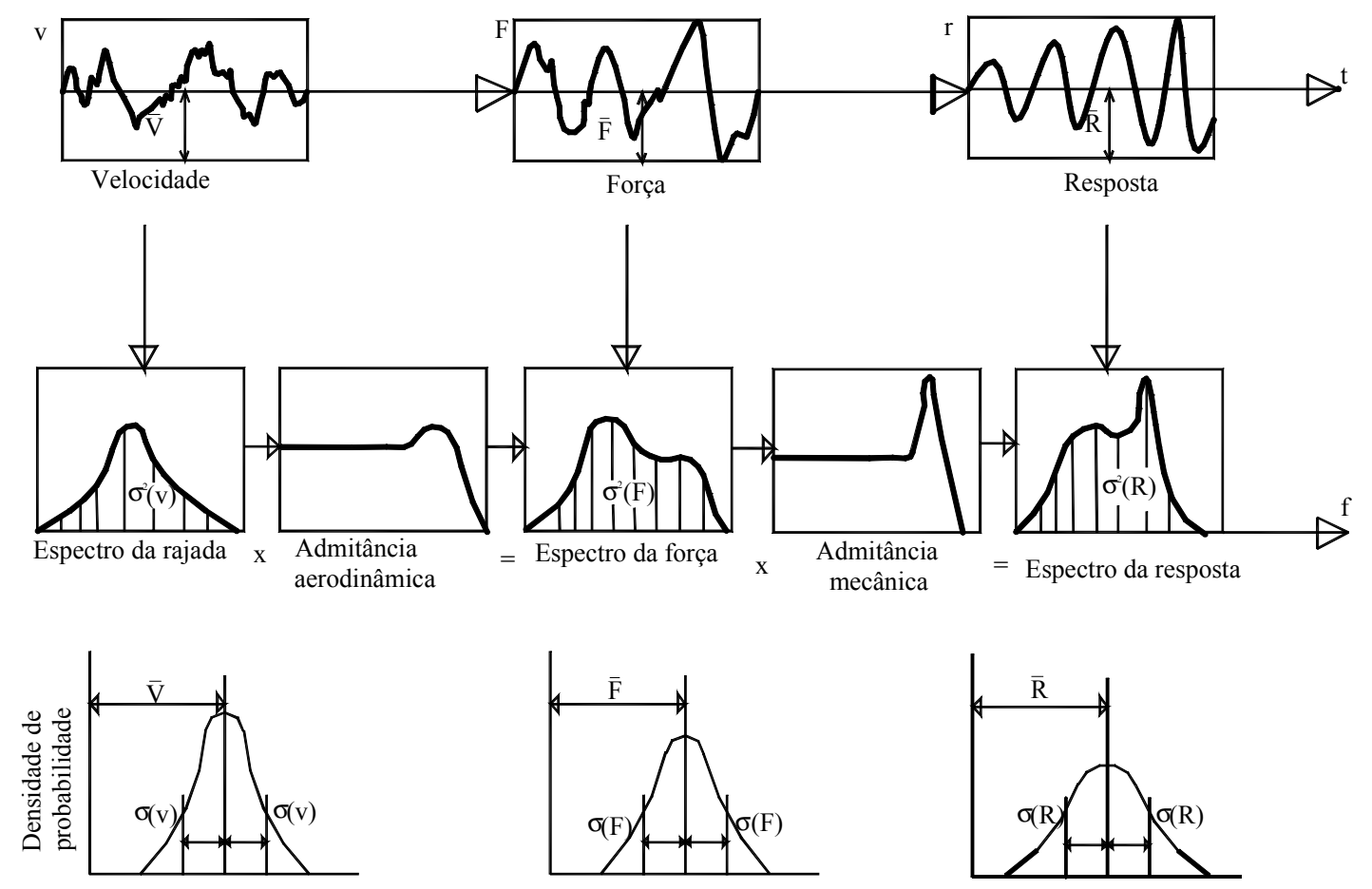

Figura 3.9 - Representação gráfica do procedimento estatístico de cálculo da resposta de estruturas esbeltas submetidas às forças das rajadas de vento.

Para se aprofundar mais nas características do vento e da camada limite atmosférica, além dos artigos já citados, outras obras são indicadas: BLESSMANN (1995), ESDU (1976, 1975, 1987), SIMIU; SCANLAN (1996), LAWSON (1980), COOK (1985) e HARRIS (1970). 


\subsection{Projeto de uma torre metálica treliçada}

Para este trabalho foi projetada, preliminarmente, uma torre metálica para ser usada como suporte de antenas de microondas, com base nos padrões das torres existentes no Brasil. Adotou-se esse projeto para a investigação numérica e experimental realizada. A figura 3.10 mostra a geometria adotada. As figuras B01, B02 e B03 no anexo B também ilustram a mesma geometria.

A torre é composta de 17 seções de 5.9 metros. Pode ser utilizada com diversas alturas utilizando-se as seções superiores para as torres de menor altura, até a altura de 100,3 metros, conforme a necessidade do cliente. Por exemplo: para uma torre de 70,8 metros, utilizam-se as seções 1 a 12 da torre.

Todas as barras principais e secundárias foram projetadas utilizando perfis de cantoneiras. Uma análise dos esforços foi realizada utilizando-se o programa de elementos finitos SAP2000. Todos os perfis foram dimensionados preliminarmente com a carga de vento da norma NBR6123/88, considerando o efeito das rajadas, sem considerar a resposta ressonante da estrutura. Para esse dimensionamento foi aplicada a norma de estruturas de aço NBR8800 (1988).

Considerou-se o efeito do vento em antenas de microondas como cargas adicionais à estrutura, desprezando-se as interferências aerodinâmicas entre a torre e as antenas. Utilizou-se a norma TIA-EIA-222-F (1996) para determinação das forças do vento nas antenas celulares. Os dados das normas utilizados para determinação das forças pseudo estáticas do vento na torre foram implantados em uma planilha Excel. A partir da velocidade de rajada, a planilha calcula as forças do vento. Determinou-se um coeficiente de arrasto diferente para cada painel da torre conforme a NBR6123 (1988). Três direções do vento foram avaliadas e uma envoltória dos esforços foi utilizada para o dimensionamento.

A tabela 3.1 mostra os perfis adotados para as barras verticais principais da torre. No anexo B apresentam-se as tabelas de dimensionamento dos perfis (tabelas B1 a B3), bem como uma vista de uma das faces da torre com todos os perfis adotados. 
Tabela 3.1 - Perfis das barras principais da torre

\begin{tabular}{|l|l|l|}
\hline Seção & Altura & Cantoneira $(\mathrm{mm})$ \\
\hline 17 & 5,9 & 2L $152 \times 152 \times 9,5$ \\
\hline 16 & 11,8 & 2L $152 \times 152 \times 9,5$ \\
\hline 15 & 17,7 & 2L $152 \times 152 \times 9,5$ \\
\hline 14 & 23,6 & 2L $152 \times 152 \times 9,5$ \\
\hline 13 & 29,5 & 2L $127 \times 127 \times 9,5$ \\
\hline 12 & 35,4 & 2L $127 \times 127 \times 9,5$ \\
\hline 11 & 41,3 & 2L $127 \times 127 \times 9,5$ \\
\hline 10 & 47,2 & 2L $102 \times 102 \times 9,5$ \\
\hline 9 & 53,1 & 2L $102 \times 102 \times 9,5$ \\
\hline 8 & 59 & 2L $102 \times 102 \times 9,5$ \\
\hline 7 & 64,9 & 2L $102 \times 102 \times 7,9$ \\
\hline 6 & 70,8 & 2L $102 \times 102 \times 6,4$ \\
\hline 5 & 76,7 & 2L $102 \times 102 \times 6,4$ \\
\hline 4 & 82,6 & 2L $102 \times 102 \times 6,4$ \\
\hline 3 & 88,5 & L $102 \times 102 \times 6,4$ \\
\hline 2 & 94,4 & L $76 \times 76 \times 6,4$ \\
\hline 1 & 100,3 & L $64 \times 64 \times 4,7$ \\
\hline
\end{tabular}

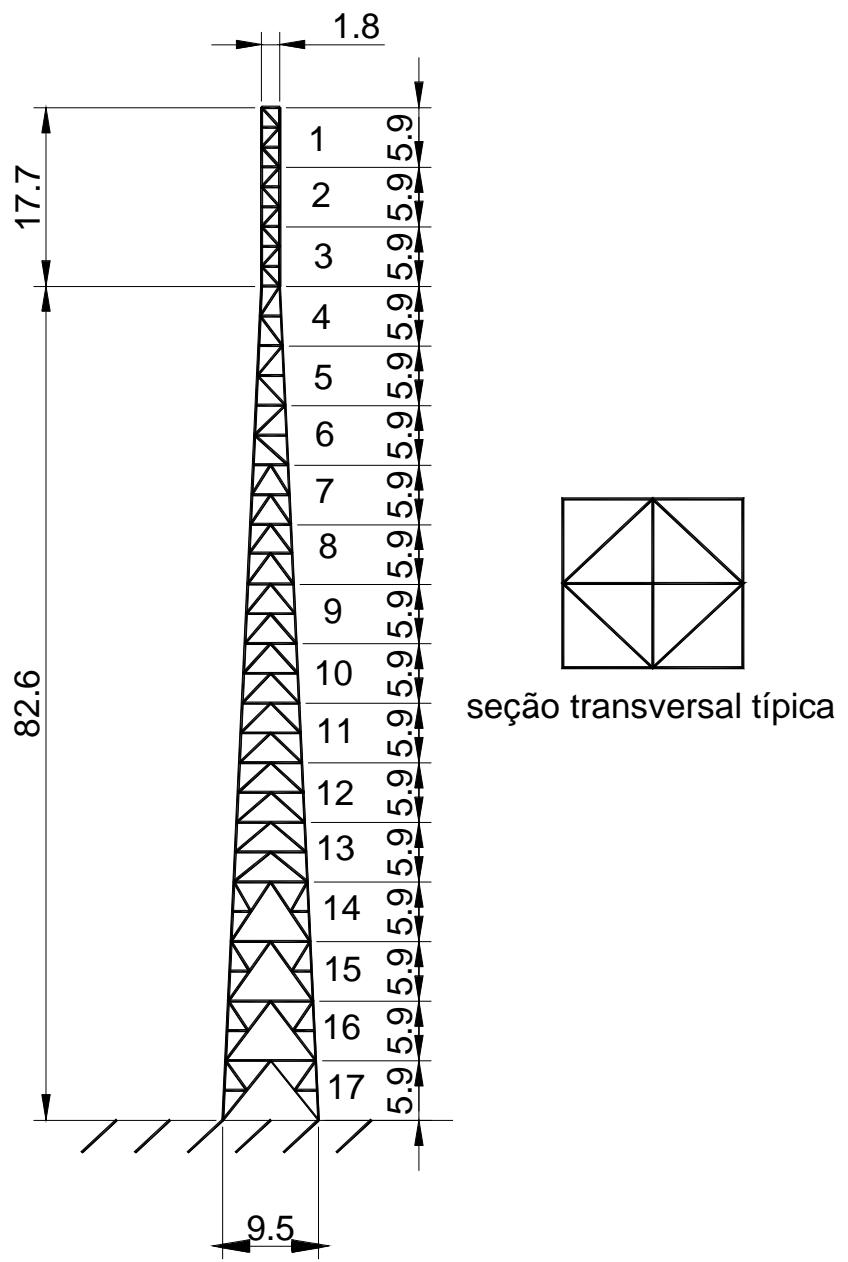

Figura 3.10 - Vista da face lateral da torre (medidas em metros) 


\subsection{Modelo de Davenport para torres de telecomunicações}

DAVENPORT (1993), utilizando linhas de influência, simplificou o processamento para calcular o fator de rajadas de estruturas esbeltas como torres, pontes e estruturas suspensas. No método, aqui descrito, considera-se a variação dos coeficientes de arrasto e do índice de área exposta da torre ao longo da altura. O método de Davenport considera um coeficiente de arrasto médio constante ao longo da altura.

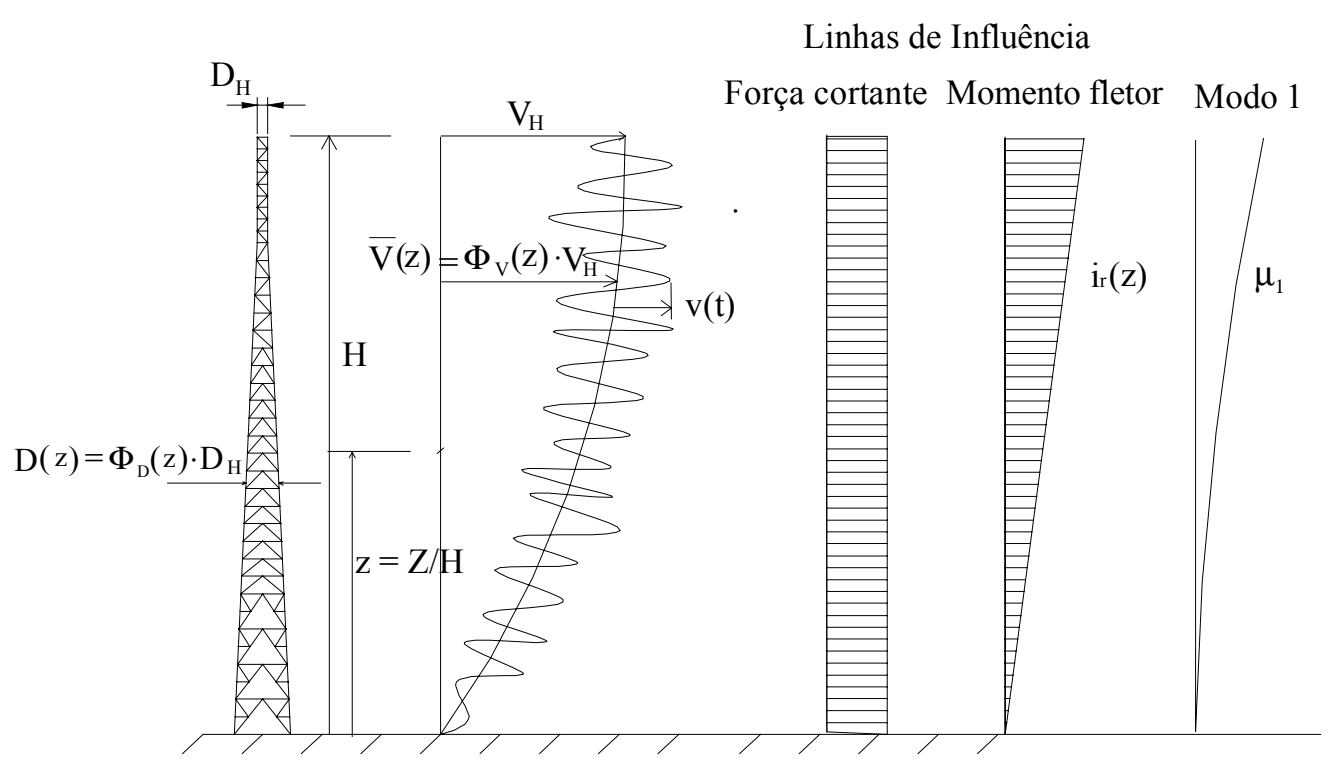

Figura 3.11 - Esboço do carregamento do vento na torre.

A força do vento em uma parte da estrutura é definida por:

$F(t)=\frac{1}{2} \rho V^{2}(t) A C_{a}$

em que A é a área da parte da estrutura onde atua a força $\mathrm{F}(\mathrm{t}), \mathrm{C}_{\mathrm{a}}$ é o coeficiente de arrasto e $\rho$ é a densidade do ar.

Considerando-se a estrutura da torre de telecomunicações da figura 3.11, a força média do vento na estrutura a uma altitude normalizada $\mathrm{z}$ é dada por:

$\overline{\mathrm{F}}(\mathrm{z})=\left(\mathrm{q}_{\mathrm{H}} \mathrm{D}_{\mathrm{H}} \mathrm{H}\right) \mathrm{C}_{\mathrm{a}}(\mathrm{z}) \phi(\mathrm{z}) \Phi_{\mathrm{V}}^{2}(\mathrm{z}) \Phi_{\mathrm{D}}(\mathrm{z})$ 
em que $\mathrm{q}_{\mathrm{H}}=(1 / 2) \rho \mathrm{V}_{\mathrm{H}}^{2}$ é a pressão dinâmica de referência no topo da estrutura. $\Phi_{\mathrm{V}}(\mathrm{z}) \mathrm{V}_{\mathrm{H}}$ e $\Phi_{\mathrm{D}}(\mathrm{z}) \mathrm{D}_{\mathrm{H}}$ são a variação da velocidade do vento e da largura da torre com a altura, $\phi(z)$ é o índice de área exposta, e $\rho$ é a densidade do ar.

A resposta média é dada por

$$
\overline{\mathrm{r}}=\int_{0}^{1} \overline{\mathrm{F}}(\mathrm{z}) \mathrm{i}_{\mathrm{r}}(\mathrm{z}) \mathrm{dz}=\left[\mathrm{q}_{\mathrm{H}} \mathrm{D}_{\mathrm{H}} \mathrm{H}\right] \int_{0}^{1}\left\{\phi(\mathrm{z}) \mathrm{C}_{\mathrm{a}}(\mathrm{z}) \Phi_{\mathrm{V}}^{2}(\mathrm{z}) \Phi_{\mathrm{D}}(\mathrm{z}) \mathrm{i}_{\mathrm{r}}(\mathrm{z})\right\} \mathrm{dz}
$$

A variância da resposta não ressonante, definida como a resposta devida à variação das forças do vento em freqüências abaixo das freqüências naturais da estrutura, é dada por:

$\widetilde{\mathrm{r}}_{\mathrm{B}}^{2}=2 \int_{0}^{1} \mathrm{R}_{\mathrm{F}}(\mathrm{z}) \int_{0}^{1-\Delta \mathrm{Z}} \widetilde{\mathrm{F}}(\mathrm{z}) \cdot \widetilde{\mathrm{F}}(\mathrm{z}+\Delta \mathrm{z}) \cdot \mathrm{i}_{\mathrm{r}}(\mathrm{z}) \cdot \mathrm{i}_{\mathrm{r}}(\mathrm{z}+\Delta \mathrm{z}) \cdot \mathrm{dz} \cdot \mathrm{d} \Delta \mathrm{z}$

onde $\mathrm{R}_{\mathrm{F}}(\mathrm{z})$ é o coeficiente de correlação espacial vertical entre duas forças $\mathrm{F}$ separadas por uma altura $\Delta z, \widetilde{F}$ é o desvio padrão da força $F$ ou valor rms ("root mean square") da componente flutuante da força $F$.

Quando a escala da correlação da força $L_{F}$ é muito grande, $H / L_{F} \rightarrow 0$, ou seja, $\mathrm{R}_{\mathrm{F}}(\mathrm{z})=1$ para toda a altura da estrutura, a resposta não ressonante é dada por:

$\mathrm{L}_{\mathrm{F}}>>>>\mathrm{H} \Rightarrow \widetilde{\mathrm{r}}_{\mathrm{B}}^{2}=\left\{\int_{0}^{1}\left[\mathrm{~F}(\mathrm{z}) \cdot \mathrm{i}_{\mathrm{r}}(\mathrm{z}) \mathrm{d}(\mathrm{z})\right]\right\}^{2}=\mathrm{G}_{0}$

Quando a correlação é local, $H / L_{F} \rightarrow \infty\left(L_{F}<<<H\right)$, ou seja, há valores de $R_{F}(z)$ apenas para pequenos espaçamentos $\Delta z$, têm-se:

$$
\begin{aligned}
& \int_{0}^{\mathrm{l}} \mathrm{R}_{\mathrm{F}}(\Delta \mathrm{z}) \mathrm{d} \Delta \mathrm{z}=\frac{\mathrm{L}_{\mathrm{F}}}{\mathrm{H}} \\
& \widetilde{\mathrm{r}}_{\mathrm{B}}^{2}=2\left(\mathrm{~L}_{\mathrm{F}} / \mathrm{H}\right) \int_{0}^{1}\left[\mathrm{~F}(\mathrm{z}) \cdot \mathrm{i}_{\mathrm{r}}(\mathrm{z})\right]^{2} \mathrm{~d}(\mathrm{z})=2\left(\mathrm{~L}_{\mathrm{F}} / \mathrm{H}\right) \mathrm{G}_{\infty}
\end{aligned}
$$


Para valores intermediários de $\mathrm{L}_{\mathrm{F}} / \mathrm{H}$, pode-se usar a aproximação dada pela seguinte fórmula de transição, válida somente quando $\mathrm{i}_{\mathrm{r}}(\mathrm{z})$ tem o mesmo sinal ao longo da altura:

$$
\widetilde{\mathrm{r}}_{\mathrm{B}}^{2}=\mathrm{G}_{0}\left(1+\left(\frac{\mathrm{H}}{2 \mathrm{~L}_{\mathrm{F}}}\right) \frac{\mathrm{G}_{0}}{\mathrm{G}_{\infty}}\right)^{-1}
$$

A parte flutuante ou o valor rms da força do vento é obtida a partir das equações 3.1 e 3.10:

$\widetilde{\mathrm{F}}(\mathrm{z})=\rho \overline{\mathrm{V}}(\mathrm{z}) \phi(\mathrm{z}) \mathrm{D}(\mathrm{z}) \mathrm{HC}_{\mathrm{a}}(\mathrm{z}) \widetilde{\mathrm{v}}=\mathrm{q}_{\mathrm{H}} \phi(\mathrm{z}) \mathrm{D}_{\mathrm{H}} \mathrm{HC}_{\mathrm{a}}(\mathrm{z}) \Phi_{\mathrm{V}} \Phi_{\mathrm{D}} 2 \mathrm{I}_{\mathrm{V}}$

em que $\mathrm{I}_{\mathrm{V}}=\widetilde{\mathrm{V}} / \mathrm{V}_{\mathrm{H}}$ é a intensidade de turbulência no topo da torre.

Para estruturas esbeltas, pode-se admitir que a escala das forças, $\mathrm{L}_{\mathrm{F}}$, é a mesma que a escala da velocidade do vento, $\mathrm{L}_{\mathrm{V}}$. Portanto, a resposta não ressonante é dada por:

$$
\widetilde{r}_{B}=q_{H} D_{H} H 2 I_{V}\left[1+\left(\frac{H}{2 L_{v}}\right)\left(\frac{G_{0}}{G_{\infty}}\right)\right]^{-\frac{1}{2}} \int_{0}^{1} \phi(z) C_{a}(z) \Phi_{V}(z) \Phi_{D}(z) i_{r}(z) d z
$$

em que:

$$
\frac{\mathrm{G}_{0}}{\mathrm{G}_{\infty}}=\frac{\left[\int_{0}^{\mathrm{l}} \phi(\mathrm{z}) \mathrm{C}_{\mathrm{a}}(\mathrm{z}) \Phi_{\mathrm{V}}(\mathrm{z}) \Phi_{\mathrm{D}}(\mathrm{z}) \mathrm{i}_{\mathrm{r}}(\mathrm{z}) \mathrm{dz}\right]^{2}}{\int_{0}^{\mathrm{l}} \phi^{2}(\mathrm{z}) \mathrm{C}_{\mathrm{a}}^{2}(\mathrm{z}) \Phi_{\mathrm{V}}^{2}(\mathrm{z}) \Phi_{\mathrm{D}}^{2}(\mathrm{z}) \mathrm{i}_{\mathrm{r}}^{2}(\mathrm{z}) \mathrm{dz}}
$$

$\mathrm{O}$ espectro da força na freqüência $f_{j}$ é:

$$
\mathrm{f}_{\mathrm{j}} \mathrm{S}_{\mathrm{F}}\left(\mathrm{f}_{\mathrm{j}}\right)=\left[\mathrm{q}_{\mathrm{H}} \mathrm{D}_{\mathrm{H}} \mathrm{H}\right]^{2} 4 \mathrm{I}_{\mathrm{v}}^{2} \mathrm{f}_{\mathrm{j}} \frac{\mathrm{S}_{\mathrm{V}}\left(\mathrm{f}_{\mathrm{j}}\right)}{\widetilde{\mathrm{v}}^{2}} \phi^{2}(\mathrm{z}) \mathrm{C}_{\mathrm{a}}^{2}(\mathrm{z}) \Phi_{\mathrm{D}}^{2}(\mathrm{z}) \Phi_{\mathrm{V}}^{2}(\mathrm{z})
$$

Na equação 3.21 vemos a representação adimensional do espectro de potência dado por $\mathrm{f} \frac{\mathrm{S}_{\mathrm{V}}(\mathrm{f})}{\widetilde{\mathrm{V}}^{2}}$. É o chamado espectro reduzido. Segundo DAVENPORT (1993), pode-se usar a seguinte expressão para o espectro reduzido do vento nas freqüências próximas às freqüências naturais de vibração de estruturas altas: 


$$
\frac{\mathrm{fS}_{\mathrm{V}}(\mathrm{f})}{\widetilde{\mathrm{v}}^{2}}=0,045\left[\frac{\mathrm{fz}}{\overline{\mathrm{V}}(\mathrm{z})}\right]^{\frac{2}{3}}
$$

Será utilizada a correlação de banda estreita dada por:

$$
\mathrm{R}_{1,2}(\mathrm{f}, \Delta \mathrm{z})=\exp \left[\mathrm{C} \frac{\mathrm{f} \Delta \mathrm{z}}{\overline{\mathrm{V}}(\mathrm{z})}\right]
$$

onde C geralmente varia de 6 a 10.

Como as excitações da estrutura nas freqüências ressonantes são localmente correlacionadas, $\mathrm{L}_{\mathrm{F}}<<<\mathrm{H}$, a resposta ressonante da estrutura pode ser determinada por um procedimento análogo ao da equação 3.16. Seguindo esse procedimento, substituindo o valor rms pelo espectro da força na freqüência natural e a linha de influência pelo modo de vibração, obtém-se o espectro das forças generalizadas para a freqüência natural do modo $\mathrm{j}$ :

$$
\mathrm{f}_{\mathrm{j}} \mathrm{S}_{\mathrm{GF}_{\mathrm{j}}}\left(\mathrm{f}_{\mathrm{j}}\right)=\frac{2 \mathrm{~L}_{\mathrm{F}}\left(\mathrm{f}_{\mathrm{j}}\right)}{\mathrm{H}} \int_{0}^{\mathrm{l}}\left[\mathrm{f}_{\mathrm{j}} \mathrm{S}_{\mathrm{F}}\left(\mathrm{f}_{\mathrm{j}}, \mathrm{z}\right) \mu_{\mathrm{j}}^{2}(\mathrm{z})\right] \mathrm{dz}
$$

onde $L_{F}\left(f_{j}\right)$ é a escala da correlação ao longo da altura na freqüência $f_{j}$.

Considerando as equações 3.15, 3.21, 3.22, 3.23 e 3.24 obtém-se:

$\mathrm{f}_{\mathrm{j}} \mathrm{S}_{\mathrm{GF}_{\mathrm{J}}}\left(\mathrm{f}_{\mathrm{j}}\right)=\left[\mathrm{q}_{\mathrm{H}} \mathrm{D}_{\mathrm{H}} \mathrm{H}\right]^{2} 4 \mathrm{I}_{\mathrm{v}}^{2} \frac{2}{\mathrm{C}}\left[\frac{\mathrm{V}_{\mathrm{H}}}{\mathrm{f}_{\mathrm{j}} \mathrm{H}}\right]^{\frac{5}{3}} 0,045 \int_{0}^{1}\left[\phi^{2}(\mathrm{z}) \mathrm{C}_{\mathrm{a}}{ }^{2}(\mathrm{z}) \Phi_{\mathrm{V}}^{11 / 3}(\mathrm{z}) \Phi_{\mathrm{D}}^{2}(\mathrm{z}) \mu_{\mathrm{j}}^{2}(\mathrm{z})\right] \mathrm{z}^{-2 / 3} \mathrm{dz}$

A resposta ressonante do modo j é dada por:

$$
\widetilde{\mathrm{r}}_{\mathrm{R}_{\mathrm{j}}}^{2}=\frac{\pi}{4} \frac{\mathrm{f}_{\mathrm{j}} \mathrm{S}_{\mathrm{GF}_{\mathrm{j}}}\left(\mathrm{f}_{\mathrm{j}}\right)}{\left(\zeta_{\mathrm{s}}+\zeta_{\mathrm{aj}}\right)}\left\{\frac{\int_{0}^{1}\left[\Phi_{\mathrm{m}}(\mathrm{z}) \mu_{\mathrm{j}}(\mathrm{z})\right]_{\mathrm{r}}(\mathrm{z}) \mathrm{dz}}{\int_{0}^{1} \Phi_{\mathrm{m}}(\mathrm{z}) \mu_{\mathrm{j}}^{2}(\mathrm{z}) \mathrm{dz}}\right\}^{2}
$$

em que: 
$\mathrm{m}_{\mathrm{H}} \Phi_{\mathrm{m}}(\mathrm{z})$ é a variação da massa com a altitude;

O coeficiente de amortecimento aerodinâmico é obtido por:

$$
\zeta_{\mathrm{aj}}=\frac{\int_{0}^{\mathrm{l}} \mathrm{A}(\mathrm{z}) \mu_{\mathrm{j}}^{2}(\mathrm{z}) \mathrm{dz}}{4 \pi \mathrm{f}_{\mathrm{j}} \mathrm{m}_{\mathrm{H}} \int_{0}^{\mathrm{l}} \Phi_{\mathrm{m}}(\mathrm{z}) \mu_{\mathrm{j}}^{2}(\mathrm{z}) \mathrm{dz}}
$$

$$
\mathrm{A}(\mathrm{z})=\rho \mathrm{V}_{\mathrm{H}} \phi(\mathrm{z}) \mathrm{D}_{\mathrm{H}} \mathrm{HC}_{\mathrm{a}}(\mathrm{z}) \Phi_{\mathrm{V}}(\mathrm{z}) \Phi_{\mathrm{D}}(\mathrm{z})
$$

A resposta total da estrutura é definida pela equação 3.9 , onde $\widetilde{\mathrm{r}}=\sigma(\mathrm{r})$ é o desvio padrão ou valor rms dado por:

$$
\widetilde{\mathrm{r}}=\sqrt{\widetilde{\mathrm{r}}_{\mathrm{B}}^{2}+\sum \widetilde{\mathrm{r}}_{\mathrm{R}_{\mathrm{j}}}^{2}}
$$

em que $\widetilde{r}_{B}$ é o valor rms da resposta não ressonante e $\widetilde{r}_{R}$ é o valor rms da resposta ressonante.

Finalmente o fator de rajada é dado por:

$\mathrm{G}=\frac{\hat{\mathrm{r}}}{\overline{\mathrm{r}}}=1+\frac{\mathrm{g}}{\overline{\mathrm{r}}} \sqrt{\widetilde{\mathrm{r}}_{\mathrm{B}}^{2}+\widetilde{\mathrm{r}}_{\mathrm{R}}^{2}}$

onde g é dado por (DAVENPORT, 1967)

$g=\sqrt{2 \ln (v T)}+\frac{0.577}{\sqrt{2 \ln (v T)}}$

em que $\mathrm{T}$ é o tempo de amostragem e $v$ é o número de vezes que o valor médio é ultrapassado por unidade de tempo,

$$
v=f_{j} \sqrt{\frac{\widetilde{r}_{R}^{2}}{\widetilde{r}_{B}^{2}+\widetilde{r}_{R}^{2}}}
$$

Outra forma de se determinar o valor da resposta de pico derivada da equação 3.9, é dada por: 
$\hat{\mathrm{r}}=\overline{\mathrm{r}}+\mathrm{r}_{\mathrm{B}} \mathrm{g} \mathrm{C}_{\mathrm{R}}$

onde

$C_{R}=\sqrt{1+\frac{r_{R}^{2}}{r_{B}^{2}}}$

\subsubsection{Exemplo}

Conforme a NBR6123/88, utilizou-se a velocidade básica do vento de rajada de 40 $\mathrm{m} / \mathrm{s}$ referente a $3 \mathrm{~s}$ de duração a $10 \mathrm{~m}$ de altura acima do chão em terreno aberto, categoria 2, com um período de retorno de 50 anos. Como as torres geralmente estão localizadas em terrenos de subúrbios (ver estudo estatístico no capítulo 2), a velocidade média horária equivalente no topo da torre é de $35 \mathrm{~m} / \mathrm{s}$.

O primeiro modo de vibração foi determinado usando o programa de elementos finitos SAP2000. A figura 3.12 apresenta o resultado.

Desenvolveu-se um programa para o cálculo da resposta dinâmica da torre, utilizando-se o Mathcad versão 2000, apresentado no anexo C. Os dados considerados no cálculo estão na tabela 3.2. A tabela 3.3 apresenta os resultados do fator de rajada, da parte ressonante e não ressonante da resposta de momento fletor e de cisalhamento à carga do vento.

Tabela 3.2 - Dados utilizados para cálculo da resposta da torre

\begin{tabular}{|c|c|c|c|}
\hline \multicolumn{2}{|c|}{ Dados da torre } & \multicolumn{2}{|c|}{ Dados do vento } \\
\hline$f_{1}$ & $0,85 \mathrm{~Hz}$ & $\mathrm{~V}_{\mathrm{H}}$ & $35 \mathrm{~m} / \mathrm{s}$ \\
\hline$\mu_{1}$ & $z^{2,69}$ & $\mathrm{I}_{\mathrm{V}}$ & 0,16 \\
\hline $\mathrm{m}_{\mathrm{H}}(\mathrm{kg} / \mathrm{m})$ & 125 & $\mathrm{~L}_{\mathrm{V}}(\mathrm{m})$ & 50 \\
\hline $\mathrm{M}_{\mathrm{H}=100,3 \mathrm{~m}}(\mathrm{~kg})$ & 625 & $\mathrm{C}$ & 8 \\
\hline $\mathrm{M}_{\mathrm{H}=82,6 \mathrm{~m}}(\mathrm{~kg})$ & 625 & $\phi$ & variável \\
\hline $\mathrm{C}_{\mathrm{a}}$ & variável & $\alpha$ & 0,20 \\
\hline$\zeta_{\mathrm{s}}$ & 0,007 & $\mathrm{z}_{0}(\mathrm{~m})$ & 0,3 \\
\hline$\Delta(\mathrm{m} / \mathrm{N})$ & 0,00001408 & & \\
\hline
\end{tabular}


Tabela 3.3 - Resultados da análise

\begin{tabular}{|c|c|c|c|c|c|c|c|c|}
\hline & \multicolumn{4}{|c|}{ Força cortante } & \multicolumn{4}{|c|}{ Momento fletor } \\
\hline $\mathrm{z}$ & $\mathrm{G}_{\text {cisal }}$ & $\begin{array}{l}\text { Não resson. } \\
\text { /média }\end{array}$ & \begin{tabular}{|l|} 
Resson \\
/média \\
\end{tabular} & $\mathrm{C}_{\mathrm{R}}$ & $\mathrm{G}_{\text {bmoment }}$ & \begin{tabular}{|l|} 
Não resson. \\
/média
\end{tabular} & $\begin{array}{l}\text { Resson } \\
\text { /média }\end{array}$ & $\mathrm{C}_{\mathrm{R}}$ \\
\hline 0 & 2,044 & 1,035 & \begin{tabular}{|l|}
0,132 \\
\end{tabular} & 1,008 & 2,023 & \begin{tabular}{|r|}
0,999 \\
\end{tabular} & $\begin{array}{l}0,219 \\
\end{array}$ & 1,024 \\
\hline 0,5 & 2,112 & 1,079 & 0,269 & 1,031 & 2,157 & 1,09 & 0,389 & 1,062 \\
\hline 0,75 & 2,247 & $\begin{array}{r}1,157 \\
\end{array}$ & 0,464 & 1,077 & 2,314 & 1,173 & 0,593 & 1,121 \\
\hline & \multicolumn{4}{|c|}{ Deslocamento no topo } & & & & \\
\hline 0 & 2,18 & 1,088 & 0,456 & 1,084 & & & & \\
\hline
\end{tabular}

$\mathrm{O}$ coeficiente de amortecimento aerodinâmico encontrado foi de $\zeta_{\mathrm{a}}=0,025$. O deslocamento médio no topo da torre foi de $27,7 \mathrm{~cm}$ e o flutuante de $32,6 \mathrm{~cm}$. A força cortante média na base da torre foi de $119000 \mathrm{~N}$ e o valor de pico de $243100 \mathrm{~N}$.

Os dados mostrados na tabela 3.2 estão a seguir descritos:

$\mathrm{f}_{1}$ freqüência natural de vibração;

$\mu_{1}$ primeiro modo de vibração;

$\mathrm{m}_{\mathrm{H}}$ massa por unidade de comprimento no topo da torre;

$\mathrm{M}_{\mathrm{H}}=100,3$ Massa pontual no topo da torre devido à plataforma e antenas;

$\mathrm{M}_{\mathrm{H}}=82,6$ Massa pontual a 82,6 metros de altura devido à plataforma e antenas;

$\mathrm{C}_{\mathrm{a}}$ coeficiente de força da área exposta de uma face da torre conforme a norma Brasileira NBR6123;

$\zeta_{\mathrm{s}}$ coeficiente de amortecimento estrutural;

$\mathrm{V}_{\mathrm{H}}$ velocidade no topo da torre;

$\mathrm{I}_{\mathrm{V}}$ Intensidade de turbulência no topo da torre;

$\mathrm{L}_{\mathrm{V}}$ escala vertical da turbulência longitudinal;

C fator de decaimento exponencial de correlação de banda estreita;

$\phi(\mathrm{z})$ índice de área exposta na altura $\mathrm{z}$ da estrutura;

$\alpha$ expoente da lei de potência da velocidade do vento na camada limite atmosférica;

$\mathrm{z}_{0}$ comprimento de rugosidade;

$\Delta$ flexibilidade no topo. 


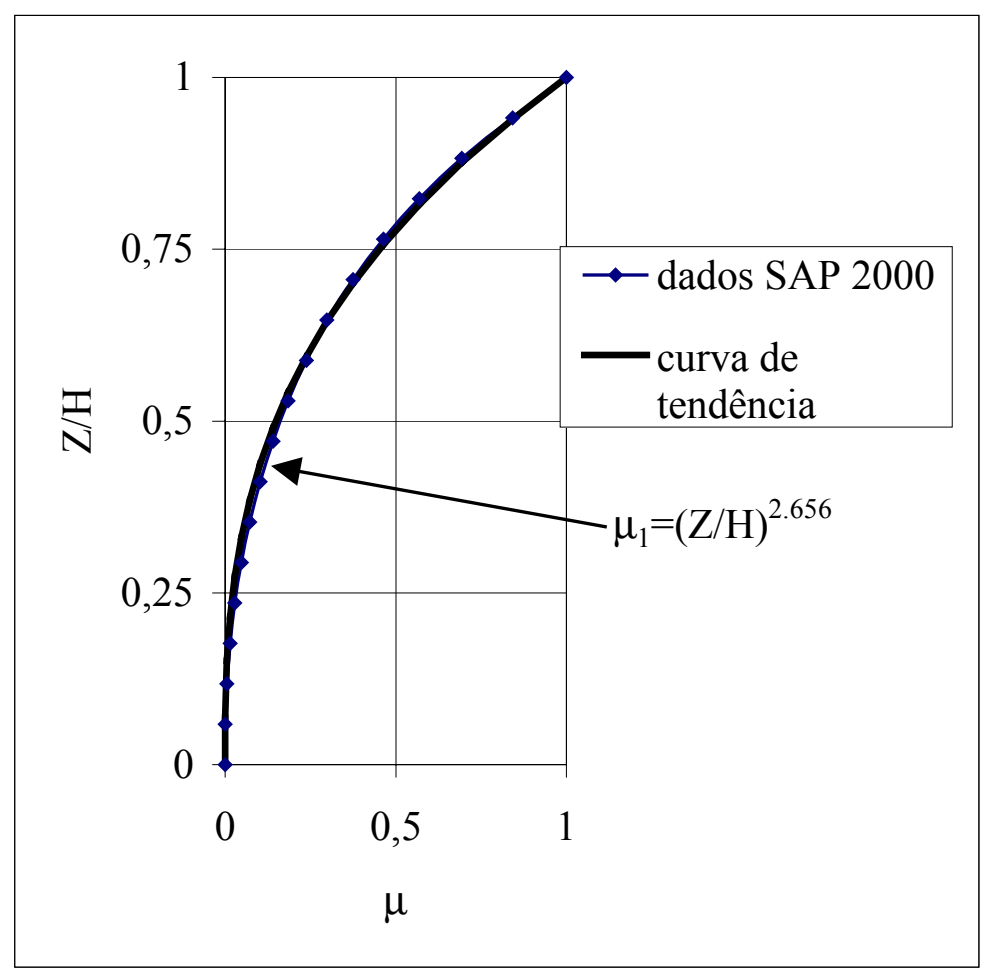

Figura 3.12 - Primeiro modo de vibração $-\mathrm{f}_{1}=0,85 \mathrm{~Hz}$

Conclui-se ,a partir dos resultados obtidos, que a resposta ressonante é menos importante que a resposta não ressonante, isto é, as forças de inércia não são significantes, e neste caso podem ser desprezadas. Embora as normas existentes sugerem que se calcule a resposta ressonante em estruturas cuja freqüência natural seja menor que $1 \mathrm{~Hz}$, a torre em questão, $\mathrm{f}=0,85 \mathrm{~Hz}$, não apresentou resposta ressonante significativa. Nas figuras 3.13 e 3.14 apresentam-se os resultados referentes à força cortante e momento fletor ao longo da altura da torre mostrando graficamente a resposta média, não ressonante e ressonante determinadas segundo o modelo de Davenport. A resposta ressonante é a diferença entre a curva do valor de pico e a curva da somatória do valor médio e o valor não ressonante. Observa-se que esse valor é muito pequeno se comparado com a resposta não ressonante. 


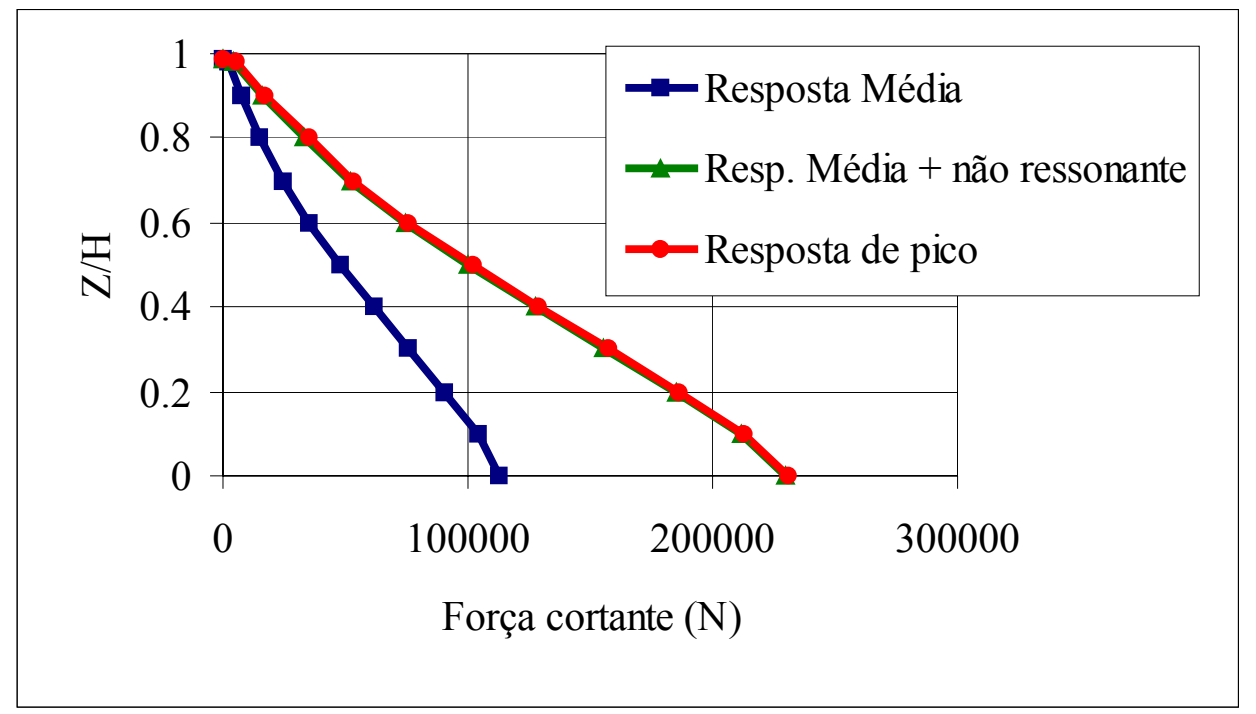

Figura 3.13 - Resposta média, não ressonante e ressonante - força cortante.

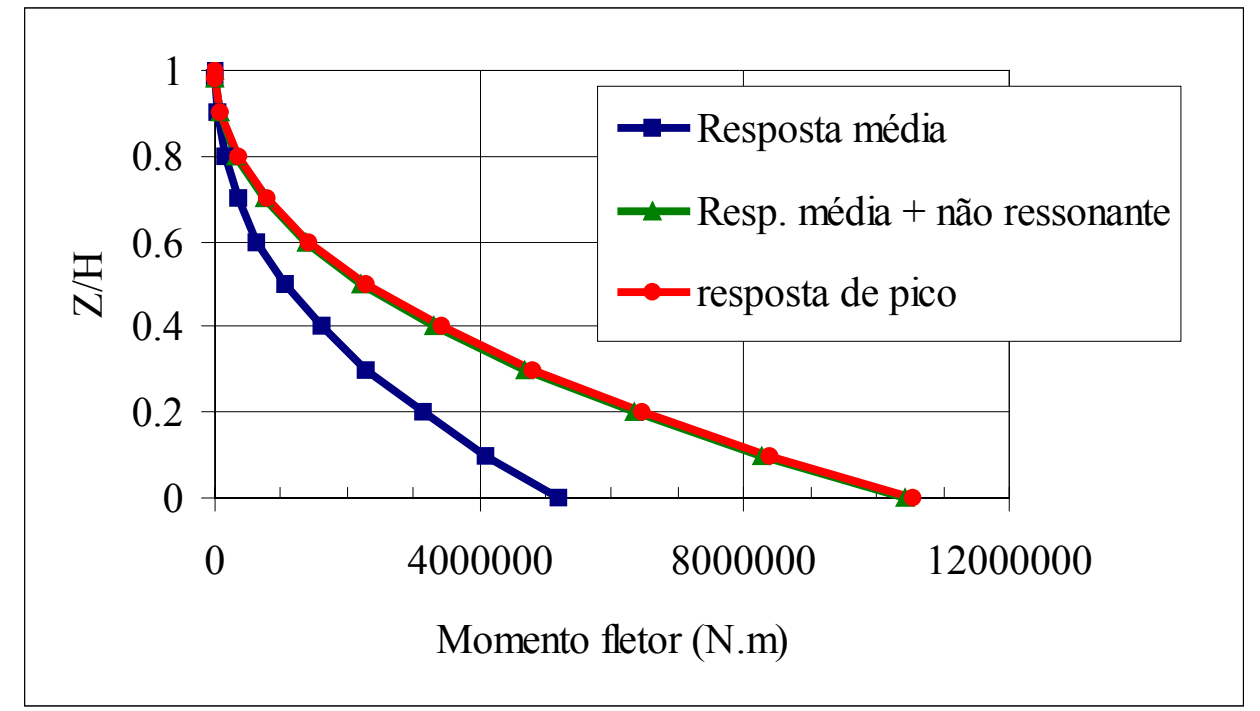

Figura 3.14 - Resposta média, não ressonante e ressonante - momento fletor 


\subsection{Modelo Discreto da NBR 6123}

Devido à geometria da torre não ser uniforme e considerando os procedimentos de cálculo apresentados pela NBR6123, utiliza-se, a seguir, o modelo discreto para determinação da resposta dinâmica da estrutura. Esse modelo é baseado no processo estatístico de cálculo de Davenport, mas difere nos parâmetros utilizados para determinar as ações do vento. Um breve resumo é aqui apresentado e aplicado. Nesse método, separa-se a resposta média da resposta flutuante que inclui a resposta não ressonante e resposta ressonante da estrutura. Embora no método não esteja implícita a separação da resposta ressonante e da resposta não ressonante, pode-se determinar a resposta não ressonante com os gráficos fornecidos pela NBR6123 para determinação do coeficiente de amplificação dinâmica, admitindo-se a estrutura rígida, ou seja, com freqüência natural de vibração infinita.

Somente é considerada, na resposta estrutural, a influência da componente na direção da velocidade média do vento. A estrutura é discretizada em n partes. A ação do vento em um determinado instante na coordenada i é dada por uma parcela média e outra flutuante:

$\mathrm{F}_{\mathrm{i}}=\overline{\mathrm{F}}_{\mathrm{i}}+\hat{\mathrm{F}}$

A força média é dada por:

$\overline{\mathrm{F}}_{\mathrm{i}}=\mathrm{q}_{0} \mathrm{~b}^{2} \mathrm{C}_{\mathrm{ai}} \mathrm{A}_{\mathrm{i}}\left(\frac{\mathrm{Z}_{\mathrm{i}}}{\mathrm{Z}_{\mathrm{r}}}\right)^{2 \mathrm{p}}$

em que $C_{a i}$ é o coeficiente de arrasto da coordenada $i, A_{i}$ é a área efetiva de uma face da torre na coordenada $\mathrm{i}, \mathrm{Z}_{\mathrm{r}}$ é a altitude de referência onde se considera a velocidade média do vento na camada limite atmosférica, $b$ e p são tabelados conforme a rugosidade do terreno e $\mathrm{q}_{0}$ é a pressão dinâmica do vento, dada por $\mathrm{q}_{0}=1 / 2 \rho \overline{\mathrm{V}}_{\mathrm{p}}^{2}(\rho$ é a densidade do ar).

No caso de uma torre treliçada, $\mathrm{A}_{\mathrm{i}}=\phi_{\mathrm{i}} \mathrm{A}_{\mathrm{Ti}}$, onde $\phi_{\mathrm{i}}$ é o índice de área exposta $\mathrm{e}$ $\mathrm{A}_{\mathrm{Ti}}$ é a área total da face da torre delimitada pelas barras externas na coordenada $\mathrm{i}$. 
Tabela 3.4 - Expoente p e parâmetro b (NBR6123, 1988)

\begin{tabular}{|l|l|l|l|l|l|}
\hline Categoria de rugosidade & I & II & III & IV & V \\
\hline P & 0,095 & 0,15 & 0,185 & 0,23 & 0,31 \\
\hline b & 1,23 & 1 & 0,86 & 0,71 & 0,5 \\
\hline
\end{tabular}

A componente flutuante $\widetilde{\mathrm{F}}(\mathrm{z})$ é dada por

$\hat{\mathrm{F}}_{\mathrm{i}}=\mathrm{F}_{\mathrm{H}} \psi_{\mathrm{i}} \mu_{\mathrm{i}}$

sendo:

$\mu_{\mathrm{i}}=\left(\frac{\mathrm{z}_{\mathrm{i}}}{\mathrm{H}}\right)^{\gamma}$

$\mathrm{F}_{\mathrm{H}}=\mathrm{q}_{0} \mathrm{~b}^{2} \mathrm{~A}_{0} \frac{\sum_{1}^{\mathrm{n}} \beta_{\mathrm{i}} \mathrm{x}_{\mathrm{i}}}{\sum_{\mathrm{i}}^{\mathrm{n}} \psi_{\mathrm{i}} \mathrm{x}_{\mathrm{i}}^{2}} \xi$

$\beta_{\mathrm{i}}=\mathrm{C}_{\mathrm{ai}} \frac{\mathrm{A}_{\mathrm{i}}}{\mathrm{A}_{0}}\left(\frac{\mathrm{z}_{\mathrm{i}}}{\mathrm{z}_{\mathrm{r}}}\right)^{\mathrm{p}}$

onde $\mathrm{m}_{\mathrm{o}}$ e $\mathrm{A}_{\mathrm{o}}$ são uma massa e uma área de referência , $\psi$ é a relação entre a massa na coordenada i e a massa de referência $\left(\mathrm{m}_{\mathrm{i}} / \mathrm{m}_{0}\right)$ e $\gamma$ é o expoente da forma modal. $\xi$ é o coeficiente da amplificação dinâmica apresentado nas figuras 14 a 18 da NBR6123 para as cinco categorias de terreno consideradas. A figura 3.15 reproduz o gráfico 16 da referida norma para a categoria III de terreno.

Para efeito de comparação, o fator resposta de rajada, relação entre a resposta média e a resposta de pico, é dado por:

$\mathrm{G}=\frac{\mathrm{F}}{\overline{\mathrm{F}}}$

onde $\mathrm{F}$ é a força cortante de pico e $\overline{\mathrm{F}}$ é a força cortante média. 

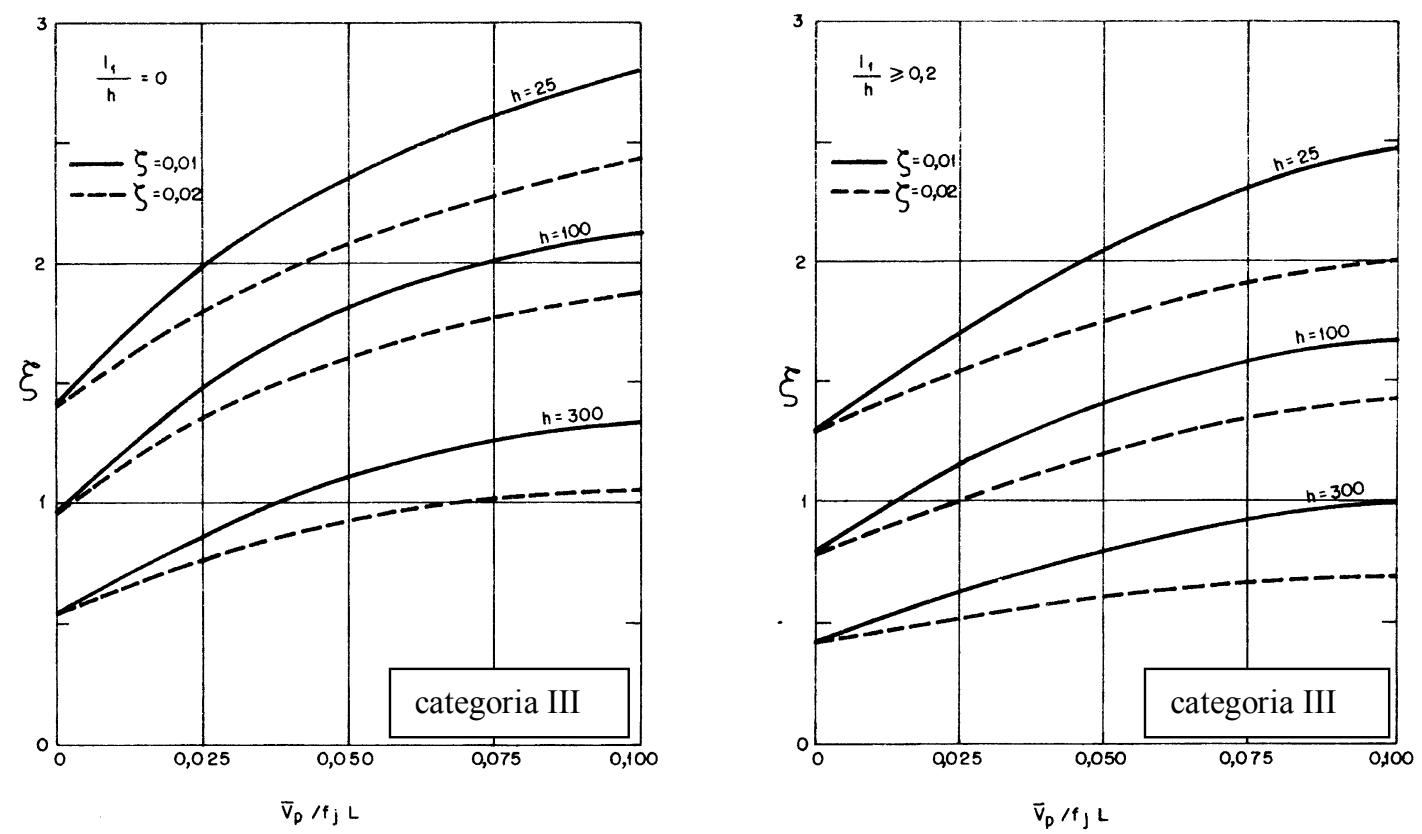

Figura 3.15 - Coeficiente de amplificação dinâmica, $\xi$, para categoria III

(NBR6123/1988)

\subsubsection{Exemplo}

Para comparação dos modelos numéricos utilizados, foram considerados os mesmos dados usados no exemplo do modelo estatístico de Davenport.

Os resultados estão apresentados nas tabela 3.5 e 3.6.

Tabela 3.5 - Resultados da força cortante F ao longo da altura da torre e do deslocamento horizontal ux no topo.

\begin{tabular}{|c|c|c|c|c|}
\hline $\mathrm{z} / \mathrm{H}$ & $\mathrm{F}_{\text {Média }}(\mathrm{N})$ & $\mathrm{F}_{\text {Flutuante }}(\mathrm{N})$ & $\mathrm{F}_{\text {Total }}(\mathrm{N})$ & $\mathrm{G}=\mathrm{F}_{\text {Total }} / \mathrm{F}_{\text {média }}$ \\
\hline 0 & 134548 & 44168 & 178716 & 1,33 \\
\hline 0,5 & 61110 & 39971 & 101080 & 1,65 \\
\hline 0,75 & 23016 & 30197 & 53213 & 2,31 \\
\hline $\mathrm{z} / \mathrm{H}$ & $\mathrm{ux}_{\text {médio }}(\mathrm{cm})$ & $\mathrm{uX}_{\text {flutuante }}$ & $\mathrm{ux}_{\text {total }}(\mathrm{cm})$ & $\mathrm{G}=\mathrm{ux}_{\text {total }} / \mathrm{ux}_{\text {médio }}$ \\
\hline 1 & 32,5 & 34,5 & 67 & 2,062 \\
\hline
\end{tabular}


Observa-se que os resultados obtidos com a NBR6123 diferem dos resultados obtidos com o modelo de Davenport devido aos diferentes valores das variáveis consideradas no cálculo. Por exemplo, a velocidade do vento refere-se a uma média de 10 minutos e não 1 hora conforme Davenport. A velocidade média de 10 minutos é $6,1 \%$ maior que a velocidade média de 1 hora, aumentando, assim, a diferença entre as respostas médias calculadas por ambos os métodos. 
Tabela 3.6 - Determinação das forças do vento na torre segundo a NBR6123

\begin{tabular}{|c|c|c|c|c|c|c|c|c|c|c|c|c|c|}
\hline Seção & & $\phi_{\mathrm{i}}$ & Área $\left(\mathrm{m}^{2}\right)$ & $z_{i}(m)$ & $\mathrm{C}_{\mathrm{a}}$ & $\mu($ modo $)$ & $\beta_{\mathrm{i}}$ & $\beta_{\mathrm{i} \cdot} \cdot \mu$ & $\mathrm{m}_{\mathrm{i}}$ & $\left(m_{i} / m_{o}\right) \mu_{i}^{2}$ & $\mathrm{~F}_{\text {médio }}$ & $\mathrm{F}(\mathrm{t})$ & Total \\
\hline 1 & $1 \mathrm{a}$ & 0,3 & 1,77 & 100,3 & 2,50 & 1,0000 & 0,57 & 0,574 & 625 & 5,000 & 1076 & 9579 & 10655 \\
\hline & $1 b$ & 0,15 & 3,54 & 98,33 & 3,15 & 0,9487 & 0,72 & 0,684 & 125 & 0,900 & 1346 & 1817 & 3163 \\
\hline & $1 \mathrm{c}$ & 0,15 & 3,54 & 96,37 & 3,15 & 0,8993 & 0,72 & 0,646 & 125 & 0,809 & 1336 & 1723 & 3059 \\
\hline & $2 a$ & 0,17 & 3,54 & 94,4 & 3,05 & 0,8513 & 0,79 & 0,669 & 125 & 0,725 & 1455 & 1631 & 3086 \\
\hline & $2 b$ & 0,17 & 3,54 & 92,43 & 3,05 & 0,8049 & 0,78 & 0,630 & 125 & 0,648 & 1443 & 1542 & 2985 \\
\hline & $2 c$ & 0,17 & 3,54 & 90,47 & 3,05 & 0,7604 & 0,78 & 0,593 & 125 & 0,578 & 1432 & 1457 & 2889 \\
\hline & $3 a$ & 0,2 & 3,54 & 88,5 & 2,90 & 0,7172 & 0,87 & 0,623 & 125 & 0,514 & 1589 & 1374 & 2963 \\
\hline & $3 b$ & 0,2 & 3,54 & 86,53 & 2,90 & 0,6756 & 0,86 & 0,584 & 125 & 0,456 & 1576 & 1294 & 2870 \\
\hline & $3 c$ & 0,35 & 3,54 & 84,57 & 2,38 & 0,6357 & 1,23 & 0,784 & 625 & 2,020 & 2239 & 6089 & 8328 \\
\hline & $4 \mathrm{a}$ & 0,23 & 6,15 & 82,6 & 2,78 & 0,5971 & 1,64 & 0,980 & 130 & 0,371 & 2966 & 1190 & 4156 \\
\hline & $4 b$ & 0,23 & 6,15 & 79,65 & 2,78 & 0,5421 & 1,63 & 0,884 & 149 & 0,350 & 2927 & 1238 & 4165 \\
\hline & $5 a$ & 0,23 & 7,74 & 76,7 & 2,78 & 0,4904 & 2,04 & 0,999 & 168 & 0,323 & 3632 & 1263 & 4895 \\
\hline & $5 b$ & 0,23 & 7,74 & 73,75 & 2,78 & 0,4419 & 2,02 & 0,894 & 187 & 0,292 & 3580 & 1267 & 4846 \\
\hline & $6 a$ & 0,21 & 9,365 & 70,8 & 2,86 & 0,3965 & 2,28 & 0,905 & 205 & 0,258 & 4008 & 1246 & 5253 \\
\hline & $6 b$ & 0,21 & 9,365 & 67,85 & 2,86 & 0,3541 & 2,26 & 0,802 & 224 & 0,225 & 3945 & 1216 & 5161 \\
\hline 7 & $7 \mathrm{a}$ & 0,2 & 11 & 64,9 & 2,90 & 0,3147 & 2,55 & 0,802 & 243 & 0,192 & 4402 & 1172 & 5574 \\
\hline & $7 b$ & 0,2 & 11 & 61,95 & 2,90 & 0,2781 & 2,53 & 0,702 & 262 & 0,162 & 4327 & 1117 & 5443 \\
\hline 8 & $8 \mathrm{a}$ & 0,18 & 12,6 & 59 & 3,02 & 0,2443 & 2,64 & 0,644 & 281 & 0,134 & 4478 & 1052 & 5531 \\
\hline & $8 b$ & 0,18 & 12,6 & 56,05 & 3,02 & 0,2132 & 2,61 & 0,557 & 300 & 0,109 & 4394 & 980 & 5374 \\
\hline 9 & $9 \mathrm{a}$ & 0,16 & 14,25 & 53,1 & 3,10 & 0,1847 & 2,72 & 0,502 & 319 & 0,087 & 4527 & 903 & 5430 \\
\hline & $9 b$ & 0,16 & 14,25 & 50,15 & 3,10 & 0,1587 & 2,69 & 0,427 & 338 & 0,068 & 4433 & 822 & 5255 \\
\hline 10 & $10 \mathrm{a}$ & 0,15 & 15,85 & 47,2 & 3,15 & 0,1351 & 2,82 & 0,381 & 357 & 0,052 & 4593 & 739 & 5332 \\
\hline & $10 \mathrm{~b}$ & 0,15 & 15,85 & 44,25 & 3,15 & 0,1138 & 2,79 & 0,317 & 376 & 0,039 & 4484 & 656 & 5140 \\
\hline
\end{tabular}


Continuação: Tabela 3.6 - Determinação das forças do vento na torre segundo a NBR6123

\begin{tabular}{|c|c|c|c|c|c|c|c|c|c|c|c|c|c|}
\hline Seção & & $\phi_{\mathrm{i}}$ & Área $\left(\mathrm{m}^{2}\right)$ & $\mathrm{Z}_{\mathrm{i}}(\mathrm{m})$ & $\mathrm{C}_{\mathrm{a}}$ & $\mathrm{x}($ modo $)$ & $\beta_{\mathrm{i}}$ & $\beta_{\mathrm{i} \cdot \mathrm{X}}$ & $\mathrm{m}_{\mathrm{i}}$ & $\left(\mathrm{m}_{\mathrm{i}} / \mathrm{m}_{\mathrm{o}}\right) \mathrm{x}_{\mathrm{i}}^{2}$ & $F_{\text {médio }}$ & $\mathrm{F}(\mathrm{t})$ & Total \\
\hline & $11 \mathrm{a}$ & 0,16 & 17,5 & 41,3 & 3,11 & 0,0947 & 3,16 & 0,299 & 395 & 0,028 & 5019 & 574 & 5593 \\
\hline & $11 \mathrm{~b}$ & 0,16 & 17,5 & 38,35 & 3,11 & 0,0778 & 3,11 & 0,242 & 413 & 0,020 & 4883 & 493 & 5376 \\
\hline 12 & $12 a$ & 0,17 & 19,1 & 35,4 & 3,05 & 0,0629 & 3,53 & 0,222 & 432 & 0,014 & 5460 & 417 & 5876 \\
\hline & $12 b$ & 0,17 & 19,1 & 32,45 & 3,05 & 0,0499 & 3,48 & 0,174 & 451 & 0,009 & 5287 & 345 & 5632 \\
\hline 13 & $13 a$ & 0,16 & 20,75 & 29,5 & 3,10 & 0,0388 & 3,57 & 0,138 & 470 & 0,006 & 5329 & 279 & 5608 \\
\hline & $13 b$ & 0,16 & 20,75 & 26,55 & 3,10 & 0,0293 & 3,50 & 0,103 & 489 & 0,003 & 5125 & 220 & 5344 \\
\hline 14 & $14 a$ & 0,15 & 22,35 & 23,6 & 3,15 & 0,0214 & 3,50 & 0,075 & 508 & 0,002 & 5011 & 167 & 5178 \\
\hline & $14 b$ & 0,15 & 22,35 & 20,65 & 3,15 & 0,0150 & 3,41 & 0,051 & 527 & 0,001 & 4770 & 121 & 4891 \\
\hline 15 & $15 a$ & 0,15 & 23,95 & 17,7 & 3,15 & 0,0100 & 3,55 & 0,035 & 546 & 0,000 & 4828 & 84 & 4911 \\
\hline & $15 \mathrm{~b}$ & 0,15 & 23,95 & 14,75 & 3,15 & 0,0061 & 3,44 & 0,021 & 565 & 0,000 & 4513 & 53 & 4566 \\
\hline 16 & $16 a$ & 0,14 & 25,6 & 11,8 & 3,20 & 0,0034 & 3,34 & 0,011 & 584 & 0,000 & 4211 & 30 & 4241 \\
\hline & $16 \mathrm{~b}$ & 0,14 & 25,6 & 8,85 & 3,20 & 0,0016 & 3,17 & 0,005 & 603 & 0,000 & 3786 & 15 & 3800 \\
\hline 17 & $17 \mathrm{a}$ & 0,14 & 27,2 & 5,9 & 3,20 & 0,0005 & 3,12 & 0,002 & 621 & 0,000 & 3462 & 5 & 3467 \\
\hline & $17 \mathrm{~b}$ & 0,14 & 27,2 & 2,95 & 3,20 & 0,0001 & 2,75 & 0,000 & 640 & 0,000 & 2679 & 1 & 2680 \\
\hline \multicolumn{3}{|c|}{ Somatórias } & 496,9 & & & & & 16,96 & & 14,40 & 134548 & 44168 & 178716 \\
\hline
\end{tabular}

Dados: $\mathrm{V}_{\mathrm{o}}=40 \mathrm{~m} / \mathrm{s}$ $\mathrm{m}_{\mathrm{o}}=125 \mathrm{~kg}$ $\mathrm{F}_{\mathrm{H}}=1915,8 \mathrm{~N}$

$\mathrm{A}_{\mathrm{o}}=3,54 \mathrm{~m}^{2}$

$\begin{array}{lc}\mathrm{S}_{1}=1 & \mathrm{~A}_{\mathrm{o}}=3,54 \mathrm{~m}^{2} \\ \mathrm{~S}_{3}=1 & \mathrm{~V}_{\mathrm{p}}=27,6 \mathrm{~m} / \mathrm{s} \\ \mathrm{b}=0,86 & \mathrm{q}_{\mathrm{o}}=467 \mathrm{~N} / \mathrm{m}^{2} \\ \mathrm{p}=0,185 & \xi=1,33 ; \gamma=2,656\end{array}$




\subsection{O método do "vento sintético"}

Esta seção trata do processo desenvolvido por FRANCO (1993) para o cálculo do efeito dinâmico do vento em estruturas esbeltas. O método é baseado na técnica de Monte Carlo para simulação das pressões flutuantes do vento que atuam em determinada estrutura. Todas as expressões aqui utilizadas são relativas a este procedimento, com exceção de algumas sugestões desta Tese. O exemplo utilizado é o da torre treliçada, para comparação com os outros processos de cálculo já apresentados.

O procedimento vale-se da possibilidade de utilizar programas de elementos finitos que permitem a inclusão de séries temporais de carregamento. Utilizando-se o espectro de potência, as forças do vento podem ser decompostas em m harmônicos, sendo um deles ressonante. Variando-se aleatoriamente o ângulo de fase, utiliza-se um modelo aproximado para representar a correlação espacial das forças do vento em função da freqüência das rajadas. A estrutura é excitada separadamente pelos $\mathrm{m}$ harmônicos, originando o espectro da resposta, seja ela esforço solicitante nas barras ou deslocamentos. A resposta de pico é determinada integrando-se o espectro da resposta. Faz-se então uma análise estatística para se determinar a resposta característica para a coordenada considerada.

Finalmente a estrutura é novamente excitada com a combinação pseudo aleatória das forças harmônicas que geraram a resposta mais próxima da resposta característica, obtendo-se assim, uma boa aproximação dos valores característicos dos deslocamentos e dos esforços solicitantes em toda a estrutura.

Para definir a relação entre as pressões flutuantes e as pressões médias, o método baseia-se na relação entre a velocidade média ( $\mathrm{t}=600$ segundos) e a velocidade de rajada $(\mathrm{t}=3$ segundos) válida para a categoria 2 da NBR6123/88 à altitude de 10 metros. FRANCO (1993) generalizou esta relação para todas as categorias e altitudes visando a simplificação do método. No entanto, sugere-se aqui uma modificação do método do "vento sintético", considerando para cada categoria e altitude, as expressões contidas a NBR6123/88 para a velocidade média e a velocidade de rajada. Desta forma, para cada altura da estrutura e cada categoria de terreno a relação entre a pressão média e a pressão máxima flutuante é diferente. 
Segundo o método do "vento sintético", a razão entre a pressão média ( $\mathrm{t}=600$ segundos) e a pressão máxima de rajada ( $\mathrm{t}=3$ segundos $)$ é:

$$
\frac{\mathrm{p}_{600}}{\mathrm{p}_{3}}=\left(\frac{\mathrm{V}_{600}}{\mathrm{~V}_{3}}\right)^{2}=0,69^{2}=0,48
$$

Portanto $48 \%$ da força total representa o valor médio e $52 \%$ representa o valor flutuante dado pelas rajadas.

Sugere-se aqui adotar a variação da velocidade média do vento com a altitude, e com a categoria de terreno, adotando os valores de $b$ e $p$, correspondentes, conforme a NBR6123/88.

$$
\mathrm{V}_{600}(\mathrm{z})=0,69 \mathrm{bV}\left(\frac{\mathrm{Z}}{10}\right)^{\mathrm{p}}
$$

$\mathrm{V}_{3}(\mathrm{z})=\mathrm{bV}_{0}\left(\frac{\mathrm{Z}}{10}\right)^{\mathrm{p}}$

onde $\mathrm{V}_{0}$ é a velocidade básica do vento medida sobre terreno de categoria II, a uma altitude de 10 metros, sobre 3 segundos. b e p são definidos na tabela 3.4 , conforme a categoria do terreno.

Com isso determina-se a parte flutuante das pressões do vento:

$$
\mathrm{p}_{\mathrm{f}}=\mathrm{p}_{3}-\mathrm{p}_{600}=0,613\left(\mathrm{~V}_{3}^{2}-\mathrm{V}_{600}^{2}\right) \mathrm{C}_{\mathrm{p}}
$$

onde $\mathrm{p}_{3}$ e $\mathrm{p}_{600}$ são as pressões obtidas com a velocidade média no tempo de 3 segundos e 600 segundos, respectivamente, e $\mathrm{C}_{\mathrm{p}}$ é o coeficiente de pressão.

A parte flutuante é então separada em harmônicos conforme o espectro de potência das rajadas. O espectro reduzido do vento adotado é o da Norma Canadense definido pela equação 3.46 .

$$
\frac{\mathrm{fS}(\mathrm{f})}{\mathrm{u}_{*}^{2}}=4 \frac{\mathrm{x}^{2}}{\left(1+\mathrm{x}^{2}\right)^{4 / 3}} ; \mathrm{x}=\frac{1220 \mathrm{f}}{\mathrm{V}}
$$


em que f é a freqüência das rajadas, $V$ é a velocidade do vento e $\mathrm{U}$ * é a velocidade de cisalhamento do vento.

Para uma região pequena da estrutura de área $\mathrm{A}$, onde se pode considerar as velocidades do vento perfeitamente correlacionadas, o espectro das pressões flutuantes devidas ao vento está relacionado com o espectro da velocidade do vento pela formula:

$S_{P}(z, f)=4 q^{2} C_{a}^{2} S_{V}(z, f)$

A componente flutuante da pressão do vento $\mathrm{p}^{\prime}(\mathrm{t})$ pode ser representada, aproximadamente, por um número finito de funções harmônicas convenientemente escolhidas com períodos entre $600 \mathrm{~s}$ e $0,5 \mathrm{~s}$ de modo a abranger pelo menos o primeiro modo de vibração da estrutura. Adota-se no mínimo 11 harmônicos com um dos períodos $\mathrm{T}_{\mathrm{r}}$ coincidente com o período fundamental da estrutura.

$$
\begin{aligned}
& \mathrm{p}^{\prime}(\mathrm{t}) \cong \sum_{\mathrm{k}=1}^{\mathrm{m}} \mathrm{C}_{\mathrm{k}} \cos \left(\frac{2 \pi}{\mathrm{T}_{\mathrm{r}} \mathrm{r}_{\mathrm{k}}} \mathrm{t}-\theta_{\mathrm{k}}\right) \\
& \mathrm{C}_{\mathrm{k}}=\sqrt{2 \int_{\mathrm{k}} \mathrm{S}_{\mathrm{P}}(\mathrm{f}) \mathrm{df}} \\
& \mathrm{r}_{\mathrm{k}}=2^{\mathrm{k}-\mathrm{r}}
\end{aligned}
$$

Os valores de $C_{k}$ são determinados por integração do espectro de potência nos intervalos de freqüência dos harmônicos m. Dessa forma, a amplitude de cada harmônico de força é dada por:

$$
\mathrm{p}_{\mathrm{k}}^{\prime}=\frac{\mathrm{C}_{\mathrm{k}}}{\sum_{\mathrm{k}=1}^{\mathrm{m}} \mathrm{C}_{\mathrm{k}}} \mathrm{p}^{\prime}=\mathrm{c}_{\mathrm{k}} \mathrm{p}^{\prime}
$$

As funções harmônicas são então combinadas conforme uma determinação pseudoaleatória dos ângulos de fase.

Seguindo a correlação de banda estreita com o coeficiente de decaimento $\mathrm{C}=7$, a favor da segurança, determina-se o comprimento da rajada para cada harmônico: 


$$
\Delta \mathrm{z}_{\mathrm{k}}=\frac{\mathrm{V}}{7 \mathrm{f}_{\mathrm{k}}}
$$

Para cada freqüência do vento adota-se uma correlação espacial representada por dois triângulos com decaimento de 1 a 0 atuando na altura total dada por:

$2 \Delta \mathrm{z}_{\mathrm{k}}=\frac{2 \mathrm{~V}}{7 \mathrm{f}_{\mathrm{k}}}$

Para aplicar o conceito de tamanho de rajada, deve-se determinar para cada harmônico a posição de seu centro na estrutura. Segundo FRANCO (1993), adota-se, a favor da segurança, o centro de rajada na posição mais desfavorável da estrutura onde a resposta desejada seja máxima (deslocamento ou esforços solicitantes). Além disso, na prática, pode-se adotar o mesmo centro para todas as rajadas elementares.

Seguindo o método proposto por FRANCO (1993) algumas condições devem ser observadas, como a seguir listadas.

- O número de harmônicos deve ser maior que 11. Quanto maior for m, mais preciso é o método;

- O período de um dos harmônicos deve coincidir com o período fundamental da estrutura;

- Os períodos das funções harmônicas restantes devem ser múltiplos de $\mathrm{T}_{\mathrm{r}}$ por um fator de 2 .

Segundo FRANCO (1993), para 11 harmônicos, a contribuição do harmônico ressonante é superestimada por um fator da ordem de 2. Este fato foi verificado pelo referido autor aumentando-se significativamente o número de harmônicos nas vizinhanças da ressonância.

Sendo $\mathrm{r}$ o valor de $\mathrm{k}$ ressonante, FRANCO sugere reduzir à metade o valor do coeficiente $c_{\mathrm{r}}$. Para garantir que a soma de $c_{\mathrm{k}}$ seja unitária, FRANCO sugere, também, aumentar $\mathrm{c}_{\mathrm{r}} / 4$ no valor dos coeficientes $\mathrm{c}_{\mathrm{r}+1}$ e $\mathrm{c}_{\mathrm{r}-1}$, ou seja: 
$\mathrm{cc}_{\mathrm{r}}=\frac{\mathrm{c}_{\mathrm{r}}}{2}$

$\mathrm{cc}_{\mathrm{r}+1}=\mathrm{c}_{\mathrm{r}+1}+\frac{\mathrm{c}_{\mathrm{r}}}{4}$

$\mathrm{cc}_{\mathrm{r}-1}=\mathrm{c}_{\mathrm{r}-1}+\frac{\mathrm{c}_{\mathrm{r}}}{4}$

A estrutura é então excitada com as várias séries temporais constituídas pelos $\mathrm{m}$ harmônicos com ângulos de fase pseudo aleatórios $\left(0 \leq \theta_{\mathrm{k}} \leq 2 \pi\right)$. Para cada série temporal de carregamento, os valores máximos da resposta da estrutura nas coordenadas relevantes são determinados. FRANCO (1993) sugere que sejam geradas ao menos 20 séries temporais de carregamento. A resposta característica da estrutura na coordenada de interesse é determinada estatisticamente. Considerando-se a distribuição de extremos tipo 1 (Gumbel), determina-se a resposta característica, adotando-se 95\% de probabilidade de que o valor da resposta seja menor que o valor característico.

Para se determinar todos os valores característicos dos esforços solicitantes ou dos deslocamentos na estrutura, adota-se a série temporal cuja resposta mais se aproxima da resposta característica determinada estatisticamente.

A seguir apresenta-se o exemplo numérico da torre em estudo.

\subsubsection{Exemplo}

A torre utilizada está descrita no item 3.2. Os coeficientes de força utilizados neste processo foram os mesmos determinados para o método de Davenport e o modelo discreto da NBR6123 conforme tabela 3.6.

Foi elaborado um programa no Mathcad versão 2000 para a geração das séries temporais de carregamento, apresentado no anexo D. Cada série consiste na somatória de 12 harmônicos cujos períodos abrangem a faixa de $0,4 \mathrm{~s}$ a 600 s do espectro do vento atmosférico. 
Inicialmente, foi determinada a posição do centro de rajada considerando o deslocamento horizontal máximo no topo da torre como parâmetro. Para isso, geraram-se séries temporais de carregamento para diversas posições do centro de rajada na torre. Carregou-se a estrutura utilizando-se o programa SAP2000. Para cada posição do centro de rajada, o deslocamento horizontal no topo da torre foi determinado. A posição do centro de rajada correspondente ao deslocamento máximo foi encontrada. Os resultados estão mostrados na tabela 3.8.

A tabela 3.7 mostra os coeficientes utilizados na decomposição espectral para geração dos harmônicos de pressão.

Determinada a posição do centro de rajada, foram gerados 20 conjuntos de séries temporais. Para cada conjunto foram gerados pseudo aleatoriamente 12 ângulos de fase, correspondentes aos 12 diferentes harmônicos. A estrutura foi, então, carregada 20 vezes com os diferentes conjuntos de séries temporais gerados. Os resultados do deslocamento no topo estão apresentados na tabela 3.8 para as 20 séries geradas.

Os resultados apresentados na tabela 3.9 foram determinados a partir da velocidade básica do vento de $40 \mathrm{~m} / \mathrm{s}$ considerando o método do "vento sintético" com a modificações aqui propostas.

Os períodos naturais da estrutura são $\mathrm{T}_{1}=1,178 \mathrm{~s}$ e $\mathrm{T}_{2}=0,441$. Utilizou-se o harmônico 3 como sendo o ressonante.

O valor médio do deslocamento no topo da torre obtido pelo método do vento sintético modificado foi de $32,46 \mathrm{~cm}$

Para efeito de comparação determinou-se o deslocamento no topo da torre utilizando-se o método do "vento sintético" sem as modificações propostas e com as modificações, tabela 3.11. As tabelas 3.8 a 3.10 e figura 3.16 referem-se aos resultados do "vento sintético" com as modificações. A série 3 da tabela 3.9 foi adotada como a série que fornece o resultado que mais se aproxima do valor característico para o deslocamento do topo da torre. 
Tabela 3.7 - Decomposição espectral das pressões flutuantes

\begin{tabular}{|r|r|c|r|r|r|}
\hline $\mathrm{k}$ & $\mathrm{r}_{\mathrm{k}}$ & $\mathrm{T}_{\mathrm{k}}$ & $\mathrm{c}_{\mathrm{k}}$ & $\mathrm{cc}_{\mathrm{k}}$ & $\Delta \mathrm{z}_{\mathrm{k}}(\mathrm{m})$ \\
\hline 1 & 0,25 & 0,294 & 4,2 & 4,2 & 1,2 \\
\hline 2 & 0,5 & 0,588 & 5,3 & 7,0 & 2,3 \\
\hline (Resson)r=3 & 1 & 1,176 & 6,7 & 3,4 & 4,6 \\
\hline 4 & 2 & 2,353 & 8,4 & 10,1 & 9,3 \\
\hline 5 & 4 & 4,706 & 10,6 & 10,6 & 18,6 \\
\hline 6 & 8 & 9,412 & 13,0 & 13,0 & 37,1 \\
\hline 7 & 16 & 18,824 & 15,0 & 15,0 & 74,2 \\
\hline 8 & 32 & 37,647 & 14,6 & 14,6 & 148,4 \\
\hline 9 & 64 & 75,294 & 10,8 & 10,8 & 296,9 \\
\hline 10 & 128 & 150,588 & 6,4 & 6,4 & 593,7 \\
\hline 11 & 256 & 301,176 & 3,4 & 3,4 & 1187 \\
\hline $\mathrm{m}=12$ & 512 & 602,353 & 1,7 & 1,7 & 2375 \\
\hline & & & 100 & 100 & \\
\hline
\end{tabular}

Tabela 3.8 - Determinação da posição do centro de rajada

\begin{tabular}{|r|r|r|}
\hline Centro de rajada & \multicolumn{2}{|c|}{ Deslocamento no topo - nó 100} \\
\hline (altitude em $\mathrm{m})$ & $\mathrm{u}_{\text {médio }}(\mathrm{m})$ & $\mathrm{u}_{\text {flutuante }}(\mathrm{m})$ \\
\hline 94,4 & 0,3246 & 0,104 \\
\hline 88,5 & 0,3246 & 0,106 \\
\hline 82,6 & 0,3246 & 0,111 \\
\hline 76,7 & 0,3246 & 0,109 \\
\hline 70,8 & 0,3246 & 0,107 \\
\hline
\end{tabular}

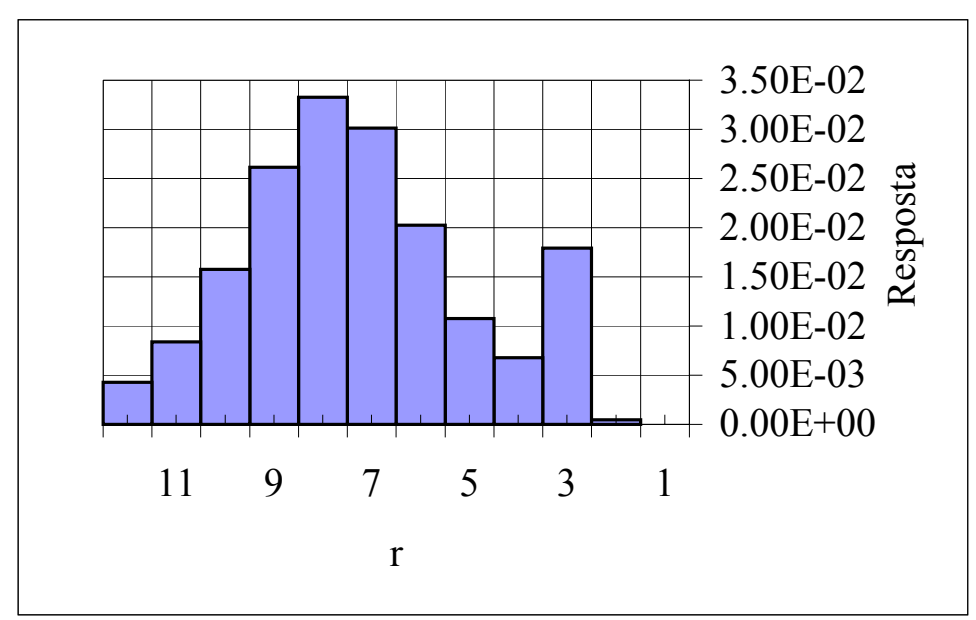

Figura 3.16 - Resposta dos harmônicos separadamente 
Tabela 3.9 - Valor característico do deslocamento no topo da estrutura

\begin{tabular}{|c|c|l|l|}
\hline Série & Deslocamentos - Nó 100 & Observação & Valor Característico \\
\hline & $\mathrm{u}_{\text {flutuante }}(\mathrm{cm})$ & & \\
\hline 1 & 14,69 & & \\
\hline 2 & 10,91 & & \\
\hline 3 & 13,7 & & \\
\hline 4 & 11,27 & & \\
\hline 5 & 13,38 & & \\
\hline 6 & 11,31 & & \\
\hline 7 & 10,53 & & \\
\hline 8 & 11,57 & & \\
\hline 9 & 12,61 & & \\
\hline 10 & 13,32 & & \\
\hline 11 & 10,89 & & \\
\hline 12 & 11,35 & & \\
\hline 13 & 10,77 & & \\
\hline 14 & 12,2 & GAUSE $(95 \%)$ \\
\hline 15 & 11,68 & & \\
\hline 16 & 12,81 & & \\
\hline 17 & 12,5 & moda & \\
\hline 18 & 12,31 & & \\
\hline 19 & 10,6 & & \\
\hline 20 & 13,1 & & \\
\hline$\mu$ & 12,08 & & \\
\hline$\sigma$ & 1,171 & & \\
\hline$v$ & 11,548 & & \\
\hline$\alpha$ & 1,095 & & \\
\hline
\end{tabular}


Tabela 3.10 - Resposta de pico dos harmônicos separadamente

\begin{tabular}{|r|r|}
\hline Harmônicos & Desloc. topo $(\mathrm{cm})$ \\
\hline 1 & 0,001453 \\
\hline 2 & 0,04852 \\
\hline 3 & 1,791 \\
\hline 4 & 0,6791 \\
\hline 5 & 1,079 \\
\hline 6 & 2,024 \\
\hline 7 & 3,011 \\
\hline 8 & 3,33 \\
\hline 9 & 2,612 \\
\hline 10 & 1,579 \\
\hline 11 & 0,8413 \\
\hline 12 & 0,428 \\
\hline Soma & 17,42 \\
\hline
\end{tabular}

A soma dos deslocamentos máximos de cada harmônico (tabela 3.10) não corresponde ao valor real do deslocamento de pico da estrutura, porque os mesmos não estão perfeitamente correlacionados.

\subsection{Comparação dos resultados}

A tabela 3.11 apresenta os resultados do deslocamento no topo relativo aos 3 métodos estudados.

Tabela 3.11 - Comparação dos resultados

\begin{tabular}{|c|c|c|c|}
\hline & $\mathrm{u}_{\text {médio }}(\mathrm{cm})$ & $\mathrm{u}_{\text {flutuante }}(\mathrm{cm})$ & Total $(\mathrm{cm})$ \\
\hline Davenport & 27,7 & 32,6 & 60,3 \\
\hline NBR6123 & 32,5 & 34,5 & 67,0 \\
\hline Vento sintético r=3 & 27,9 & 16,4 & 44,3 \\
\hline $\begin{array}{c}\text { Vento sintético } \\
\text { modificado r=3 }\end{array}$ & 32,5 & 13,7 & 46,2 \\
\hline (NBR/Davenport) & 1,17 & 1,06 & 1,11 \\
\hline (Vsintét/Davenport) & 1,17 & 0,42 & 0,77 \\
\hline
\end{tabular}

O resultado obtido pelo método do "vento sintético" modificado apresentou diferenças grandes em relação ao método de Davenport e a NBR6123. Futuros estudos são necessários para verificar a aderência do método com outros procedimentos, com novas simulações em torres treliçadas. 
Em relação à resposta média, encontraram-se diferenças de $17 \%$ entre o procedimento da norma brasileira e o de Davenport, porque, principalmente, a NBR6123/88 utiliza para o cálculo das forças do vento na estrutura, a velocidade média tomada no período de 10 minutos, enquanto que o método de Davenport utiliza a média tomada em uma hora.

Os resultados finais obtidos com a NBR6123 diferiram pouco dos resultados obtidos com o modelo de Davenport, e sempre a favor da segurança, indicando valores aceitáveis. As diferenças encontradas se devem às diferentes considerações que caracterizam cada método. A amplificação dinâmica especificada pela NBR6123/88, por exemplo, foi obtida considerando uma forma modal linear. A forma modal da torre é não linear e foi determinada por elementos finitos usando o programa SAP2000, figura 3.2. Segundo BLESSMANN (1998), a consideração da forma modal $x(z)=(Z / H)^{\beta}$, introduz variações em $\xi$ menores que $3 \%$ para $0,5<\alpha<1,5$. No entanto, segundo HOLMES et al.(1993), para torres treliçadas usadas em telecomunicações os valores de $\beta$ são geralmente maiores. No caso do exemplo, $\beta$ é 2,656. Já o processo de Davenport considera a forma modal não linear com o valor de $\beta$ real. 


\section{INVESTIGAÇÃO EXPERIMENTAL}

Apresentam-se, neste capítulo, resultados de uma investigação experimental sobre alguns aspectos da determinação das forças devidas ao vento em torres metálicas para telecomunicações. No item 4.1 apresenta-se a descrição dos modelos projetados para a investigação experimental. No item 4.2 descreve-se o arranjo experimental e os equipamentos utilizados para determinação das forças de arrasto e de sustentação do modelo. Os resultados aparecem sob a forma de tabelas e gráficos no item 4.3, onde se faz uma análise dos resultados obtidos. Há também um estudo sobre a presença de antenas de microondas interferindo no carregamento do vento na torre.

\subsection{Modelo}

Foram construídos três modelos da torre feitos em acrílico e poliestireno na oficina da "University of Western Ontario" (UWO), Canada, com o auxílio financeiro da CAPES. Adotou-se a escala geométrica de 1:40. O modelo representa parte da torre (ver figura 3.10) a uma altura de 50 metros aproximadamente.

Foram modelados três diferentes espaçamentos entre faces da torre. O modelo básico (modelo 1) que representa uma seção da torre quadrada possui 1,035 metros de comprimento por 0,102 metros de largura. Os outros dois modelos (modelos 2 e 3) foram construídos retangulares com a relação entre os lados do retângulo de 1/2 e 1/3 para avaliar o efeito de proteção do vento entre as faces da torre (figuras 4.1, 4.2 e 4.3). As figuras 4.4 a 4.8 mostram as etapas da fabricação dos modelos. A figura 4.9 mostra o modelo instalado no túnel de vento BLWT II, da UWO.

Foram investigados dois diferentes índices de área exposta, relação entre a área frontal efetiva da face da torre e a área total. Para tal, após os primeiros ensaios, foram adicionadas tiras de poliestireno de diversas espessuras: nas barras principais usaram-se tiras de 3,2 milímetros; e nas barras secundárias usaram-se tiras de 2 milímetros. Cada tira foi colada no modelo com o auxílio de fitas adesivas de dupla face, permitindo a retirada das mesmas, para maior flexibilidade dos ensaios. Com isso resultaram modelos com índice de área exposta iguais a $\phi=0,162$ e $\phi=0,267$. Portanto, além dos modelos 1 , 2 e 3 especificados nas figuras 4.1 a 4.3, mais dois modelos derivados dos modelos 1 e 2 
foram testados: modelo $4(0,102 \times 0,102 \times 1,035 \mathrm{~m}), \phi=0,267$ e modelo $5(0,102 \times 0,204$ x $1,035 \mathrm{~m}), \phi=0,267$.

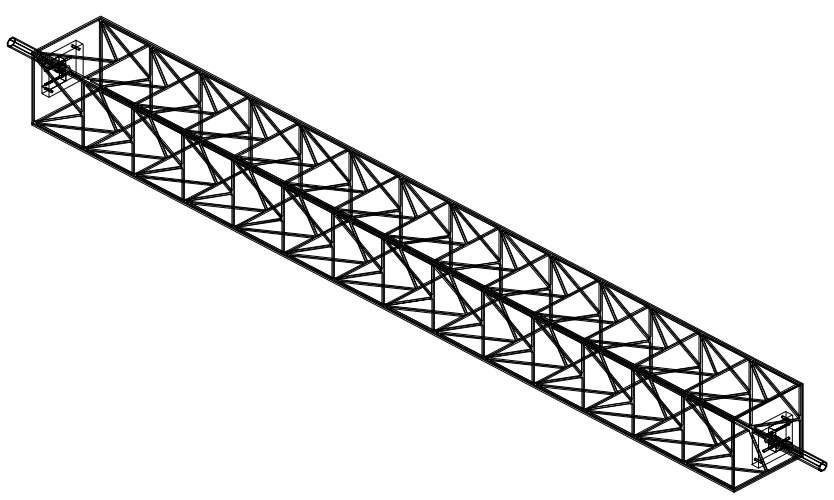

Figura 4.1 - Modelo $1(0,102 \times 0,102 \times 1,035 \mathrm{~m}), \phi=0,162$

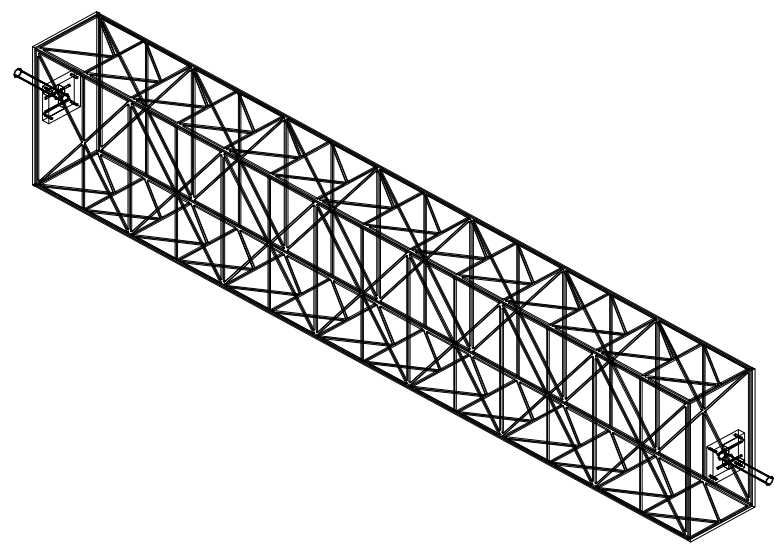

Figura 4.2 - Modelo $2(0,102$ x 0,204 x 1,035m), $\phi=0,162$

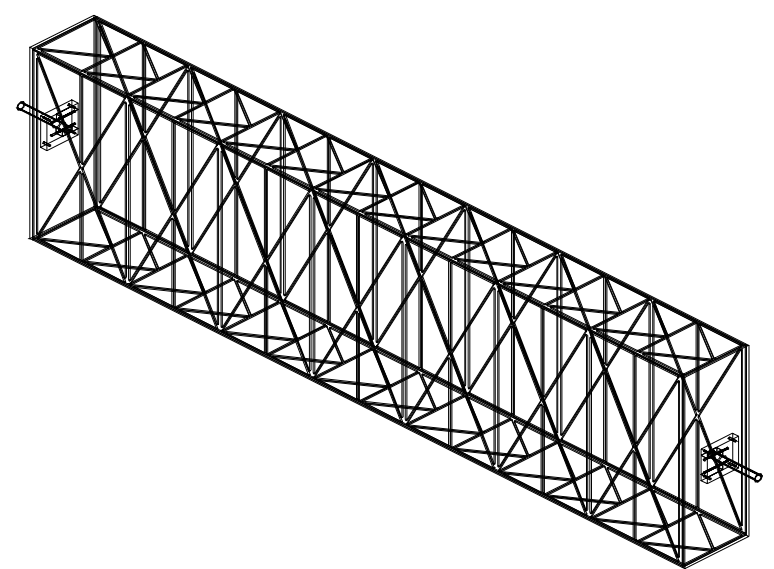

Figura 4.3 - Modelo $3(0,102$ x 0,306 x 1,035m), $\phi=0,162$ 


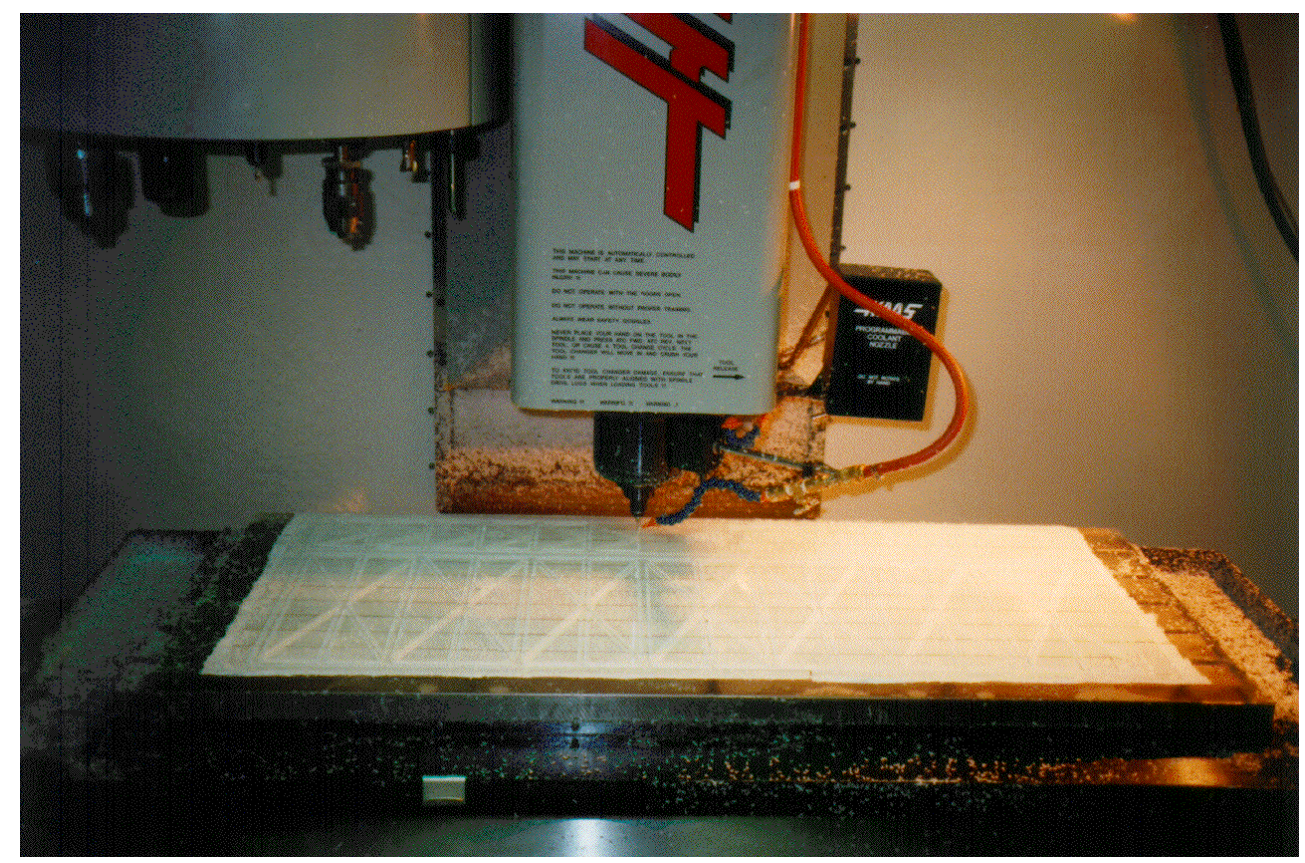

Figura 4.4 - Fabricação do modelo - Máquina de comando numérico

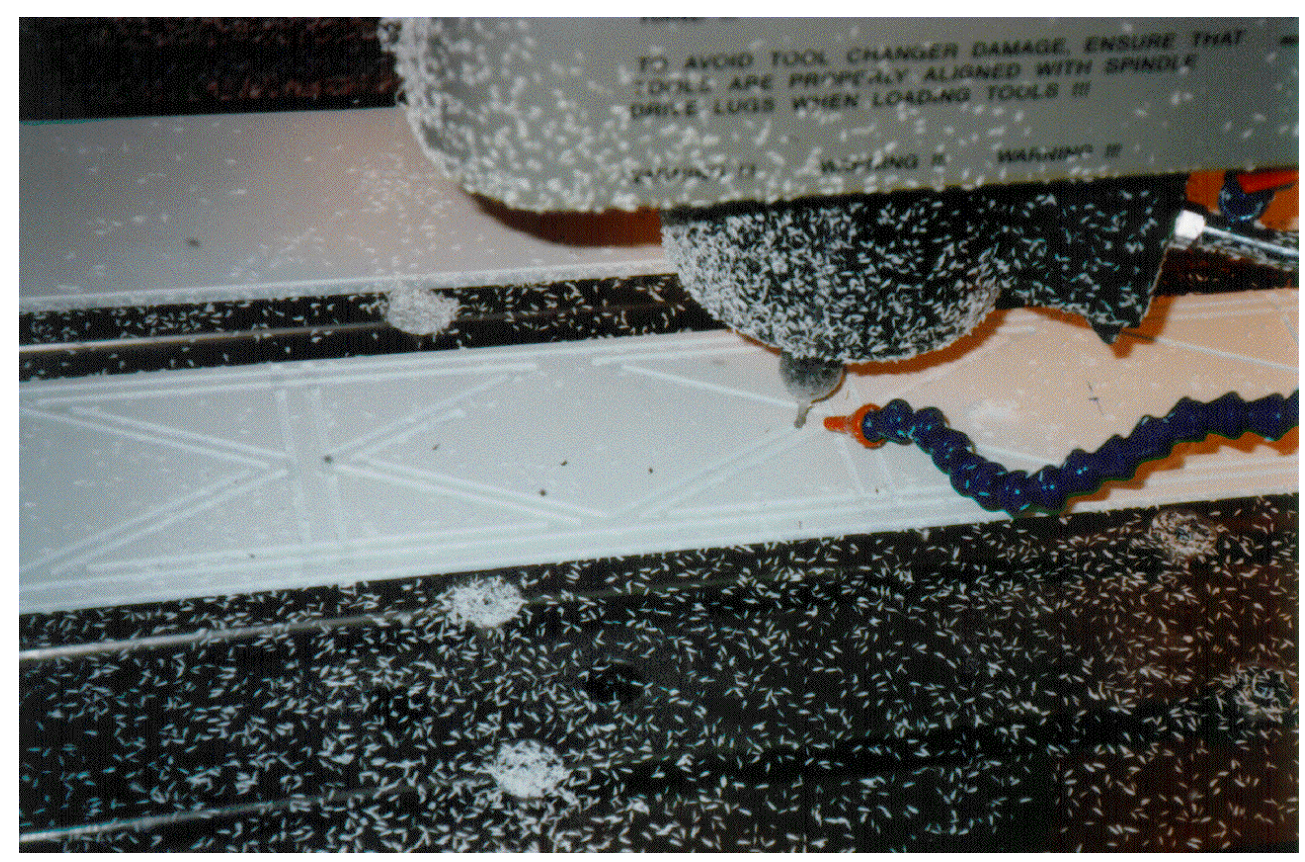

Figura 4.5 - Fabricação do modelo - Detalhe da chapa de acrílico na máquina de comando numérico. 


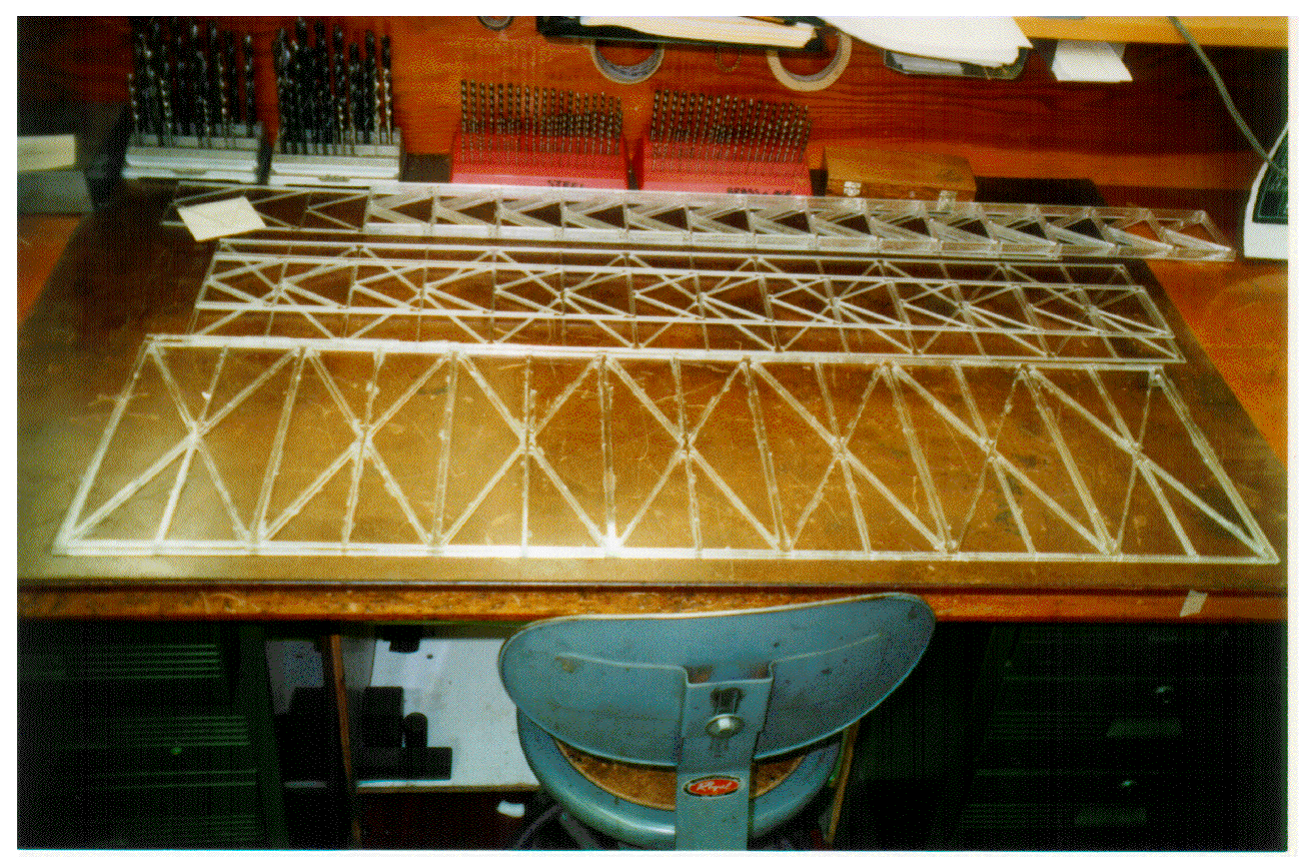

Figura 4.6 - Partes do modelo - faces laterais (acrílico)

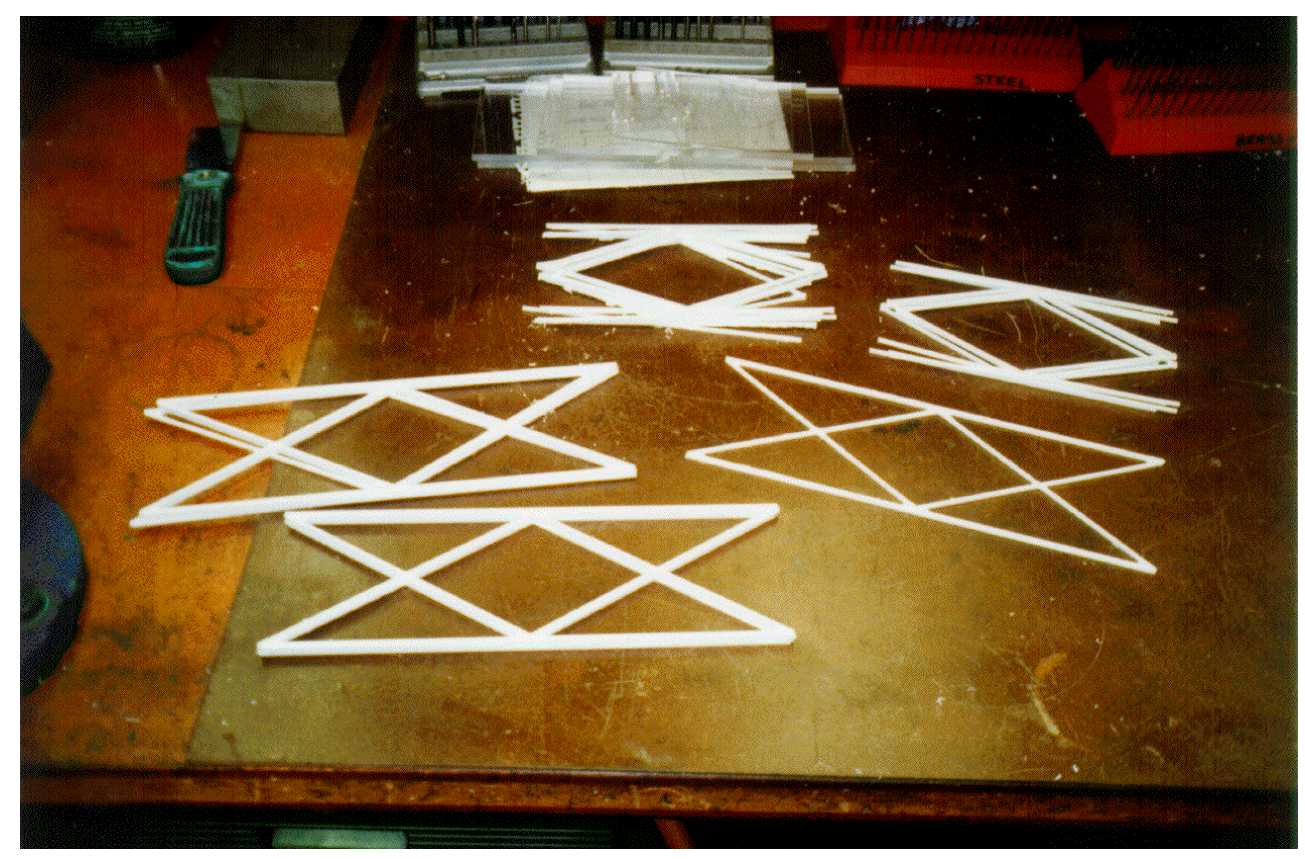

Figura 4.7 - Partes do modelo - chapas de topo e seções transversais (poliestireno) 


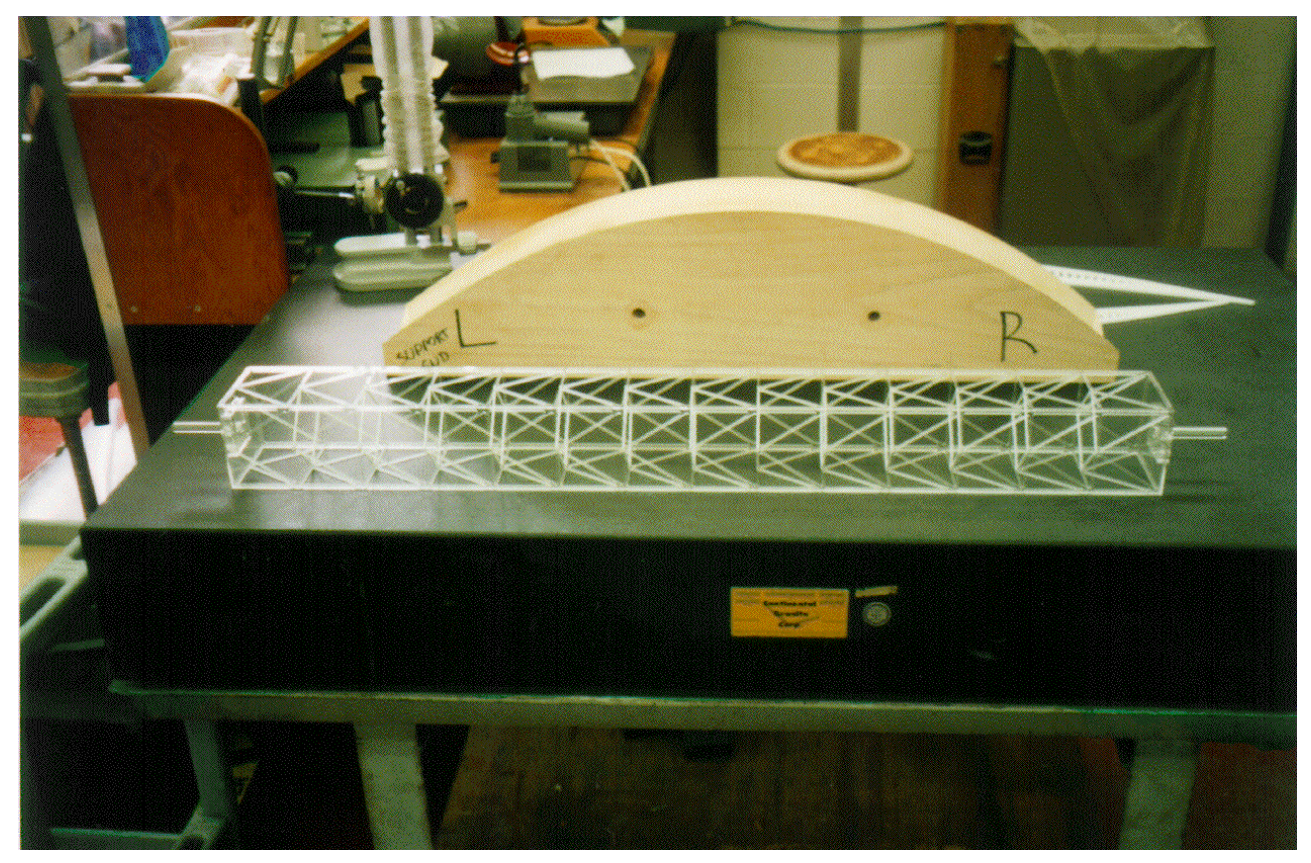

Figura 4.8 - Vista geral do modelo 1 na bancada

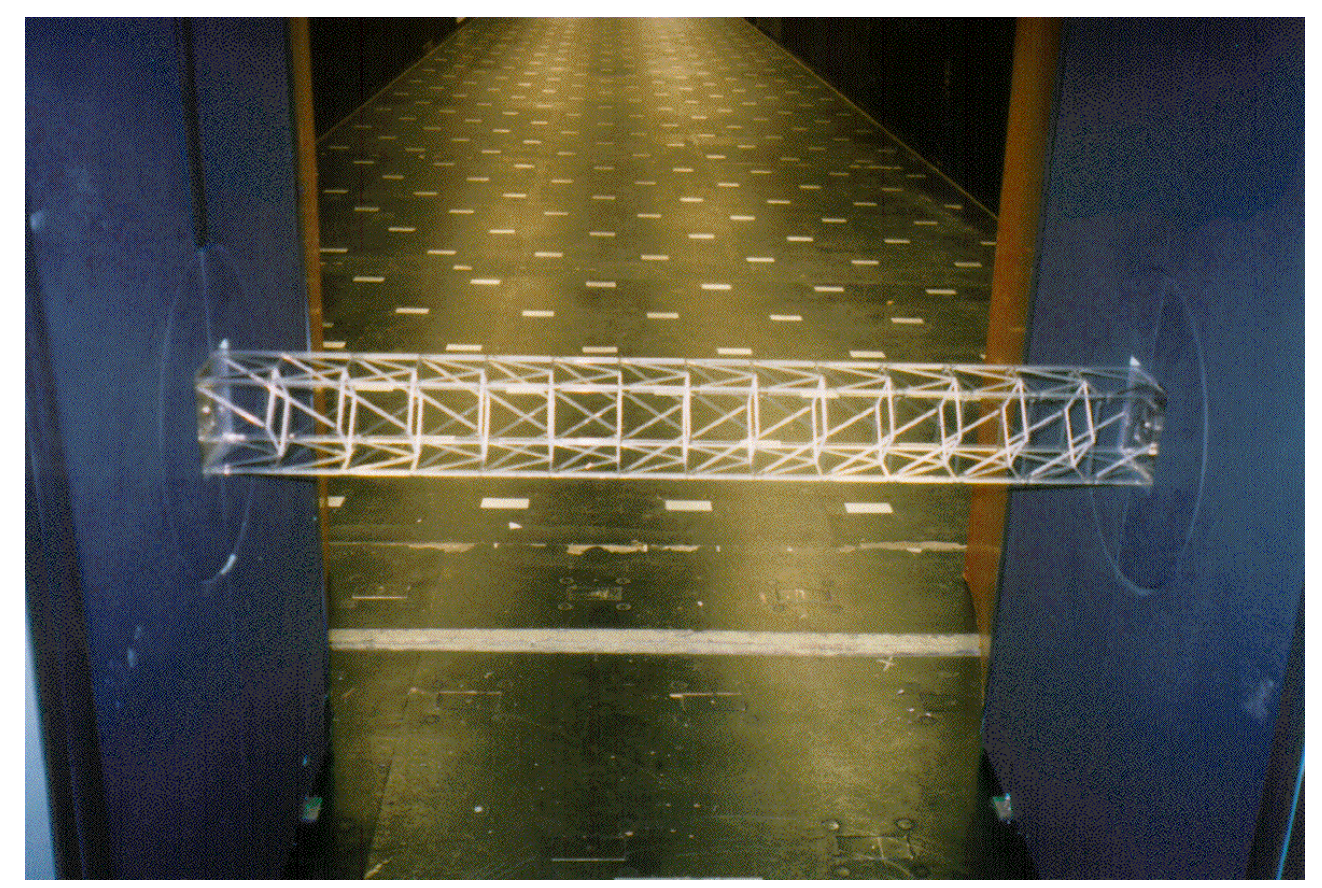

Figura 4.9 - Vista geral do modelo 1 no túnel de vento BLWT II 
Os modelos com $\phi=0,162$ possuem barras principais em cantoneira de 4,6 milímetros de largura e 2 milímetros de espessura representando os lados de uma cantoneira de 180 milímetros. Todas as outras barras foram projetadas em seção quadrada com dois milímetros de lado representando a face de uma cantoneira de 80 milímetros. Devido à escala do modelo, não foi possível simular a geometria exata das barras da torre, mas as dimensões externas dos perfis reais foram simuladas. Espera-se, com isso, que a esteira criada pelo perfil tenha aproximadamente as mesmas características da esteira de um perfil de cantoneira, pois os coeficientes de força dependem do tamanho da esteira. Além disso, foi simulada a massa do modelo por metro linear para futuros ensaios aeroelásticos.

Os testes foram conduzidos com números de Reynolds da ordem de 4000 a 11000. Admitindo um comportamento das barras do modelo semelhante ao comportamento de placas planas, observa-se que (figura 4.10) o coeficiente de arrasto é constante a partir do número de Reynolds igual a 5000. Entre 3000 e 4000 há uma pequena variação da ordem de $2 \%$. Pode-se admitir, portanto, a independência do número de Reynolds entre os coeficientes aerodinâmicos do modelo e da estrutura real. Além do número de Reynolds, foram avaliadas em todos os ensaios, as leis de similaridade entre o modelo e a estrutura real.

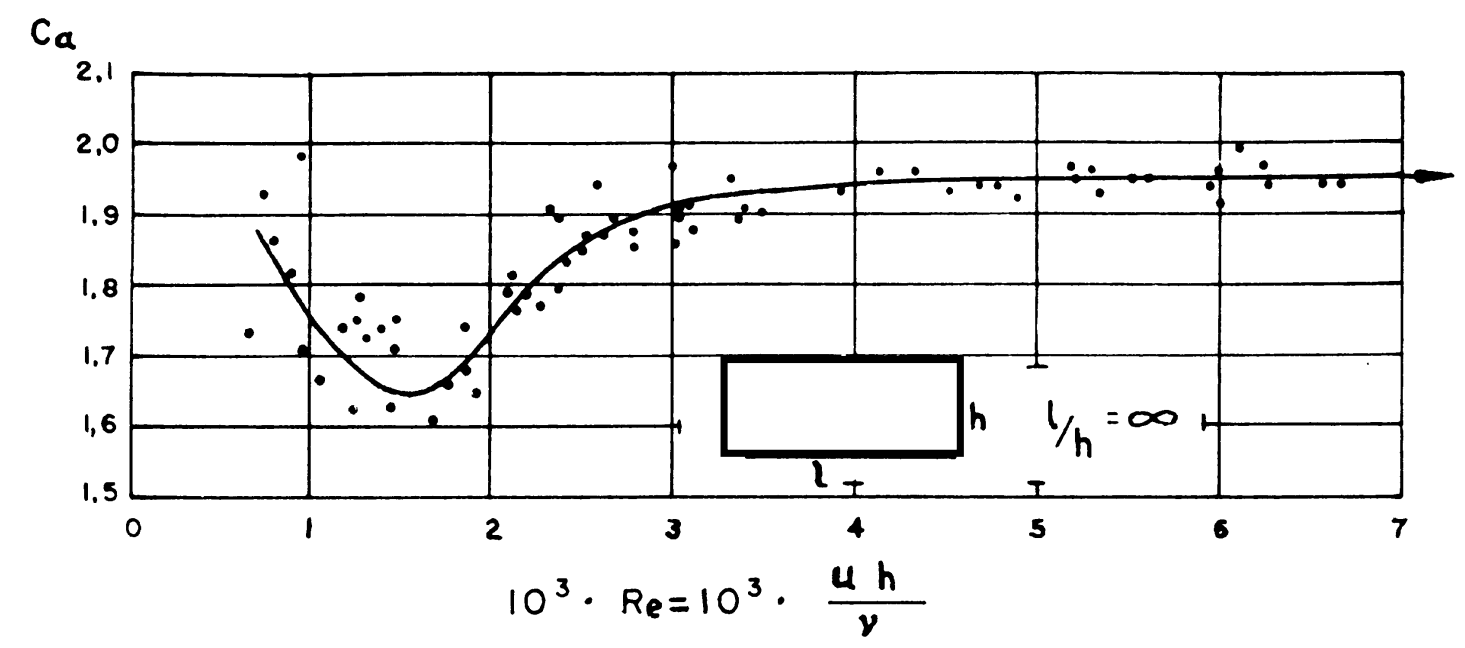

Figura 4.10 - Coeficiente de arrasto de placas planas em função do número de Reynolds (FLASHBART, 1932 apud BLESSMANN, 1990) 
Os valores médios dos coeficientes de arrasto e da força lateral foram medidos para cada ângulo de incidência de 15 graus. A definição matemática desses coeficientes é:

$\mathrm{C}_{\mathrm{L}}=\frac{\mathrm{F}_{\mathrm{L}}}{\mathrm{qBH} \phi}$

$\mathrm{C}_{\mathrm{a}}=\frac{\mathrm{F}_{\mathrm{a}}}{\mathrm{qBH} \phi}$

em que $F_{L}$ e $F_{a}$ são as forças médias lateral e de arrasto atuando no modelo.

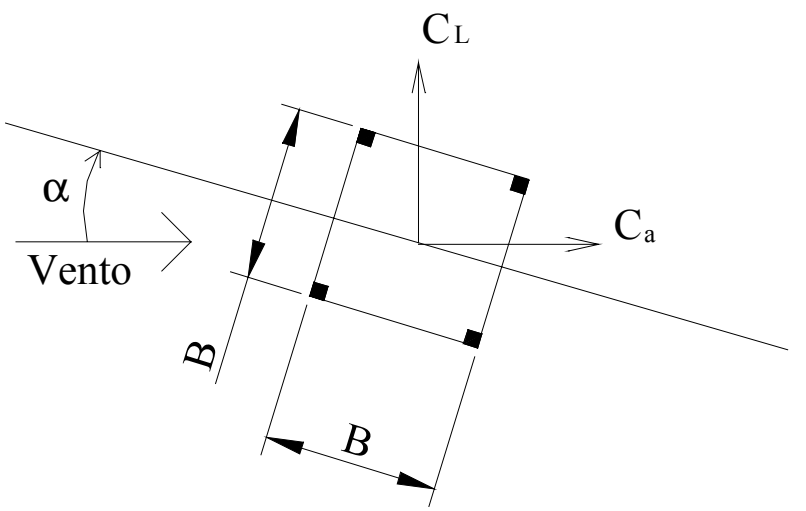

Figura 4.11 - Convenção de sinais para as forças de arrasto e lateral

Os coeficientes foram tornados adimensionais usando a pressão dinâmica do modelo, $q=(1 / 2) \rho V^{2}$, onde $\rho$ é a densidade do ar e $\mathrm{V}$ é a velocidade média horária na altura de referência. Utilizou-se, também, a dimensão $\mathrm{B}$, definida na figura 4.11, o comprimento $\mathrm{H}$ do modelo, que corresponde à parte do modelo exposto ao vento, e o índice de área exposta $(\phi)$ do modelo $(\mathrm{B}=0,102 \mathrm{~m}, \mathrm{H}=1,022 \mathrm{~m}$ e $\phi=0,162$ ou $\phi=0,267)$. Todos os coeficientes variam com o ângulo de incidência do vento.

\subsection{Arranjo experimental}

O modelo foi montado em duas balanças com seis graus de liberdade, com capacidade $45 \mathrm{~N}$ ou $13 \mathrm{~N}$, dependendo da sua calibração. As balanças foram fixadas em um suporte dentro do túnel. Esse suporte é utilizado para ensaios de seções de pontes e foi adaptado para ensaiar a seção da torre. Duas placas de isopor foram fixadas em cada 
lado do suporte cortando o vento a barlavento para simular o fluxo bidimensional e permitir o encaixe e o giro do modelo. Foi utilizado o túnel BLWT II do Boundary Layer Wind Tunnel Laboratory (BLWTL) da UWO com capacidade de ventos até 25 $\mathrm{m} / \mathrm{s}$.

Todos os experimentos foram feitos em fluxo suave e em turbulento, este último gerado por uma grade colocada à frente do modelo. Devido à escala do modelo, somente as freqüências mais altas (freqüências ressonantes) foram simuladas. Comparou-se o espectro gerado pela grade com o espectro fornecido pelo ESDU 74031 (1975), figura 4.12. Não foi possível simular o espectro de potência do vento experimental nas freqüências mais baixas das rajadas de vento natural, devido ao tamanho da grelha disponível. Como a estrutura analisada tem características não ressonantes, essa parte, que não foi simulada, é, também, importante para a determinação dos valores de pico da resposta da estrutura. Neste trabalho, utilizaram-se apenas os coeficientes médios obtidos experimentalmente. Trabalhos futuros podem ser realizados para avaliar a possibilidade de correção dos valores rms a partir da área do espectro que não foi simulada experimentalmente. Em estruturas cuja energia da parte ressonante é majoritária, o espectro simulado é suficiente para determinar a resposta da estrutura, o que não é o caso.

Utilizaram-se dois tubos de pitot fixados no teto do túnel para medir a velocidade do vento na seção transversal do túnel na altura do modelo. As figuras 4.13 e 4.14 mostram o arranjo experimental com o modelo, suporte, tubo de pitot e grade de turbulência.

Cada balança foi conectada a um sistema de aquisição de dados composto de conversores, filtros e placas de aquisição de dados conectados a um microcomputador, de onde se controla todo o processo (figura 4.15). As figuras 4.16 a 4.19 mostram os diferentes modelos ensaiados. 


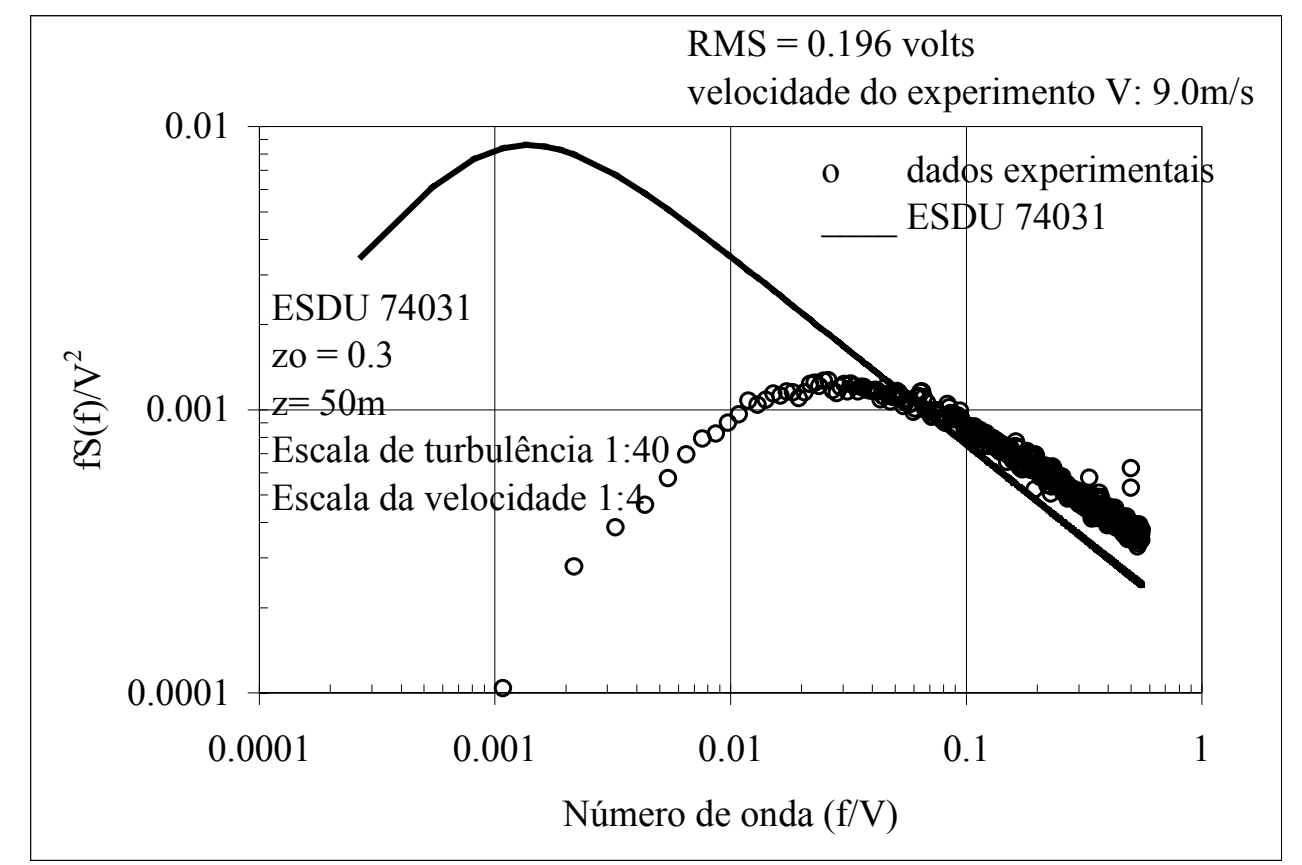

Figura 4.12 - Comparação do espectro de potência (exposição 2) das rajadas geradas pela grelha e fornecido por ESDU 70431 (1975).

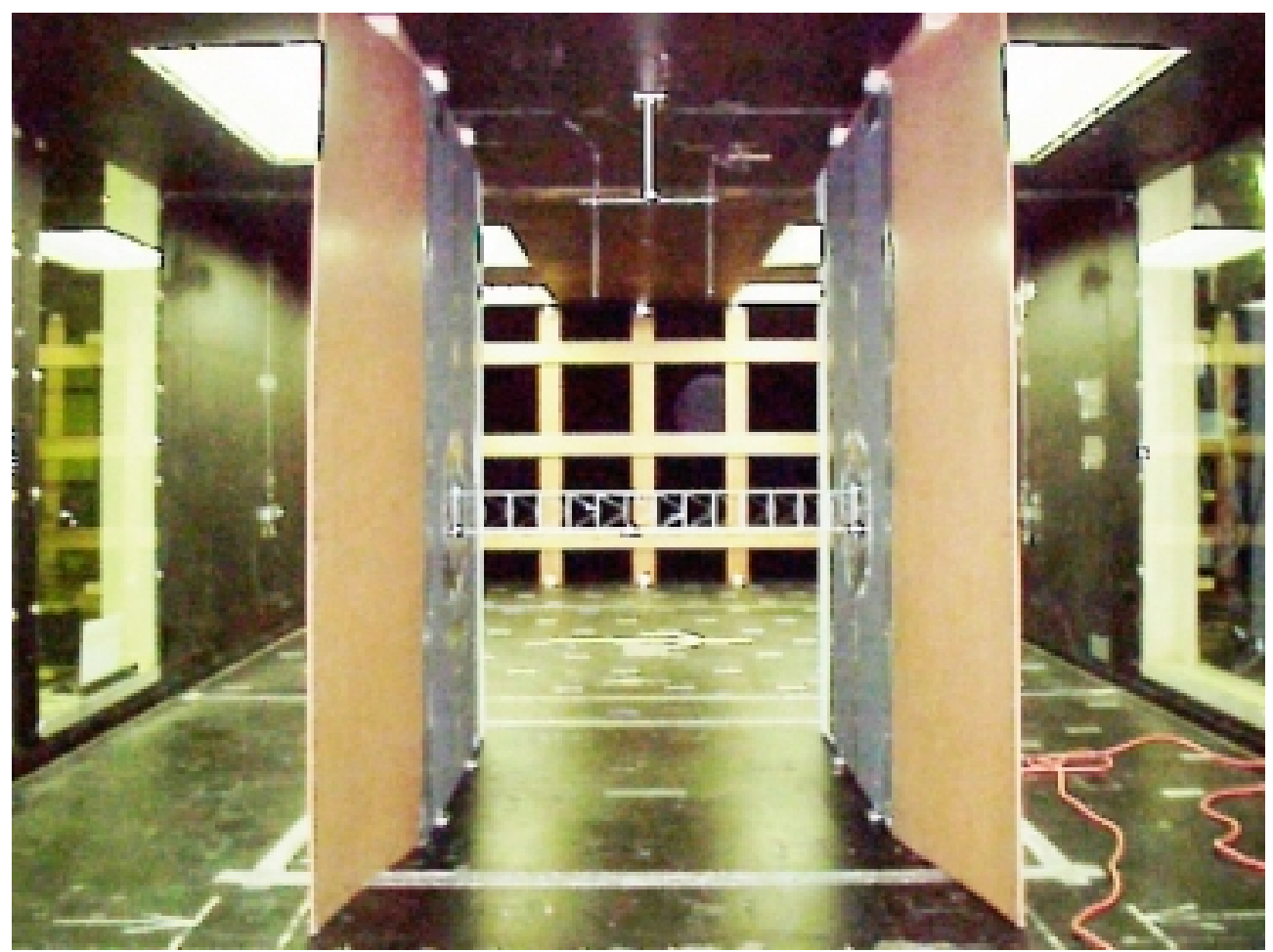

Figura 4.13 - Arranjo experimental - suporte, grelha e modelo. 


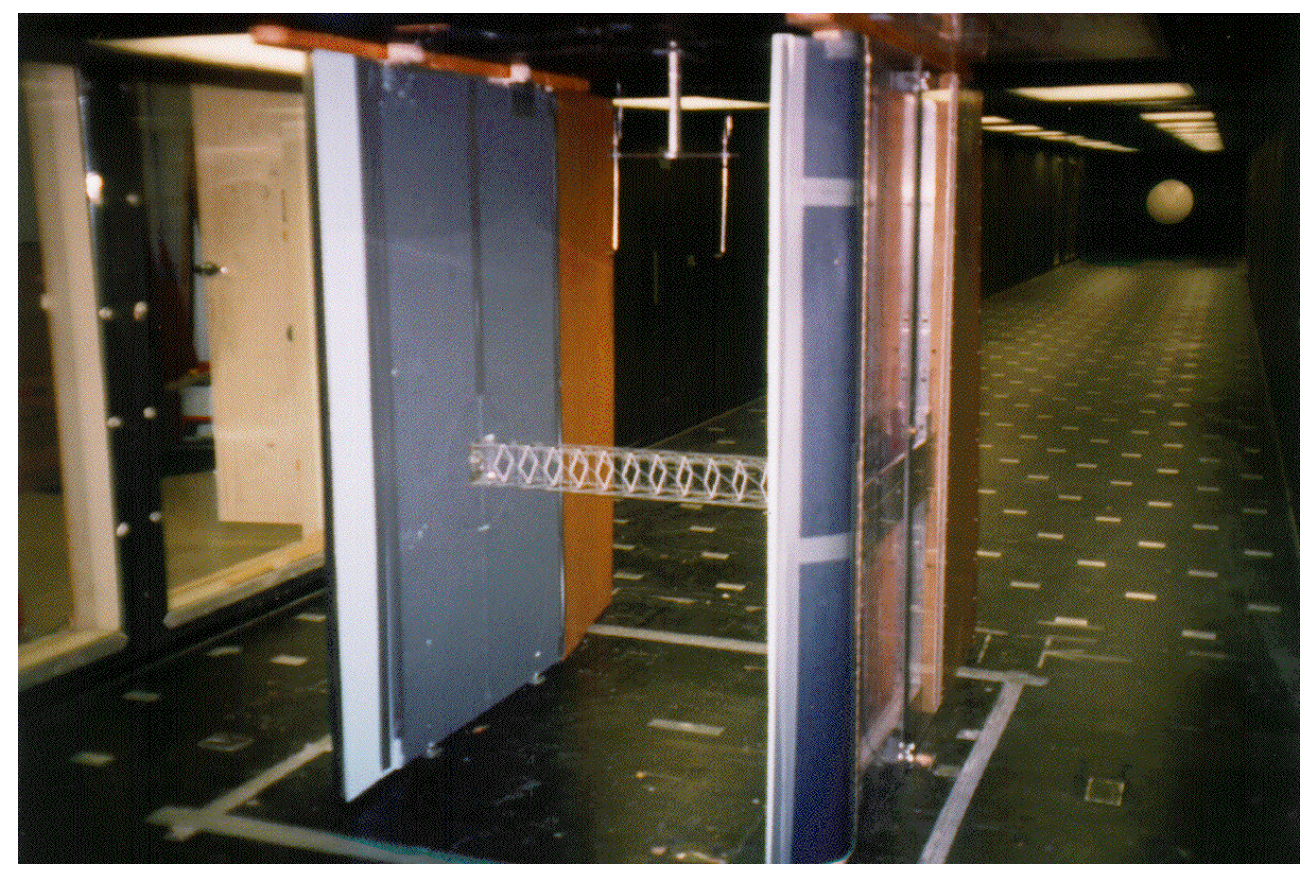

Figura 4.14 - Arranjo experimental - vista lateral do suporte.

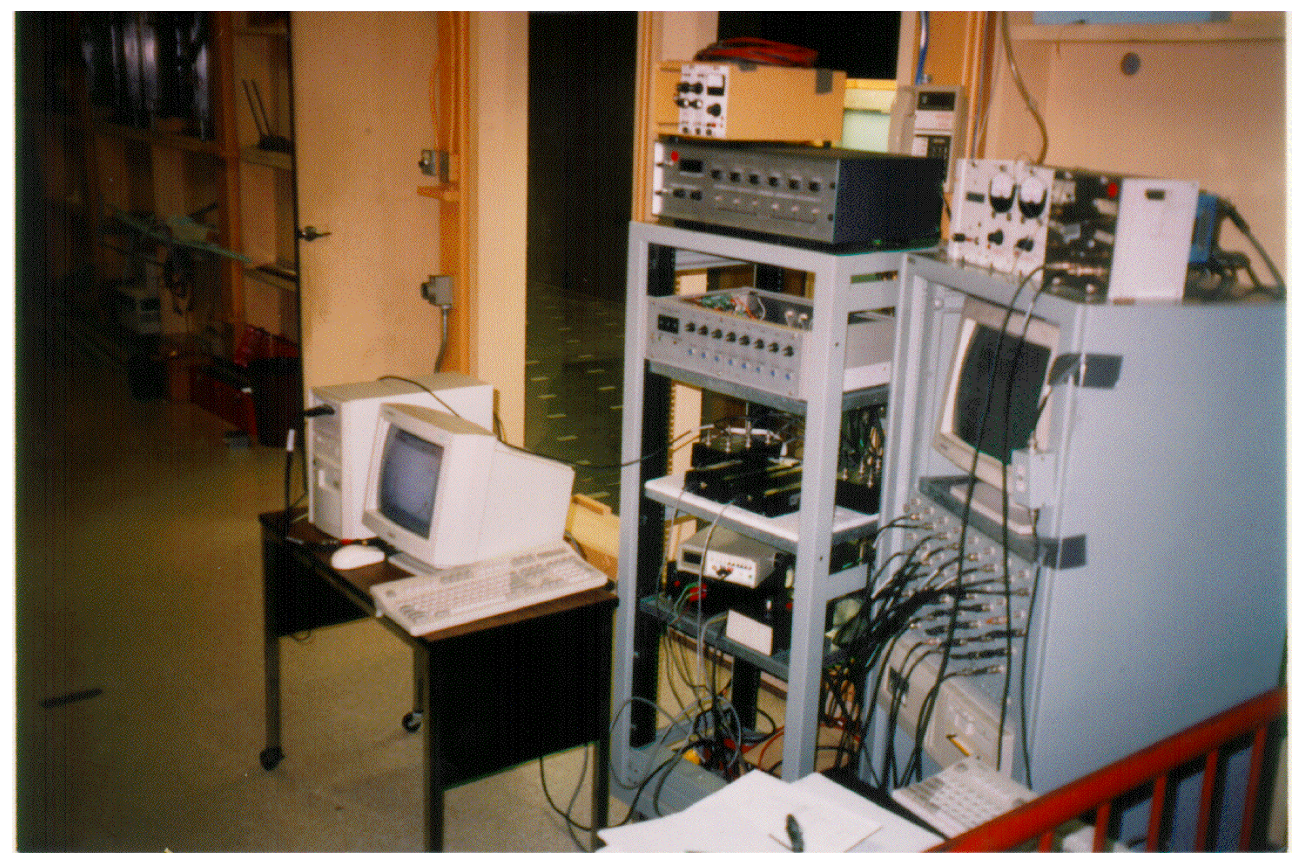

Figura 4.15 - Equipamentos utilizados no ensaio 


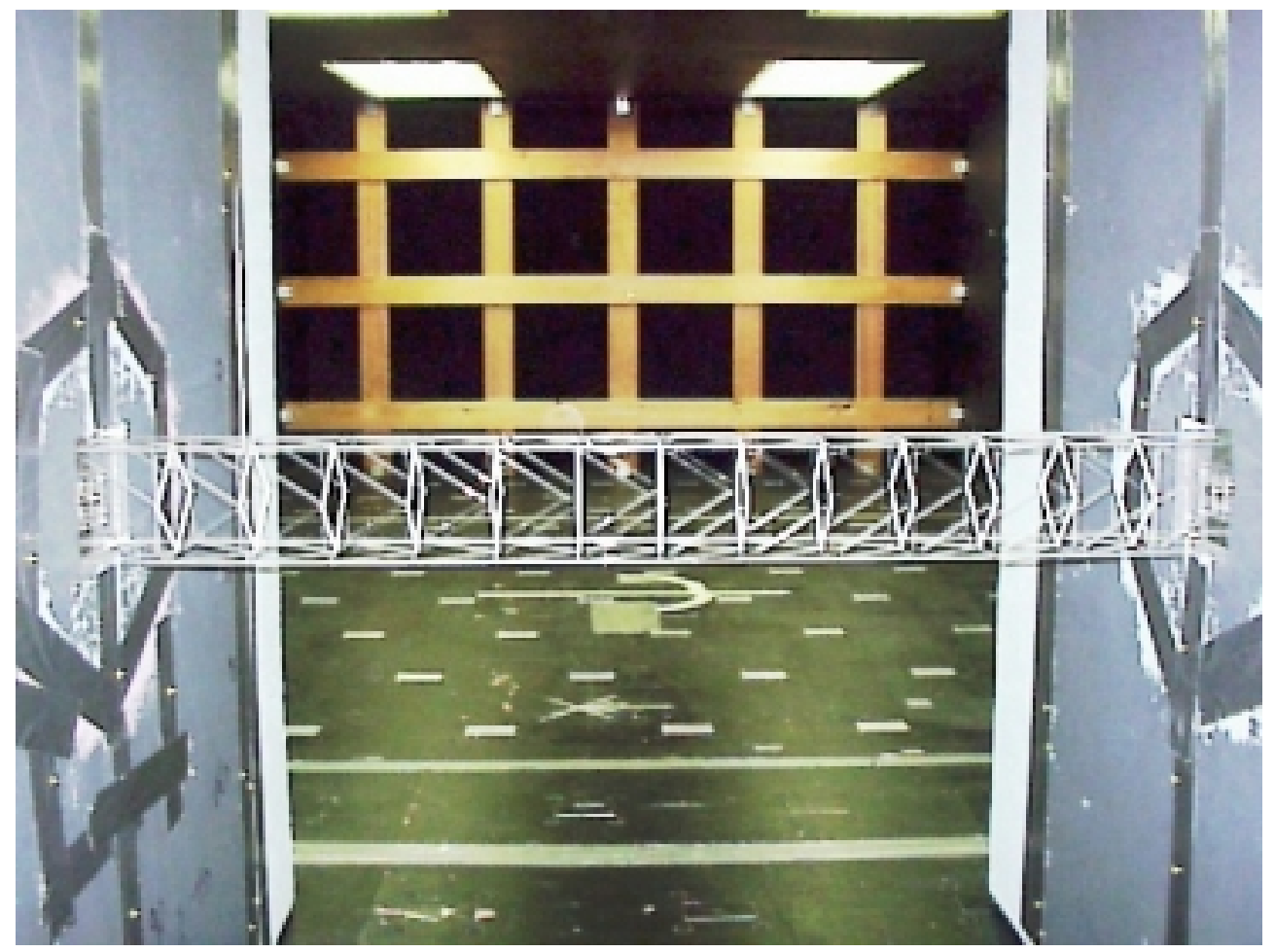

Figura 4.16 - Vista do modelo 1 - exposição 2

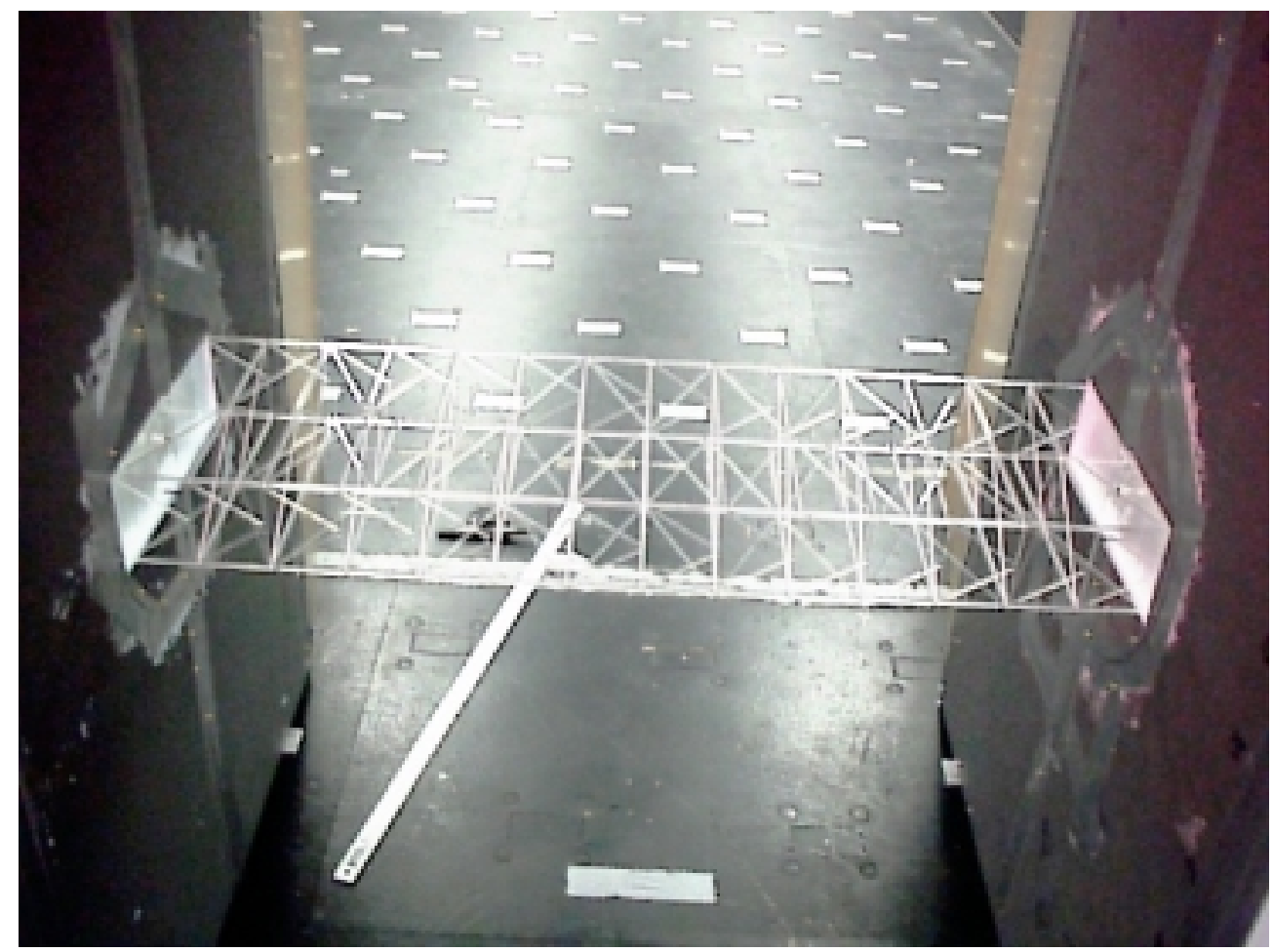

Figura 4.17 - Vista do modelo 3 


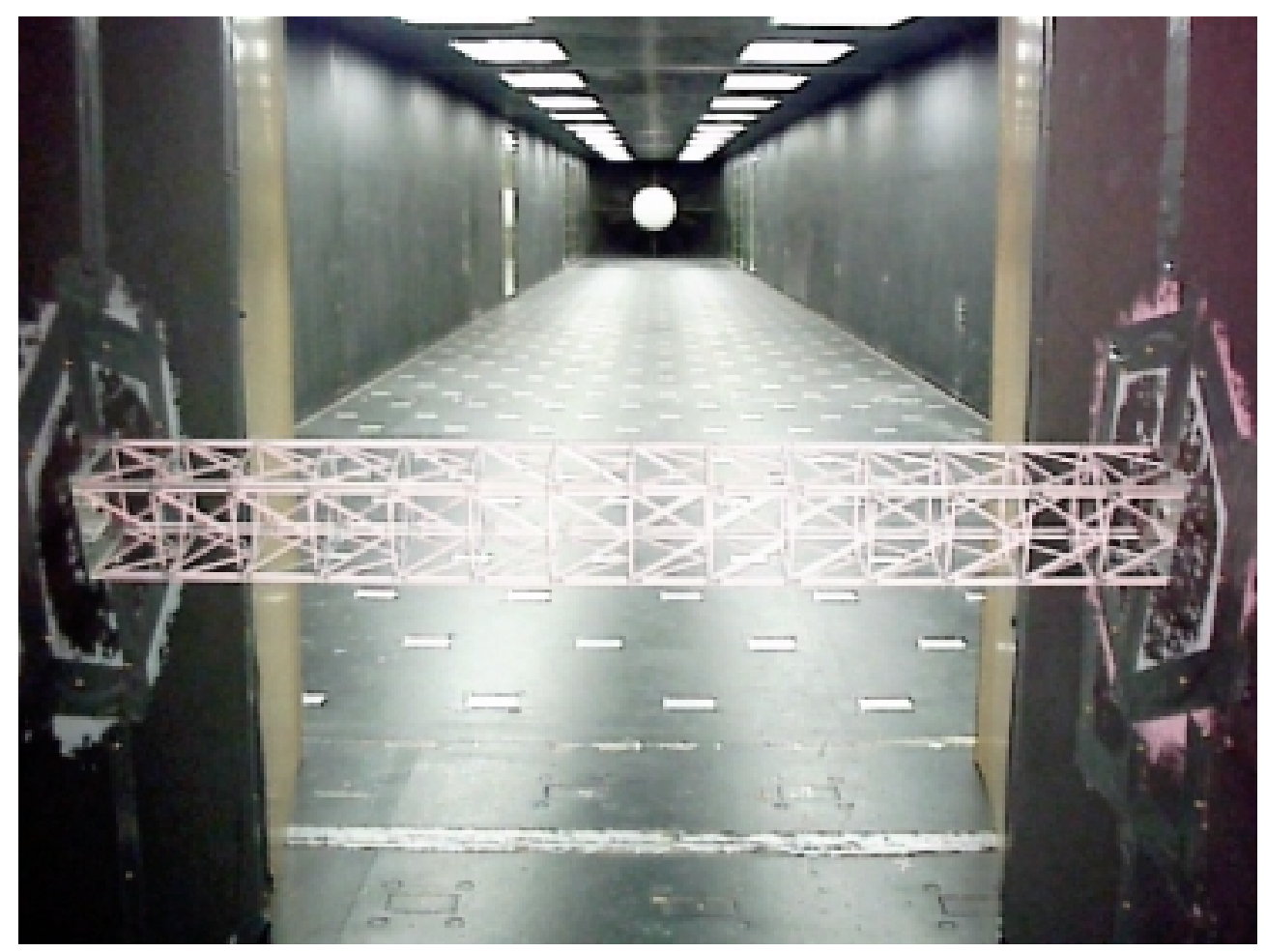

Figura 4.18 - Vista do modelo 4

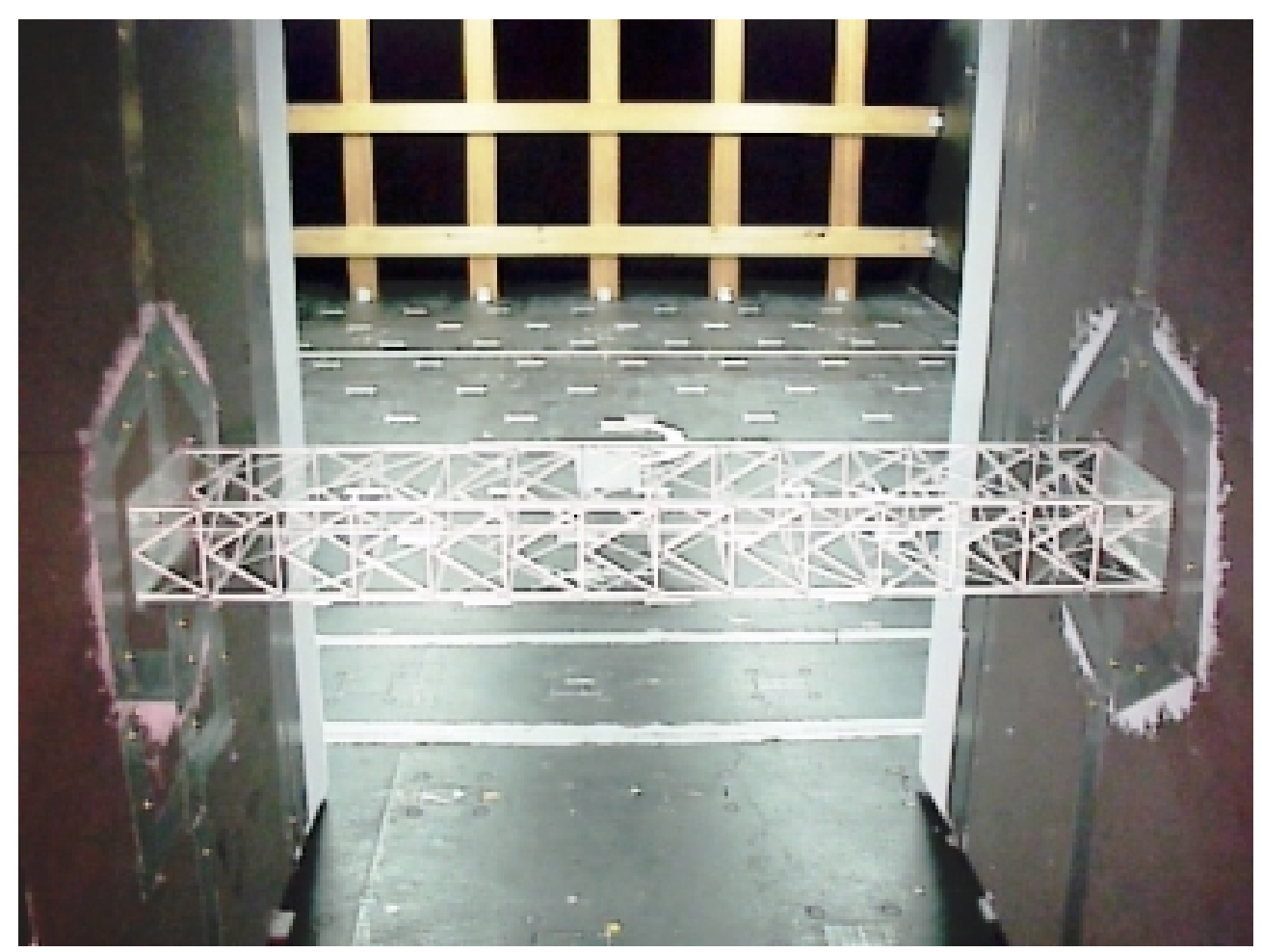

Figura 4.19 - Vista do modelo 5 (similar ao modelo 2) 


\subsection{Apresentação e análise dos resultados}

Os resultados experimentais dos valores médios dos coeficientes de força na direção do vento (arrasto) e na direção transversal ao vento (sustentação) são aqui apresentados para cada modelo. Os primeiros ensaios foram realizados para ângulos de incidência variando de 15 graus até 180 graus para avaliar a simetria dos resultados. Os primeiros ensaios foram repetidos para confirmação dos resultados. Todos os ensaios foram feitos para duas velocidades de fluxo diferentes para avaliar possíveis variações devidas ao número de Reynolds do modelo.

Um estudo sobre a interferência das antenas celulares na determinação das forças de arrasto é apresentado no item 4.3.5. Os resultados obtidos foram comparados com os dados obtidos de ESDU 81028 (1990).

Os modelos testados são identificados na tabela 4.1. Os parâmetros B e s estão mostrados na figura 4.20 .

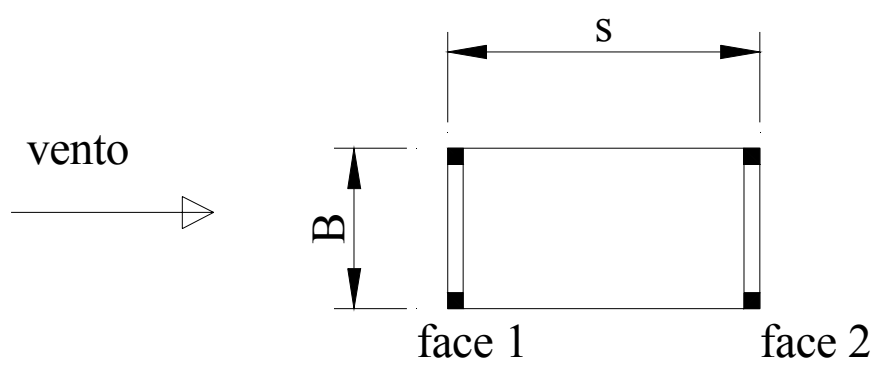

Figura 4.20 - Parâmetros B e s do modelo, seção transversal.

Tabela 4.1 - Propriedades dos modelos ensaiados.

\begin{tabular}{|c|c|r|r|c|c|}
\hline $\begin{array}{c}\text { Mo } \\
\text { delo }\end{array}$ & Área frontal exposta ao vento $\left(\mathrm{m}^{2}\right)$ & $\phi$ & $\mathrm{B}(\mathrm{m})$ & $\mathrm{s}(\mathrm{m})$ & $\mathrm{B} / \mathrm{s}$ \\
\hline 1 & 0,104 & 0,162 & 0,102 & 0,102 & 1 \\
\hline 2 & 0,104 & 0,162 & 0,102 & 0,204 & 2 \\
\hline 3 & 0,104 & 0,162 & 0,102 & 0,306 & 3 \\
\hline 4 & 0,104 & 0,267 & 0,102 & 0,102 & 1 \\
\hline 5 & 0,104 & 0,267 & 0,102 & 0,204 & 2 \\
\hline
\end{tabular}




\subsubsection{Modelo 1}

A figura 4.21 mostra os coeficientes médios de arrasto e os de sustentação para o fluxo suave. Observa-se que há uma simetria dos resultados a 90 graus. O ensaio foi repetido para ângulos de incidência de 0 a 90 graus.

Em todas as figuras e tabelas, exceto onde indicado, o número de Reynolds foi determinado por $\mathrm{Re}=70000 \mathrm{Vd}$, em que $\mathrm{V}$ é dado em $\mathrm{m} / \mathrm{s}$ e d é a largura das barras do modelo, 4,6 milímetros para os modelos 1 a 3 e 7,8 milímetros para os modelos 4 e 5 .

A tabela 4.2 mostra os resultados médios e o desvio padrão obtido para fluxo suave. Foram testadas duas velocidades diferentes. Observa-se que os resultados não apresentaram diferenças significativas.

O ensaio foi repetido para ângulos de incidência de 0 a 90 graus em fluxo suave e turbulento. A figura 4.22 e a tabela 4.3 mostram os resultados repetidos obtidos para fluxo suave para duas velocidades diferentes. Novamente, observa-se que os resultados não apresentaram diferenças significativas.

A repetição dos ensaios foi feita com um ângulo de incidência adicional de $82,5^{\circ}$ para verificar melhor a inclinação negativa do coeficiente de arrasto lateral para o ângulo de incidência do vento igual a $90^{\circ}$.

Um dos critérios para avaliar a instabilidade por galope é através do critério de DEN HARTOG (1985) que foi o primeiro a identifica-la em linhas de transmissão de energia elétrica. Esse critério estabelece que a estrutura é instável se a inclinação negativa do coeficiente de sustentação for maior que o valor do coeficiente de arrasto, ou seja:

$$
\frac{\mathrm{dC}_{\mathrm{L}}}{\mathrm{d} \alpha}+\mathrm{C}_{\mathrm{a}}<0
$$

Observa-se que, no ângulo de incidência de 90 graus, a somatória da inclinação do coeficiente de sustentação $(-2,2)$ com o coeficiente de arrasto $(2,8)$ fornecem um valor positivo de 0,6. A instabilidade por galope depende do número de Reynolds e da resposta ressonante. As instabilidades normalmente ocorrem com freqüências naturais 
de vibração abaixo de $0,5 \mathrm{~Hz}$. Conforme visto no capítulo 3 a resposta ressonante para esses tipos de estruturas não é significativa para o primeiro modo de vibração de $0,85 \mathrm{~Hz}$.

A figura 4.23 e a tabela 4.4 mostram os resultados dos coeficientes de arrasto e dos coeficientes de sustentação para o fluxo turbulento e para ângulos de incidência de $0 \mathrm{a}$ 90 graus a cada 15 graus. Foram ensaiadas duas velocidades diferentes. Comparando as tabelas 4.3 e 4.4 observa-se que não há diferenças significativas entre o fluxo suave e o turbulento, ver item 4.3.4. Além disso, a turbulência do vento não alterou significativamente a inclinação da curva do coeficiente de sustentação para o ângulo de incidência de 0 grau ou 90 graus. Era esperado que a inclinação da curva diminuísse com a turbulência do vento.

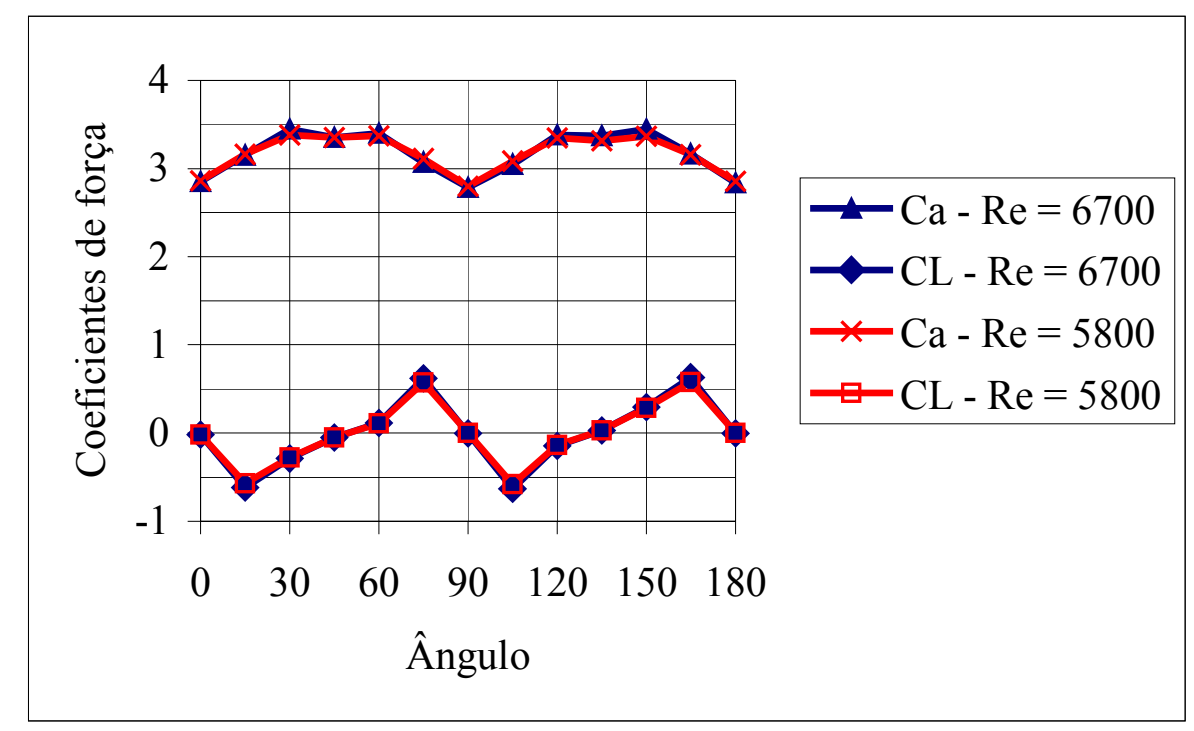

Figura 4.21 - Modelo 1- Coeficientes de arrasto e de sustentação da seção da torre em fluxo suave. (definição de $C_{L}$ e $C_{a}$ no item 4.1, figura 4.5). 


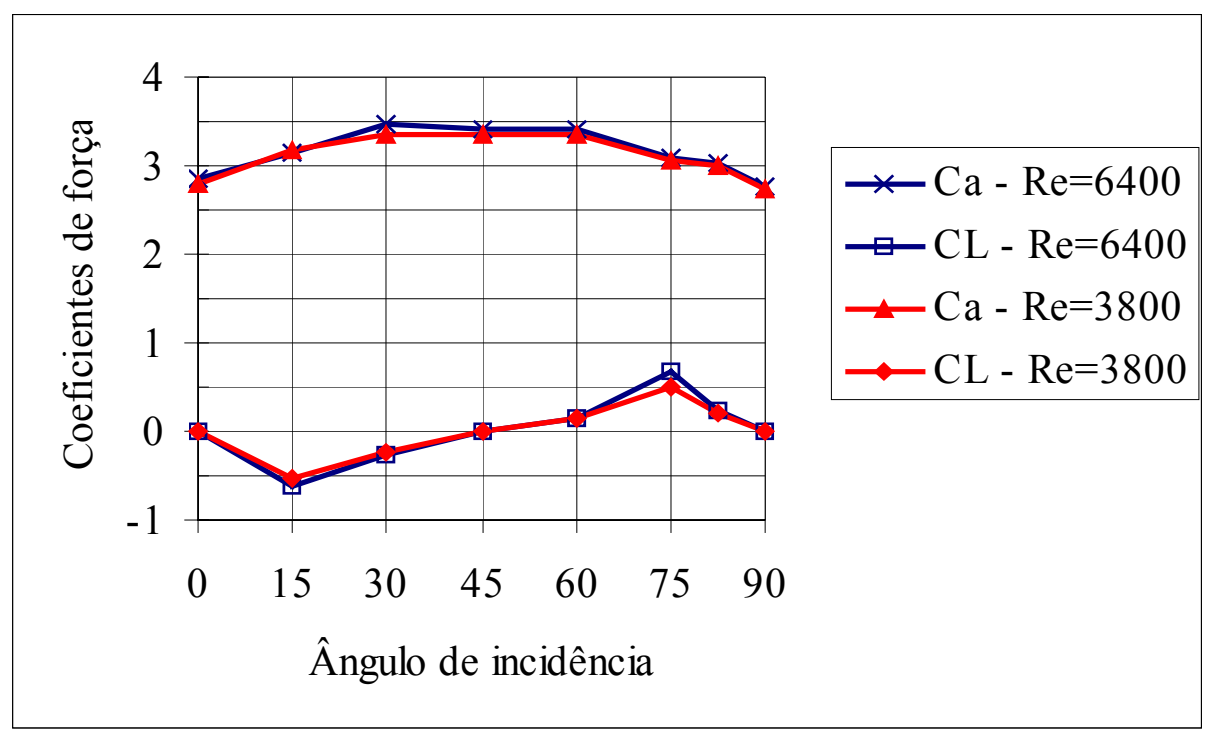

Figura 4.22 - Modelo 1 - Coeficientes de arrasto e de sustentação da seção da torre em fluxo suave (teste repetido)

Tabela 4.2- Modelo 1 - Coeficientes de arrasto e de sustentação da seção da torre. Exposição 1.

\begin{tabular}{|r|r|r|r|r|r|r|r|r|}
\hline Ângulo & $\begin{array}{l}\mathrm{C}_{\mathrm{L}} \\
\mathrm{Re}=6700\end{array}$ & $\mathrm{rms}$ & $\begin{array}{l}\mathrm{C}_{\mathrm{a}} \\
\mathrm{Re}=6700\end{array}$ & $\mathrm{rms}$ & $\begin{array}{l}\mathrm{C}_{\mathrm{L}} \\
\mathrm{Re}=5800\end{array}$ & $\mathrm{rms}$ & \multicolumn{2}{l|}{$\begin{array}{l}\mathrm{l} \\
\mathrm{Re}=5800\end{array}$} \\
\hline 0 & $-0,02$ & 0,013 & 2,85 & 0,032 & $-0,02$ & 0,015 & 2,86 & 0,032 \\
\hline 15 & $-0,62$ & 0,016 & 3,15 & 0,036 & $-0,57$ & 0,017 & 3,16 & 0,045 \\
\hline 30 & $-0,29$ & 0,025 & 3,45 & 0,040 & $-0,28$ & 0,026 & 3,38 & 0,041 \\
\hline 45 & $-0,05$ & 0,022 & 3,35 & 0,049 & $-0,05$ & 0,022 & 3,35 & 0,049 \\
\hline 60 & 0,12 & 0,024 & 3,40 & 0,037 & 0,11 & 0,026 & 3,37 & 0,050 \\
\hline 75 & 0,62 & 0,020 & 3,07 & 0,035 & 0,57 & 0,020 & 3,11 & 0,035 \\
\hline 90 & 0 & 0,014 & 2,78 & 0,032 & 0 & 0,016 & 2,80 & 0,032 \\
\hline 105 & $-0,63$ & 0,019 & 3,05 & 0,037 & $-0,58$ & 0,019 & 3,09 & 0,036 \\
\hline 120 & $-0,14$ & 0,024 & 3,38 & 0,038 & $-0,14$ & 0,024 & 3,34 & 0,050 \\
\hline 135 & 0,03 & 0,022 & 3,37 & 0,039 & 0,03 & 0,023 & 3,31 & 0,042 \\
\hline 150 & 0,29 & 0,025 & 3,45 & 0,039 & 0,29 & 0,026 & 3,36 & 0,040 \\
\hline 165 & 0,63 & 0,019 & 3,17 & 0,036 & 0,58 & 0,018 & 3,16 & 0,049 \\
\hline 180 & 0 & 0,015 & 2,84 & 0,033 & 0 & 0,015 & 2,86 & 0,033 \\
\hline
\end{tabular}


Tabela 4.3 - Modelo 1 - Coeficientes de arrasto e de sustentação da seção da torre em fluxo suave (teste repetido)

\begin{tabular}{|c|c|c|c|c|c|c|c|c|}
\hline Ângulo & $\begin{array}{l}C_{L} \\
R e=3900\end{array}$ & rms & $\begin{array}{l}C_{a} \\
R e=3900\end{array}$ & $\mathrm{rms}$ & $\begin{array}{l}C_{L} \\
R e=6800\end{array}$ & rms & $\begin{array}{l}C_{a} \\
R e=6800\end{array}$ & $\mathrm{rms}$ \\
\hline 0 & 0,01 & 0,017 & 2,80 & 0,027 & 0,01 & 0,012 & 2,84 & 0,030 \\
\hline 15 & $-0,54$ & 0,015 & 3,17 & 0,024 & $-0,62$ & 0,014 & 3,15 & 0,027 \\
\hline 30 & $-0,23$ & 0,023 & 3,37 & 0,034 & $-0,27$ & 0,021 & 3,48 & 0,031 \\
\hline 45 & $-0,01$ & 0,022 & 3,35 & 0,026 & $-0,01$ & 0,018 & 3,40 & 0,027 \\
\hline 60 & 0,15 & 0,022 & 3,35 & 0,021 & 0,16 & 0,021 & 3,42 & 0,032 \\
\hline 75 & 0,51 & 0,021 & 3,07 & 0,038 & 0,66 & 0,019 & 3,08 & 0,032 \\
\hline 82,5 & 0,21 & 0,014 & 2,99 & 0,030 & 0,24 & 0,012 & 3,02 & 0,031 \\
\hline 90 & 0,01 & 0,017 & 2,75 & 0,027 & 0 & 0,013 & 2,77 & 0,029 \\
\hline
\end{tabular}

Tabela 4.4 - Modelo 1 - Coeficientes de arrasto e de sustentação para fluxo turbulento.

\begin{tabular}{|r|r|l|l|l|l|l|l|l|}
\hline Ângulo & $\begin{array}{l}\mathrm{C}_{\mathrm{L}} \\
\mathrm{Re}=4000\end{array}$ & $\mathrm{rms}$ & $\begin{array}{l}\mathrm{C}_{\mathrm{a}} \\
\mathrm{Re}=4000\end{array}$ & $\mathrm{rms}$ & $\begin{array}{l}\mathrm{C}_{\mathrm{L}} \\
\mathrm{Re}=6400\end{array}$ & $\mathrm{rms}$ & $\begin{array}{l}\mathrm{C}_{\mathrm{a}} \\
\mathrm{Re}=6400\end{array}$ & \multicolumn{1}{r|}{} \\
\hline 0 & 0,02 & 0,032 & 2,90 & 0,130 & 0,01 & 0,028 & 2,85 & 0,122 \\
\hline 15 & $-0,46$ & 0,059 & 3,07 & 0,138 & $-0,50$ & 0,064 & 3,01 & 0,137 \\
\hline 30 & $-0,1$ & 0,092 & 3,34 & 0,150 & $-0,11$ & 0,096 & 3,29 & 0,156 \\
\hline 45 & 0,08 & 0,077 & 3,41 & 0,152 & 0,07 & 0,078 & 3,34 & 0,155 \\
\hline 60 & 0,33 & 0,097 & 3,44 & 0,156 & 0,33 & 0,100 & 3,37 & 0,160 \\
\hline 75 & 0,59 & 0,051 & 3,20 & 0,145 & 0,63 & 0,056 & 3,13 & 0,145 \\
\hline 82,5 & 0,29 & 0,030 & 3,11 & 0,141 & 0,32 & 0,029 & 3,03 & 0,141 \\
\hline 90 & 0,03 & 0,034 & 2,98 & 0,134 & 0,02 & 0,028 & 2,91 & 0,131 \\
\hline
\end{tabular}

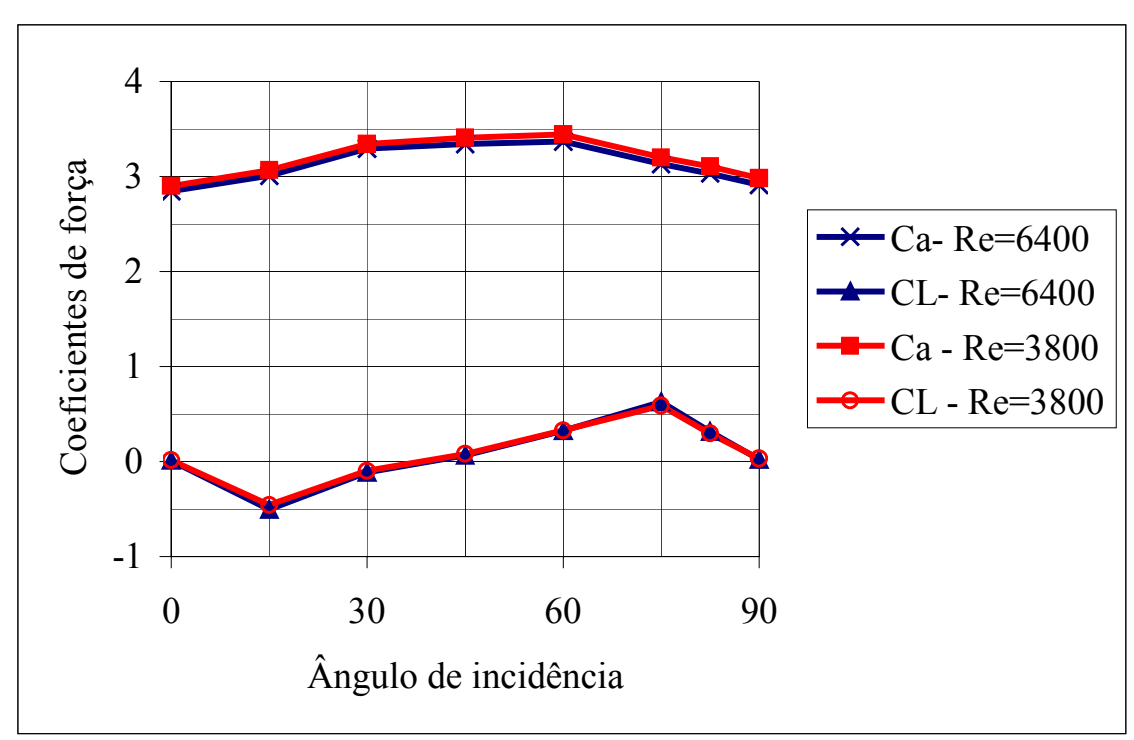

Figura 4.23 - Modelo 1 - Coeficientes de arrasto e de sustentação para fluxo turbulento 


\subsubsection{Modelos 2, 3 e 5.}

Os modelos 2, 3 e 5 foram testados apenas para ângulos de incidência do vento de 0 grau com o objetivo de comparar os resultados do fator de proteção relacionados ao espaçamento relativo entre as faces da torre. Os resultados dos modelos 2 e 3 estão apresentados na tabela 4.5. Os resultados do modelo 5 estão apresentados na tabela 4.6. A exposição 1 refere ao fluxo suave e a exposição 2 refere ao fluxo turbulento do vento longitudinal.

Tabela 4.5 - Modelos 2 e 3- Coeficientes de arrasto e de sustentação para fluxo suave, (exp. 1) e fluxo turbulento (exp. 2).

\begin{tabular}{|c|c|c|c|c|c|c|c|c|c|c|c|}
\hline & \multicolumn{6}{|c|}{ Modelo 2 } & \multicolumn{5}{|c|}{ Modelo 3 } \\
\hline exp. & $\mathrm{C}_{\mathrm{L}}$ & rms & $\mathrm{C}_{\mathrm{a}}$ & $\mathrm{rms}$ & $\mathrm{Re}$ & exp. & $\mathrm{C}_{\mathrm{L}}$ & $\mathrm{rms}$ & $\mathrm{C}_{\mathrm{a}}$ & $\mathrm{rms}$ & $\mathrm{Re}$ \\
\hline 1 & 0,01 & 0,016 & 2,91 & 0,047 & 3976 & 1 & 0,04 & 0,020 & 3,04 & 0,025 & 3960 \\
\hline 1 & 0 & 0,017 & 3,15 & 0,020 & 6881 & 1 & 0,04 & 0,016 & 3,04 & 0,029 & 4817 \\
\hline 2 & 0 & 0,031 & 3,00 & 0,124 & 4012 & 1 & 0,05 & 0,016 & 3,05 & 0,022 & 6875 \\
\hline 2 & 0,01 & 0,012 & 2,94 & 0,024 & 5019 & 2 & 0,04 & 0,042 & 3,19 & 0,127 & 4008 \\
\hline 2 & 0 & 0,011 & 3,17 & 0,022 & 6414 & 2 & 0,01 & 0,043 & 3,18 & 0,127 & 5010 \\
\hline & & & & & & 2 & 0,05 & 0,049 & 3,11 & 0,126 & 6423 \\
\hline
\end{tabular}

Tabela 4.6 - Modelo 5 - Coeficientes de arrasto e de sustentação para fluxo turbulento (exposição 2).

\begin{tabular}{|r|r|r|r|r|r|}
\hline & \multicolumn{5}{|c|}{ Modelo 5 } \\
\hline Exposição & $\mathrm{C}_{\mathrm{L}}$ & $\mathrm{rms}$ & $\mathrm{C}_{\mathrm{a}}$ & $\mathrm{rms}$ & \multicolumn{1}{c|}{$\mathrm{Re}$} \\
\hline 2 & 0,01 & 0,013 & 2,81 & 0,116 & 6800 \\
\hline 2 & 0,01 & 0,013 & 2,77 & 0,109 & 8583 \\
\hline 2 & 0,01 & 0,013 & 2,74 & 0,116 & 10996 \\
\hline
\end{tabular}

\subsubsection{Modelo 4}

O modelo 4 corresponde ao modelo 1 com barras adicionais coladas, conforme especificado no item 4.1. A diferença está no índice de área exposta, $\phi=0,267$. Os ensaios foram realizados para cada 15 graus de ângulo de incidência. O modelo foi testado apenas em fluxo turbulento. A figura 4.24 e a tabela 4.7 mostram os resultados obtidos. 
Observa-se que a inclinação da curva do coeficiente de sustentação para ângulos de incidência 0 ou 90 graus diminuiu em relação ao modelo 1. Essa mudança de comportamento sugere como causa o índice de área exposta maior.

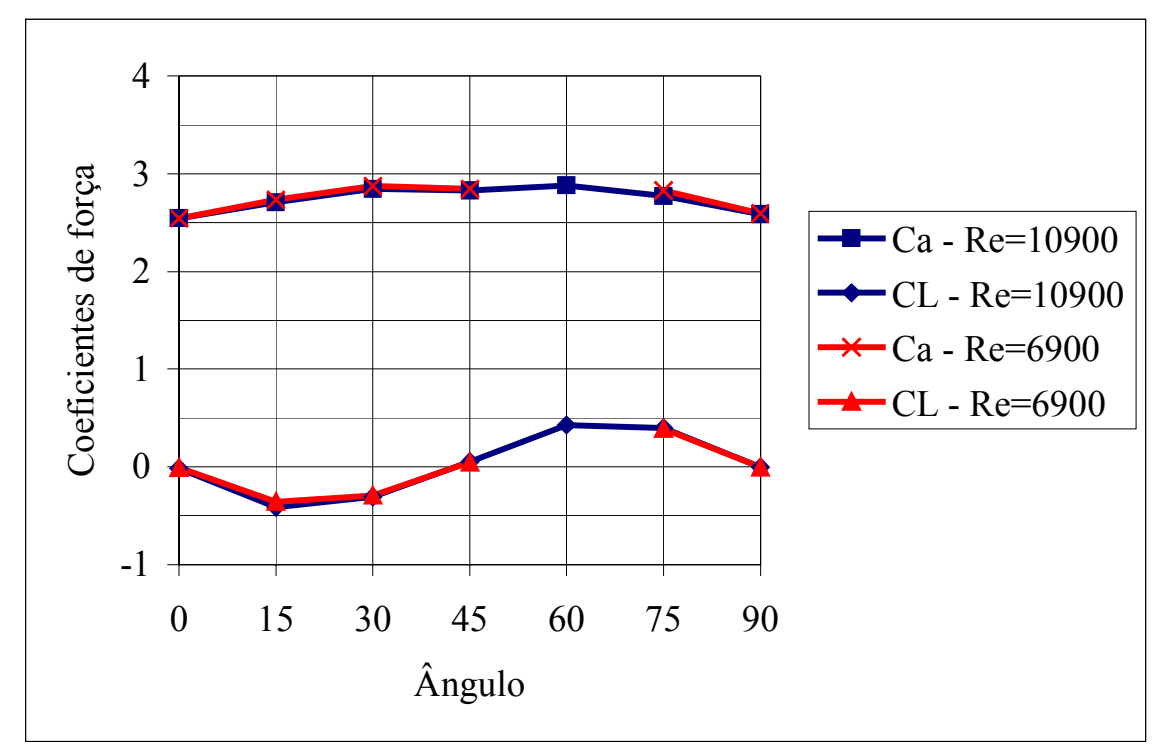

Figura 4.24 - Modelo 4 - Coeficientes de arrasto e de sustentação para fluxo turbulento

Tabela 4.7 - Modelo 4 - Coeficientes de arrasto e de sustentação para fluxo turbulento

\begin{tabular}{|c|c|c|c|c|c|c|c|c|c|c|}
\hline Ângulo & $\mathrm{C}_{\mathrm{L}}$ & $\mathrm{rms}$ & $\mathrm{C}_{\mathrm{a}}$ & $\mathrm{rms}$ & $\mathrm{Re}$ & $\mathrm{C}_{\mathrm{L}}$ & $\mathrm{rms}$ & $\mathrm{C}_{\mathrm{a}}$ & $\mathrm{rms}$ & $\mathrm{V}(\mathrm{m} / \mathrm{s})$ \\
\hline 0 & $-0,008$ & 0,039 & 2,55 & 0,083 & 6983 & $-0,013$ & 0,042 & 2,55 & 0,117 & 6830 \\
\hline 15 & $-0,356$ & 0,042 & 2,74 & 0,121 & 6966 & $-0,412$ & 0,041 & 2,71 & 0,125 & 10958 \\
\hline 30 & $-0,289$ & 0,084 & 2,87 & 0,129 & 6792 & $-0,304$ & 0,081 & 2,85 & 0,131 & 10904 \\
\hline 45 & 0,048 & 0,079 & 2,84 & 0,127 & 6803 & 0,054 & 0,078 & 2,83 & 0,128 & 10909 \\
\hline 60 & - & - & - & - & - & 0,429 & 0,081 & 2,88 & 0,134 & 10903 \\
\hline 75 & 0,391 & 0,035 & 2,83 & 0,129 & 6764 & 0,399 & 0,034 & 2,77 & 0,128 & 10881 \\
\hline 90 & $-0,003$ & 0,050 & 2,59 & 0,115 & 6792 & $-0,003$ & 0,043 & 2,59 & 0,119 & 10881 \\
\hline
\end{tabular}

\subsubsection{Tipo de exposição.}

Adotou-se para fluxo suave a nomenclatura exposição 1 e para fluxo turbulento, exposição 2. As figuras 4.25 e 4.26 mostram os resultados dos coeficientes de força do modelo 1 para os dois números de Reynolds ensaiados. 
Verifica-se que os resultados médios são pouco afetados pela turbulência gerada pela grelha. As diferenças entre os valores do coeficiente de arrasto $C_{a}$ dos modelos $2 \mathrm{e}$ 3 submetidos à exposição 1 e à exposição 2 não ultrapassam $3 \%$ para o modelo 2 e $5 \%$ para o modelo 3, ver tabela 4.5. Já para o modelo 1, tabelas 4.3 e 4.4, obtêm-se diferenças de até $8 \%$ para o ângulo de 90 graus. Para outros ângulos a diferença atinge no máximo $5.5 \%$.

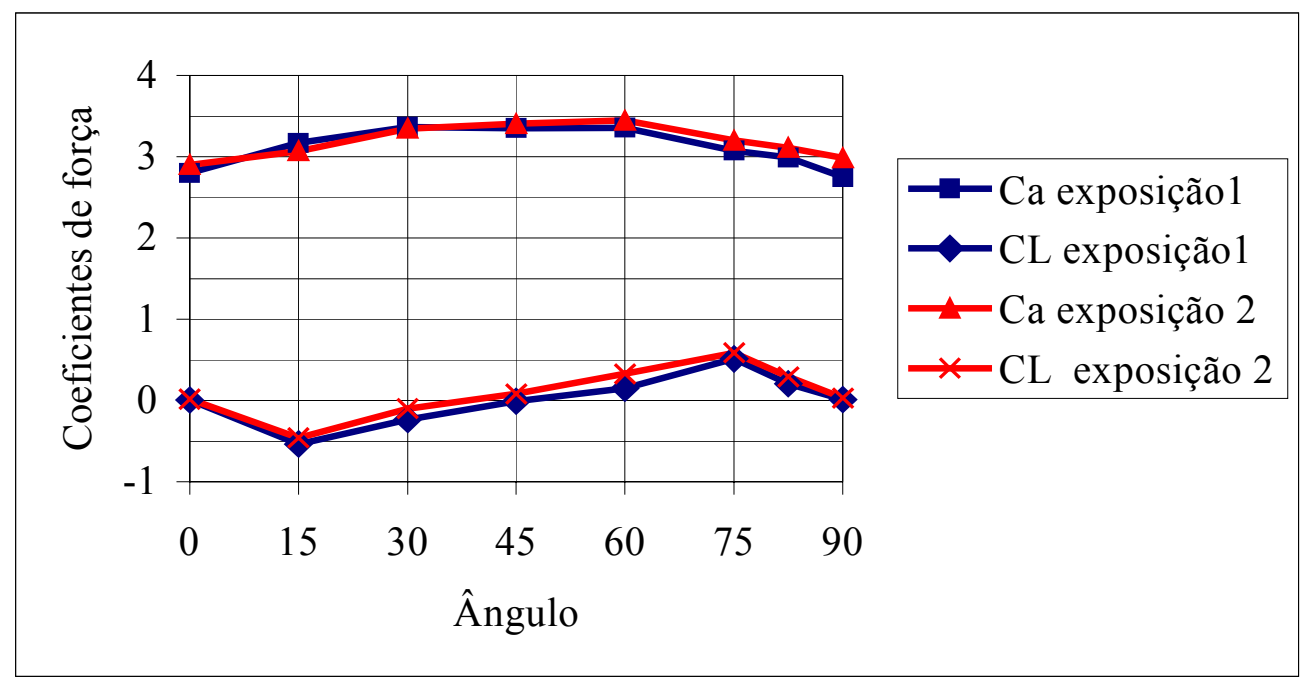

Figura 4.25 - Modelo 1 - Comparação entre os resultados obtidos com a exposição 1 e exposição $2-\operatorname{Re}=3864$

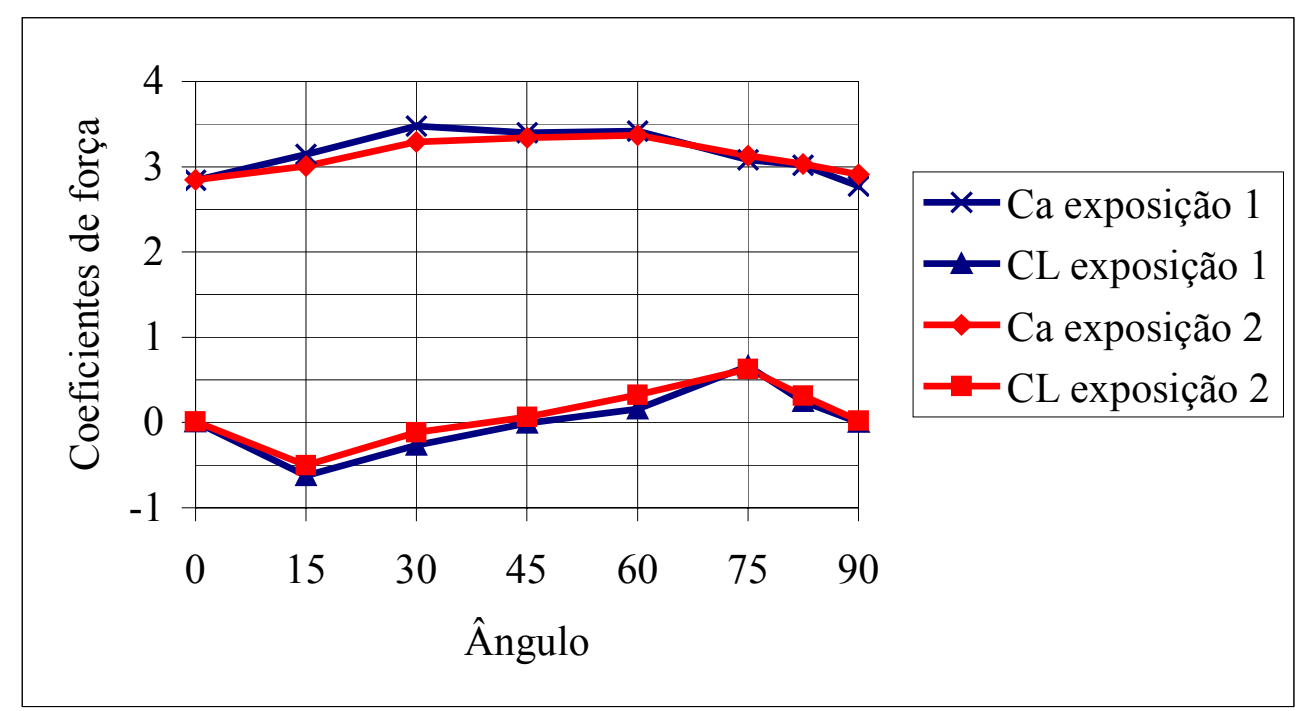

Figura 4.26 - Modelo 1 - Comparação entre os resultados obtidos com a exposição 1 e exposição $2 . \operatorname{Re}=6440$ 


\subsubsection{Antenas de microondas}

Um procedimento normal das projetistas é considerar o carregamento nas antenas de microondas separadamente da estrutura da torre. Devido à presença das antenas na torre, há efeitos de proteção do vento que interferem no carregamento final. Uma investigação experimental foi realizada para avaliar essa interferência aerodinâmica e verificar se o procedimento é correto. Não se pretende resolver o problema completamente devido aos diversos parâmetros envolvidos como: a posição da antena, o tipo de torre, a direção do vento incidente e a quantidade de antenas. Pretende-se apenas fornecer uma idéia do comportamento do carregamento do vento, isolando alguns dos parâmetros especificados.

Os primeiros trabalhos sobre a interferência de objetos adicionados a torres reticuladas foram realizados pelo National Maritime Institute entre 1976 a 1978 mas não foram publicados. WHITBREAD (1981) menciona seus próprios trabalhos.

Para considerar o efeito de proteção ou efeito de interferência nos coeficientes de força em objetos adicionados à torre reticulada, ESDU 81028 (1990) definiu um fator de interferência dado por:

$\mathrm{f}_{\mathrm{a}}=\frac{\Delta \mathrm{C}_{\mathrm{a}_{\_} \text {antena_na_torre }}}{\mathrm{C}_{\mathrm{a}_{-} \text {antena_separada }}}$

A mesma publicação propôs uma expressão empírica para o fator de interferência em função do índice de área exposta e do coeficiente de arrasto da torre:

$\mathrm{f}_{\mathrm{a}}=\exp \left[-\mathrm{k}\left(\mathrm{C}_{\mathrm{a}} \phi\right)^{2}\right]$

Onde k é 1,2 para torre de base quadrada; $\mathrm{C}_{\mathrm{a}}$ é o coeficiente de arrasto para 0 graus de ângulo de incidência do vento e $\phi$ é o índice de área exposta.

Para ângulo de incidência do vento diferente de 0 graus, define-se o fator $f_{\alpha}$ como sendo:

$\mathrm{f}_{\alpha}=\frac{\Delta \mathrm{C}_{\mathrm{a}}}{\Delta \mathrm{C}_{\mathrm{a} 0}}$ 
Os gráficos apresentados por ESDU 81028 (1990) sugerem para $f_{\alpha}$ valores iguais ou menores que 1 , considerando estruturas adicionais tipo placas ou reticulados. No entanto para antenas de microondas em torres reticuladas para telecomunicações, HOLMES et al (1993) acharam valores maiores que a unidade. Baseado em seus resultados experimentais, HOLMES sugere uma modificação à equação 4.5 para levar em consideração os diferentes ângulos de incidência do vento:

$$
\mathrm{f}_{\mathrm{a}}=\exp \left[-\mathrm{k}\left(\mathrm{C}_{\mathrm{a}} \phi\right)^{2} \mathrm{I}(1+\mathrm{b})+\mathrm{b} \cos 2\left(\alpha-\alpha_{\mathrm{d}}-90\right)\right]
$$

onde b é um parâmetro de ajuste; $\alpha_{d}$ é o ângulo da normal ao disco de antena relativo à torre; e $\alpha$ é o ângulo de incidência do vento relativo à torre. A figura 4.27 esclarece as definições de $\alpha_{d}$ e $\alpha$.

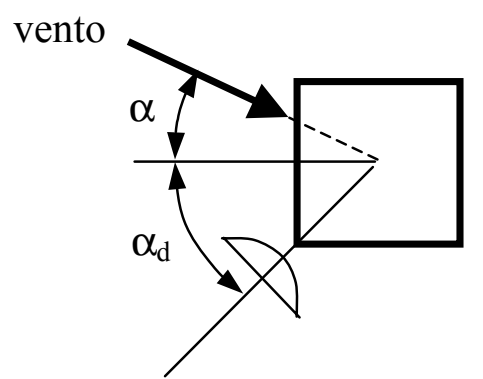

Figura 4.27 - Detalhe do ângulo de incidência do vento e do ângulo da antena relativo à torre.

No presente trabalho, determinaram-se os valores do fator de interferência apenas para $\alpha_{\mathrm{d}}$ e $\alpha$ nulos.

Para a investigação experimental das forças do vento nas antenas de microondas, fabricaram-se discos de isopor na escala 1:40 simulando uma antena circular protegida, figura 4.28. Cada disco possui um diâmetro de seis centímetros e profundidade de 2,25 centímetros, simulando uma antena de 2,4 metros de diâmetro com uma espessura de 0,9 metros. Essas medidas foram tiradas do catálogo do fabricante "Andrew" para antenas parabólicas com proteção. Não se simularam geometricamente os detalhes da antena na face de sotavento. $\mathrm{O}$ ensaio foi realizado apenas para o ângulo de incidência do vento perpendicular à face de barlavento da antena igual à da torre, ou seja, ângulo de incidência zero. 


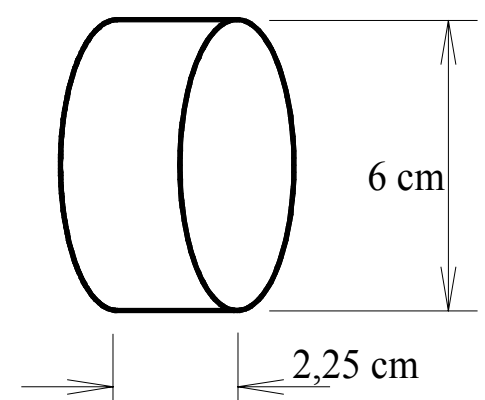

Figura 4.28 - Modelo de isopor da antena de microondas

Nos ensaios realizados fixou-se a direção do vento e a posição da antena e variou-se a quantidade de antenas e o índice de área exposta. Os discos foram fixados na parte central da face de barlavento dos modelos. Foram ensaiados os modelos 1 e 4 com 1, 2, 4 e 6 discos colocados na face de barlavento do modelo.

Foram medidas as forças médias geradas pelo vento suave e pelo vento turbulento com duas velocidades diferentes. As medidas das forças do vento no modelo foram feitas sem as antenas e com as antenas. Para cada ensaio as antenas foram colocadas em posições diferentes: para o ensaio com uma antena usou-se a posição 1 indicada na figura 4.29; para o ensaio com duas antenas usou-se a posição 2; para o ensaio com 4 antenas usaram-se as posições 2 e 3; e para o ensaio com 6 antenas usaram-se as posições 2,3 e 4 . A figura 4.30 mostra o detalhe da antena fixada na posição 2 do modelo.

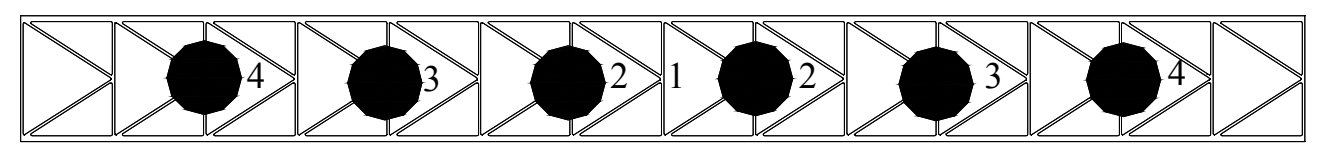

Figura 4.29 - Detalhe da posição das antenas de microondas no modelo

A força do vento no disco da antena foi medida com um arranjo experimental separado, utilizando um túnel de vento de seção transversal 50 x 50 centímetros. Utilizou-se uma mini balança capaz de medir forças da ordem de 0,1 N. As figuras 4.31, 4.32 e 4.33 mostram detalhes da câmara de ensaio e do arranjo experimental no túnel de 
vento. Utilizou-se uma haste rígida fixada à base do túnel e à balança. Fixou-se a antena na balança com uma barra de alumínio.

Para avaliar a interferência da balança e de seu suporte, realizou-se um ensaio com a antena posicionada, mas sem conexão com a balança, figura 4.33. A diferença entre o ensaio com a conexão e sem a conexão fornece o valor real da força de arrasto do vento na antena.

Para bloqueios, relação entre a área de projeção frontal do modelo e a área da seção transversal da câmara de ensaio do túnel de vento, maiores que $5 \%$, correções dos coeficientes de arrasto devem ser feitas, devido ao acréscimo da velocidade do vento causada pela presença do modelo. Neste ensaio, calculou-se o bloqueio de 1,1\%, desprezando assim as respectivas correções dos coeficientes aerodinâmicos.

As tabelas 4.8, 4.9 e 4.10 apresentam os resultados dos coeficientes de sustentação e de arrasto para o ângulo de incidência de 0 grau. Esses coeficientes foram tornados adimensionais com a área efetiva da face do modelo sem considerar a área das antenas, equações 4.1 e 4.2. A tabela 4.11 apresenta um resumo do acréscimo do coeficiente de arrasto, $\Delta \mathrm{C}_{\mathrm{a}}$, devido à inclusão das antenas.

Em todas as tabelas, exceto onde indicado, o número de Reynolds foi determinado com a espessura das barras principais do modelo, ou seja, 4,6 milímetros para o modelo 1 e 7,8 milímetros para o modelo 4 . Os resultados experimentais da antena isolada são apresentados na tabela 4.12. A tabela 4.13 e a figura 4.36 mostram os valores experimentais dos coeficientes de arrasto das antenas na torre e os valores experimentais dos coeficientes de arrasto da antena isolada, normalizados pela área frontal do disco de antena. 


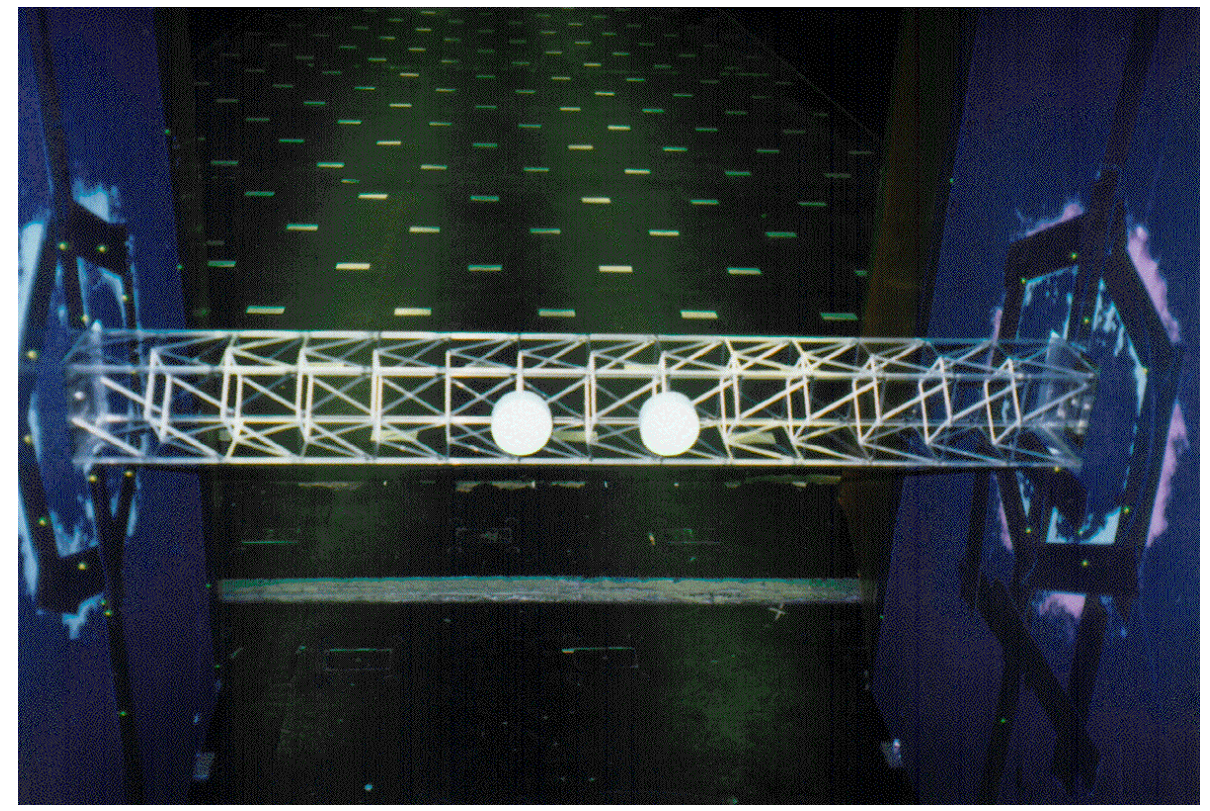

Figura 4.30 - Antenas na posição 2 do modelo no túnel de vento BLWT II.

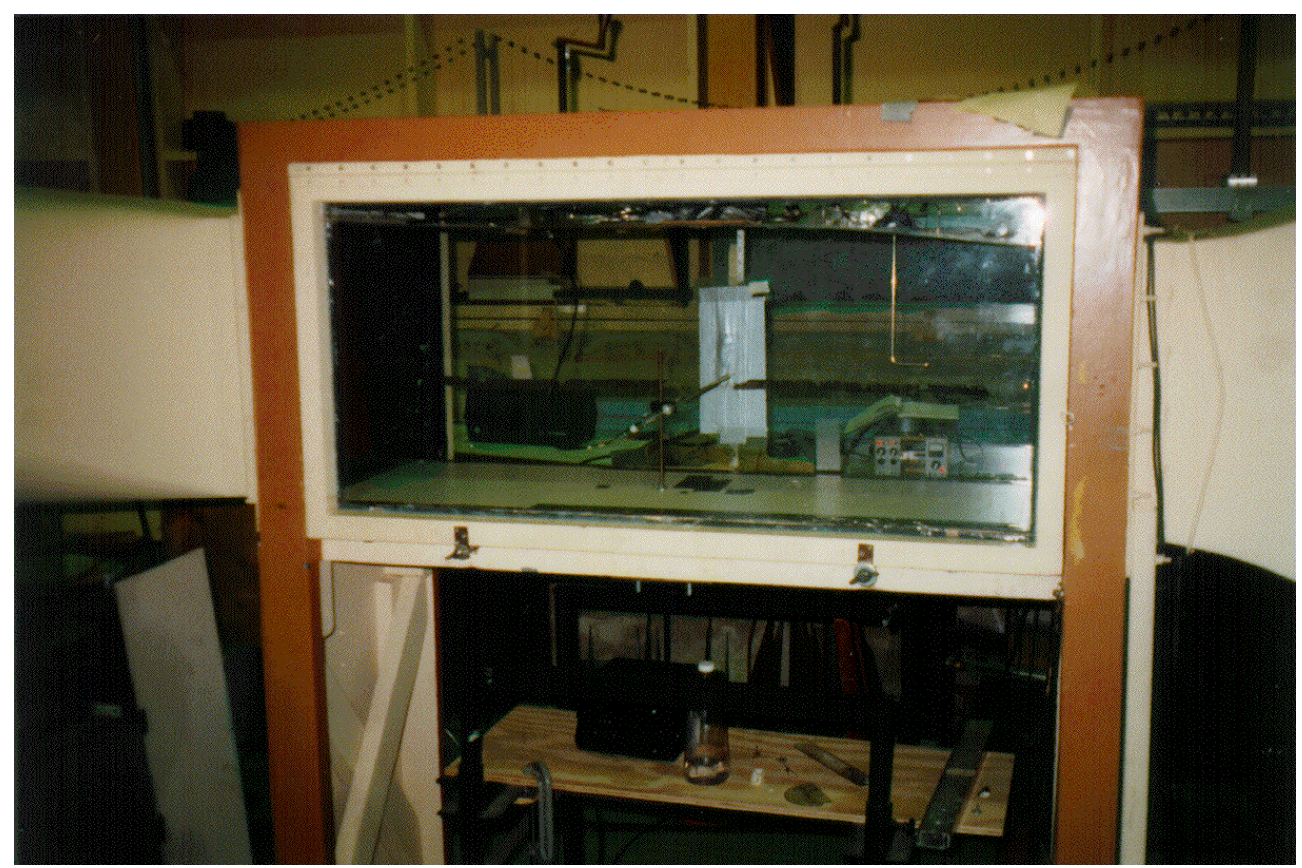

Figura 4.31 - Detalhe da seção de ensaio do túnel de vento usado para o ensaio da antena separadamente. 


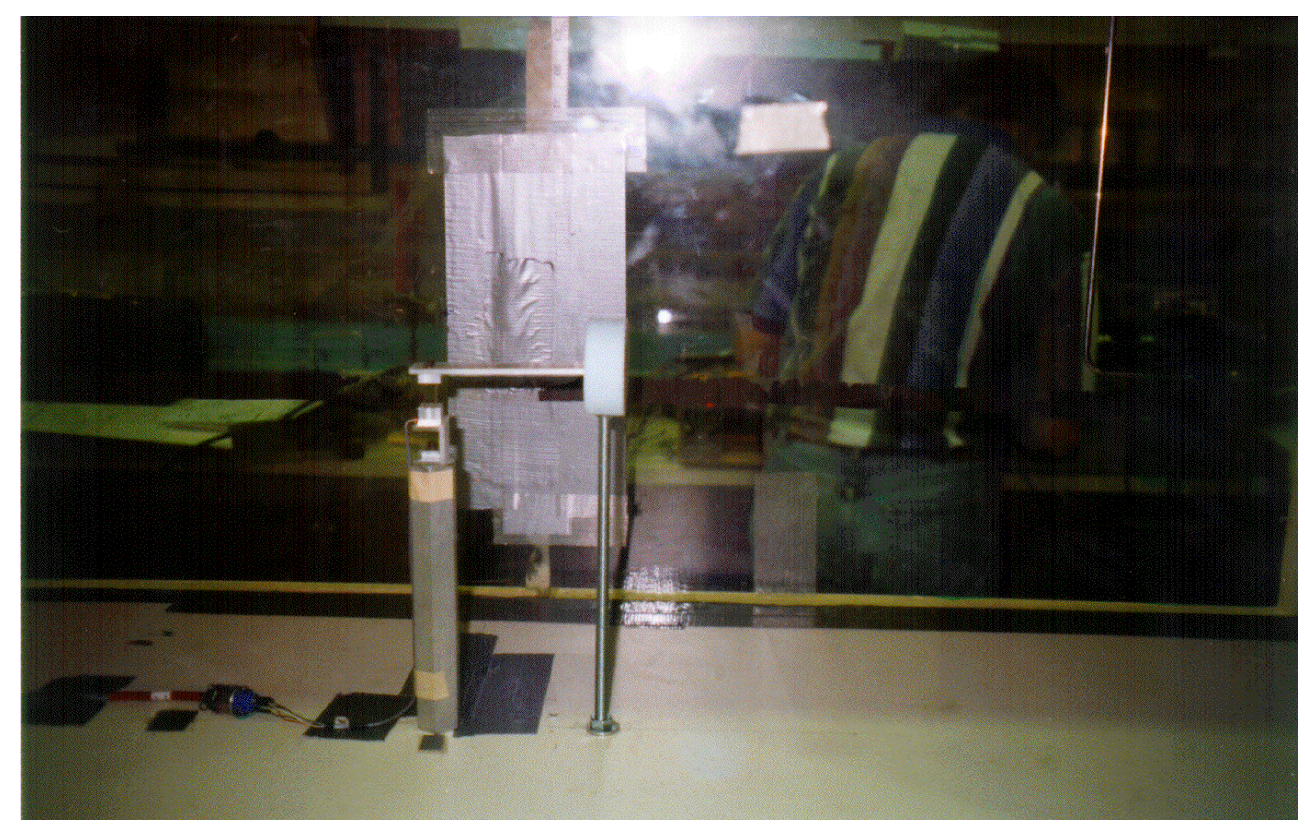

Figura 4.32 - Detalhes do arranjo experimental no túnel de vento de 50 x 50 centímetros de seção de ensaio - Antena posicionada sem a conexão com a balança

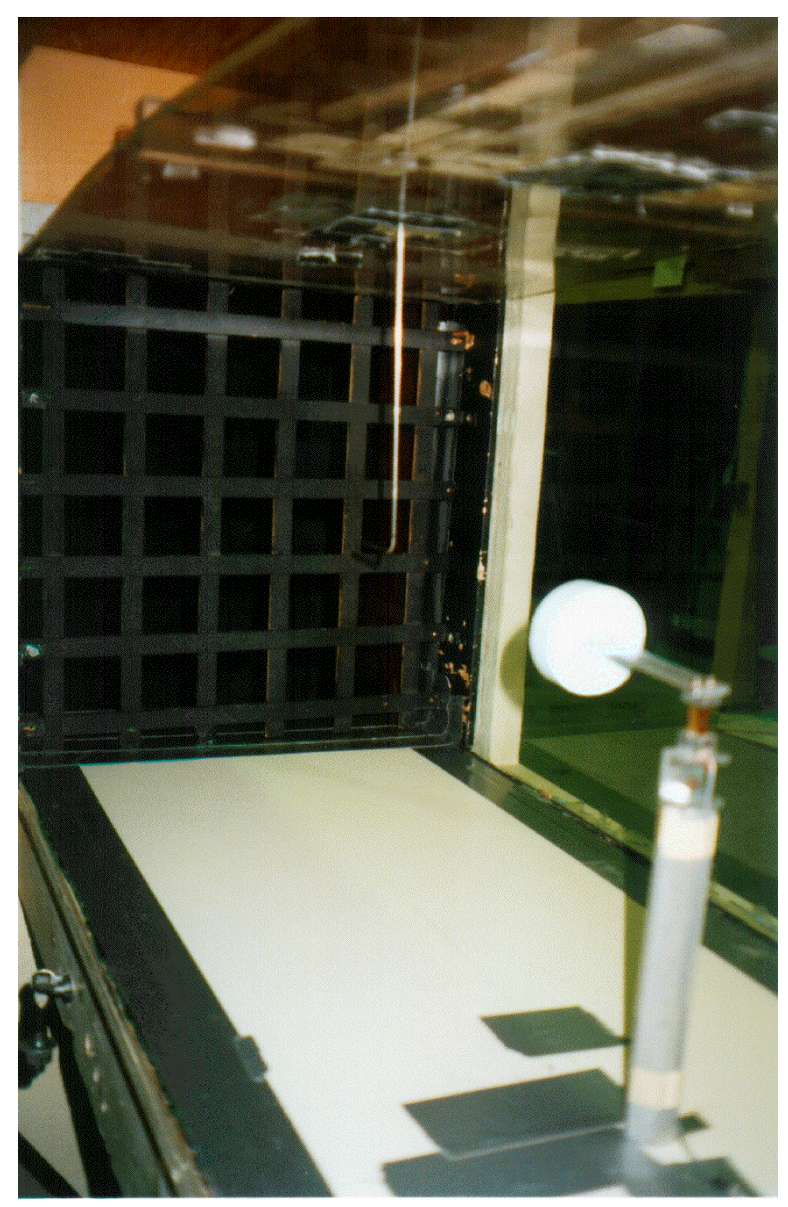

Figura 4.33 - Vista da grelha, do tubo de pitot e da antena conectada à balança. 
Tabela 4.8 - Modelo 1 e antenas - Coeficientes de sustentação e arrasto. Acréscimo do coeficiente de arrasto, $\Delta \mathrm{C}_{\mathrm{a}}$, normalizado pela área efetiva da face do modelo sem as antenas. Exposição 1.

\begin{tabular}{|c|c|c|c|c|c|c|}
\hline Antenas & $\mathrm{C}_{\mathrm{L}}$ & $\mathrm{rms}$ & $\mathrm{C}_{\mathrm{a}}$ & $\mathrm{rms}$ & $\Delta \mathrm{C}_{\mathrm{a}}$ & $\mathrm{Re}$ \\
\hline 0 & 0,02 & 0,016 & 2,71 & 0,026 & 0,00 & 3964 \\
\hline 1 & 0,02 & 0,017 & 2,88 & 0,040 & 0,17 & 3948 \\
\hline 2 & 0,01 & 0,017 & 3,03 & 0,038 & 0,31 & 3961 \\
\hline 4 & 0,02 & 0,017 & 3,35 & 0,047 & 0,63 & 3961 \\
\hline 6 & 0,01 & 0,019 & 3,66 & 0,044 & 0,94 & 3948 \\
\hline 0 & 0,02 & 0,012 & 2,76 & 0,027 & 0,00 & 6855 \\
\hline 1 & 0,01 & 0,013 & 2,93 & 0,025 & 0,17 & 5912 \\
\hline 2 & 0,01 & 0,014 & 3,08 & 0,029 & 0,32 & 5912 \\
\hline 4 & 0,01 & 0,015 & 3,35 & 0,050 & 0,59 & 5909 \\
\hline
\end{tabular}

Tabela 4.9 - Modelo 1 e antenas - Coeficientes de sustentação e arrasto. Acréscimo do coeficiente de arrasto,$\Delta \mathrm{C}_{\mathrm{a}}$, normalizado pela área efetiva da face do modelo sem as antenas. Exposição 2.

\begin{tabular}{|c|c|c|c|c|c|c|}
\hline Antenas & $\mathrm{C}_{\mathrm{L}}$ & $\mathrm{rms}$ & $\mathrm{C}_{\mathrm{a}}$ & $\mathrm{rms}$ & $\Delta \mathrm{C}_{\mathrm{a}}$ & $\mathrm{Re}$ \\
\hline 0 & 0,01 & 0,031 & 2,89 & 0,132 & 0,00 & 4218 \\
\hline 1 & 0,02 & 0,032 & 3,04 & 0,136 & 0,16 & 4218 \\
\hline 2 & 0,01 & 0,033 & 3,17 & 0,139 & 0,28 & 4218 \\
\hline 4 & 0,02 & 0,033 & 3,47 & 0,149 & 0,58 & 4214 \\
\hline 6 & 0,01 & 0,034 & 3,75 & 0,168 & 0,87 & 4205 \\
\hline 0 & 0,01 & 0,029 & 2,91 & 0,132 & 0,00 & 6018 \\
\hline 1 & 0,01 & 0,029 & 3,02 & 0,131 & 0,12 & 6031 \\
\hline 2 & 0,01 & 0,030 & 3,14 & 0,134 & 0,24 & 6018 \\
\hline 4 & 0,01 & 0,030 & 3,42 & 0,146 & 0,52 & 5999 \\
\hline 6 & 0,01 & 0,033 & 3,67 & 0,166 & 0,77 & 5999 \\
\hline
\end{tabular}


Tabela 4.10 - Modelo 4 e antenas - Coeficientes de sustentação e arrasto. Acréscimo do coeficiente de arrasto, $\Delta \mathrm{C}_{\mathrm{a}}$, normalizado pela área efetiva da face do modelo sem as antenas. Exposição 2

\begin{tabular}{|c|c|c|c|c|c|c|c|}
\hline Antenas & $\mathrm{C}_{\mathrm{L}}$ & $\mathrm{rms}$ & $\mathrm{C}_{\mathrm{a}}$ & $\mathrm{rms}$ & $\mathrm{V} \mathrm{m} / \mathrm{s}$ & $\Delta \mathrm{C}_{\mathrm{a}}$ & $\mathrm{Re}$ \\
\hline 0 & 0,00 & 0,043 & 2,59 & 0,119 & 20,05 & 0,00 & 10947 \\
\hline 1 & 0,02 & 0,043 & 2,62 & 0,120 & 20,13 & 0,04 & 10991 \\
\hline 2 & 0,02 & 0,044 & 2,66 & 0,121 & 20,14 & 0,07 & 10996 \\
\hline 4 & 0,03 & 0,045 & 2,74 & 0,122 & 20,22 & 0,15 & 11040 \\
\hline 6 & 0,05 & 0,048 & 2,88 & 0,125 & 20,10 & 0,29 & 10975 \\
\hline 0 & 0,00 & 0,050 & 2,59 & 0,113 & 12,59 & 0,00 & 6874 \\
\hline 1 & 0,02 & 0,052 & 2,66 & 0,118 & 12,56 & 0,07 & 6858 \\
\hline 2 & 0,02 & 0,051 & 2,71 & 0,123 & 12,59 & 0,11 & 6874 \\
\hline 4 & 0,02 & 0,052 & 2,80 & 0,122 & 12,57 & 0,21 & 6863 \\
\hline 6 & 0,04 & 0,053 & 2,87 & 0,124 & 12,58 & 0,28 & 6869 \\
\hline
\end{tabular}

Tabela 4.11 - Resumo de $\Delta \mathrm{C}_{\mathrm{a}}$ apresentado nas tabelas 4.8, 4.9 e 4.10.

\begin{tabular}{|r|r|r|r|r|r|r|}
\hline & \multicolumn{3}{|c|}{ Modelo 1 $\phi=0,162$} & \multicolumn{2}{c|}{ Modelo 4 - $\phi=0,277$} \\
\cline { 2 - 7 } & \multicolumn{2}{|c|}{ exposição 1 } & \multicolumn{2}{c|}{ exposição 2 } & \multicolumn{2}{c|}{ exposição 2 } \\
\hline Antenas & $\mathrm{Re}=3956$ & $\mathrm{Re}=5911$ & $\mathrm{Re}=4215$ & $\mathrm{Re}=6013$ & $\mathrm{Re}=6868$ & $\mathrm{Re}=10990$ \\
\hline 0 & 0 & 0 & 0 & 0 & 0 & 0 \\
\hline 1 & 0,17 & 0,17 & 0,16 & 0,12 & 0,07 & 0,04 \\
\hline 2 & 0,32 & 0,32 & 0,28 & 0,24 & 0,12 & 0,07 \\
\hline 4 & 0,63 & 0,59 & 0,58 & 0,52 & 0,21 & 0,15 \\
\hline 6 & 0,95 & - & 0,87 & 0,77 & 0,28 & 0,29 \\
\hline
\end{tabular}

Tabela 4.12 - Coeficiente de arrasto da antena derivado do ensaio no túnel de vento pequeno. $\left(\mathrm{C}_{\mathrm{a}}=\mathrm{F}_{\mathrm{a} \_ \text {antena }} / \mathrm{qA}_{\text {antena }}\right)$.

\begin{tabular}{|c|r|c|c|c|}
\hline \multicolumn{2}{|c|}{} & \multicolumn{3}{|c|}{$\mathrm{Re}=70000 \mathrm{Vd}$} \\
\hline Fluxo & $\mathrm{C}_{\mathrm{a}}$ & $\begin{array}{c}\text { Antena } \\
\mathrm{d}=0,06 \mathrm{~m}\end{array}$ & $\begin{array}{c}\text { Modelo1 } \\
\mathrm{d}=0,0046 \mathrm{~m}\end{array}$ & $\begin{array}{c}\text { Modelo 4 } \\
\mathrm{d}=0,0078 \mathrm{~m}\end{array}$ \\
\hline \multirow{2}{*}{ exposição 1 } & 1,13 & 24192 & 1854 & 10318 \\
\cline { 2 - 5 } & 1,12 & 44405 & 3404 & 18939 \\
\hline \multirow{3}{*}{ exposição 2 } & 1,02 & 24342 & 1866 & 10382 \\
\cline { 2 - 5 } & 0,9 & 42542 & 3266 & 18148 \\
\cline { 2 - 5 } & 1,03 & 24342 & 1866 & 10382 \\
\cline { 2 - 5 } & 0,86 & 44405 & 3404 & 18939 \\
\hline
\end{tabular}


Na tabela 4.12, observam-se diferenças sensíveis nos coeficientes de arrasto para diferentes números de Reynolds e tipo de exposição. A explicação para o fato pode ser devida à geometria do disco de antena com 6 centímetros de diâmetro e espessura de 2,3 centímetros conforme figura 4.28. Parece que houve um recolamento da camada limite devido à turbulência e à rugosidade da antena. No entanto, para se ter uma posição definitiva, mais ensaios deverão ser realizados. $\mathrm{O}$ espectro de potência do vento incidente no túnel menor (exposição 2) está mostrado na figura 4.34. A intensidade de turbulência é de $9,7 \%$.

Para determinar o fator de interferência da antena na torre foram considerados os números de Reynolds mais próximos, já que os ensaios do modelo com as antenas e da antena sozinha foram realizados em túneis de vento diferentes. A tabela 4.13 apresenta os coeficientes de arrasto da antena isolada adotados para cada condição de ensaio da antena na torre. Esses valores foram adotados em função da proximidade do número de Reynolds e do tipo de exposição dos dois ensaios. A tabela 4.13 apresenta também os coeficientes de arrasto das antenas determinados quando as antenas se encontram fixadas no modelo da torre. Para efeito de comparação, a tabela 4.12 apresenta os números de Reynolds equivalentes baseados nas barras principais do modelo 1 e do modelo 4.

Tabela 4.13 - Coeficiente de arrasto em um disco de antena $(\mathrm{d}=6 \mathrm{~cm})$ derivado dos resultados experimentais. $\left(\mathrm{C}_{\mathrm{a} \text { antena no modelo }}=\Delta \mathrm{F}_{\mathrm{a}} / \mathrm{A}_{\text {antena }}\right)$

\begin{tabular}{|r|r|r|r|r|r|r|}
\hline & \multicolumn{4}{|c|}{ Modelo 1 - $\phi=0,162$} & \multicolumn{2}{c|}{ Modelo 4 - $\phi=0,162$} \\
\hline \multirow{3}{*}{ Antenas } & \multicolumn{2}{|c|}{ exposição 1 } & \multicolumn{2}{c|}{ exposição 2 } & \multicolumn{2}{c|}{ exposição 2 } \\
\cline { 2 - 8 } & $\mathrm{Re}=3956$ & $\mathrm{Re}=5911$ & $\mathrm{Re}=4215$ & $\mathrm{Re}=6013$ & $\mathrm{Re}=6868$ & $\mathrm{Re}=10990$ \\
\hline 1 & 1,026 & 1,015 & 0,933 & 0,705 & 0,673 & 0,377 \\
\hline 2 & 0,940 & 0,948 & 0,844 & 0,715 & 0,595 & 0,362 \\
\hline 4 & 0,947 & 0,879 & 0,868 & 0,769 & 0,541 & 0,394 \\
\hline Antena isolada & 0,940 & 0,896 & 0,864 & 0,764 & 0,477 & 0,493 \\
\hline
\end{tabular}




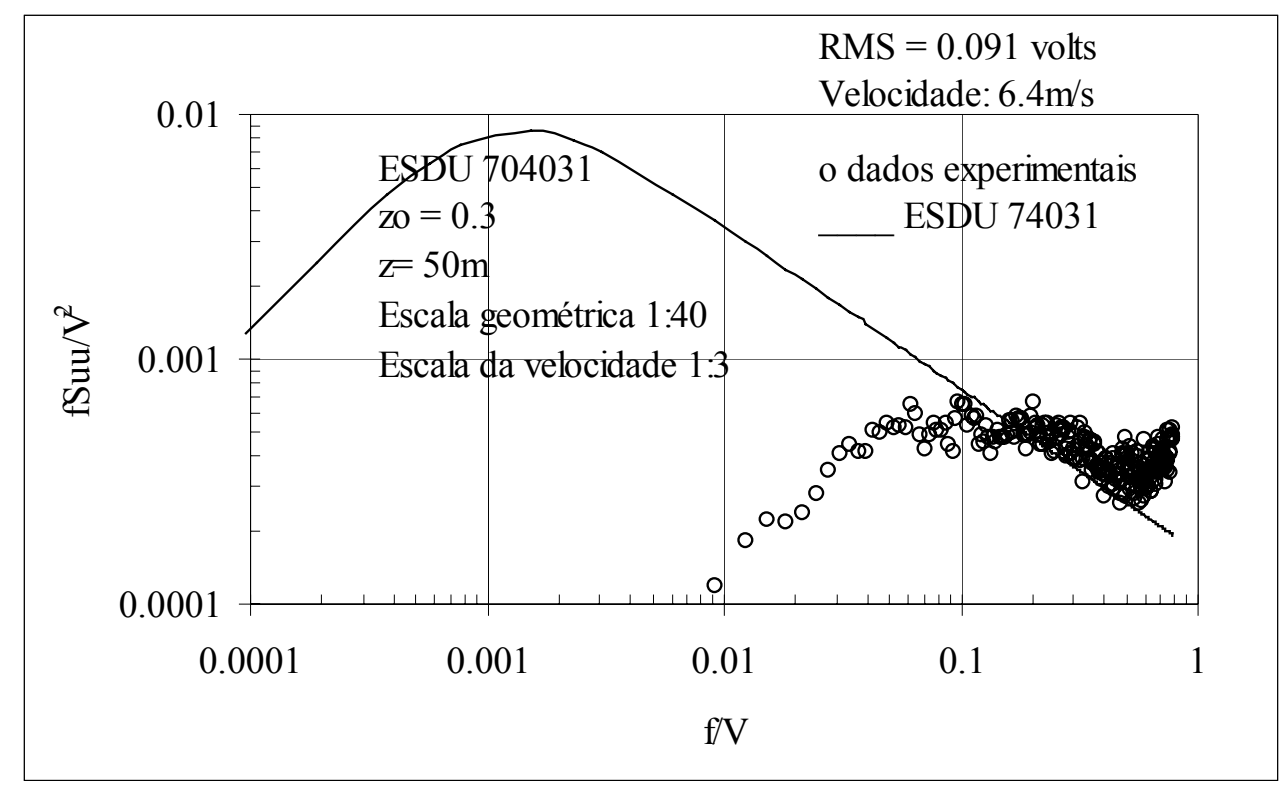

Figura 4.34 - Espectro de potência do vento incidente (exposição 2) gerado para determinação das forças na antena separadamente. $\mathrm{I}_{\mathrm{V}}=9,7 \%$

Observa-se que há duas tendências de comportamento para a variação do coeficiente de arrasto na figura 4.35 que indica uma dependência da interferência aerodinâmica da antena com o índice de área exposta da torre. Pela inclinação da reta, verifica-se que há interferências maiores para o índice de área exposta de 0,277, ou seja, o acréscimo de forças no modelo $4(\phi=0,277)$ devido à adição das antenas foi menor que o acréscimo das forças no modelo $1(\phi=0,162)$.

A relação entre o coeficiente de arrasto obtido nos testes da antena na torre pelo coeficiente da antena separada da torre, $\mathrm{f}_{\mathrm{a}}=\Delta \mathrm{C}_{\mathrm{a} \_ \text {antena na torre }} \mathrm{C}_{\mathrm{a} \_ \text {antena, é apresentada na }}$ tabela 4.14 . 


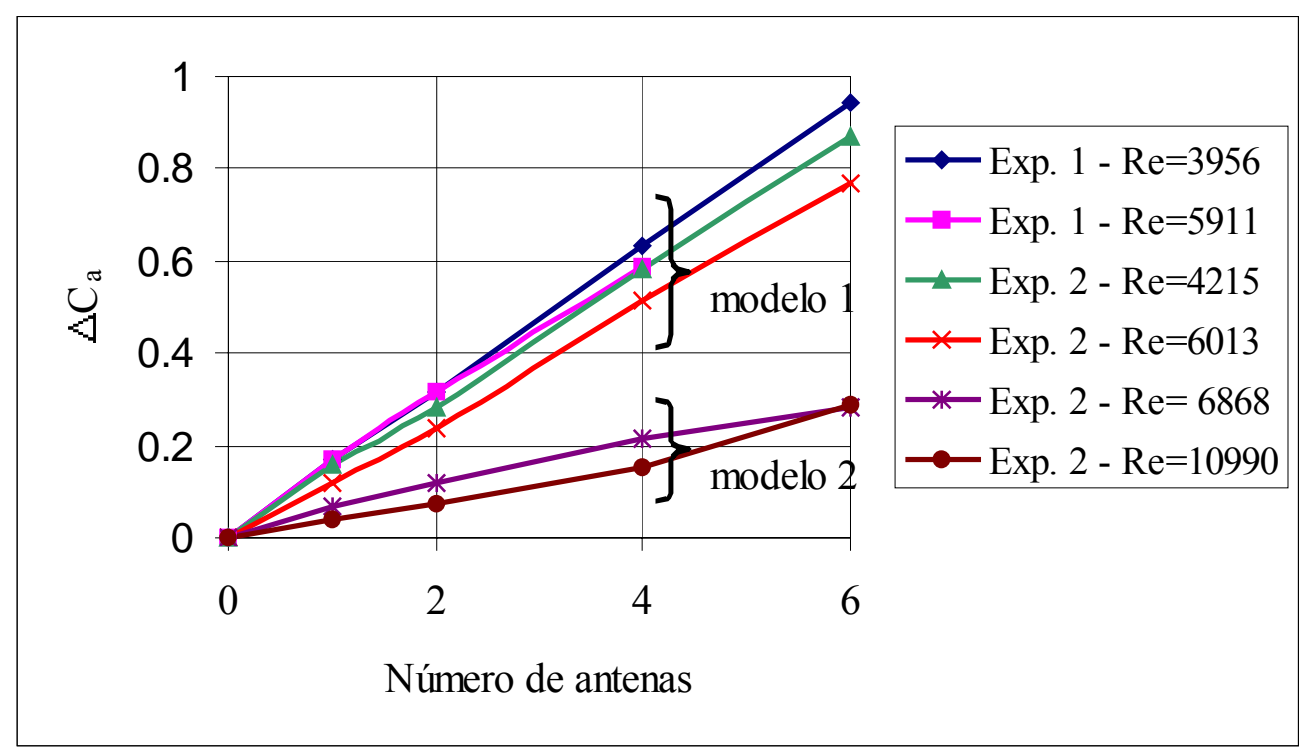

Figura 4.35 - Modelo 1 e modelo 4- Variação dos coeficientes de força $\Delta \mathrm{C}_{\mathrm{a}}$ com o número de antenas.

Tabela 4.14 - Fator de interferência $\left(\Delta \mathrm{C}_{\mathrm{a} \_ \text {antena na torre }} / \mathrm{C}_{\mathrm{a} \_ \text {antena separada }}\right)$

\begin{tabular}{|r|c|c|c|c|c|c|}
\hline & \multicolumn{4}{|c|}{$\phi=0,162$} & \multicolumn{2}{c|}{$\phi=0,277$} \\
\cline { 2 - 7 } & \multicolumn{2}{|c|}{ exposição 1 } & \multicolumn{2}{c|}{ exposição 2 } & \multicolumn{2}{c|}{ exposição 2 } \\
\hline Antenas & $\mathrm{Re}=3956$ & $\mathrm{Re}=5911$ & $\mathrm{Re}=4215$ & $\mathrm{Re}=6013$ & $\mathrm{Re}=6868$ & $\mathrm{Re}=10990$ \\
\hline 1 & 0,916 & 0,906 & 1,037 & 0,783 & 0,660 & 0,369 \\
\hline 2 & 0,839 & 0,847 & 0,937 & 0,794 & 0,583 & 0,355 \\
\hline 4 & 0,846 & 0,785 & 0,965 & 0,855 & 0,531 & 0,386 \\
\hline 6 & 0,840 & 0,800 & 0,960 & 0,849 & 0,468 & 0,484 \\
\hline
\end{tabular}

Observa-se que, dependendo do índice de área exposta, a consideração das forças do vento na antena isolada fornece bons resultados. A tabela 4.14 mostra que a interferência é mais sentida em estruturas treliçadas com índices de área exposta maiores.

A figura 4.36 mostra os valores de $C_{a}$ normalizados pela área das antenas existentes no modelo. Estes dados foram retirados das tabelas 4.13. A figura 4.37 apresenta uma comparação entre os resultados experimentais e a curva fornecida pela equação 4.5 de ESDU 81028 (1990). 


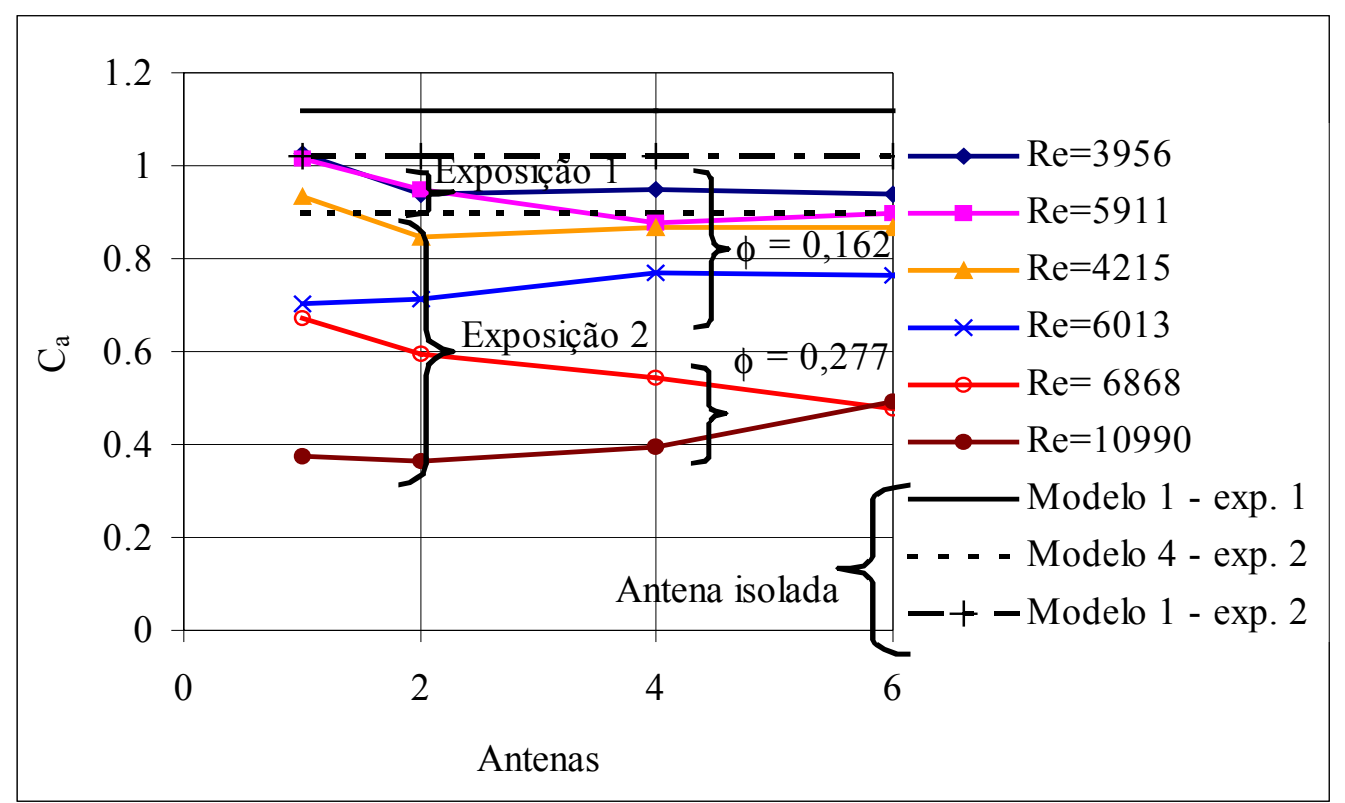

Figura $4.36-C_{a}$ de uma antena. $R e=D_{\text {model }} V / v$

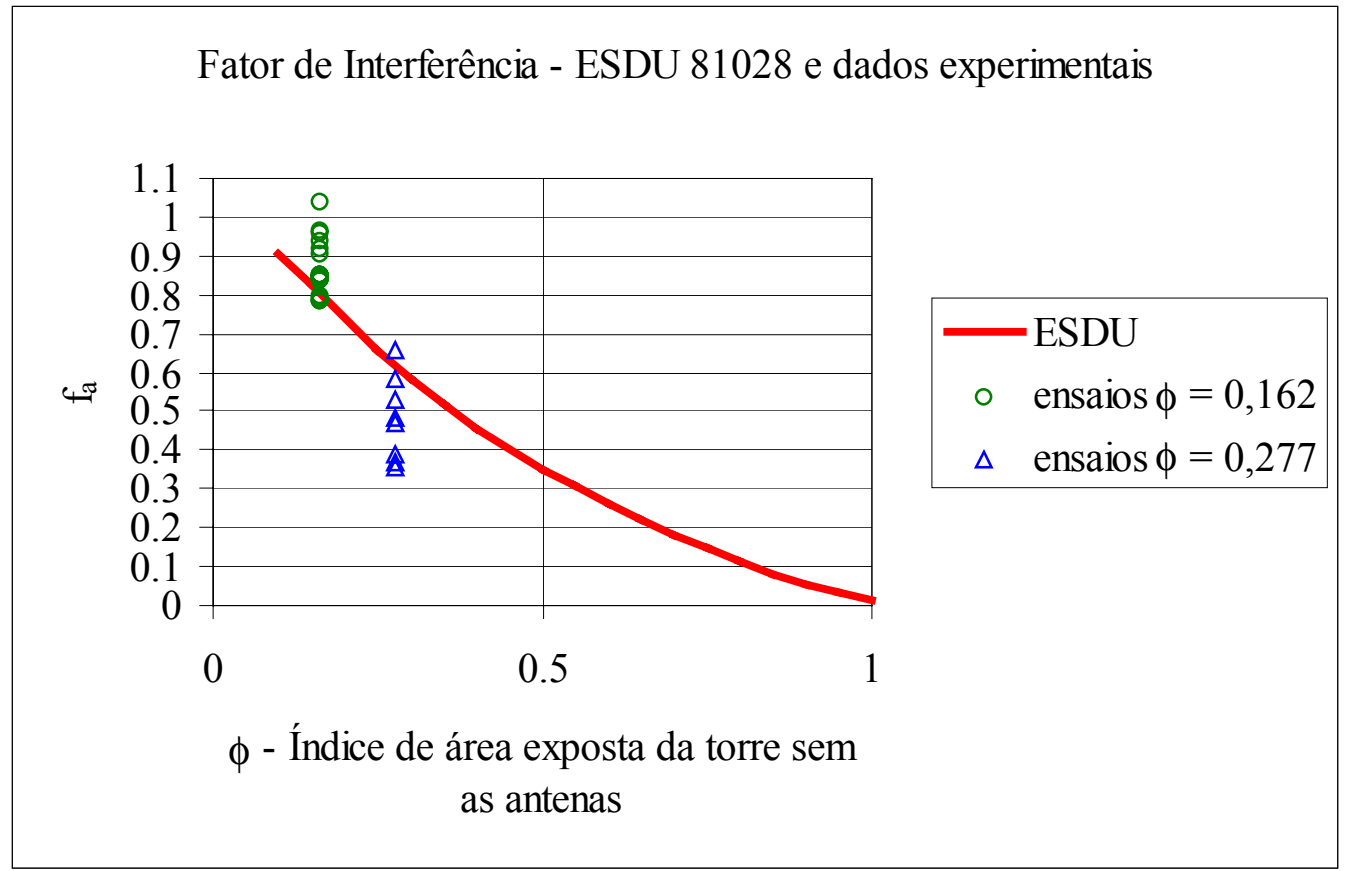

Figura 4.37 - Fator de interferência - dados experimentais e ESDU 81028 (1990) 


\section{RESULTADOS EXPERIMENTAIS: COMPARAÇÕES E COMENTÁRIOS}

Neste capítulo, os resultados experimentais apresentados no capítulo 4 são comentados e comparados com os valores apresentados nas principais normas existentes, norma Canadense NBCC (1995), Americana (ASCE 7-95), Australiana AS 1170.2 (1989), Britânica BS8100 (1986), Européia EUROCODE 1 (1995) e a norma Brasileira NBR6123 (1988).

Comparações são feitas a respeito do índice de área exposta e do fator de proteção em estruturas de torres de seção quadrada. Os resultados aqui considerados referem-se aos ângulos de incidência $0^{\circ}$ e $45^{\circ}$ que são os valores extremos dos coeficientes de arrasto em torres de seção quadrada.

\section{1 Índice de área exposta}

Todos os resultados experimentais estão apresentados na tabela 5.1. A tabela 5.3 apresenta o coeficiente de arrasto das principais normas existentes e a média dos valores experimentais. A figura 5.1 mostra a comparação entre as normas e os resultados experimentais.

Observa-se que os resultados experimentais são ligeiramente menores do que aqueles das normas existentes, porém apresentando uma boa concordância. Observa-se que somente a Norma Canadense apresenta valores discrepantes em relação aos resultados obtidos no ensaio e especificados em outras normas. A discrepância maior ocorre na faixa de índice de esbeltez 0,1 a 0,3 que são usuais em torres treliçadas. Embora a favor da segurança, verifica-se que esses valores chegam a mais de $10 \% \mathrm{em}$ relação a outras normas. Em relação à média dos resultados experimentais, para $\phi=0,162$, o valor do coeficiente de arrasto da NBCC (1995) é $17,6 \%$ maior.

Era esperada uma maior diferença dos resultados experimentais e das normas conforme afirmado por GIORGIOU (1979). Essa afirmação parece apenas ser válida para a 
norma canadense. Em relação aos coeficientes de arrasto em torres treliçadas de seção quadrada, as normas se atualizaram e os dados estão mais consistentes.

Todas as normas estão a favor da segurança em relação aos dados experimentais, exceto a norma Européia EUROCODE 1 (1995), que para ângulos de incidência do vento de $45^{\circ}$, apresenta valores quase iguais aos valores médios encontrados experimentalmente, mas não a favor da segurança.

A norma canadense não especifica uma curva do coeficiente de arrasto em função do índice de área exposta como em outras normas (figura 5.1). A curva apresentada é derivada do processo de cálculo das forças de arrasto em torres treliçadas especificado pela NBCC (1995). Esse processo é baseado na determinação das forças do vento em cada face da torre a partir dos fatores de proteção especificados. Esses fatores foram determinados experimentalmente a partir de reticulados planos isolados sem considerar a contribuição das estruturas adjacentes, como é o caso das faces laterais da torre.

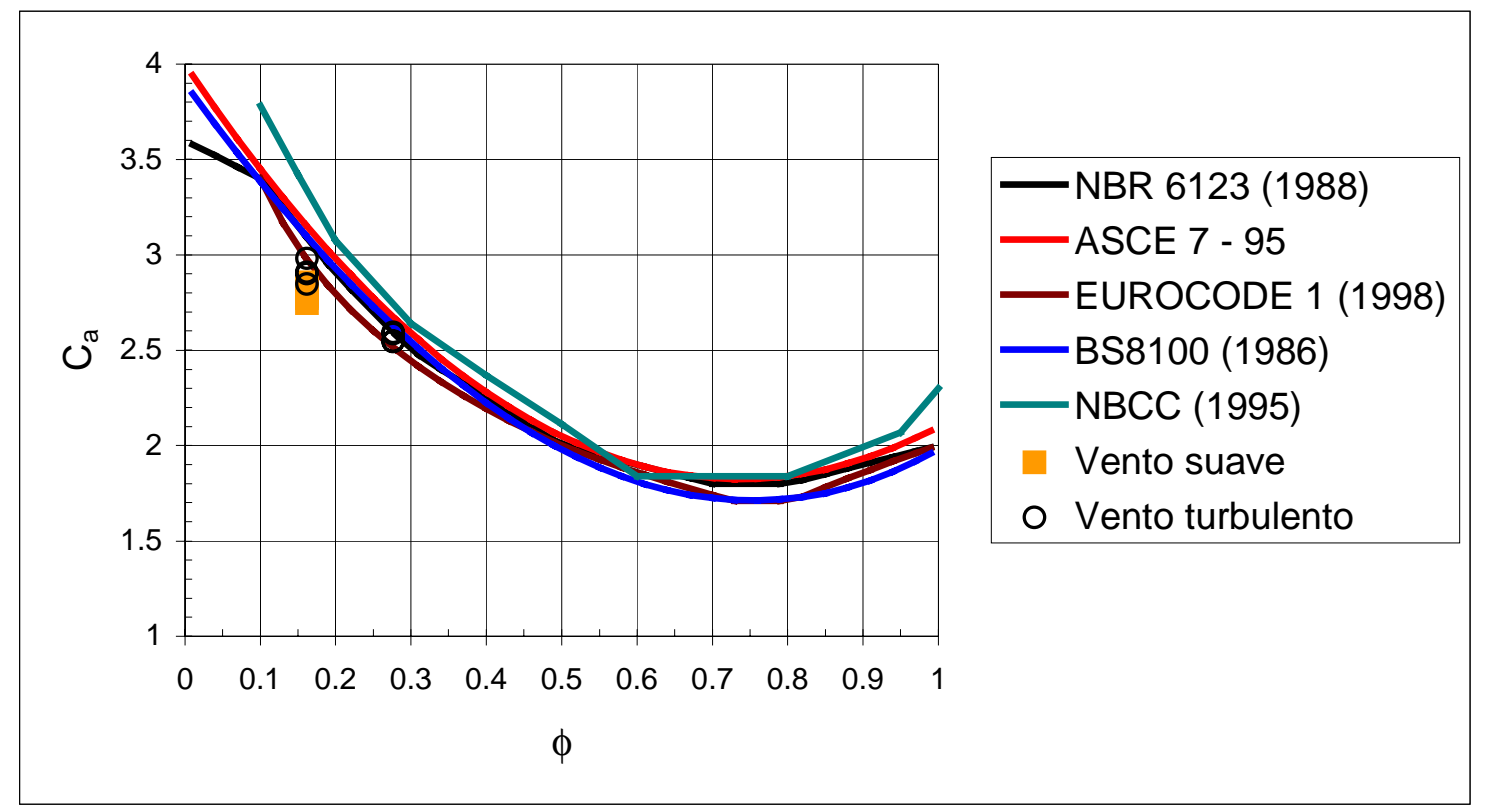

Figura 5.1 - Coeficientes de arrasto em função do índice de área exposta - normas e dados experimentais 
Tabela 5.1 - Coeficiente de arrasto, dados experimentais.

\begin{tabular}{|c|c|c|c|c|c|c|c|c|c|c|c|c|}
\hline \multirow[b]{3}{*}{$\phi / \alpha$} & \multicolumn{8}{|c|}{ Exposição 1} & \multicolumn{4}{|c|}{ Exposição 2} \\
\hline & \multicolumn{2}{|c|}{$\mathrm{Re} \cong 6000$} & \multicolumn{2}{|c|}{$\mathrm{Re} \cong 6800$} & \multicolumn{2}{|c|}{$\mathrm{Re} \cong 3900$} & \multicolumn{2}{|c|}{$\mathrm{Re} \cong 6800$} & \multicolumn{2}{|c|}{$\mathrm{Re} \cong 3900$} & \multicolumn{2}{|c|}{$\mathrm{Re} \cong 6400$} \\
\hline & $0^{\circ}$ & $45^{\circ}$ & $0^{\circ}$ & $45^{\circ}$ & $0^{\circ}$ & $45^{\circ}$ & $0^{\circ}$ & $45^{\circ}$ & $0^{\circ}$ & $45^{\circ}$ & $0^{\circ}$ & $45^{\circ}$ \\
\hline \multirow{3}{*}{0,162} & 2,86 & 3,35 & 2,85 & 3,35 & 2,80 & 3,35 & 2,84 & 3,40 & 2,90 & 3,41 & 2,85 & 3,34 \\
\hline & 2,80 & 3,31 & 2,78 & 3,37 & 2,75 & & 2,77 & & 2,98 & & 2,91 & \\
\hline & 2,86 & & 2,84 & & & & & & & & & \\
\hline & & & & & & & & & \multicolumn{2}{|c|}{$\mathrm{Re} \cong 6800$} & \multicolumn{2}{|c|}{$\mathrm{Re} \cong 10900$} \\
\hline \multirow{3}{*}{0,277} & & & & & & & & & 2,55 & 2,84 & 2,55 & 2,83 \\
\hline & & & & & & & & & 2,59 & & 2,59 & \\
\hline & & & & & & & & & & & & \\
\hline
\end{tabular}

Tabela 5.2 - Diferenças entre os resultados dos dados experimentais -

$\left(\mathrm{C}_{\mathrm{a} \max }-\mathrm{C}_{\mathrm{a} \min }\right) / \mathrm{C}_{\mathrm{a} \min }$

\begin{tabular}{|c|c|c|c|c|c|}
\hline$\phi$ & Angulo & $\mathrm{C}_{\text {amédio }}$ & $\mathrm{C}_{\mathrm{amax}}$ & $\mathrm{C}_{\mathrm{amin}}$ & Diferenças (\%) \\
\hline \multirow{3}{*}{0,162} & $0^{\circ}$ & 2,84 & 2,98 & 2,75 & 8,4 \\
\cline { 2 - 6 } & $45^{\circ}$ & 3,36 & 3,41 & 3,31 & 3,0 \\
\hline \multirow{2}{*}{0,277} & $0^{\circ}$ & 2,57 & 2,59 & 2,55 & 1,6 \\
\cline { 2 - 6 } & $45^{\circ}$ & 2,84 & 2,84 & 2,83 & 0,4 \\
\hline
\end{tabular}

Tabela 5.3 - Coeficiente de arrasto das normas

\begin{tabular}{|c|c|c|c|c|}
\hline Índice de área exposta & \multicolumn{2}{|c|}{$\phi=0,162$} & \multicolumn{2}{|c|}{$\phi=0,277$} \\
\hline Ângulo de incidência & $0^{\circ}$ & $45^{\circ}$ & $0^{\circ}$ & $45^{\circ}$ \\
\hline NBR 6123 (1988) & 3,09 & 3,58 & 2,59 & 3,01 \\
\hline ASCE 7-95 & 3,15 & 3,53 & 2,67 & 2,99 \\
\hline EUROCODE 1 (1998) & 2,98 & 3,34 & 2,51 & 2,94 \\
\hline AUSTR. AS 1170.2 (1989) & 3,07 & 3,68 & 2,57 & 3,08 \\
\hline NBCC (1995) & 3,34 & 4,15 & 2,73 & 3,41 \\
\hline BS8100 (1986) & 3,09 & 3,55 & 2,63 & 3,17 \\
\hline Média experimental & 2,84 & 3,36 & 2,57 & 2,84 \\
\hline
\end{tabular}

As causas das diferenças nos resultados experimentais provavelmente se devem aos erros experimentais no ajuste manual do ângulo de incidência, calibração dos equipamentos, tipo de exposição, diferentes números de Reynolds e imperfeições do modelo. 
As velocidades do vento foram automaticamente aferidas para cada caso para minimizar erros de ordem humana. Para os casos de ensaios com calibrações distintas, as diferenças chegam a $8,4 \%$, tabela 5.3. As diferenças que têm como causa o número de Reynolds são insignificantes (da ordem de 2\%), calculadas a partir da tabela 5.1. As diferenças entre os coeficientes de arrasto devidas ao tipo de exposição apresentam valores altos de $8,4 \%$, mas também são conseqüentes de erros devidos à calibração distinta.

Observa-se que o número de Reynolds do modelo ensaiado e o tipo de exposição do modelo, fluxo turbulento ou fluxo suave, não são variáveis importantes na determinação do coeficiente de arrasto. Corroborando com os resultados obtidos, observa-se que os coeficientes médios de arrasto das normas existentes são baseados, em sua maioria, em experimentos com fluxo suave.

\subsection{Fator de proteção}

Para estudar o fator de proteção dos reticulados da torre, a força de arrasto foi medida para três diferentes razões entre o espaçamento dos reticulados e a largura da torre (s/B da figura 4.7). Para cada modelo foram medidas as forças de arrasto globais que envolvem os efeitos de proteção do reticulado de barlavento em relação ao reticulado de sotavento.

O fator de proteção é definido como:

$\mathrm{K}_{\mathrm{x}}=\frac{\mathrm{C}_{\mathrm{a}_{2}}-\mathrm{C}_{\mathrm{a}_{1}}}{\mathrm{C}_{\mathrm{a}_{1}}}$

em que $\mathrm{C}_{\mathrm{a} 2}$ é o coeficiente de arrasto do reticulado a sotavento e $\mathrm{C}_{\mathrm{a} 1}$ é o coeficiente de arrasto do reticulado de barlavento.

Como o fator de proteção é especificado pelas normas existentes, os resultados experimentais foram comparados com as normas utilizando a equação 5.2.

$\frac{\mathrm{C}_{\mathrm{an}}}{\mathrm{C}_{\mathrm{a} 1}}=\frac{\left(1+\mathrm{K}_{\mathrm{x}}\right)_{\mathrm{n}}}{\left(1+\mathrm{K}_{\mathrm{x}}\right)_{1}}$ 
em que n é a relação s/B.

Os resultados são apresentados na tabela 5.4 e figura 5.2.

Tabela 5.4 - Fator de proteção: normas e dados experimentais.

\begin{tabular}{|c|c|c|c|c|c|c|c|c|}
\hline & & \multicolumn{3}{|c|}{$\mathrm{K}_{\mathrm{x}}$} & \multicolumn{3}{|c|}{$\mathrm{C}_{\mathrm{an}} / \mathrm{C}_{\mathrm{a} 1}$} \\
\hline & & $\phi$ & $\mathrm{s} / \mathrm{B}=1$ & $\mathrm{~s} / \mathrm{B}=2$ & $\mathrm{~s} / \mathrm{B}=3$ & $\mathrm{~s} / \mathrm{B}=1$ & $\mathrm{~s} / \mathrm{B}=2$ & $\mathrm{~s} / \mathrm{B}=3$ \\
\hline \multirow{2}{*}{\multicolumn{2}{|c|}{ NBR 6123(1988) }} & 0,162 & 0,884 & 0,902 & 0,93 & 1 & 1,01 & 1,024 \\
\hline & & 0,277 & 0,731 & 0,785 & 0,823 & 1 & 1,031 & 1,053 \\
\hline \multirow{2}{*}{\multicolumn{2}{|c|}{ AS 1170.2 (1989) }} & 0,162 & 0,876 & 0,938 & 0,969 & 1 & 1,033 & 1,05 \\
\hline & & 0,277 & 0,723 & 0,878 & 0,919 & 1 & 1,013 & 1,042 \\
\hline \multirow{2}{*}{\multicolumn{2}{|c|}{ NBCC (1995) }} & 0,162 & 0,878 & 0,919 & 0,929 & 1 & 1,022 & 1,027 \\
\hline & & 0,277 & 0,687 & 0,762 & 0,785 & 1 & 1,045 & 1,058 \\
\hline \multirow{3}{*}{ Ensaio } & exposição 1 & 0,162 & - & - & - & 1 & 1,067 & 1,071 \\
\hline & exposição 1 & 0,277 & - & - & - & 1 & 1,047 & 1,09 \\
\hline & exposição 2 & 0,277 & - & - & - & 1 & 1,09 & - \\
\hline
\end{tabular}

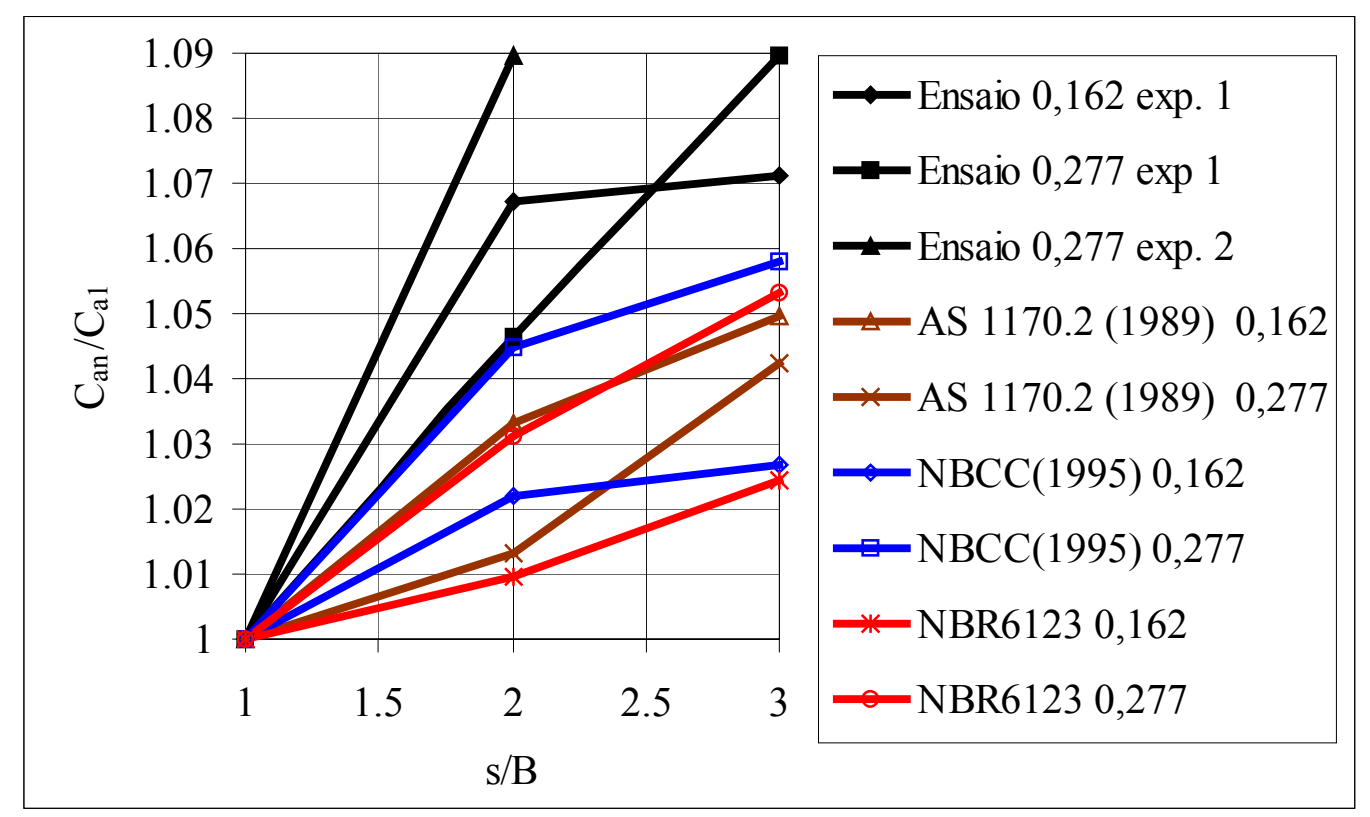

Figura 5.2 - Fator de proteção: normas e dados experimentais

Verifica-se que os resultados experimentais obtidos neste trabalho foram ligeiramente maiores que os valores contidos nas normas. Isso mostra a contribuição dos reticulados adjacentes da torre na força global de arrasto. As normas de ação do 
vento em edificações não consideram as estruturas adjacentes aos reticulados na definição do efeito de proteção.

Observa-se, também, que as diferenças entre as forças globais de arrasto para os diferentes espaçamentos $(\mathrm{s} / \mathrm{B}=1,2,3)$ são tão pequenas que, para efeitos práticos, não são significativas.

Geralmente, o fator de proteção no projeto de torres é usado somente para determinar as forças que atuam em cada face da torre, separadamente. A maioria das torres é quadrada ou triangular usando somente o fator de proteção para s/B=1.

Entre as normas pesquisadas, somente a norma canadense utiliza os fatores de proteção para o cálculo da força de arrasto global. As demais normas apresentam um coeficiente de arrasto global em função do índice de área exposta de uma face. Esse coeficiente contém as contribuições de todas as faces da torre, incluindo os efeitos de proteção entre as faces. 


\section{CONCLUSÕES E TRABALHOS FUTUROS}

\subsection{Conclusões}

O objetivo principal desta tese, a realização de um estudo numérico e experimental envolvendo as estruturas de torres metálicas treliçadas para suporte de antenas celulares, foi atingido com a análise numérica da resposta de torres esbeltas sob o efeito dinâmico do vento e com uma investigação experimental desenvolvida no Boundary Layer Wind Tunnel Laboratory da University of Western Ontario, London, Ontario, Canadá.

Em relação à análise numérica, foram apresentados os procedimentos de projeto para o cálculo das forças do vento em torres treliçadas. Para a análise dos efeitos dinâmicos provocados pela turbulência atmosférica, foram apresentados três diferente métodos de cálculo: o método de Davenport, o modelo discreto da NBR6123/88 e método do "vento sintético" de FRANCO (1993). Para o método de Davenport e o método do "vento sintético", elaboraram-se programas no Mathcad versão 2000, em anexo, aplicando-os a um exemplo de torre de telecomunicação. O mesmo foi feito utilizando-se uma planilha Excel para o modelo discreto da NBR6123/88. As conclusões referentes aos resultados obtidos com esse exemplo estão apresentadas a seguir.

- As respostas da estrutura às rajadas do vento são, principalmente, respostas não ressonantes nas freqüências abaixo das freqüências naturais da estrutura. Embora pequena, se comparada com a resposta não ressonante, a resposta ressonante aumenta com a altitude do trecho da torre onde a resposta é considerada (a resposta do momento fletor a 3/4 da altura da torre é maior que a resposta a 0,5 da altura da torre, e maior que a resposta ressonante na base da torre).

- O coeficiente de amortecimento aerodinâmico do primeiro modo de vibração determinado pelo método de Davenport é da ordem de 2,5\%. Este valor alto se deve à estrutura da torre metálica treliçada ter pouca massa, e estar submetida a velocidades altas de vento. 
- Os resultados obtidos com o modelo da NBR6123 (1988) diferem pouco dos resultados obtidos com o modelo de Davenport, indicando valores aceitáveis. As diferenças encontradas provavelmente se devem às diferentes considerações que caracterizam cada método.

- O resultado obtido com o método do "vento sintético" de FRANCO (1993) apresenta diferenças relativamente grandes em relação aos resultados do modelo da NBR6123 e do modelo de Davenport. Essas diferenças, embora grandes, diminuem com as modificações aqui sugeridas.

Em relação à investigação experimental deste trabalho, as seguintes conclusões são listadas a seguir.

- O efeito da turbulência nos coeficientes médios de força em estruturas treliçadas é insignificante e pode ser desconsiderado.

- Não se encontraram diferenças significantes nos resultados dos coeficientes de força do modelo devido à variação do número de Reynolds.

- Os coeficientes de arrasto médio obtido experimentalmente para torres treliçadas de seção quadrada e perfis com bordas afiladas confirmaram os valores dos mesmos obtidos pelas normas existentes.

- As curvas do coeficiente arrasto em função do índice de área exposta de diferentes normas são, na sua maioria, bem ajustadas às normas, com exceção da norma Canadense. Para o índice de área exposta menor que 0,3, a Norma Canadense fornece coeficientes de arrasto cerca de 10\% maiores que os valores obtidos por outras normas, e cerca de $17,6 \%$ maior que a média dos valores obtidos experimentalmente neste trabalho.

- Os resultados experimentais deste trabalho referentes ao efeito de proteção da face de barlavento na face de sotavento da torre, quando o espaçamento entre as faces varia, mostraram resultados experimentais ligeiramente maiores que os valores obtidos pelas normas existentes. Isso provavelmente se deve ao fato de que as normas existentes não consideram as estruturas adjacentes na 
determinação do fator de proteção. No entanto, as diferenças entre as forças globais de arrasto para os diferentes espaçamentos $(\mathrm{s} / \mathrm{b}=1,2,3)$ são tão pequenas que, para efeito prático, podem ser desprezadas.

- Dependendo do índice de área exposta da face da torre, a consideração das forças do vento nas antenas separadamente da estrutura da torre não é uma boa aproximação. A interferência aumenta com o aumento do índice de área exposta. Embora haja uma dispersão grande dos resultados experimentais, os mesmos seguem a curva sugerida pelo ESDU 81028 (1990). Mais experimentos são necessários, pois o fator de interferência depende também da posição da antena e do ângulo de incidência do vento.

- Para antenas dispostas perpendicularmente à incidência do vento, sugere-se que, para valores do índice de área exposta menor que 0,2 , se considere as forças do vento na antena separadamente das forças do vento na torre; os resultados podem ser simplesmente adicionados. Para valores maiores que 0,2 sugere-se aplicar o fator de interferência especificado por ESDU 81028 (1990).

\subsection{Futuros trabalhos.}

Sabe-se que o coeficiente de amortecimento aerodinâmico é favorável, ou seja, quanto maior for o amortecimento, menor será a resposta da estrutura. Embora os estudos indiquem que a resposta ressonante para o tipo de estrutura estudada seja pequena, novas investigações experimentais com os modelos construídos podem ser realizadas para avaliar o coeficiente de amortecimento aerodinâmico, que ainda é uma das incertezas do processo.

Em relação ao método do "vento sintético" de FRANCO (1993), futuras investigações serão necessárias para avaliar a aderência do método com outros procedimentos, com novas simulações em torres treliçadas.

Novos estudos experimentais devem ser realizados para corrigir os valores rms obtidos nesses experimentos e determinar a resposta dinâmica da torre a partir dos dados experimentais. Esses estudos envolvem a correção do espectro de potência do 
vento gerado experimentalmente nas faixas de freqüência abaixo da freqüência natural da estrutura analisada.

Os resultados dos coeficientes de força para valores do índice de área exposta maiores que os estudados neste trabalho podem ser avaliados com novos ensaios experimentais para confirmar os resultados derivados das principais normas existentes no mundo.

O fator de interferência das antenas celulares pode ser analisado com novas investigações experimentais considerando diferentes posições da antena e a variação do ângulo de incidência do vento.

Não se considerou nesse trabalho a resposta dinâmica transversal de torres de telecomunicações. Os procedimentos aqui apresentados podem ser melhorados com a inclusão dessa resposta, podendo ser utilizados para edifícios altos ou chaminés.

Investigações experimentais com modelos aeroelásticos de torres treliçadas, simulando pelo menos um modo de vibração, podem ser realizados para comprovar os resultados teóricos encontrados. 
ANEXO A - DADOS SOBRE A CONSTRUÇÃO DE TORRES METÁLICAS NO BRASIL

Tabela A1 - Dados sobre a construção de torres metálicas para telecomunicações nos últimos quatro anos no Brasil

\begin{tabular}{|c|c|c|c|c|}
\hline & LOCALIDADE & Altura & Seção & Localização \\
\hline 1 & ANÁPOLIS & 80 & Triangular & Área densa de casas \\
\hline 2 & ANICUNS-IU & 30 & Quadrada & Área densa de casas \\
\hline 3 & BELA VISTA DE GO. & 33 & Quadrada & Área densa de casas \\
\hline 4 & BOM JESUS DE GOIÁS & 90 & Quadrada & Área densa de casas \\
\hline 5 & CACHOEIRA ALTA & 40 & Quadrada & Área densa de casas \\
\hline 6 & CAIAPÔNIA & 20 & Quadrada & Área densa de casas \\
\hline 7 & CERES & 99 & Triangular & Área densa de casas \\
\hline 8 & COLINAS DO TOC. & 70 & Quadrada & Área densa de casas \\
\hline 9 & CORUMBÁ DE GOIÁS & 45 & Quadrada & Área densa de casas \\
\hline 10 & CORUMBAIBA & 33 & Quadrada & Área densa de casas \\
\hline 11 & EDEIA & 40 & Quadrada & Área densa de casas \\
\hline 12 & EDEIA & 70 & Quadrada & Área densa de casas \\
\hline 13 & FORMOSO & 40 & Quadrada & Área densa de casas \\
\hline 14 & GNA-ALVORADA & 40 & Quadrada & Área densa de casas \\
\hline 15 & GNA-ART & 30 & Quadrada & Área densa de casas \\
\hline 16 & GNA-ARUANA/RIVIERA & 30 & Quadrada & Área densa de casas \\
\hline 17 & GNA-CAEL-ERB & 70 & Triangular & Área densa de casas \\
\hline 18 & GNA-CAPUAVA & 40 & Quadrada & Área densa de casas \\
\hline 19 & GNA-CASTELO BRANCO & 35 & Quadrada & Área densa de casas \\
\hline 20 & GNA-FAMA & 30 & Quadrada & Área densa de casas \\
\hline 21 & GNA-GARAVELO & 60 & Quadrada & Área densa de casas \\
\hline 22 & GNA-JD. PALMEIRAS & 20 & Quadrada & Área densa de casas \\
\hline 23 & GNA-JD.GUANABARA-ERB & 80 & Triangular & Área densa de casas \\
\hline 24 & GNA-NOROESTE-ERB & 70 & Triangular & Área densa de casas \\
\hline 25 & GNA-ST. COIMBRA & 30 & Quadrada & Área densa de casas \\
\hline 26 & GNA-ST. SERRINHA & 30 & Quadrada & Área densa de casas \\
\hline 27 & GNA-ST.UNIVERSITÁRIO & 30 & Quadrada & Área densa de casas \\
\hline 28 & GNA-SUDOESTE & 50 & Quadrada & Área densa de casas \\
\hline 29 & GNA-URIAS MAGALHÃES & 30 & Quadrada & Área densa de casas \\
\hline 30 & GNA-V.CRUZ-ERB & 80 & Quadrada & Área densa de casas \\
\hline 31 & GNA-VILA MUTIRÃO & 30 & Quadrada & Área densa de casas \\
\hline 32 & GNA-VILA NOVA & 35 & Quadrada & Área densa de casas \\
\hline 33 & GNA-VILA PEDROSO & 30 & Quadrada & Área densa de casas \\
\hline 34 & GOIATUBA & 20 & Triangular & Área densa de casas \\
\hline 35 & GUAPO & 80 & Quadrada & Área densa de casas \\
\hline 36 & GUARAI & 40 & Quadrada & Área densa de casas \\
\hline
\end{tabular}




\begin{tabular}{|c|c|c|c|c|}
\hline & LOCALIDADE & Altura & Seção & Localização \\
\hline 37 & GUARAI & 80 & Quadrada & Área densa de casas \\
\hline 38 & IPAMERI & 55 & Quadrada & Área densa de casas \\
\hline 39 & ITABERAI & 42 & Quadrada & Área densa de casas \\
\hline 40 & JATAI & 50 & Quadrada & Área densa de casas \\
\hline 41 & JOVIÂNIA & 70 & Quadrada & Área densa de casas \\
\hline 42 & LEOPOLDO DE BULHÕES & 60 & Quadrada & Área densa de casas \\
\hline 43 & MIRACEMA DO TOC. & 80 & Quadrada & Área densa de casas \\
\hline 44 & MOZARLÂNDIA & 78 & Triangular & Área densa de casas \\
\hline 45 & PALMEIRAS DE GO. & 33 & Quadrada & Área densa de casas \\
\hline 46 & PARAÍSO DO TOC. & 30 & Quadrada & Área densa de casas \\
\hline 47 & PIRACANJUBA & 30 & Quadrada & Área densa de casas \\
\hline 48 & PIRES DO RIO & 60 & Quadrada & Área densa de casas \\
\hline 49 & PORANGATU & 70 & Quadrada & Área densa de casas \\
\hline 50 & PORTO NACIONAL & 54 & Quadrada & Área densa de casas \\
\hline 51 & QUIRINÓPOLIS & 100 & Quadrada & Área densa de casas \\
\hline 52 & SÃO LUÍS M. BELOS & 27 & Quadrada & Área densa de casas \\
\hline 53 & STA. HELENA GO & 45 & Quadrada & Área densa de casas \\
\hline 54 & TOCANTINÓPOLIS & 80 & Quadrada & Área densa de casas \\
\hline 55 & TRINDADE (ERB/CEL) & 50 & Triangular & Área densa de casas \\
\hline 56 & URUÇU & 65 & Quadrada & Área densa de casas \\
\hline 57 & VIANÓPOLIS & 70 & Quadrada & Área densa de casas \\
\hline 58 & ANÁPOLIS & 40 & Quadrada & Centro grandes cidades \\
\hline 59 & ARAGUAINA & 32 & Quadrada & Centro grandes cidades \\
\hline 60 & BARRA DO GARÇAS & 27 & Quadrada & Centro grandes cidades \\
\hline 61 & CALDAS NOVAS & 45 & Quadrada & Centro grandes cidades \\
\hline 62 & GNA-CAMPINAS & 36 & Quadrada & Centro grandes cidades \\
\hline 63 & GNA-CENTRO DE CONV. & 40 & Quadrada & Centro grandes cidades \\
\hline 64 & GNA-CEPAL & 40 & Quadrada & Centro grandes cidades \\
\hline 65 & GNA-DQ12 & 30 & Quadrada & Centro grandes cidades \\
\hline 66 & GNA-IU & 20 & Retangular & Centro grandes cidades \\
\hline 67 & GNA-MARISTA & 25 & Quadrada & Centro grandes cidades \\
\hline 68 & GNA-MUTIRAMA & 30 & Quadrada & Centro grandes cidades \\
\hline 69 & GNA-NOVA SUÍÇA & 36 & Quadrada & Centro grandes cidades \\
\hline 70 & GNA-PECUÁRIA & 40 & Quadrada & Centro grandes cidades \\
\hline 71 & GNA-RUA 3 & 24 & Triangular & Centro grandes cidades \\
\hline 72 & GNA-RUA 74 & 30 & Triangular & Centro grandes cidades \\
\hline 73 & GNA-RUA 93 & 25 & Triangular & Centro grandes cidades \\
\hline 74 & GURUPI & 32 & Quadrada & Centro grandes cidades \\
\hline 75 & GURUPI & 78 & Quadrada & Centro grandes cidades \\
\hline 76 & PALMAS & 60 & Quadrada & Centro grandes cidades \\
\hline 77 & RIO VERDE & 40 & Quadrada & Centro grandes cidades \\
\hline 78 & ABADIA DE GOIÁS & 18 & Triangular & Cidade pequena \\
\hline
\end{tabular}




\begin{tabular}{|c|c|c|c|c|}
\hline & LOCALIDADE & Altura & Seção & Localização \\
\hline 79 & ALEXÂNIA & 50 & Quadrada & Cidade pequena \\
\hline 80 & ALVORADA DO TOC. & 50 & Quadrada & Cidade pequena \\
\hline 81 & ANHANGUERA & 50 & Quadrada & Cidade pequena \\
\hline 82 & ARACU & 30 & Quadrada & Cidade pequena \\
\hline 83 & ARAGARÇAS & 30 & Quadrada & Cidade pequena \\
\hline 84 & ARAGOIÂNIA & 30 & Quadrada & Cidade pequena \\
\hline 85 & ARUANA & 40 & Quadrada & Cidade pequena \\
\hline 86 & AUGUSTINÓPOLIS & 50 & Quadrada & Cidade pequena \\
\hline 87 & AURILÂNDIA & 40 & Quadrada & Cidade pequena \\
\hline 88 & AXIXA DO TOCANTINS & 33 & Quadrada & Cidade pequena \\
\hline 89 & BARRO ALTO & & Quadrada & Cidade pequena \\
\hline 90 & BRITÂNIA & 55 & Quadrada & Cidade pequena \\
\hline 91 & $\mathrm{CAÇU}$ & 40 & Quadrada & Cidade pequena \\
\hline 92 & CAMPINORTE & 45 & Quadrada & Cidade pequena \\
\hline 93 & CARMO DO RIO VERDE & 20 & Quadrada & Cidade pequena \\
\hline 94 & CRISTALÂNDIA & 40 & Quadrada & Cidade pequena \\
\hline 95 & CROMÍNIA & 30 & Quadrada & Cidade pequena \\
\hline 96 & CUMARI & 45 & Quadrada & Cidade pequena \\
\hline 97 & FAZENDA NOVA & 30 & Quadrada & Cidade pequena \\
\hline 98 & GOIANÁPOLIS & 50 & Quadrada & Cidade pequena \\
\hline 99 & GOIANDIRA & 33 & Triangular & Cidade pequena \\
\hline 100 & GOIATINS & 65 & Quadrada & Cidade pequena \\
\hline 101 & ITAJÁ & 20 & Quadrada & Cidade pequena \\
\hline 102 & ITARUMA & 42 & Quadrada & Cidade pequena \\
\hline 103 & MARA ROSA & 30 & Quadrada & Cidade pequena \\
\hline 104 & MAURILÂNDIA (GO) & 80 & Quadrada & Cidade pequena \\
\hline 105 & MONTE DO CARMO & 60 & Quadrada & Cidade pequena \\
\hline 106 & MOSSÂMEDES & 40 & Quadrada & Cidade pequena \\
\hline 107 & MUNDO NOVO & 50 & Quadrada & Cidade pequena \\
\hline 108 & NAZARIO & 30 & Quadrada & Cidade pequena \\
\hline 109 & NOVA VENEZA & 40 & Quadrada & Cidade pequena \\
\hline 110 & NOVO BRASIL & 30 & Quadrada & Cidade pequena \\
\hline 111 & ORIZONA & 50 & Quadrada & Cidade pequena \\
\hline 112 & PALESTINA & 50 & Triangular & Cidade pequena \\
\hline 113 & PALMINÓPOLIS & 30 & Quadrada & Cidade pequena \\
\hline 114 & PETROLINA DE GOIÁS & 30 & Triangular & Cidade pequena \\
\hline 115 & PONTALINA & 42 & Quadrada & Cidade pequena \\
\hline 116 & PROFESSOR JAMIL & 50 & Quadrada & Cidade pequena \\
\hline 117 & RIO QUENTE & 60 & Quadrada & Cidade pequena \\
\hline 118 & SANCLERLÂNDIA & 30 & Quadrada & Cidade pequena \\
\hline 119 & SÃO GERALDO DO ARAG. & 30 & Quadrada & Cidade pequena \\
\hline 120 & SENADOR CANEDO & 30 & Quadrada & Cidade pequena \\
\hline
\end{tabular}




\begin{tabular}{|c|c|c|c|c|}
\hline & LOCALIDADE & Altura & Seção & Localização \\
\hline 121 & SENADOR CANEDO & 60 & Quadrada & Cidade pequena \\
\hline 122 & STA. BARBARA DE GO. & 30 & Triangular & Cidade pequena \\
\hline 123 & STA. RITA ARAGUAIA & 40 & Quadrada & Cidade pequena \\
\hline 124 & STA. TEREZINHA GOIÁS & 30 & Quadrada & Cidade pequena \\
\hline 125 & STO. ANTÔNIO BARRA & 42 & Quadrada & Cidade pequena \\
\hline 126 & TURVELÂNDIA & 42 & Quadrada & Cidade pequena \\
\hline 127 & GOIÂNIA RD & 70 & Quadrada & Cidade peq. - Morro \\
\hline 128 & ANÁPOLIS DAIA & 80 & Triangular & Casas esparças-suburb. \\
\hline 129 & ARAGUAINA ERB & 80 & Quadrada & Casas esparças-suburb. \\
\hline 130 & BR-153 - ERB & 100 & Quadrada & Casas esparças-suburb \\
\hline 131 & BURITI ALEGRE REP & 42 & Quadrada & Casas esparças-suburb \\
\hline 132 & CATALÃO RD & 80 & Quadrada & Casas esparças-suburb \\
\hline 133 & GNA-BAIRRO GOYA & 30 & Quadrada & Casas esparças-suburb. \\
\hline 134 & MINEIROS RD & 35 & Quadrada & Casas esparças-suburb \\
\hline 135 & MORRINHOS RD & 90 & Quadrada & Casas esparças-suburb \\
\hline 136 & PIRACANJUBA-ERB & 50 & Quadrada & Casas esparças-suburb \\
\hline 137 & STA. HELENA GO. ERB & 25 & Quadrada & Casas esparças-suburb \\
\hline 138 & GURUPI RD & 25 & Quadrada & Zona rural \\
\hline 139 & HIDROLÂNDIA -ERB & 50 & Quadrada & Zona rural \\
\hline 140 & MONTIVIDIU (RVD) RD & 100 & Quadrada & Zona rural \\
\hline 141 & NERÓPOLIS - ERB & 80 & Quadrada & Zona rural \\
\hline 142 & P.FISCAL B. VALADARES & 33 & Quadrada & Zona rural \\
\hline 143 & P.FISCAL E.SOARES & 33 & Triangular & Zona rural \\
\hline 144 & P.FISCAL J.PINHEIROS & 33 & Quadrada & Zona rural \\
\hline 145 & BR-01 -ERB & 80 & Triangular & Zona rural \\
\hline 146 & BR-02 -ERB & 100 & Quadrada & Zona rural \\
\hline 147 & EMBRAPA & 18 & Triangular & Zona rural \\
\hline 148 & CAMPO ALEGRE -ERB & 80 & Quadrada & Zona rural \\
\hline 149 & ITAJÁ RD & 100 & Quadrada & Zona rural \\
\hline 150 & ORIZONA -ERB & 50 & Quadrada & Zona rural \\
\hline 151 & BR-03 -ERB & 70 & Triangular & Zona rural - Morro \\
\hline 152 & BR-04 -ERB & 70 & Triangular & Zona rural - Morro \\
\hline 153 & CACHOEIRA ALTA RD & 50 & Quadrada & Zona rural - Morro \\
\hline 154 & CAIAPÔNIA RD & 36 & Quadrada & Zona rural - Morro \\
\hline 155 & CALDAS NOVAS RD & 45 & Quadrada & Zona rural - Morro \\
\hline 156 & CAMPINAÇU REP & 60 & Triangular & Zona rural - Morro \\
\hline 157 & CORUMBAIBA RD & 54 & Quadrada & Zona rural - Morro \\
\hline 158 & IPAMERI RD & 90 & Quadrada & Zona rural - Morro \\
\hline 159 & ITARUMA REP & 50 & Quadrada & Zona rural - Morro \\
\hline 160 & JARAGUA RD & 32 & Quadrada & Zona rural - Morro \\
\hline 161 & MARINÁPOLIS-ERB & 70 & Triangular & Zona rural - Morro \\
\hline 162 & PARAÍSO DO TOC. RD & 35 & Quadrada & Zona rural - Morro \\
\hline
\end{tabular}




\begin{tabular}{|r|r|r|r|r|}
\hline & LOCALIDADE & Altura & Seção & Localização \\
\hline 163 & PILAR DE GOIÁS REP & 54 & Quadrada & Zona rural - Morro \\
\hline 164 & PORTO NACIONAL RD & 32 & Quadrada & Zona rural - Morro \\
\hline 165 & SÃO LUÍS M.BELOS RD & 42 & Quadrada & Zona rural - Morro \\
\hline 166 & SERRANOPOLIS-ERB & 100 & Quadrada & Zona rural - Morro \\
\hline 167 & STA. TERESA DE GO. RD & 50 & Triangular & Zona rural - Morro \\
\hline 168 & TRÊS RANCHOS REP. & 30 & Quadrada & Zona rural - Morro \\
\hline 169 & XAMBIOA RD & 30 & Quadrada & Zona rural - Morro \\
\hline
\end{tabular}

Fonte: Telegoias 


\section{ANEXO B - TABELAS DE DIMENSIONAMENTO DOS PERFIS DA TORRE}

As equações e os símbolos utilizados nas tabelas B1 a B3 estão especificados a seguir (NBR8800/86):

$\mathrm{f}_{\mathrm{y}}$ é a tensão de escoamento do aço $\left(\mathrm{f}_{\mathrm{y}}=25 \mathrm{kN} / \mathrm{cm}^{2}\right)$

$\mathrm{E}$ - módulo de elasticidade do material $\left(\mathrm{E}=20500 \mathrm{kN} / \mathrm{cm}^{2}\right)$

L - comprimento da barra

B - largura da cantoneira

$\mathrm{t}$ - espessura da cantoneira

A - área da seção transversal da cantoneira

$r$ - raio de giração mínimo da cantoneira $r=\sqrt{\frac{I_{\min }}{A}}$

$\mathrm{I}_{\min }$-momento de inércia mínimo

$\mathrm{k}$ - Parâmetro de flambagem

$\lambda=\mathrm{k} \frac{\mathrm{L}}{\mathrm{r}}-$ índice de esbeltez

$\mathrm{Q}_{\mathrm{s}}=1.34-0.77 \frac{\mathrm{b}}{\mathrm{t}} \sqrt{\frac{\mathrm{f}_{\mathrm{y}}}{\mathrm{E}}}$ - coeficiente que leva em conta a flambagem local dos elementos não enrijecidos

$$
\rho=1
$$

para $0 \leq \lambda<0.2$

$\rho=\beta-\sqrt{\beta^{2}-\frac{1}{\bar{\lambda}^{2}}}$

para $\lambda \geq 0.2$

$\beta=\frac{1}{2 \bar{\lambda}^{2}}\left[1+\alpha \sqrt{\bar{\lambda}^{2}-0.04}+\bar{\lambda}^{2}\right]$, Para cantoneiras, $\alpha=0,384$

$\bar{\lambda}=\frac{1}{\pi} \frac{\mathrm{kL}}{\mathrm{r}} \sqrt{\frac{\mathrm{Qf}_{\mathrm{y}}}{\mathrm{E}}}$ 
Tabela B1 - Verificação das barras principais verticais da torre.

\begin{tabular}{|c|c|c|c|c|c|c|c|c|c|c|c|c|c|c|c|c|c|c|c|c|}
\hline \multirow[b]{2}{*}{ Seção } & \multirow[b]{2}{*}{ Barras } & \multicolumn{2}{|l|}{$\mathrm{Nd}(\mathrm{kN})$} & \multirow[b]{2}{*}{$\mathrm{L}_{\mathrm{x}}$} & \multicolumn{7}{|c|}{ Perfil cantoneira } & \multicolumn{9}{|c|}{ Verificação segundo a NBR 8800/86 } \\
\hline & & Tração & Compr. & & $\mathrm{L}_{\mathrm{y}}$ & b & $\mathrm{t}$ & $\mathrm{A}\left(\mathrm{cm}^{2}\right)$ & $r_{x}$ & $\mathrm{r}_{\mathrm{y}}$ & $\mathrm{r}_{\min }$ & $\mathrm{k}$ & $\lambda$ & $\bar{\lambda}$ & $\beta$ & $\rho$ & $\phi_{\mathrm{c}} \mathrm{Nn}$ & Verif. & $\mathrm{b} / \mathrm{t}$ & $\mathrm{Q}_{\mathrm{s}}$ \\
\hline 17 & $\begin{array}{c}1 \\
7 \\
745 \\
753\end{array}$ & 918 & -953 & 296 & 296 & $\begin{array}{c}152 \\
2 \mathrm{~L}\end{array}$ & 9,5 & 56,2 & 6,05 & 6,55 & 6,05 & 1 & 49 & 0,5176 & 2,708 & 0,797 & $\begin{array}{l}-928,1 \\
1264,5\end{array}$ & $\begin{array}{c}\sim \mathrm{Ok} ! \\
\mathrm{Ok} !\end{array}$ & 16,0 & 0,91 \\
\hline 16 & $\begin{array}{c}15 \\
21 \\
731 \\
739\end{array}$ & 858 & -880 & 296 & 296 & $\begin{array}{c}152 \\
2 \mathrm{~L}\end{array}$ & 9,5 & 56,2 & 6,05 & 6,55 & 6,05 & 1 & 49 & 0,5176 & 2,708 & 0,810 & $\begin{array}{l}-928,1 \\
1264,5\end{array}$ & $\begin{array}{l}\text { Ok! } \\
\text { Ok! }\end{array}$ & 16,0 & 0,91 \\
\hline 15 & $\begin{array}{c}29 \\
35 \\
717 \\
725 \\
\end{array}$ & 798 & -808 & 296 & 296 & $\begin{array}{c}152 \\
2 \mathrm{~L}\end{array}$ & 9,5 & 56,2 & 6,05 & 6,55 & 6,05 & 1 & 49 & 0,5176 & 2,708 & 0,810 & $\begin{array}{l}-928,1 \\
1264,5\end{array}$ & $\begin{array}{l}\text { Ok! } \\
\text { Ok! }\end{array}$ & 16,0 & 0,91 \\
\hline 14 & $\begin{array}{c}43 \\
49 \\
703 \\
711\end{array}$ & 737 & -807 & 296 & 296 & $\begin{array}{c}152 \\
2 \mathrm{~L}\end{array}$ & 9,5 & 56,2 & 6,05 & 6,55 & 6,05 & 1 & 49 & 0,5176 & 2,708 & 0,810 & $\begin{array}{l}-928,1 \\
1264,5\end{array}$ & $\begin{array}{l}\text { Ok! } \\
\text { Ok! }\end{array}$ & 16,0 & 0,91 \\
\hline 13 & $\begin{array}{c}60 \\
71 \\
684 \\
696 \\
\end{array}$ & 715 & -700 & 296 & 296 & $\begin{array}{c}127 \\
2 \mathrm{~L}\end{array}$ & 9,5 & 46,6 & 4,97 & 5,51 & 4,97 & 1 & 60 & 0,6545 & 1,947 & 0,740 & $\begin{array}{l}-758,8 \\
1048,5\end{array}$ & $\begin{array}{l}\text { Ok! } \\
\text { Ok! }\end{array}$ & 13,4 & 0,98 \\
\hline
\end{tabular}


Continuação: Tabela B1 - Verificação das barras principais verticais da torre.

\begin{tabular}{|c|c|c|c|c|c|c|c|c|c|c|c|c|c|c|c|c|c|c|c|c|}
\hline & & \multicolumn{2}{|c|}{$\mathrm{Nd}(\mathrm{kN})$} & & & \multicolumn{6}{|c|}{ Perfil cantoneira } & \multicolumn{9}{|c|}{ Verificação segundo a NBR 8800/86 } \\
\hline Seção & Barras & Tração & Compr. & $\mathrm{L}_{\mathrm{x}}$ & $\mathrm{L}_{\mathrm{y}}$ & $\mathrm{b}$ & $\mathrm{t}$ & $\begin{array}{c}\mathrm{A} \\
\left(\mathrm{cm}^{2}\right)\end{array}$ & $r_{x}$ & $r_{y}$ & $r_{\min }$ & $\mathrm{k}$ & $\lambda$ & $\bar{\lambda}$ & $\beta$ & $\rho$ & $\begin{array}{c}\phi_{\mathrm{c}} \mathrm{Nn} \\
(\mathrm{kN})\end{array}$ & Verif. & $\mathrm{b} / \mathrm{t}$ & $\mathrm{Q}_{\mathrm{s}}$ \\
\hline 12 & $\begin{array}{c}84 \\
99 \\
659 \\
678\end{array}$ & 656 & -734 & 296 & 296 & $\begin{array}{l}127 \\
2 \mathrm{~L}\end{array}$ & 9,5 & 46,6 & 4,97 & 5,51 & 4,97 & 1 & 60 & 0,654 & 1,947 & 0,740 & $\begin{array}{l}-758,8 \\
1048,5\end{array}$ & $\begin{array}{l}\text { Ok! } \\
\text { Ok! }\end{array}$ & 13,4 & 0,98 \\
\hline 11 & $\begin{array}{l}109 \\
122 \\
632 \\
646 \\
\end{array}$ & 561 & -634 & 296 & 296 & $\begin{array}{l}127 \\
2 \mathrm{~L}\end{array}$ & 9,5 & 46,6 & 4,97 & 5,51 & 4,97 & 1 & 60 & 0,654 & 1,947 & 0,740 & \begin{tabular}{|l}
$-758,8$ \\
1048,5
\end{tabular} & $\begin{array}{l}\text { Ok! } \\
\text { Ok! }\end{array}$ & 13,4 & 0,98 \\
\hline 10 & $\begin{array}{l}136 \\
139 \\
615 \\
622 \\
\end{array}$ & 541 & -497 & 296 & 296 & $\begin{array}{l}102 \\
2 \mathrm{~L}\end{array}$ & 9,5 & 36,9 & 3,93 & 4,5 & 3,93 & 1 & 75 & 0,837 & 1,436 & 0,639 & $\begin{array}{c}-530,4 \\
830,3\end{array}$ & $\begin{array}{l}\text { Ok! } \\
\text { Ok! }\end{array}$ & 10,7 & 1,00 \\
\hline 9 & $\begin{array}{l}151 \\
145 \\
603 \\
609\end{array}$ & 485 & -532 & 296 & 296 & $\begin{array}{l}102 \\
2 \mathrm{~L}\end{array}$ & 9,5 & 36,9 & 3,93 & 4,5 & 3,93 & 1 & 75 & 0,837 & 1,436 & 0,639 & $\begin{array}{c}-530,4 \\
830,3\end{array}$ & $\begin{array}{c}\sim \mathrm{Ok} ! \\
\mathrm{Ok} !\end{array}$ & 10,7 & 1,00 \\
\hline 8 & $\begin{array}{l}159 \\
169 \\
585 \\
601 \\
\end{array}$ & 431 & -470 & 296 & 296 & $\begin{array}{l}102 \\
2 \mathrm{~L}\end{array}$ & 9,5 & 36,9 & 3,93 & 4,5 & 3,93 & 1 & 75 & 0,837 & 1,436 & 0,639 & \begin{tabular}{|c|}
$-530,4$ \\
830,3
\end{tabular} & $\begin{array}{l}\text { Ok! } \\
\text { Ok! }\end{array}$ & 10,7 & 1,00 \\
\hline 7 & $\begin{array}{l}179 \\
575 \\
581 \\
183\end{array}$ & 409 & -389 & 296 & 296 & $\begin{array}{l}102 \\
2 \mathrm{~L}\end{array}$ & 7,9 & 31 & 3,98 & 4,47 & 3,98 & 1 & 74 & 0,822 & 1,466 & 0,647 & $\begin{array}{c}-449,8 \\
697,5\end{array}$ & $\begin{array}{l}\text { Ok! } \\
\text { Ok! }\end{array}$ & 12,9 & 0,99 \\
\hline
\end{tabular}


Continuação: Tabela B1 - Verificação das barras principais verticais da torre.

\begin{tabular}{|c|c|c|c|c|c|c|c|c|c|c|c|c|c|c|c|c|c|c|c|c|c|}
\hline & & \multicolumn{2}{|c|}{$\mathrm{Nd}(\mathrm{kN})$} & & & \multicolumn{6}{|c|}{ Perfil cantoneira } & \multicolumn{10}{|c|}{ Verificação segundo a NBR $8800 / 86$} \\
\hline Seção & Barras & Tração & Compr. & $\mathrm{L}_{\mathrm{x}}$ & $\mathrm{L}_{\mathrm{y}}$ & $\mathrm{b}$ & $\mathrm{t}$ & $\mathrm{A}\left(\mathrm{cm}^{2}\right)$ & $r_{x}$ & $\mathrm{r}_{\mathrm{y}}$ & $\mathrm{r}_{\mathrm{mir}}$ & $\mathrm{k}$ & $\lambda$ & & $\overline{\bar{\lambda}}$ & $\beta$ & $\rho$ & $\begin{array}{c}\phi_{\mathrm{c}} \mathrm{Nn} \\
(\mathrm{kN})\end{array}$ & Verif & $\mathrm{b} / \mathrm{t}$ & $\mathrm{Q}_{\mathrm{s}}$ \\
\hline 6 & $\begin{array}{l}214 \\
221 \\
528 \\
543\end{array}$ & 335 & -331 & 296 & 296 & $\begin{array}{c}102 \\
2 \mathrm{~L}\end{array}$ & 6,4 & 25 & 4,01 & 4,4 & 4,0 & 1 & 72 & & 0,782 & 1,556 & 0,670 & $\begin{array}{c}-342,3 \\
562,5\end{array}$ & $\begin{array}{l}\text { Ok! } \\
\text { Ok! }\end{array}$ & 15,9 & 0,91 \\
\hline 5 & $\begin{array}{l}239 \\
263 \\
490 \\
518 \\
\end{array}$ & 282 & -272 & 296 & 296 & $\begin{array}{c}102 \\
2 \mathrm{~L}\end{array}$ & 6,4 & 25 & 4,01 & 4,4 & 4,0 & 1 & 72 & & 0,782 & 1,556 & 0,670 & $\begin{array}{c}-342,3 \\
562,5\end{array}$ & $\begin{array}{l}\text { Ok! } \\
\text { Ok! }\end{array}$ & 15,9 & 0,91 \\
\hline 4 & $\begin{array}{l}274 \\
294 \\
463 \\
485 \\
\end{array}$ & 227 & -211 & 296 & 296 & $\begin{array}{c}102 \\
2 \mathrm{~L}\end{array}$ & 6,4 & 25 & 4,01 & 4,4 & 4,0 & 1 & 72 & & 0,782 & 1,556 & 0,670 & $\begin{array}{c}-342,3 \\
562,5\end{array}$ & $\begin{array}{l}\text { Ok! } \\
\text { Ok! }\end{array}$ & 15,9 & 0,91 \\
\hline 3 & $\begin{array}{l}315 \\
323 \\
414 \\
416 \\
\end{array}$ & 163 & -75 & 196 & 196 & $\begin{array}{c}102 \\
\mathrm{~L}\end{array}$ & 6,4 & 12,51 & 3,17 & $3,1^{\prime}$ & 2 & 1 & 98 & & 1,038 & 1,146 & 0,526 & $\begin{array}{c}-134,3 \\
281,5\end{array}$ & $\begin{array}{l}\text { Ok! } \\
\text { Ok! }\end{array}$ & 15,9 & 0,91 \\
\hline 2 & $\begin{array}{l}327 \\
335 \\
417 \\
419 \\
\end{array}$ & 38 & -74 & 196 & 196 & $\begin{array}{l}76 \\
\mathrm{~L}\end{array}$ & 6,4 & 9,29 & 2,36 & 2,3 & 1,5 & 1 & 13 & & 1,452 & 0,868 & 0,339 & $\begin{array}{l}-71,0 \\
209,0\end{array}$ & $\begin{array}{c}\sim \mathrm{Ok} ! \\
\mathrm{Ok} !\end{array}$ & 11,9 & 1,00 \\
\hline 1 & $\begin{array}{l}308 \\
311 \\
422 \\
420\end{array}$ & 4 & -20 & 196 & 196 & $\begin{array}{c}64 \\
\mathrm{~L}\end{array}$ & 4,8 & 4,57 & 1,96 & 1,9 & 1,2 & $4 \quad 1$ & 15 & & 1,738 & 0,775 & 0,256 & $\begin{array}{l}-25,7 \\
102,8\end{array}$ & $\begin{array}{l}\text { Ok! } \\
\text { Ok! }\end{array}$ & 13,3 & 0,98 \\
\hline
\end{tabular}


Tabela B2 - Verificação das barras diagonais da torre.

\begin{tabular}{|c|c|c|c|c|c|c|c|c|c|c|c|c|c|c|c|c|c|c|}
\hline & & \multicolumn{2}{|c|}{$\mathrm{Nd}(\mathrm{kN})$} & \multicolumn{5}{|c|}{ Perfil cantoneira } & \multicolumn{10}{|c|}{ Verificação segundo a NBR 8800/86 } \\
\hline Seção & Barras & Tração & Compr. & $\mathrm{L}(\mathrm{cm})$ & $\mathrm{b}$ & $\mathrm{t}$ & $\mathrm{A}\left(\mathrm{cm}^{2}\right)$ & $\mathrm{r}(\mathrm{cm})$ & $\mathrm{k}$ & $\lambda$ & $\bar{\lambda}$ & $\beta$ & $\rho$ & $\begin{array}{c}\phi_{\mathrm{c}} \mathrm{Nn} \\
(\mathrm{kN})\end{array}$ & $\mathrm{b} / \mathrm{t}$ & Qs & Verif & $\lambda \leq 200$ \\
\hline 17 & $\begin{array}{cc}2 & 754 \\
4 & 755 \\
10 & 57 \\
11 & 259\end{array}$ & 90 & -88 & 379 & 127 & 9,5 & 23,29 & 2,51 & 1 & 151 & 1,679 & 0,791 & 0,271 & $\begin{array}{c}-138,6 \\
524,0\end{array}$ & 13,4 & 0,98 & $\begin{array}{l}\text { Ok! } \\
\text { Ok! }\end{array}$ & Ok! \\
\hline & $\begin{array}{ll}748 & 486 \\
749 & 695 \\
748 & 749 \\
754 & 755\end{array}$ & $\begin{array}{c}\text { Diagonal } \\
\text { Secundária }\end{array}$ & & 363 & 102 & 6,4 & 12,51 & 2 & 1 & 182 & 2,018 & 0,718 & 0,199 & $\begin{array}{l}-50,8 \\
281,5\end{array}$ & 15,9 & 0,91 & $\begin{array}{l}\text { Ok! } \\
\text { Ok! }\end{array}$ & Ok! \\
\hline 16 & $\begin{array}{cc}76 & 469 \\
272 & 671 \\
79 & 487 \\
289 & 679\end{array}$ & 89 & -79 & 371 & 102 & 9,5 & 18,45 & 2 & 1 & 186 & 2,062 & 0,710 & 0,191 & $\begin{array}{l}-79,4 \\
415,1\end{array}$ & 10,7 & 1,00 & $\begin{array}{l}\text { Ok! } \\
\text { Ok! }\end{array}$ & Ok! \\
\hline & $\begin{array}{cc}16 & 18 \\
24 & 25 \\
734 & 735 \\
740 & 743 \\
\end{array}$ & $\begin{array}{l}\text { Diagonal } \\
\text { Secundária }\end{array}$ & & 354 & 102 & 6,4 & 12,51 & 2 & 1 & 177 & 1,968 & 0,726 & 0,207 & $\begin{array}{l}-53,0 \\
281,5\end{array}$ & 15,9 & 0,91 & $\begin{array}{l}\text { Ok! } \\
\text { Ok! }\end{array}$ & Ok! \\
\hline
\end{tabular}


Continuação - Tabela B2 - Verificação das barras diagonais da torre.

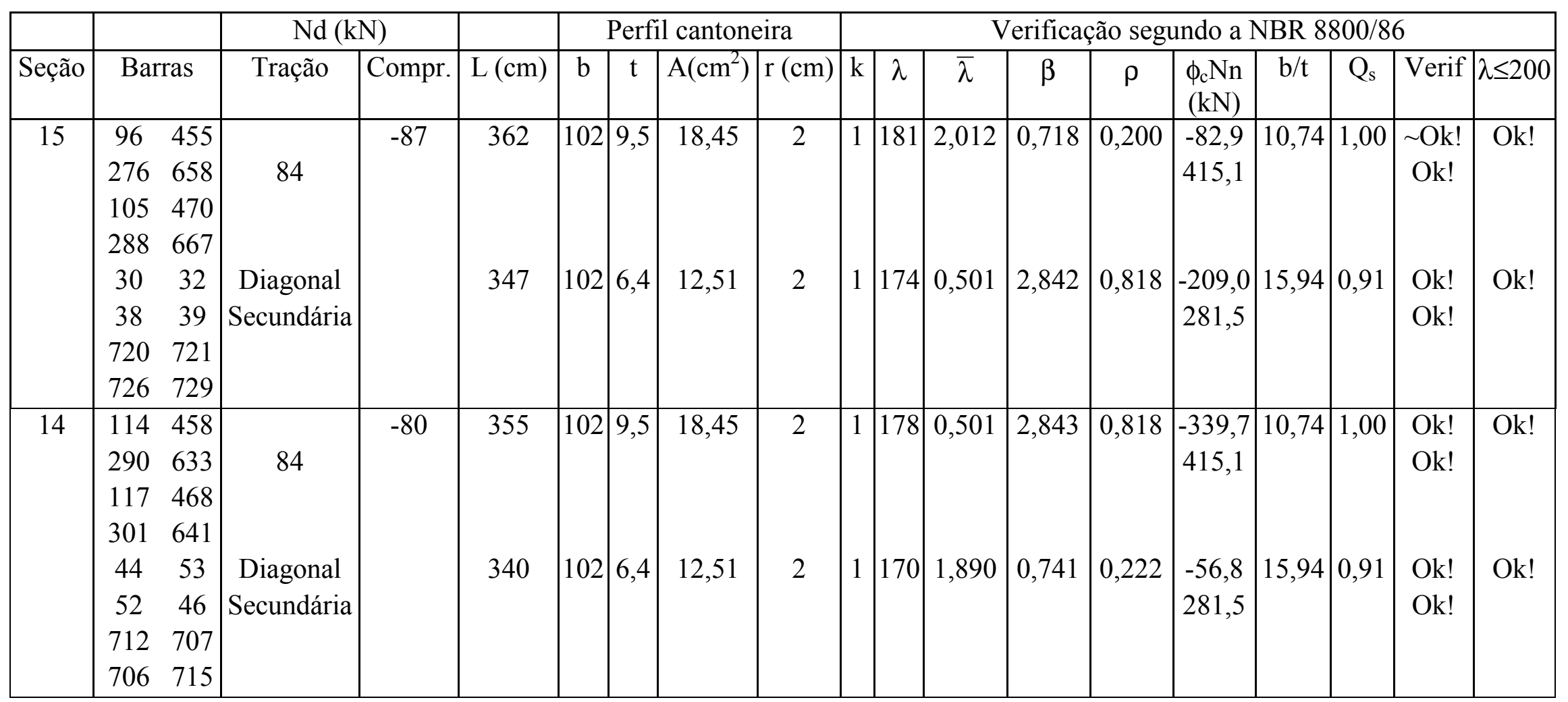


Continuação - Tabela B2 - Verificação das barras diagonais da torre.

\begin{tabular}{|c|c|c|c|c|c|c|c|c|c|c|c|c|c|c|c|c|c|c|}
\hline & & \multicolumn{2}{|c|}{$\mathrm{Nd}(\mathrm{kN})$} & & \multicolumn{4}{|c|}{ Perfil cantoneira } & \multicolumn{10}{|c|}{ Verificação segundo a NBR 8800/86 } \\
\hline Seção & Barras & Tração & Compr. & $\mathrm{L}(\mathrm{cm})$ & $\mathrm{b}$ & $\mathrm{t}$ & $\mathrm{A}\left(\mathrm{cm}^{2}\right)$ & $\mathrm{r}(\mathrm{cm})$ & $\mathrm{k}$ & $\lambda$ & $\bar{\lambda}$ & $\beta$ & $\rho$ & $\begin{array}{c}\phi_{\mathrm{c}} \mathrm{Nn} \\
(\mathrm{kN})\end{array}$ & $\mathrm{b} / \mathrm{t}$ & $\mathrm{Q}_{\mathrm{s}}$ & Verif & $\lambda \leq 200$ \\
\hline 13 & $\begin{array}{cc}186 & 566 \\
202 & 554 \\
196 & 572 \\
210 & 568 \\
61 & 63 \\
74 & 69 \\
698 & 700 \\
687 & 689\end{array}$ & 50 & -52 & 470 & 127 & 9,5 & 23,29 & 2,51 & 1 & 187 & 2,082 & 0,707 & 0,188 & $\begin{array}{l}-96,4 \\
524,0\end{array}$ & 13,37 & 0,98 & $\begin{array}{l}\text { Ok! } \\
\text { Ok! }\end{array}$ & Ok! \\
\hline 12 & $\begin{array}{cc}198 & 538 \\
212 & 541 \\
208 & 556 \\
220 & 550 \\
86 & 88 \\
97 & 101 \\
669 & 668 \\
662 & 664\end{array}$ & 80 & -48 & 448 & 127 & 9,5 & 23,29 & 2,51 & 1 & 178 & 1,984 & 0,723 & 0,205 & $\begin{array}{r}-104,7 \\
524,0\end{array}$ & 13,37 & 0,98 & $\begin{array}{l}\text { Ok! } \\
\text { Ok! }\end{array}$ & Ok! \\
\hline 11 & $235 \quad 540$ & 44 & -45 & 428 & 102 & 6,4 & 12,51 & 2 & 1 & 214 & 2,379 & 0,669 & 0,149 & $\begin{array}{l}-38,0 \\
281,5\end{array}$ & 15,94 & 0,91 & $\begin{array}{c}\sim \mathrm{Ok} ! \\
\mathrm{Ok} !\end{array}$ & $\sim \mathrm{Ok} !$ \\
\hline 10 & $245 \quad 525$ & 41 & -42 & 408 & 102 & 6,4 & 12,51 & 2 & 1 & 204 & 2,268 & 0,682 & 0,162 & $\begin{array}{l}-41,4 \\
281,5\end{array}$ & 15,94 & 0,91 & $\begin{array}{c}\sim \mathrm{Ok} ! \\
\mathrm{Ok} !\end{array}$ & $\sim \mathrm{Ok} !$ \\
\hline
\end{tabular}


Continuação - Tabela B2 - Verificação das barras diagonais da torre.

\begin{tabular}{|c|c|c|c|c|c|c|c|c|c|c|c|c|c|c|c|c|c|c|}
\hline & & \multicolumn{2}{|c|}{$\mathrm{Nd}(\mathrm{kN})$} & & \multicolumn{4}{|c|}{ Perfil cantoneira } & \multicolumn{10}{|c|}{ Verificação segundo a NBR 8800/86 } \\
\hline Seção & Barras & Tração & Compr. & $\mathrm{L}(\mathrm{cm})$ & $\mathrm{b}$ & $\mathrm{t}$ & $\mathrm{A}\left(\mathrm{cm}^{2}\right)$ & $\mathrm{r}(\mathrm{cm})$ & $\mathrm{k}$ & $\lambda$ & $\bar{\lambda}$ & $\beta$ & $\rho$ & $\begin{array}{c}\phi_{\mathrm{c}} \mathrm{Nn} \\
(\mathrm{kN})\end{array}$ & $\mathrm{b} / \mathrm{t}$ & $\mathrm{Q}_{\mathrm{s}}$ & Verif. & $\lambda \leq 200$ \\
\hline 9 & 256509 & 38 & -39 & 390 & 102 & 6,4 & 12,51 & 2 & 1 & 195 & 2,168 & 0,695 & 0,175 & $\begin{array}{l}-44,8 \\
281,5\end{array}$ & 15,94 & 0,91 & $\begin{array}{l}\text { Ok! } \\
\text { Ok! }\end{array}$ & Ok! \\
\hline 8 & 287475 & 35 & -35 & 373 & 102 & 6,4 & 12,51 & 2 & 1 & 187 & 2,073 & 0,709 & 0,190 & \begin{tabular}{|l|}
$-48,4$ \\
281,5
\end{tabular} & 15,94 & 0,91 & $\begin{array}{l}\text { Ok! } \\
\text { Ok! }\end{array}$ & Ok! \\
\hline 7 & $300 \quad 467$ & 33 & -33 & 357 & 102 & 6,4 & 12,51 & 2 & 1 & 179 & 1,984 & 0,723 & $\begin{array}{l}0,205 \\
281,5\end{array}$ & $\begin{array}{c}-52,2 \\
\text { Ok! }\end{array}$ & 15,94 & 0,91 & Ok! & Ok! \\
\hline 6 & 402400 & 41 & -43 & 444 & 127 & 9,5 & 23,29 & 2,51 & 1 & 177 & 1,966 & 0,726 & 0,208 & $\begin{array}{c}-106,4 \\
524,0\end{array}$ & 13,37 & 0,98 & $\begin{array}{l}\text { Ok! } \\
\text { Ok! }\end{array}$ & Ok! \\
\hline 5 & $405 \quad 397$ & 40 & -40 & 404 & 102 & 6,4 & 12,51 & 2 & 1 & 202 & 2,245 & 0,684 & 0,165 & \begin{tabular}{|l|}
$-42,1$ \\
281,5
\end{tabular} & 15,94 & 0,91 & $\begin{array}{l}\text { Ok! } \\
\text { Ok! }\end{array}$ & $\sim \mathrm{Ok} !$ \\
\hline 4 & $407 \quad 376$ & 40 & -43 & 369 & 102 & 6,4 & 12,51 & 2 & 1 & 185 & 2,051 & 0,712 & 0,193 & $\begin{array}{l}-49,3 \\
281,5\end{array}$ & 15,94 & 0,91 & $\begin{array}{l}\text { Ok! } \\
\text { Ok! }\end{array}$ & Ok! \\
\hline 3 & $\begin{array}{ll}378 & 380 \\
382 & \\
\end{array}$ & 44 & -48 & 267 & 76 & 6,4 & 9,29 & 1,5 & 1 & 178 & 1,979 & 0,724 & 0,205 & $\begin{array}{l}-43,7 \\
209,0\end{array}$ & 11,88 & 1,02 & $\begin{array}{c}\sim \mathrm{Ok} ! \\
\text { Ok! }\end{array}$ & Ok! \\
\hline 2 & $\begin{array}{ll}386 & 388 \\
384 & \end{array}$ & 27 & -24 & 267 & 76 & 6,4 & 9,29 & 1,5 & 1 & 178 & 1,979 & 0,724 & 0,205 & $\begin{array}{l}-43,7 \\
209,0\end{array}$ & 11,88 & 1,02 & $\begin{array}{l}\text { Ok! } \\
\text { Ok! }\end{array}$ & Ok! \\
\hline 1 & \begin{tabular}{|ll}
390 & 392 \\
394 & \\
\end{tabular} & 22 & -8 & 267 & 76 & 6,4 & 9,29 & 1,5 & 1 & 178 & 1,979 & 0,724 & 0,205 & $\begin{array}{l}-43,7 \\
209,0\end{array}$ & 11,88 & 1,02 & $\begin{array}{l}\text { Ok! } \\
\text { Ok! }\end{array}$ & Ok! \\
\hline
\end{tabular}


Tabela B3 - Verificação das barras horizontais da torre.

\begin{tabular}{|c|c|c|c|c|c|c|c|c|c|c|c|c|c|c|c|c|}
\hline & & \multicolumn{2}{|c|}{$\mathrm{Nd}(\mathrm{kN})$} & & \multicolumn{4}{|c|}{ Perfil cantoneira } & \multicolumn{8}{|c|}{ Verificação segundo a NBR $8800 / 86$} \\
\hline Seção & Barras & Tração & Compr. & $\mathrm{L}(\mathrm{cm})$ & $\mathrm{b}$ & $\mathrm{t}$ & $\begin{array}{c}\mathrm{A} \\
\left(\mathrm{cm}^{2}\right)\end{array}$ & $\mathrm{r}(\mathrm{cm})$ & $\mathrm{k}$ & $\lambda$ & $\bar{\lambda}$ & $\beta$ & $\rho$ & $\phi_{\mathrm{c}} \mathrm{Nn}(\mathrm{kN})$ & Verif. & $\lambda \leq 200$ \\
\hline 17 & $\begin{array}{cc}157 & 593 \\
166 & 602 \\
3 & 5\end{array}$ & $\begin{array}{c}86 \\
0\end{array}$ & -60 & $\begin{array}{c}447,5 \\
223\end{array}$ & $\begin{array}{l}\text { L127x127 } \\
\text { L64x6464 }\end{array}$ & 9,5 & $\begin{array}{r}23,29 \\
5,8\end{array}$ & $\begin{array}{l}2,51 \\
1,24\end{array}$ & 1 & 180 & $\begin{array}{l}1,982 \\
1,999\end{array}$ & $\begin{array}{l}0,7237 \\
0,7207\end{array}$ & 0,202 & $\begin{array}{r}-107,385 \\
524,025 \\
-26,346 \\
130,500\end{array}$ & $\begin{array}{l}\text { Ok! } \\
\text { Ok! } \\
\text { Ok! } \\
\text { Ok! }\end{array}$ & $\begin{array}{l}\text { Ok! } \\
\text { Ok! }\end{array}$ \\
\hline 16 & $176 \quad 592$ & $\begin{array}{l}45 \\
0,1\end{array}$ & $\begin{array}{l}-58 \\
-0,1\end{array}$ & $\begin{array}{l}420 \\
210\end{array}$ & $\begin{array}{r}\text { L127x } 127 \\
\text { L51x51 }\end{array}$ & $\begin{array}{l}9,5 \\
4,8\end{array}$ & $\begin{array}{r}23,29 \\
4,57\end{array}$ & $\begin{array}{l}2,51 \\
1,02\end{array}$ & 1 & $\begin{array}{l}167 \\
206\end{array}$ & $\begin{array}{l}1,860 \\
2,289\end{array}$ & $\begin{array}{l}0,7471 \\
0,6790\end{array}$ & $\begin{array}{l}0,228 \\
0,159\end{array}$ & $\begin{array}{c}-119,643 \\
524,025 \\
-16,377 \\
102,825\end{array}$ & $\begin{array}{l}\text { Ok! } \\
\text { Ok! } \\
\text { Ok! } \\
\text { Ok! }\end{array}$ & $\begin{array}{l}\text { Ok! } \\
\sim \mathrm{Ok} !\end{array}$ \\
\hline 15 & 184582 & $\begin{array}{l}44 \\
0,1\end{array}$ & $\begin{array}{l}-54 \\
-0,1\end{array}$ & $\begin{array}{l}393 \\
196\end{array}$ & $\begin{array}{r}\text { L127x } 127 \\
\text { L51x51 }\end{array}$ & 4,8 & $\begin{array}{r}23,29 \\
4,57\end{array}$ & $\begin{array}{l}2,51 \\
1,02\end{array}$ & 1 & $\begin{array}{l}157 \\
192\end{array}$ & $\begin{array}{l}1,740 \\
2,136\end{array}$ & $\begin{array}{l}0,7746 \\
0,6991\end{array}$ & $\begin{array}{l}0,255 \\
0,180\end{array}$ & $\begin{array}{c}-133,666 \\
524,025 \\
-18,500 \\
102,825\end{array}$ & $\begin{array}{l}\text { Ok! } \\
\text { Ok! } \\
\text { Ok! } \\
\text { Ok! }\end{array}$ & $\begin{array}{l}\text { Ok! } \\
\text { Ok! }\end{array}$ \\
\hline 14 & $195 \quad 571$ & $\begin{array}{l}38 \\
0,1\end{array}$ & $\begin{array}{l}-48 \\
-0,1\end{array}$ & $\begin{array}{l}365 \\
183\end{array}$ & $\begin{array}{r}\text { L102x } 102 \\
\text { L44x44 }\end{array}$ & 6,4 & $\begin{array}{c}12,51 \\
4\end{array}$ & $\begin{array}{c}2 \\
0,89\end{array}$ & 1 & $\begin{array}{l}183 \\
206\end{array}$ & $\begin{array}{l}2,029 \\
2,286\end{array}$ & $\begin{array}{l}0,7157 \\
0,6794\end{array}$ & $\begin{array}{l}0,197 \\
0,160\end{array}$ & $\begin{array}{c}-55,402 \\
281,475 \\
-14,367 \\
90,000\end{array}$ & $\begin{array}{l}\text { Ok! } \\
\text { Ok! } \\
\text { Ok! } \\
\text { Ok! }\end{array}$ & $\begin{array}{l}\text { Ok! } \\
\sim \mathrm{Ok} !\end{array}$ \\
\hline 13 & 209567 & 37 & -42 & 351 & L102x102 & 6,4 & 12,51 & 2 & 1 & 176 & 1,951 & 0,7293 & 0,211 & $\begin{array}{l}-59,262 \\
281,475\end{array}$ & $\begin{array}{l}\text { Ok! } \\
\text { Ok! }\end{array}$ & Ok! \\
\hline 12 & 219549 & 33 & -38 & 323 & L102x 102 & 6,4 & 12,51 & 2 & 1 & 162 & 1,795 & 0,7614 & 0,242 & $\begin{array}{l}-68,204 \\
281,475\end{array}$ & $\begin{array}{l}\text { Ok! } \\
\text { Ok! }\end{array}$ & Ok! \\
\hline 11 & 232533 & 30 & -35 & 296 & L76x76 & 6,4 & 9,29 & 1,5 & 1 & 197 & 2,194 & 0,6911 & 0,172 & $\begin{array}{l}-35,889 \\
209,025\end{array}$ & $\begin{array}{l}\text { Ok! } \\
\text { Ok! }\end{array}$ & Ok! \\
\hline
\end{tabular}


Continuação: Tabela B3 - Verificação das barras horizontais da torre.

\begin{tabular}{|c|c|c|c|c|c|c|c|c|c|c|c|c|c|c|c|c|}
\hline & & \multicolumn{2}{|c|}{$\mathrm{Nd}(\mathrm{kN})$} & & \multicolumn{4}{|c|}{ Perfil cantoneira } & \multicolumn{8}{|c|}{ Verificação segundo a NBR 8800/86 } \\
\hline Seção & Barras & Tração & Compr. & $\mathrm{L}(\mathrm{cm})$ & $\mathrm{b}$ & $\mathrm{t}$ & $\begin{array}{c}\mathrm{A} \\
\left(\mathrm{cm}^{2}\right) \\
\end{array}$ & $\mathrm{r}(\mathrm{cm})$ & $\mathrm{k}$ & $\lambda$ & $\bar{\lambda}$ & $\beta$ & $\rho$ & $\begin{array}{c}\phi_{\mathrm{c}} \mathrm{Nn} \\
(\mathrm{kN}) \\
\end{array}$ & Verif. & $\lambda<=200$ \\
\hline 10 & $257 \quad 514$ & 28 & -34 & 268 & L76x76 & 6,4 & 9,29 & 1,5 & 1 & 179 & 1,986 & 0,7229 & 0,204 & $\begin{array}{l}-42,678 \\
209,025\end{array}$ & $\begin{array}{l}\text { Ok! } \\
\text { Ok! }\end{array}$ & Ok! \\
\hline 9 & 268496 & 23 & -29 & 241 & L76x76 & 6,4 & 9,29 & 1,5 & 1 & 161 & 1,786 & 0,7636 & 0,244 & $\begin{array}{l}-51,087 \\
209,025 \\
\end{array}$ & $\begin{array}{l}\text { Ok! } \\
\text { Ok! }\end{array}$ & Ok! \\
\hline 8 & $284 \quad 477$ & 20 & -25 & 214 & L76x76 & 6,4 & 9,29 & 1,5 & 1 & 143 & 1,586 & 0,8189 & 0,296 & $\begin{array}{l}-61,959 \\
209,025\end{array}$ & $\begin{array}{l}\text { Ok! } \\
\text { Ok! }\end{array}$ & Ok! \\
\hline 7 & $348 \quad 461$ & 12 & -22 & 186 & L76x76 & 6,4 & 9,29 & 1,5 & 1 & 124 & 1,378 & 0,9010 & 0,367 & $\begin{array}{l}-76,654 \\
209,025\end{array}$ & $\begin{array}{l}\text { Ok! } \\
\text { Ok! }\end{array}$ & Ok! \\
\hline 6 & $\begin{array}{ll}404 & 401 \\
216 & 240 \\
349 & 351\end{array}$ & 1 & -5 & 317,5 & L76x76 & 6,4 & 9,29 & 1,5 & 1 & 212 & 2,353 & 0,6716 & 0,152 & $\begin{array}{l}-31,685 \\
209,025\end{array}$ & $\begin{array}{l}\text { Ok! } \\
\text { Ok! }\end{array}$ & $\sim \mathrm{Ok} !$ \\
\hline 5 & 354398 & 0,2 & $-4,5$ & 262,5 & L76x76 & 6,4 & 9,29 & 1,5 & 1 & 175 & 1,945 & 0,7303 & 0,212 & $\begin{array}{l}-44,224 \\
209,025\end{array}$ & $\begin{array}{l}\text { Ok! } \\
\text { Ok! }\end{array}$ & Ok! \\
\hline 4 & $355 \quad 357$ & 2,6 & $-0,1$ & 207,5 & L76x76 & 6,4 & 9,29 & 1,5 & 1 & 138 & 1,538 & 0,8353 & 0,311 & $\begin{array}{l}-65,029 \\
209,025\end{array}$ & $\begin{array}{l}\text { Ok! } \\
\text { Ok! }\end{array}$ & Ok! \\
\hline 3 & 359363 & 2,3 & $-2,3$ & 180 & L51x51 & 4,8 & 4,58 & 1,02 & 1 & 176 & 1,962 & 0,7273 & 0,209 & $\begin{array}{l}-21,492 \\
103,050\end{array}$ & $\begin{array}{l}\text { Ok! } \\
\text { Ok! }\end{array}$ & Ok! \\
\hline 2 & 365369 & 1,5 & $-8,4$ & 180 & L51x51 & 4,8 & 4,58 & 1,02 & 1 & 176 & 1,962 & 0,7273 & 0,209 & $\begin{array}{l}-21,492 \\
103,050\end{array}$ & $\begin{array}{l}\text { Ok! } \\
\text { Ok! }\end{array}$ & Ok! \\
\hline 1 & 371375 & 2,7 & -4 & 180 & L51x51 & 4,8 & 4,58 & 1,02 & 1 & 176 & 1,962 & 0,7273 & 0,209 & $\begin{array}{l}-21,492 \\
103,050\end{array}$ & $\begin{array}{l}\text { Ok! } \\
\text { Ok! }\end{array}$ & Ok! \\
\hline
\end{tabular}




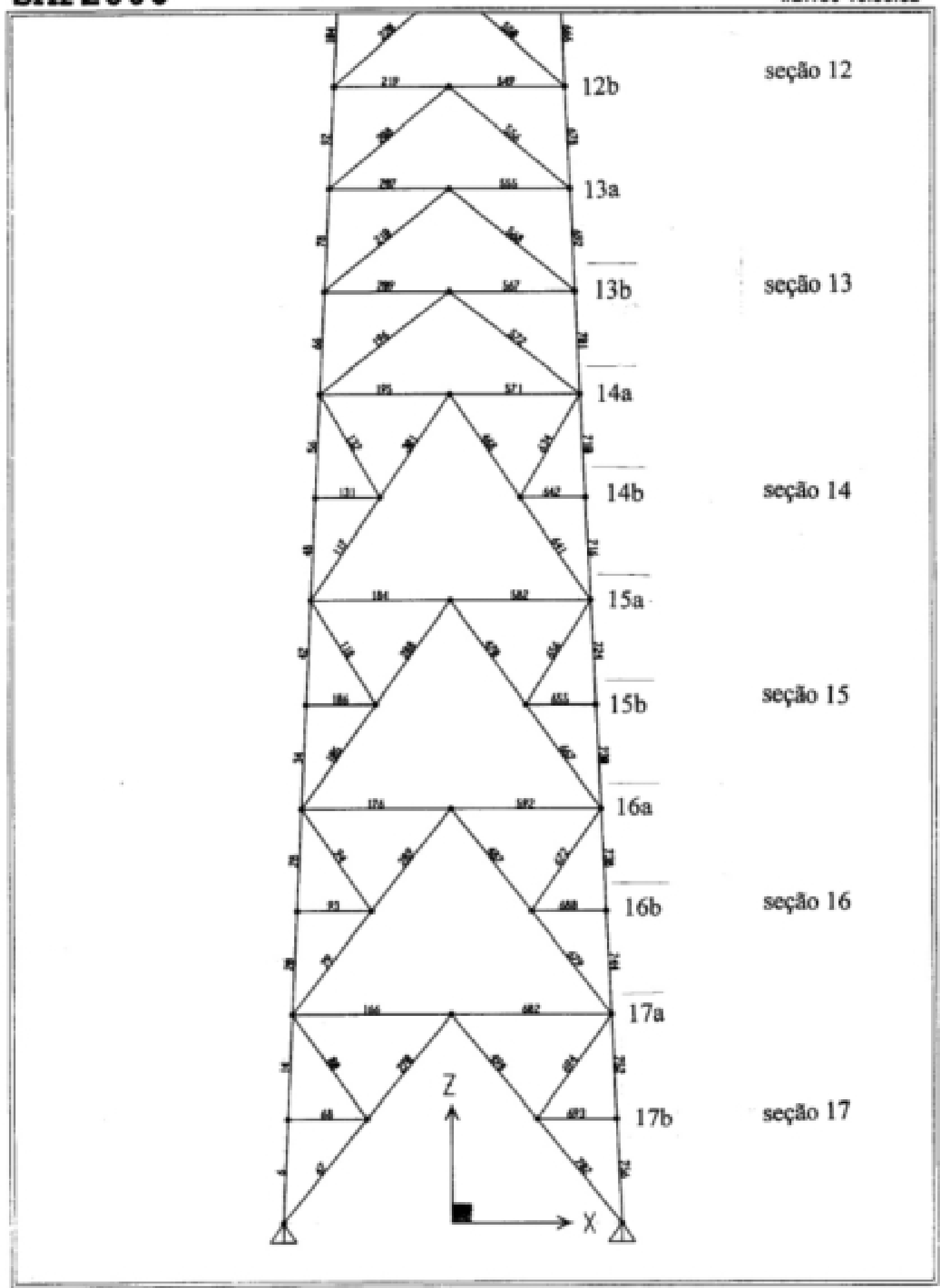

SAP2000 v7.12 - Fle angletower_NBR2 - 3-D View - N-m Units

Figura B01 - Vista da face lateral da torre. Numeração das barras 


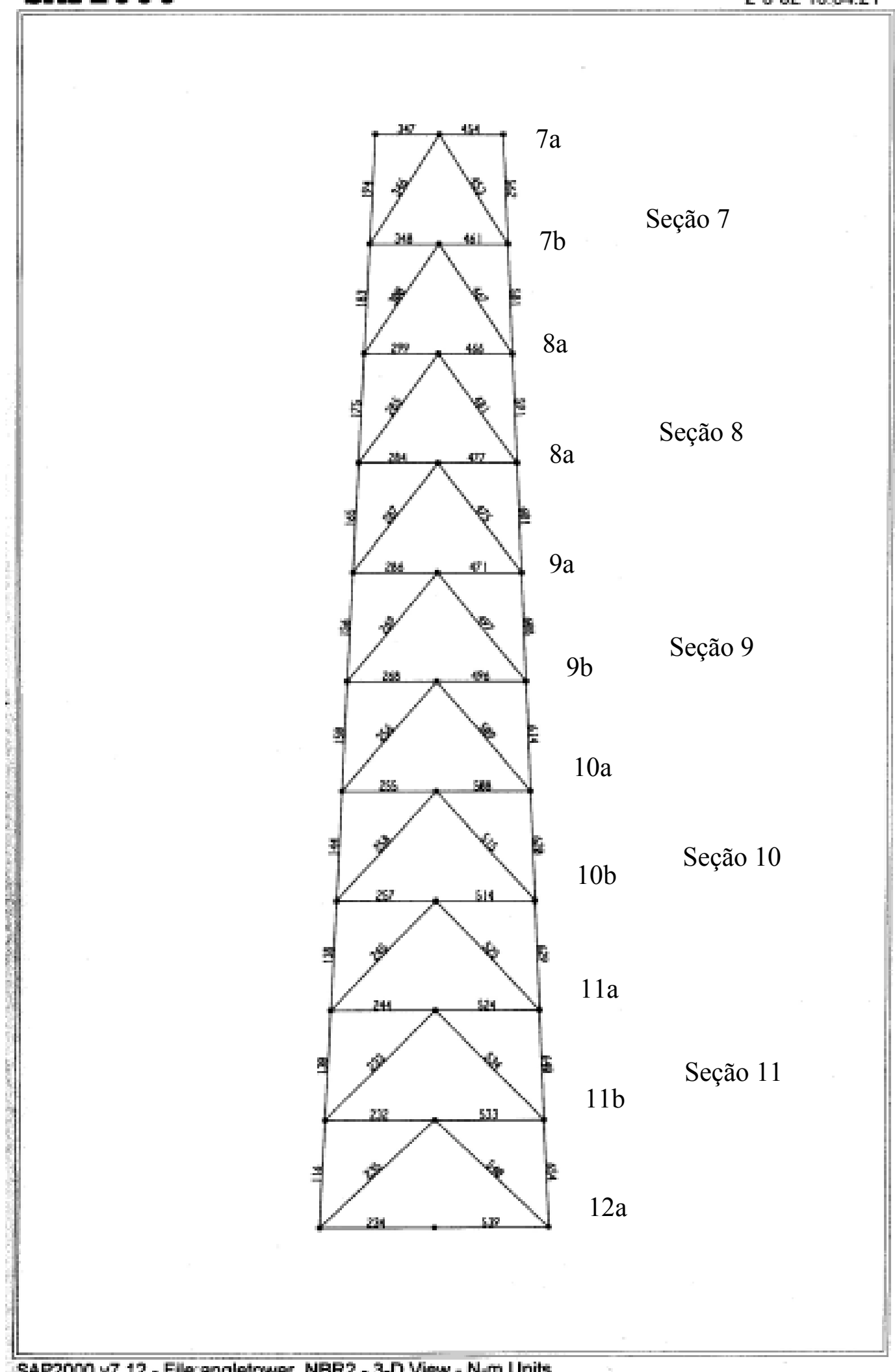

SAP2000 v7.12 - Filecangletower_NBR2 - 3-D View - N-m Units

Continuação - Figura B01 - Vista da face lateral da torre. Numeração das barras 


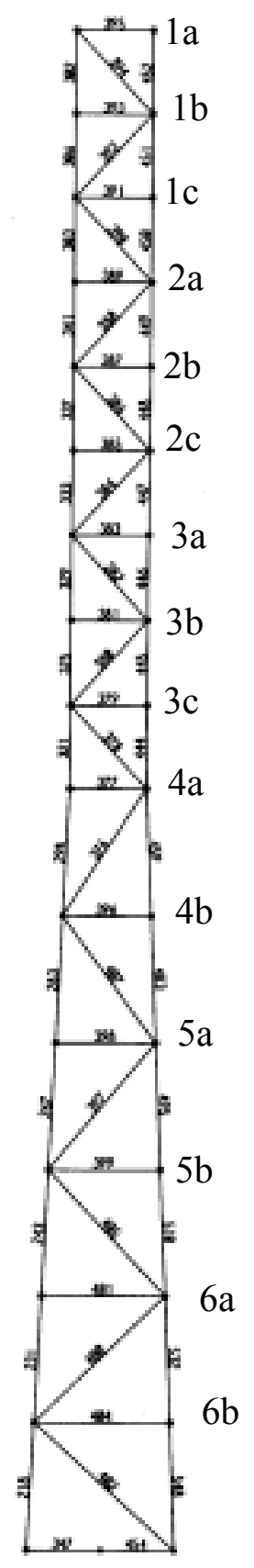

Seção 1

Seção 2

Seção 3

Seção 4

Seção 5

Seção 6

SAP2000 v7.12 - Filecangletower_NBR2 - 3-D View - N-m Units

Continuação - Figura B01 - Vista da face lateral da torre. Numeração das barras 


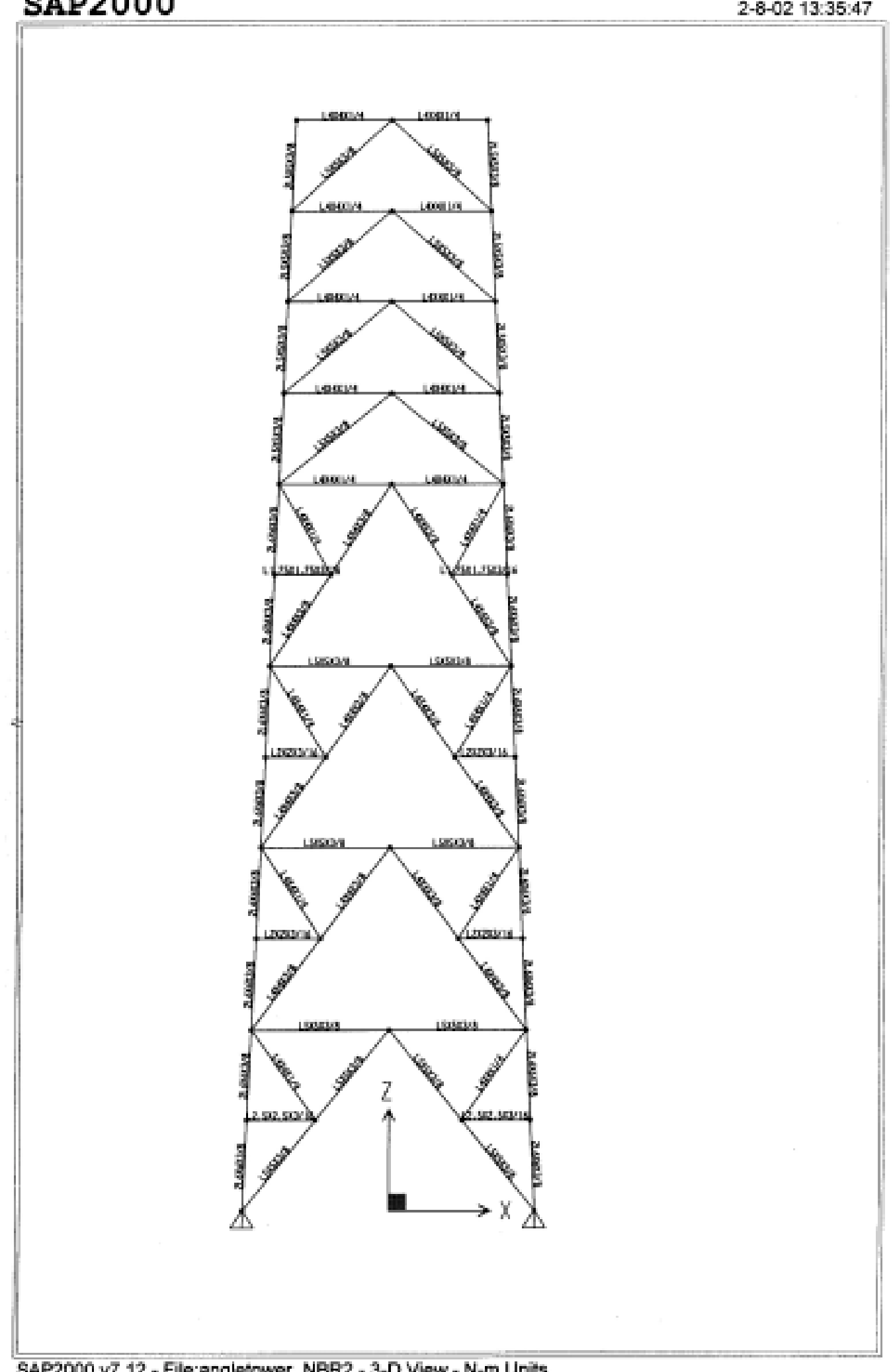

SAP2000 v7.12 - File:angletower_NBR2 - 3-D View - N-m Units

Figura B02 - Vista da face lateral da torre. Perfis adotados 


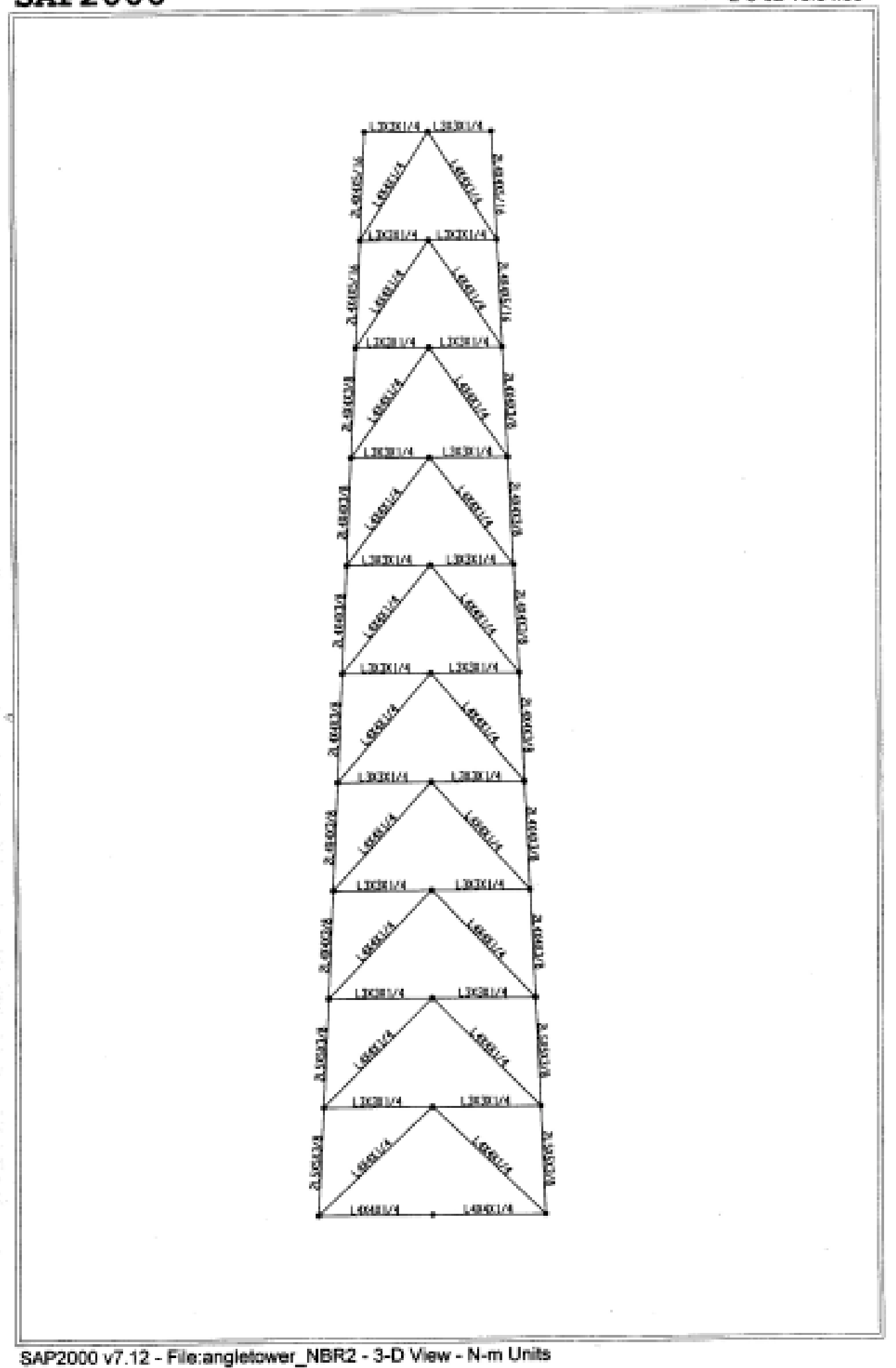

Continuação - Figura B02 - Vista da face lateral da torre. Perfis adotados 


\section{SAP2000}

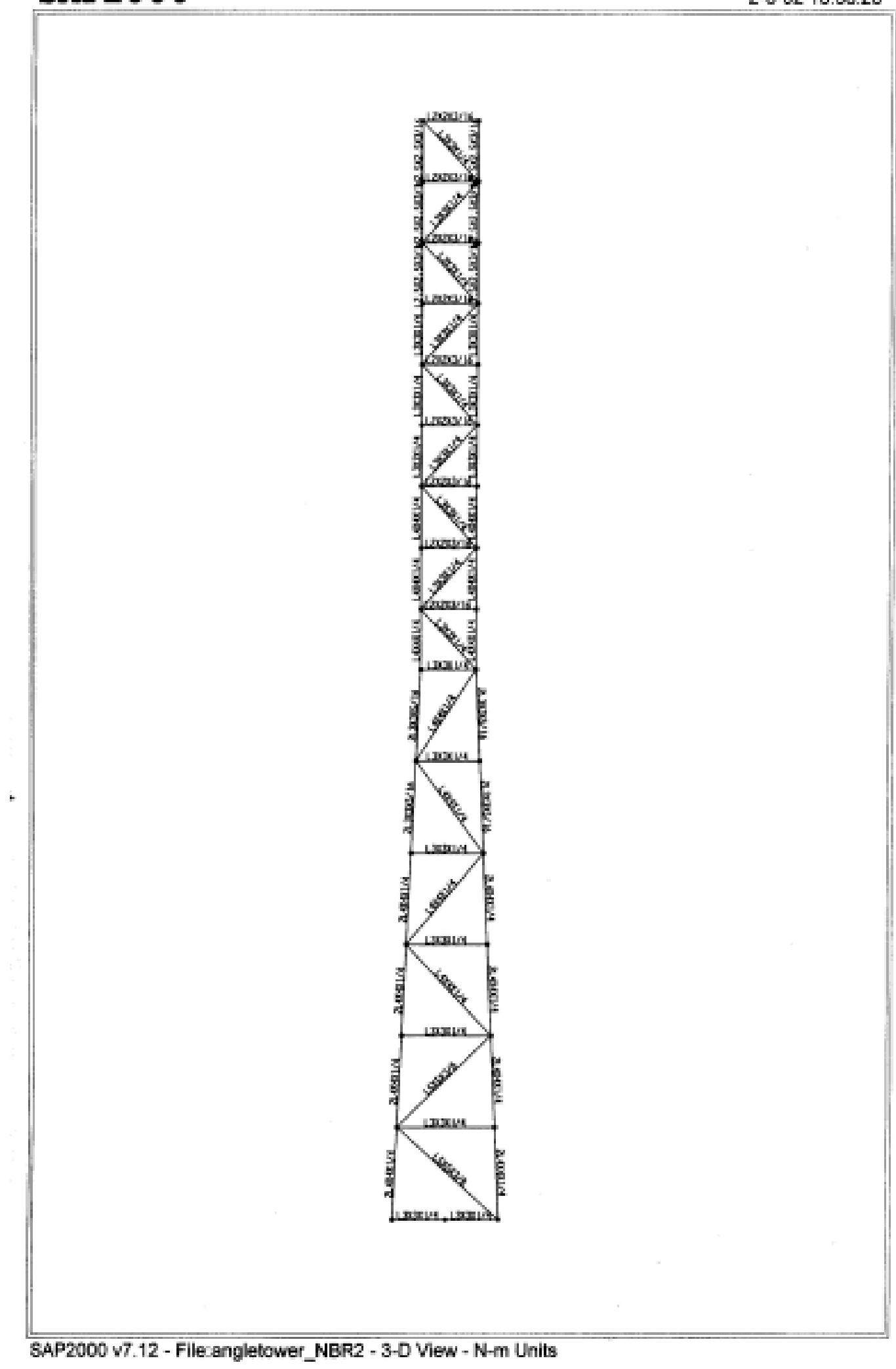

Continuação - Figura B02 - Vista da face lateral da torre. Perfis adotados 


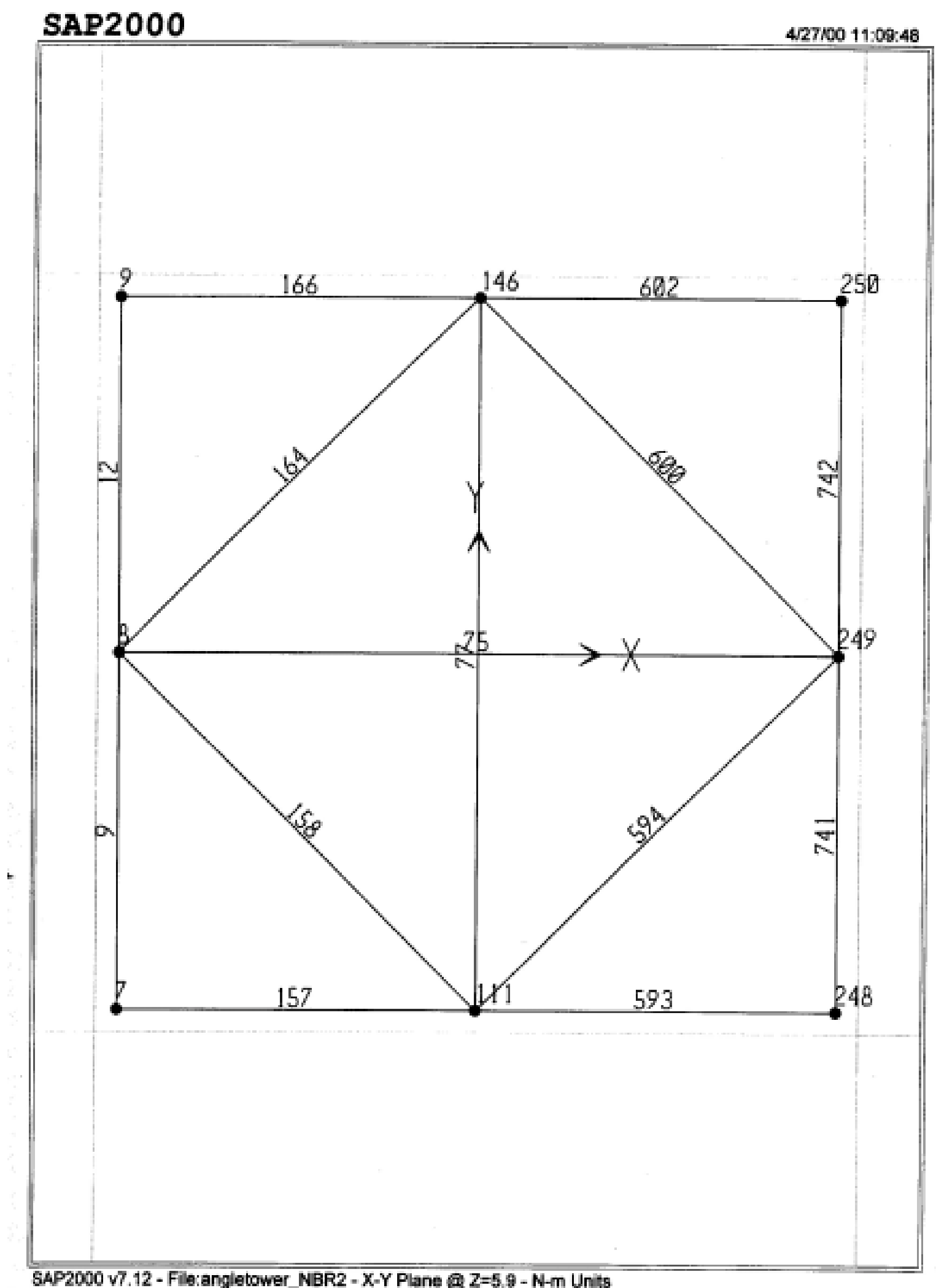

Figura B03 - Travamento horizontal típico. Numeração das barras 


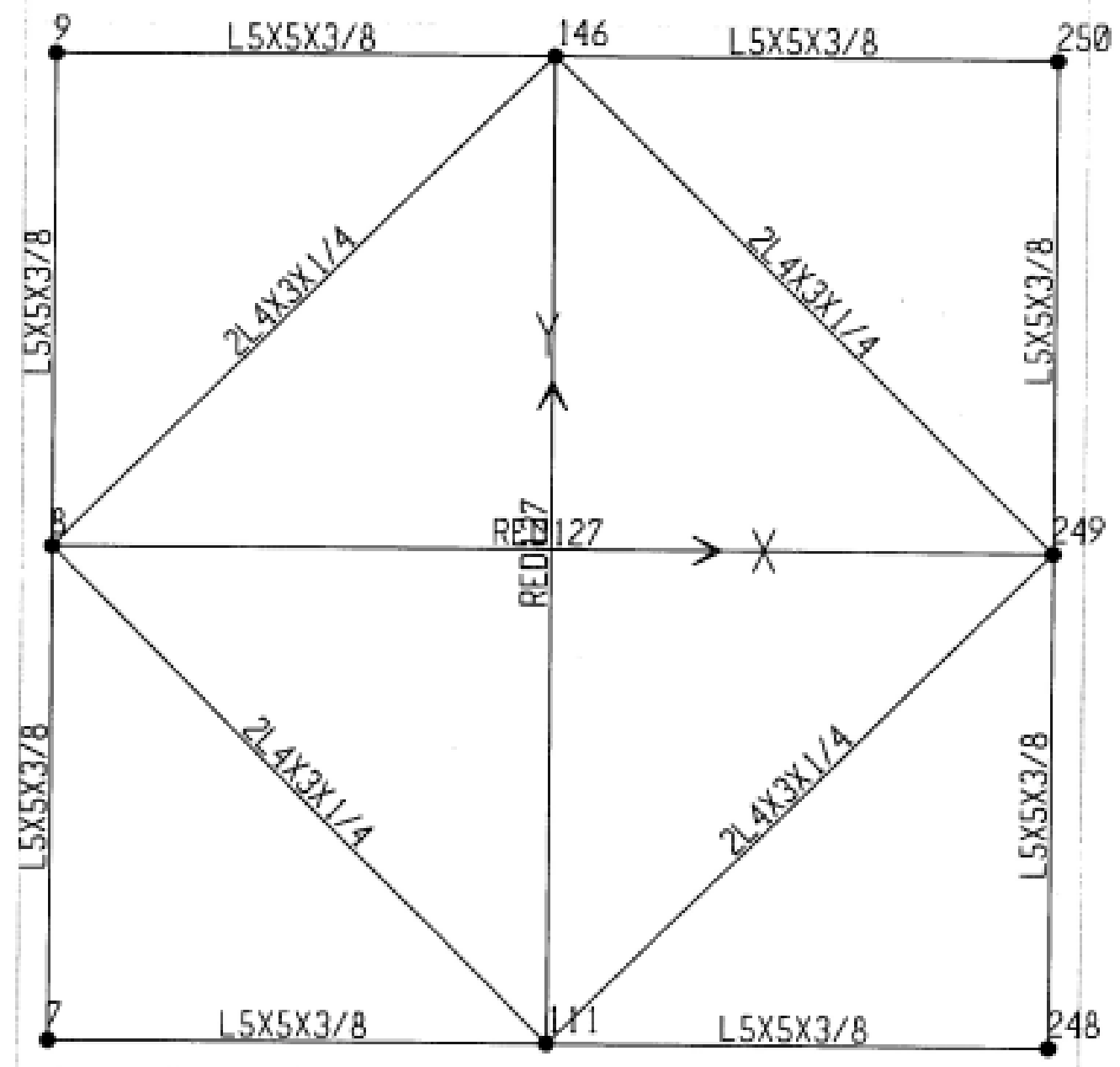

SAP2000 v7.12 - File:angletower_NBR2 - X-Y Plane @ Z Z=5.9 - N-m Units

Figura B03 - Travamento horizontal típico. Perfis adotados 


\section{ANEXO C - RESPOSTA DINÂMICA DA TORRE AO LONGO DO VENTO, MÉTODO DE DAVENPORT.}

\section{C1. Dados da torre}

$\mathrm{z}:=0,0.0294 . .1$

$\mathrm{H}:=100.3 \quad \mathrm{D}_{\mathrm{H}}:=1.8$

$\mathrm{H}_{0}:=\mathrm{H}-17.7$

$\mathrm{H}_{0}=\mathbf{I} \quad \mathrm{D}_{0}:=9.5$

$\theta:=\frac{\mathrm{D}_{0}-\mathrm{D}_{\mathrm{H}}}{\mathrm{D}_{\mathrm{H}}}$
Altitude normalizada pela altura da torre $(\mathrm{z}=\mathrm{Z} / \mathrm{H})$

Altura da torre e largura no topo da torre: ver figura 3.11 pag 36

Altitude e largura da parte onde há mudança na inclinação das barras principais da torre

$$
\phi_{\mathrm{D}}(\mathrm{z}):= \begin{cases}1 \text { if } \frac{\mathrm{H}_{0}}{\mathrm{H}} \leq \mathrm{z} \leq 1 & \begin{array}{l}
\text { Variação da largura da torre ao } \\
\text { longo da altitude. }
\end{array} \\
{\left[1+\left(1-\mathrm{z} \cdot \frac{\mathrm{H}}{\mathrm{H}_{0}}\right) \cdot \theta\right] \text { if } \mathrm{z} \leq \frac{\mathrm{H}_{0}}{\mathrm{H}}} & \end{cases}
$$

$\mathrm{m}_{\mathrm{H}}:=125$

$\Delta:=0.00001408$
Massa por unidade de comprimento no topo da torre.

Deslocamento no topo da torre submetida a uma carga unitária.

$$
\phi_{\mathrm{m}}(\mathrm{z}):=\mid \begin{aligned}
& 5 \text { if } 0.99 \leq \mathrm{z} \leq 1 \\
& 1 \text { if }\left(\frac{\mathrm{H}_{0}}{\mathrm{H}}+0.01\right) \leq \mathrm{z}<0.99 \\
& 5 \text { if }\left(\frac{\mathrm{H}_{0}}{\mathrm{H}}\right) \leq \mathrm{z}<\left(\frac{\mathrm{H}_{0}}{\mathrm{H}}+0.01\right) \\
& {\left[1+\left(1-\mathrm{z} \cdot \frac{\mathrm{H}}{\mathrm{H}_{0}}\right) \cdot \theta\right] \text { if } \mathrm{z}<\frac{\mathrm{H}_{0}}{\mathrm{H}}}
\end{aligned}
$$

Variação da massa ao longo da altitude. 


$$
\delta(z):=\mid \begin{aligned}
& 0.3 \text { if } 1 \geq z>0.98 \\
& 0.15 \text { if } 0.98 \geq z>0.941 \\
& 0.17 \text { if } 0.941 \geq z \geq 0.8824 \\
& 0.2 \text { if } 0.8824 \geq z>0.842 \\
& 0.35 \text { if } 0.842 \geq z>0.824 \\
& 0.23 \text { if } 0.824 \geq z>0.765 \\
& 0.23 \text { if } 0.765 \geq z>0.706 \\
& 0.21 \text { if } 0.706 \geq z>0.647 \\
& 0.2 \text { if } 0.647 \geq z>0.588 \\
& 0.18 \text { if } 0.588 \geq z>0.529 \\
& 0.16 \text { if } 0.529 \geq z>0.471 \\
& 0.15 \text { if } 0.471 \geq z>0.412 \\
& 0.16 \text { if } 0.412 \geq z>0.353 \\
& 0.17 \text { if } 0.353 \geq z>0.294 \\
& 0.16 \text { if } 0.294 \geq z>0.235 \\
& 0.15 \text { if } 0.235 \geq z>0.118 \\
& 0.14 \text { otherwise }
\end{aligned}
$$

Índice de área exposta de uma face da torre ao longo da altitude.

$$
\begin{array}{ll}
\zeta_{S}:=0.007 & \text { Coeficiente de amortecimento estrutural } \\
\beta:=2.656 & \text { Coeficiente do primeiro modo de vivração } \\
\mu(z):=z^{\beta} & \text { Frimeiro modo de vibração } \\
\mathrm{f}_{1}:=0.85 & \text { Frêencia do primeiro modo de vibração }
\end{array}
$$

$$
C_{D}(z):=\mid \begin{array}{ll}
-2.5 \cdot \delta(z)+3.25 \text { if } 1 \geq z>0.98 & \begin{array}{l}
\text { Coeficiente de arrasto ao } \\
\text { longo de } z \text { conforme } \\
-2.5 \cdot \delta(z)+3.25 \text { if } 0.842 \geq z>0.824
\end{array} \\
-4 \cdot \delta(z)+3.7 \text { if } 0.824 \geq z>0.647 & \\
-5 \cdot \delta(z)+3.9 \text { otherwise } &
\end{array}
$$




\section{C2. Dados do vento}

\begin{tabular}{|c|c|c|}
\hline $\mathrm{U}_{\mathrm{H}}:=35 \mathrm{~m} / \mathrm{s}$ & & Vento médio - Categoria III - NBR6123 (1988) \\
\hline$\alpha:=0.20$ & $\phi_{\mathrm{U}}(\mathrm{z}):=\mathrm{z}^{\alpha}$ & Perfil de velocidade do vento - lei da potência \\
\hline $\mathrm{z}_{0}:=0.3 \quad \mathrm{~m}$ & & Rugosidade - Categoria III - NBR6123 (1988) \\
\hline $\mathrm{I}_{\mathrm{U}}(\alpha):=0.16$ & & $\begin{array}{l}\text { Intensidade de turbulência da velocidade longitudinal do } \\
\text { vento no topo da torre }\end{array}$ \\
\hline $\mathrm{L}_{\mathrm{U}}:=50 \quad \mathrm{~m}$ & & Escala vertical da turbulência longitudinal \\
\hline$C:=8$ & & Coeficiente de decaimento exponencial \\
\hline$\rho:=1.225$ & $\mathrm{~kg} / \mathrm{m}^{3}$ & Densidade do ar \\
\hline $\mathrm{q}_{\mathrm{H}}:=\frac{1}{2} \cdot \rho \cdot \mathrm{U}_{\mathrm{H}}^{2}$ & & Pressão dinâmica de referência \\
\hline
\end{tabular}

\section{C3. Resposta da torre ao longo do vento}

A resposta $\mathrm{r}$ que será considerada é o deslocamento horizontal no topo da torre.
$\mathrm{i}_{\mathrm{r}}(\mathrm{z}):=1$
Linha de influência do cisalhamento na base da torre.
$\mathrm{i}_{\mathrm{r}}(\mathrm{z}):=\mathrm{H} \cdot \mathrm{z}$
Linha de influência do momento fletor na base da torre.
$\mathrm{i}_{\mathrm{r}}(\mathrm{z}):=\Delta \cdot \mathrm{z}^{3.6563}$
Linha de influência do deslocamento horizontal no topo da torre.

\section{C3.1 Resposta média}

$$
\begin{aligned}
& \mathrm{F}_{\text {mean }}(\mathrm{z}):=\mathrm{q}_{\mathrm{H}} \cdot \mathrm{D}_{\mathrm{H}} \cdot \mathrm{H} \cdot \mathrm{C}_{\mathrm{D}}(\mathrm{z}) \cdot \phi_{\mathrm{U}}(\mathrm{z})^{2} \cdot \phi_{\mathrm{D}}(\mathrm{z}) \cdot \delta(\mathrm{z}) \\
& \mathrm{r}_{\text {MEAN }}:=\int_{0}^{1}\left(\mathrm{~F}_{\text {mean }}(\mathrm{z}) \cdot \mathrm{i}_{\mathrm{r}}(\mathrm{z})\right) \mathrm{dz}
\end{aligned}
$$


C3.2 Resposta não ressonante

$$
\begin{array}{ll}
\mathrm{F}_{\mathrm{rms}}(\mathrm{z}):=\mathrm{q}_{\mathrm{H}} \cdot \mathrm{D}_{\mathrm{H}} \cdot \delta(\mathrm{z}) \cdot \mathrm{H} \cdot \mathrm{C}_{\mathrm{D}}(\mathrm{z}) \cdot \phi_{\mathrm{U}}(\mathrm{z}) \cdot \phi_{\mathrm{D}}(\mathrm{z}) \cdot 2 \cdot \mathrm{I}_{\mathrm{U}}(\alpha) & \text { Força rms } \\
\mathrm{G}_{0}:=\left[\int_{0}^{1}\left(\mathrm{~F}_{\mathrm{rms}}(\mathrm{z}) \cdot \mathrm{i}_{\mathrm{r}}(\mathrm{z})\right) \mathrm{dz}\right]^{2} & \mathrm{G}_{\mathrm{inf}}:=\int_{0}^{1}\left(\mathrm{~F}_{\mathrm{rms}}(\mathrm{z})^{2} \cdot \mathrm{i}_{\mathrm{r}}(\mathrm{z})^{2}\right) \mathrm{dz} \\
\mathrm{rms}_{-} \mathrm{r}_{\mathrm{bg}}:=\sqrt{\frac{\mathrm{G}_{0}}{1+\frac{\mathrm{H}}{2 \cdot \mathrm{L}_{\mathrm{U}}} \cdot\left(\frac{\mathrm{G}_{0}}{\mathrm{G}_{\mathrm{inf}}}\right)}} & \text { Resposta rms não ressonante }
\end{array}
$$

\section{C3.3 Resposta ressonante}

$\mathrm{f}:=\mathrm{f}_{1}$

Espectro das forças generalizadas:

$\mathrm{fS}_{\mathrm{GF}}:=\left(\mathrm{q}_{\mathrm{H}} \cdot \mathrm{D}_{\mathrm{H}} \cdot \mathrm{H}\right)^{2} \cdot 4 \cdot \mathrm{I}_{\mathrm{U}}(\alpha)^{2} \cdot \frac{2}{\mathrm{C}} \cdot\left(\frac{\mathrm{U}_{\mathrm{H}}}{\mathrm{f} \cdot \mathrm{H}}\right)^{\frac{5}{3}} 0.045 \cdot \int_{0}^{1}(\mathrm{z})^{\frac{11}{3}}\left(\delta(\mathrm{z}) \mathrm{C}_{\mathrm{D}}(\mathrm{z})\right)^{2} \phi_{\mathrm{D}}(\mathrm{z})^{2} \mu(\mathrm{z})^{2} \mathrm{z}^{-\frac{2}{3}} \mathrm{dz}$

$A(z):=\rho \cdot U_{H} \cdot \delta(z) \cdot D_{H} \cdot C_{D}(z) \cdot \phi_{U}(z) \cdot \phi_{D}(z)$

$\zeta_{\mathrm{a}}:=\frac{\int_{0}^{1}\left(\mathrm{~A}(\mathrm{z}) \cdot \mu(\mathrm{z})^{2}\right) \mathrm{dz}}{4 \cdot \pi \cdot \mathrm{f} \cdot \mathrm{m}_{\mathrm{H}} \cdot \int_{0}^{1}\left(\phi_{\mathrm{m}}(\mathrm{z}) \cdot \mu(\mathrm{z})^{2}\right) \mathrm{dz}} \quad \zeta_{\mathrm{a}}=0.02517 \quad \begin{aligned} & \text { Coeficiente de amorteciment } \\ & \text { aerodinâmico. }\end{aligned}$

Square_r $\mathrm{r}_{\mathrm{RES}}:=\frac{\pi}{4} \cdot \frac{\mathrm{fS}_{\mathrm{GF}}}{\zeta_{\mathrm{S}}+\zeta_{\mathrm{a}}} \cdot \frac{\left(\int_{0}^{1} \phi_{\mathrm{m}}(\mathrm{z}) \cdot \mu(\mathrm{z}) \cdot \mathrm{i}_{\mathrm{r}}(\mathrm{z}) \mathrm{dz}\right)^{2}}{\left(\int_{0}^{1} \phi_{\mathrm{m}}(\mathrm{z}) \cdot \mu(\mathrm{z})^{2} \mathrm{dz}\right)^{2}}$ 


$$
\begin{aligned}
& \mathrm{r}_{\mathrm{RES}}:=\sqrt{\text { Square_} \mathrm{r}_{\text {RES }}} \\
& \mathrm{v}:=\left(\frac{\mathrm{r}_{\mathrm{RES}}}{\left.\sqrt{{\mathrm{rms} \_\mathrm{r}_{\mathrm{bg}}{ }^{2}+\mathrm{r}_{\mathrm{RES}}^{2}}^{2}}\right) \cdot \mathrm{f}} \quad \mathrm{v}=0.327\right. \\
& \mathrm{T}:=3600 \quad \mathrm{~s} \\
& \mathrm{~g}:=\sqrt{2 \cdot \ln (\mathrm{v} \cdot \mathrm{T})}+\frac{0.577}{\sqrt{2 \cdot \ln (\mathrm{v} \cdot \mathrm{T})}} \quad \mathrm{g}=3.914 \quad \text { Fator de pico }
\end{aligned}
$$

C3.4 Resultados finais

$$
\begin{aligned}
& \mathrm{r}_{\text {PEAK }}:=\mathrm{r}_{\text {MEAN }}+\mathrm{g} \cdot \sqrt{\mathrm{rms}_{-} \mathrm{r}_{\mathrm{bg}}{ }^{2}+\mathrm{r}_{\mathrm{RES}}{ }^{2}} \quad \mathrm{r}_{\text {PEAK }}=0.603 \quad \text { Resposta de pico } \\
& \mathrm{r}_{\text {MEAN }}=0.277 \\
& \mathrm{G}:=\frac{\mathrm{r}_{\text {PEAK }}}{\mathrm{r}_{\text {MEAN }}} \quad \mathrm{G}=2.178 \\
& \mathrm{rb}:=\frac{\sqrt{\left(\mathrm{g} \cdot \mathrm{rms} \_\mathrm{r}_{\mathrm{bg}}\right)^{2}}}{\mathrm{r}_{\mathrm{MEAN}}} \quad \mathrm{rb}=1.088 \quad \text { Resposta não ressonate /resposta méd } \\
& \mathrm{rr}:=\frac{\sqrt{\left(\mathrm{g} \cdot \mathrm{r}_{\mathrm{RES}}\right)^{2}}}{\mathrm{r}_{\mathrm{MEAN}}} \\
& \mathrm{C}_{\mathrm{R}}:=\sqrt{1+\frac{\mathrm{r}_{\mathrm{RES}}{ }^{2}}{\left(\mathrm{rms} \__{\mathrm{bg}}\right)^{2}}} \quad \mathrm{C}_{\mathrm{R}}=\mathbf{I} \quad \text { Fator de amplificação dinâmica } \\
& \text { Resposta ressonante / resposta média } \\
& \mathrm{r}_{\mathrm{MEAN}}+\mathrm{g} \cdot \sqrt{{\mathrm{rms} \_\mathrm{rgg}^{2}}^{2}}=\mathbf{I} \\
& \text { Resposta média e resposta não } \\
& \text { ressonante }
\end{aligned}
$$




\section{ANEXO D - VENTO SINTÉTICO MODIFICADO}

\section{D1. Dados do vento}

$\begin{array}{ll}\text { Vo }:=40 & \text { Velocidade característica } \\ \text { Uo }:=0.69 \mathrm{Vo} & \text { Velocidade média sobre } 10 \text { minutos - Categora II da NBR6123/88 }\end{array}$

D2. Espectro da velocidade do vento (Davenport)

$\mathrm{f}:=0.0017,0.0034 . .2 .5 \quad$ freqüência de $0.001 \mathrm{a} 10 \mathrm{~Hz}$

$$
x(f):=\frac{1220 \cdot f}{\text { Uo }} \quad \operatorname{Sr}(f):=4 \cdot \frac{\frac{\left(1+x(f)^{2}\right)^{\frac{4}{3}}}{f}}{2}
$$

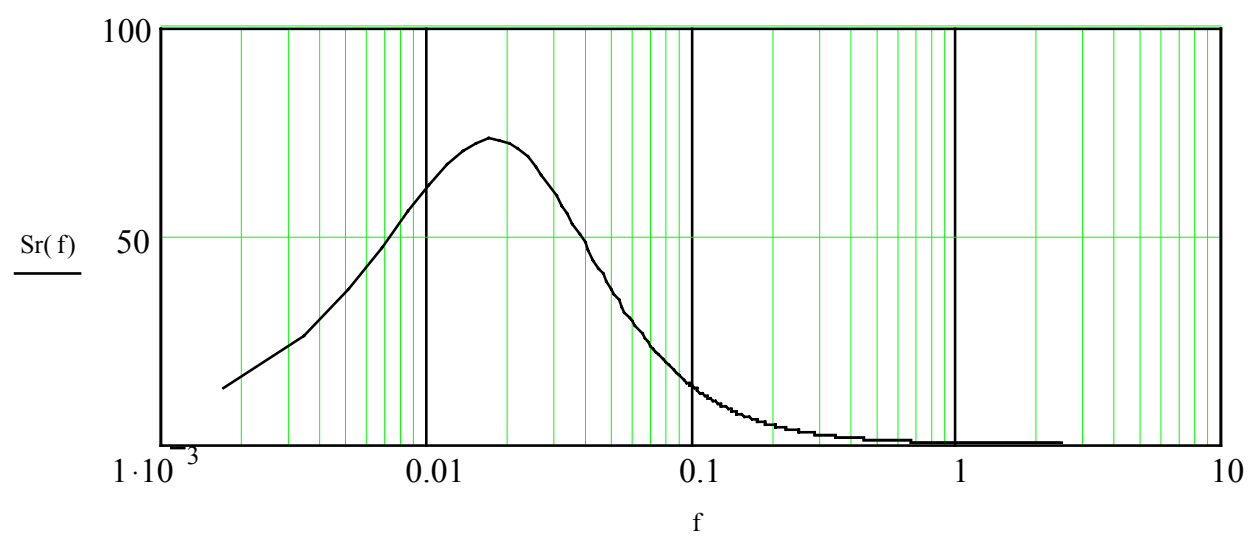

Figura D01- Espectro de potência do vento (Davenport) 


\section{D3. Dados da torre - coeficientes aerodinâmicos}

$\mathrm{r}:=0.85$

Coeficiente de arrasto

$$
\begin{array}{ll}
\mathrm{Ca}_{1}:=2.5 & \mathrm{~A}_{1}:=0.531 \\
\mathrm{Ca}_{2}:=3.15 & \mathrm{~A}_{2}:=0.531 \\
\mathrm{Ca}_{3}:=3.15 & \mathrm{~A}_{3}:=0.531 \\
\mathrm{Ca}_{4}:=3.05 & \mathrm{~A}_{4}:=0.602 \\
\mathrm{Ca}_{5}:=3.05 & \mathrm{~A}_{5}:=0.602 \\
\mathrm{Ca}_{6}:=3.05 & \mathrm{~A}_{6}:=0.602 \\
\mathrm{Ca}_{7}:=2.9 & \mathrm{~A}_{7}:=0.708 \\
\mathrm{Ca}_{8}:=2.9 & \mathrm{~A}_{8}:=0.708 \\
\mathrm{Ca}_{9}:=2.38 & \mathrm{~A}_{9}:=1.239 \\
\mathrm{Ca}_{10}:=2.78 & \mathrm{~A}_{10}:=1.4145 \\
\mathrm{Ca}_{11}:=2.78 & \mathrm{~A}_{11}:=1.4145 \\
\mathrm{Ca}_{12}:=2.78 & \mathrm{~A}_{12}:=1.78 \\
\mathrm{Ca}_{13}:=2.78 & \mathrm{~A}_{13}:=1.78 \\
\mathrm{Ca}_{14}:=2.86 & \mathrm{~A}_{14}:=1.967 \\
\mathrm{Ca}_{15}:=2.86 & \mathrm{~A}_{15}:=1.967 \\
\mathrm{Ca}_{16}:=2.9 & \mathrm{~A}_{16}:=2.2 \\
\mathrm{Ca}_{17}:=2.9 & \mathrm{~A}_{17}:=2.2 \\
\mathrm{Ca}_{18}:=3.02 & \mathrm{~A}_{18}:=2.23 \\
\mathrm{Ca}_{19}:=3.02 & \mathrm{~A}_{19}:=2.23 \\
\mathrm{Ca}_{20}:=3.1 & \mathrm{~A}_{20}:=2.28 \\
&
\end{array}
$$

Área frontal da seção média $\mathrm{A}$ $\left(\mathrm{m}^{2}\right)$
Frequência natural da estrutura

Coeficiente de arrasto

Área frontal da seção média $\mathrm{A}$ $\left(\mathrm{m}^{2}\right)$

$$
\mathrm{Ca}_{21}:=3.1
$$$$
\mathrm{A}_{21}:=2.28
$$$$
\mathrm{Ca}_{22}:=3.15
$$$$
\mathrm{A}_{22}:=2.3775
$$

$\mathrm{Ca}_{23}:=3.15$

$\mathrm{A}_{23}:=2.3775$

$\mathrm{Ca}_{24}:=3.11$

$\mathrm{A}_{24}:=2.765$

$\mathrm{Ca}_{25}:=3.11$

$\mathrm{A}_{25}:=2.765$

$\mathrm{Ca}_{26}:=3.05$

$\mathrm{A}_{26}:=3.247$

$\mathrm{Ca}_{27}:=3.05$

$\mathrm{A}_{27}:=3.247$

$\mathrm{Ca}_{28}:=3.1$

$\mathrm{A}_{28}:=3.341$

$\mathrm{Ca}_{29}:=3.1$

$\mathrm{A}_{29}:=3.341$

$\mathrm{Ca}_{30}:=3.15$

$\mathrm{A}_{30}:=3.353$

$\mathrm{Ca}_{31}:=3.15$

$\mathrm{A}_{31}:=3.353$

$\mathrm{Ca}_{32}:=3.15$

$\mathrm{A}_{32}:=3.59$

$\mathrm{Ca}_{33}:=3.15$

$\mathrm{A}_{33}:=3.59$

$\mathrm{Ca}_{34}:=3.2$

$\mathrm{Ca}_{35}:=3.2$

$\mathrm{A}_{35}:=3.58$

$\mathrm{Ca}_{36}:=3.2$

$\mathrm{A}_{36}:=3.808$

$\mathrm{Ca}_{37}:=3.2$

$\mathrm{A}_{37}:=3.808$ 


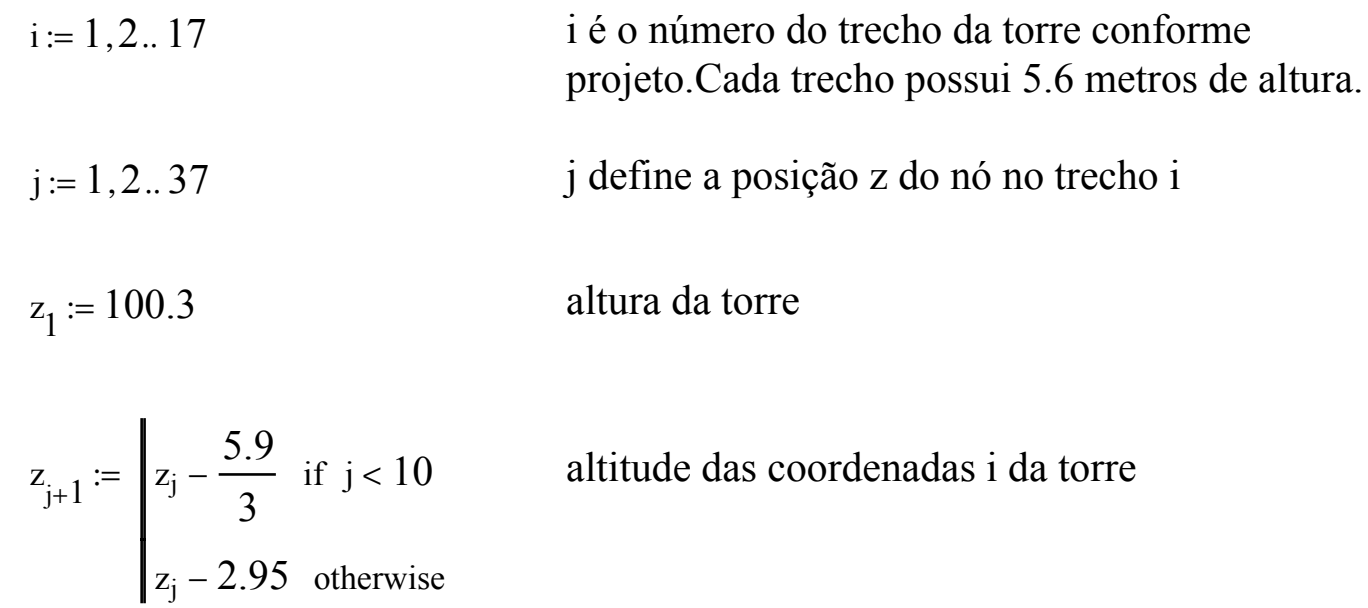

\title{
D4. Decomposição das pressões flutuantes
}

\author{
$\mathrm{k}:=1,2 . .12 \quad$ Adotado 12 harmônicos. \\ $\mathrm{R}:=3 \quad$ Harmônico ressonante.
}

$$
\begin{array}{ll}
\mathrm{f}_{\mathrm{k}}:=\frac{\mathrm{r}}{2^{\mathrm{k}-\mathrm{R}}} \quad \mathrm{T}_{\mathrm{k}}:=\frac{1}{\mathrm{f}_{\mathrm{k}}} \quad \mathrm{fa}_{\mathrm{k}}:=\frac{\mathrm{r}}{2^{(\mathrm{k}-0.5-\mathrm{R})}} \quad \mathrm{fp}_{\mathrm{k}}:=\frac{\mathrm{r}}{2^{(\mathrm{k}+0.5-\mathrm{R})}} \\
\mathrm{C}_{\mathrm{k}}:=\sqrt{2 \cdot \int_{\mathrm{fp}_{\mathrm{k}}}^{\mathrm{f}_{\mathrm{k}}} \operatorname{Sr}(\mathrm{f}) \mathrm{df}} \quad \mathrm{c}_{\mathrm{k}}:=\frac{\mathrm{C}_{\mathrm{k}}}{\sum_{\mathrm{k}} \mathrm{C}_{\mathrm{k}}}
\end{array}
$$

Ângulos de fase gerados pseudo aleatoriamente e adotados como valores característico:

$$
\begin{array}{llllll}
\theta_{1}:=5.417 & \theta_{2}:=4.899 & \theta_{3}:=6.263 & \theta_{4}:=3.842 & \theta_{5}:=1.673 & \theta_{6}:=5.279 \\
\theta_{7}:=2.362 & \theta_{8}:=4.255 & \theta_{9}:=0.055 & \theta_{10}:=1.733 & \theta_{11}:=3.694 & \theta_{12}:=5.263
\end{array}
$$


$t:=0,0.1 . .600$

tempo

$\mathrm{P}(\mathrm{t}, \mathrm{k}):=\cos \left(2 \cdot \frac{\pi}{\mathrm{T}_{\mathrm{R}} \cdot 2^{\mathrm{k}-\mathrm{R}}} \cdot \mathrm{t}-\theta_{\mathrm{k}}\right)$

Harmônicos

$\mathrm{rx}_{\mathrm{k}}:=\frac{\mathrm{T}_{\mathrm{k}}}{\mathrm{T}_{\mathrm{R}}} \quad \mathrm{cc}_{\mathrm{k}}:=\mathrm{c}_{\mathrm{k}} \quad \mathrm{cc}_{\mathrm{R}}:=\frac{\mathrm{c}_{\mathrm{R}}}{2} \quad \quad \mathrm{cc}_{\mathrm{R}-1}:=\mathrm{c}_{\mathrm{R}-1}+\frac{\mathrm{c}_{\mathrm{R}}}{4} \quad \quad \mathrm{cc}_{\mathrm{R}+1}:=\mathrm{c}_{\mathrm{R}+1}+\frac{\mathrm{c}_{\mathrm{R}}}{4}$

$\mathrm{f}_{\mathrm{k}}:=\frac{1}{\mathrm{~T}_{\mathrm{k}}} \quad \sum_{\mathrm{k}} \mathrm{c}_{\mathrm{k}}=1$

$\mathrm{k}=$
\begin{tabular}{|r|} 
\\
\hline 2 \\
\hline 3 \\
\hline 4 \\
\hline 5 \\
\hline 6 \\
\hline 7 \\
\hline 8 \\
\hline 9 \\
\hline 10 \\
\hline 11 \\
\hline 12 \\
\hline
\end{tabular}

$\mathrm{rx}_{\mathrm{k}}=$
\begin{tabular}{|r|}
\hline 0.25 \\
\hline 0.5 \\
\hline 1 \\
\hline 2 \\
\hline 4 \\
\hline 8 \\
\hline 16 \\
\hline 32 \\
\hline 64 \\
\hline 128 \\
\hline 256 \\
\hline 512 \\
\hline
\end{tabular}

$\mathrm{f}_{\mathrm{k}}=$

\begin{tabular}{|r|}
\hline 3.4 \\
\hline 1.7 \\
\hline 0.85 \\
\hline 0.425 \\
\hline 0.213 \\
\hline 0.106 \\
\hline 0.053 \\
\hline 0.027 \\
\hline 0.013 \\
\hline $6.641 \cdot 10^{-3}$ \\
\hline $3.32 \cdot 10^{-3}$ \\
\hline $1.66 \cdot 10^{-3}$ \\
\hline
\end{tabular}

$\frac{\mathrm{c}_{\mathrm{k}}}{\%}=$
\begin{tabular}{|r|}
\hline 4.223 \\
\hline 5.32 \\
\hline 6.701 \\
\hline 8.429 \\
\hline 10.552 \\
\hline 12.969 \\
\hline 14.955 \\
\hline 14.574 \\
\hline 10.844 \\
\hline 6.381 \\
\hline 3.353 \\
\hline 1.699 \\
\hline
\end{tabular}

$\frac{\mathrm{cc}_{\mathrm{k}}}{\%}=$

$\mathrm{T}_{\mathrm{k}}=$

\begin{tabular}{|r|}
\hline 0.294 \\
\hline 0.588 \\
\hline 1.176 \\
\hline 2.353 \\
\hline 4.706 \\
\hline 9.412 \\
\hline 18.824 \\
\hline 37.647 \\
\hline 75.294 \\
\hline 150.588 \\
\hline 301.176 \\
\hline 602.353 \\
\hline
\end{tabular}

\begin{tabular}{|r|}
\hline 4.223 \\
\hline 6.995 \\
\hline 3.35 \\
\hline 10.104 \\
\hline 10.552 \\
\hline 12.969 \\
\hline 14.955 \\
\hline 14.574 \\
\hline 10.844 \\
\hline 6.381 \\
\hline 3.353 \\
\hline 1.699 \\
\hline
\end{tabular}

$\mathrm{Pp}(\mathrm{t}, \mathrm{k}):=\mathrm{P}(\mathrm{t}, \mathrm{k}) \cdot \mathrm{cc}_{\mathrm{k}}$

\section{D5. Correlação espacial}

$$
\begin{aligned}
& \Delta \mathrm{Zo}_{\mathrm{k}}:=\frac{\mathrm{Uo}}{7 \cdot \mathrm{f}_{\mathrm{k}}} \\
& \mathrm{L}_{\mathrm{k}}:=2 \cdot \Delta \mathrm{Zo}_{\mathrm{k}} \\
& \mathrm{Gc}:=100.3-\frac{\mathrm{L}_{\mathrm{R}}}{2}
\end{aligned}
$$

Tamanho da rajada equivalente 
Adotado Gc $:=82.6 \quad$ Posição do centro de rajada

Coeficiente de redução das pressões flutuantes.

$$
\operatorname{Cr}(\mathrm{j}, \mathrm{k}):=\mid \begin{aligned}
& {\left[\frac{1}{\Delta \mathrm{Zo}_{\mathrm{k}}} \cdot\left(\mathrm{Gc}-\mathrm{z}_{\mathrm{j}}\right)+1\right] \text { if } \mathrm{Gc} \leq \mathrm{z}_{\mathrm{j}} \leq \mathrm{Gc}+\Delta \mathrm{Zo}_{\mathrm{k}}} \\
& {\left[\frac{-1}{\Delta \mathrm{Zo}_{\mathrm{k}}} \cdot\left(\mathrm{Gc}-\mathrm{z}_{\mathrm{j}}\right)+1\right] \text { if } \mathrm{Gc}-\Delta \mathrm{Zo}_{\mathrm{k}} \leq \mathrm{z}_{\mathrm{j}} \leq \mathrm{Gc}} \\
& 0 \text { otherwise }
\end{aligned}
$$

D6. Hamônicos de força nos nós da torre

$$
\begin{array}{lll}
\text { categoria III, 600s: } & \mathrm{Vm}_{\mathrm{j}}:=0.5934 \cdot \mathrm{Vo} \cdot\left(\frac{\mathrm{z}_{\mathrm{j}}}{10}\right)^{0.185} & \text { Velocidade média } \\
\text { categoria III, 3s : } & \mathrm{V}_{\mathrm{j}}:=0.94 \cdot \mathrm{Vo} \cdot\left(\frac{\mathrm{z}_{\mathrm{j}}}{10}\right)^{0.1} & \text { Velocidade de pico } \\
\mathrm{q}_{\mathrm{j}}:=0.613 \cdot\left(\mathrm{V}_{\mathrm{j}}\right)^{2} & & \text { Pressão de pico } \\
\mathrm{q}_{\mathrm{est}}:=0.613 \cdot\left(\mathrm{Vm}_{\mathrm{j}}\right)^{2} & \mathrm{~F}_{\mathrm{est}}:=\mathrm{Ca}_{\mathrm{j}} \cdot \mathrm{A}_{\mathrm{j}} \cdot \mathrm{q}_{\mathrm{est}}{ }_{\mathrm{j}} & \text { Carregamento estático } \\
\mathrm{q}_{\mathrm{j}}:=\mathrm{q}_{\mathrm{j}}-\mathrm{q}_{\mathrm{est}} & &
\end{array}
$$$$
\text { Harmônicos k=1 a m (m é o número de harmônicos) } \quad \mathrm{V}_{1}=47.35
$$$$
\mathrm{Q}(\mathrm{t}, \mathrm{j}, \mathrm{k}):=\mathrm{q}_{\mathrm{j}} \cdot \operatorname{Cr}(\mathrm{j}, \mathrm{k}) \cdot \operatorname{Pp}(\mathrm{t}, \mathrm{k})
$$$$
F f(t, j, k):=\mathrm{Ca}_{\mathrm{j}} \cdot \mathrm{A}_{\mathrm{j}} \cdot \mathrm{Q}(\mathrm{t}, \mathrm{j}, \mathrm{k}) \quad \text { Harmônicos flutuantes }
$$$$
\operatorname{Pdin}(\mathrm{t}, \mathrm{j}):=\sum_{\mathrm{k}} \mathrm{Ff}(\mathrm{t}, \mathrm{j}, \mathrm{k})
$$

Série temporal dos harmônicos para car coordenada da torre 


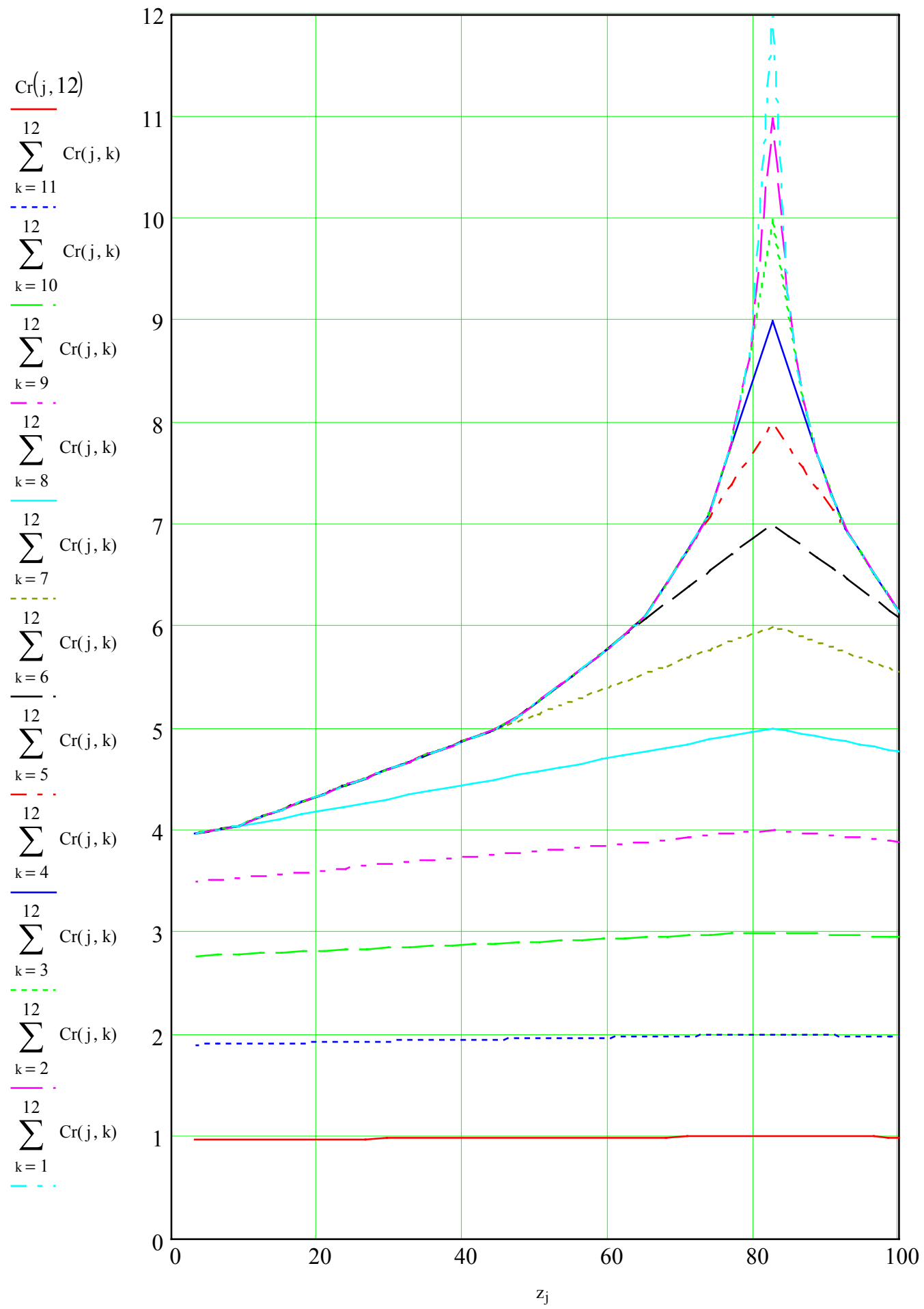

Figura D02. Coeficientes de redução das pressões flutuantes 
D7. Gravação das séries temporais para serem utilizados pelo SAP2000

\begin{tabular}{|c|c|c|}
\hline vento1 := "vento1.dat" & vento2 := "vento2.dat" & vento3 := "vento3.dat" \\
\hline vento4 := "vento4.dat" & vento5 := "vento5.dat" & vento6 := "vento6.dat" \\
\hline vento7 := "vento7.dat" & vento8 := "vento8.dat" & vento9 := "vento9.dat" \\
\hline vento10 := "vento10.dat" & vento11 := "vento11.dat" & vento12 := "vento12.dat" \\
\hline vento13 := "vento13.dat" & vento14 := "vento14.dat" & vento15 := "vento15.dat" \\
\hline vento16 := "vento16.dat" & vento17 := "vento17.dat" & vento18 := "vento18.dat" \\
\hline vento19 := "vento19.dat" & vento20 := "vento20.dat" & vento21 := "vento21.dat" \\
\hline vento22 := "vento22.dat" & vento23 := "vento23.dat" & vento24 := "vento24.dat" \\
\hline vento25:= "vento25.dat" & vento26 := "vento26.dat" & vento27 := "vento27.dat" \\
\hline vento28 := "vento28.dat" & vento29 := "vento29.dat" & vento30 := "vento30.dat" \\
\hline vento31 := "vento31.dat" & vento32 := "vento32.dat" & vento33 := "vento33.dat" \\
\hline vento34 := "vento34.dat" & vento35 := "vento35.dat" & vento36 := "vento36.dat" \\
\hline
\end{tabular}

$1:=1,2 . .6000$

$$
\begin{array}{lll}
\mathrm{P} 1_{1}:=\mathrm{Pdin}\left(\frac{1-1}{10}, 1\right) & \mathrm{P} 2_{1}:=\mathrm{Pdin}\left(\frac{1-1}{10}, 2\right) & \mathrm{P} 3_{1}:=\mathrm{Pdin}\left(\frac{1-1}{10}, 3\right) \\
\mathrm{P} 4_{1}:=\mathrm{Pdin}\left(\frac{1-1}{10}, 4\right) & \mathrm{P} 5_{1}:=\mathrm{Pdin}\left(\frac{1-1}{10}, 5\right) & \mathrm{P} 6_{1}:=\mathrm{Pdin}\left(\frac{1-1}{10}, 6\right) \\
\mathrm{P} 7_{1}:=\mathrm{Pdin}\left(\frac{1-1}{10}, 7\right) & \mathrm{P} 8_{1}:=\mathrm{Pdin}\left(\frac{1-1}{10}, 8\right) & \mathrm{P} 9_{1}:=\mathrm{Pdin}\left(\frac{1-1}{10}, 9\right) \\
\mathrm{P} 10_{1}:=\mathrm{Pdin}\left(\frac{1-1}{10}, 10\right) & \mathrm{P} 11_{1}:=\mathrm{Pdin}\left(\frac{1-1}{10}, 11\right) & \mathrm{P} 12_{1}:=\mathrm{Pdin}\left(\frac{1-1}{10}, 12\right)
\end{array}
$$




$$
\begin{aligned}
& \mathrm{P} 13_{1}:=\operatorname{Pdin}\left(\frac{1-1}{10}, 13\right) \quad \mathrm{P} 14_{1}:=\operatorname{Pdin}\left(\frac{1-1}{10}, 14\right) \quad \mathrm{P} 15_{1}:=\operatorname{Pdin}\left(\frac{1-1}{10}, 15\right) \\
& \mathrm{P} 16_{1}:=\operatorname{Pdin}\left(\frac{1-1}{10}, 16\right) \quad \mathrm{P} 17_{1}:=\operatorname{Pdin}\left(\frac{1-1}{10}, 17\right) \quad \mathrm{P} 18_{1}:=\operatorname{Pdin}\left(\frac{1-1}{10}, 18\right) \\
& \mathrm{P} 19_{1}:=\operatorname{Pdin}\left(\frac{1-1}{10}, 19\right) \quad \mathrm{P} 20_{1}:=\mathrm{P} \operatorname{din}\left(\frac{1-1}{10}, 20\right) \quad \mathrm{P} 21_{1}:=\operatorname{Pdin}\left(\frac{1-1}{10}, 21\right) \\
& \mathrm{P} 22_{1}:=\operatorname{Pdin}\left(\frac{1-1}{10}, 22\right) \quad \mathrm{P} 23_{1}:=\operatorname{Pdin}\left(\frac{1-1}{10}, 23\right) \quad \mathrm{P} 24_{1}:=\operatorname{Pdin}\left(\frac{1-1}{10}, 24\right) \\
& \mathrm{P} 25_{1}:=\operatorname{Pdin}\left(\frac{1-1}{10}, 25\right) \quad \mathrm{P} 26_{1}:=\operatorname{Pdin}\left(\frac{1-1}{10}, 26\right) \quad \mathrm{P} 27_{1}:=\operatorname{Pdin}\left(\frac{1-1}{10}, 27\right) \\
& \mathrm{P} 28_{1}:=\mathrm{Pdin}\left(\frac{1-1}{10}, 28\right) \quad \mathrm{P} 29_{1}:=\mathrm{P} \operatorname{din}\left(\frac{1-1}{10}, 29\right) \quad \mathrm{P} 30_{1}:=\mathrm{P} \operatorname{din}\left(\frac{1-1}{10}, 30\right) \\
& \mathrm{P} 31_{1}:=\operatorname{Pdin}\left(\frac{1-1}{10}, 31\right) \quad \mathrm{P} 32_{1}:=\operatorname{Pdin}\left(\frac{1-1}{10}, 32\right) \quad \mathrm{P} 33_{1}:=\operatorname{Pdin}\left(\frac{1-1}{10}, 33\right) \\
& \mathrm{P} 34_{1}:=\operatorname{Pdin}\left(\frac{1-1}{10}, 34\right) \quad \mathrm{P} 35_{1}:=\mathrm{P} \operatorname{din}\left(\frac{1-1}{10}, 35\right) \quad \mathrm{P} 36_{1}:=\operatorname{Pdin}\left(\frac{1-1}{10}, 36\right) \\
& \mathrm{P} 37_{1}:=\operatorname{Pdin}\left(\frac{1-1}{10}, 37\right)
\end{aligned}
$$

PRNPRECISION $=6$

$$
\begin{aligned}
& \text { qest := "qest.dat" } \quad \text { WRITEPRN(qest }):=\mathrm{F}_{\text {est }} \\
& \text { WRITEPRN(vento1) }:=\text { P1 WRITEPRN(vento2) }:=\text { P2 } \\
& \text { WRITEPRN(vento3 ) := P3 WRITEPRN(vento4) := P4 } \\
& \text { WRITEPRN(vento5) := P5 WRITEPRN(vento6) := P6 } \\
& \text { WRITEPRN(vento7) := P7 WRITEPRN(vento8) := P8 } \\
& \begin{array}{ll}
\text { WRITEPRN(vento9) }:=\text { P9 } & \text { WRITEPRN(vento10) }:=\text { P10 }
\end{array} \\
& \text { WRITEPRN (vento11) := P11 WRITEPRN(vento12) }:=\mathrm{P} 12 \\
& \text { WRITEPRN(vento13) }:=\text { P13 WRITEPRN(vento14) }:=\text { P14 }
\end{aligned}
$$




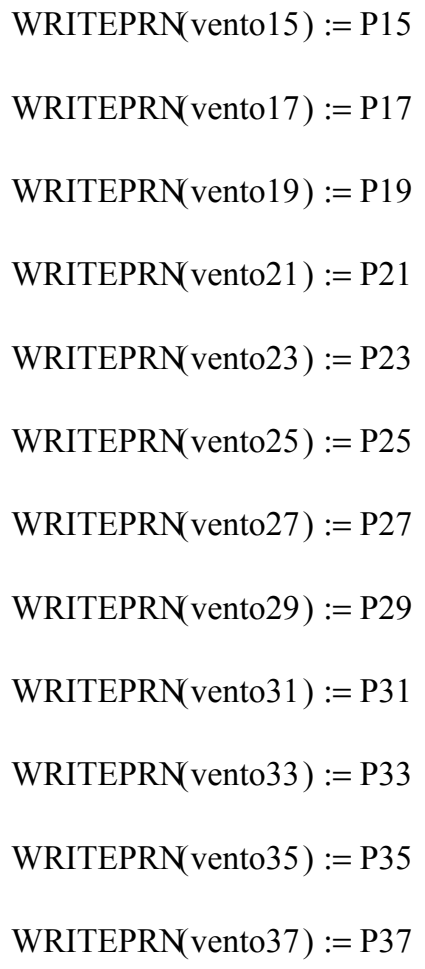

\author{
WRITEPRN(vento16) $:=$ P16 \\ WRITEPRN(vento18) := P18 \\ WRITEPRN(vento20) := P20 \\ WRITEPRN(vento22) := P22 \\ WRITEPRN(vento24) := P24 \\ WRITEPRN(vento26) := P26 \\ WRITEPRN(vento28) := P28 \\ WRITEPRN(vento30) := P30 \\ WRITEPRN(vento32) := P32 \\ WRITEPRN(vento34) := P34 \\ WRITEPRN(vento36) $:=$ P36
}




\section{REFERENCIAS BIBLIOGRAFICAS}

ANTHONY, K.C. The background to statistical approach: the modern design of windsensitive structures. In: SEMINAR AT INSTITUTION OF CIVIL ENGINEERS, London, 1970. Proceedings. London, ICE, 1970. Paper 2, p.17-27.

AMERICAN NATIONAL STANDARD INSTITUTE. Structural standards for steel antenna towers and antenna supporting structures - ANSI/TIA/EIA-222-F-1996. Arlington, Telecommunications Industry Association, 1996.

AMERICAN SOCIETY OF CIVIL ENGINEERS. Minimum design loads for buildings and structure - ASCE 7-95. New York, 1995.

ASSOCIAÇÃO BRASILEIRA DE NORMAS TÉCNICAS. Forças devidas ao vento em edificações - NBR 6123. Rio de Janeiro, 1988.

. Projeto e execução de estruturas de aço de edifícios - NBR 8800. Rio de Janeiro, 1986.

BLESSMANN, J. Aerodinâmica das construções. 2.ed. Porto Alegre, Sagra, 1990

BLESSMANN, J. Acidentes causados pelos ventos. 3.ed. Porto Alegre, UFRGS, 1986.

. O vento na engenharia estrutural. 1.ed. Porto Alegre, UFRGS, 1995.

. Introdução ao estudo das ações dinâmicas do vento. 1.ed. Porto Alegre, UFRGS, 1998.

BRITISH STANDARD. Lattice towers and mast - BS 8100. Part 1. Code of practice for loading. London, 1986.

COOK, N.J. The designer's guide to wind loading of building and structures. London, Butterworths, 1985. Part 1: Background, damage survey, wind data and structural classification.

DAVENPORT, A.G. The application of statistical concepts to the wind loading of structures. Proceedings/Institution of Civil Engineers, v.19, p 449-72, Aug.1961. 
. The treatment of wind loading on tall buildings. In: SYMPOSIUM ON TALL

BUILDINGS, Southampton, 1966. Proceedings. Oxford, Pergamon, 1966. p3-45.

. Gust loading factors. Journal of Structural Division. American Society of Civil Engineers, p.11-34, June 1967.

_. The generalization and simplification of wind loads and implication for computational methods. Journal of Wind Engineering, v.52, p.18-23, Aug. 1992.

- The response of slender structures to wind. In: WIND CLIMATE IN CITIES, Waldbronn, Proceedings of NATO Advanced Study Institute. s.L., s.ed., 1993. n.p.

. How can we simplify and generalize wind loads. Journal of Wind Engineering and Industrial Aerodynamics, v.54/55, p.657-69, 1995.

DEN HARTOG, J.P. Mechanical vibration. 4.ed. New York, Dover, 1985.

EIFFEL, G. Résistance de l'air et l'aviation: expériences effectuées au laboratoire du Champ-de-Mars. Paris, Dunod, 1911.

ENGINEERING SCIENCE DATA UNIT. Characteristics of atmospheric turbulence near ground - Item 74030. Part I: definitions and general information. London, 1976.

. Characteristics of atmospheric turbulence near ground - Item 74031. Part II: single point data for strong winds (neural atmosphere). London, 1975.

. Characteristics of atmospheric turbulence near ground - Item 85020. Part II: single point data for strong winds (neural atmosphere). London, 1987.

. Lattice structures - Item 81027. Part I: mean fluid forces on single and multiple plane frames. London, 1982.

. Lattice structures - Item 81028. Part I: mean fluid forces on tower-like space frames. London, 1990.

EUROPEAN COMMITTEE FOR STANDARDIZATION. EUROCODE 1 basis of design and actions on structures - part 2-4: actions on structures - wind actions. s.L., CEN, 1995. 
FLACHBART, O. Messungen an ebenen und gewölbten Platten. Ergebnisse der Aerodynamischen Versuchsanstalt zu Göttingen, (4) p.96-100, 1932

FLACHBART, O. Wind pressure on solid-walled and framed structures. Mémoires. Association Internationale des Ponts et Charpentes, v.1, p.153-72, 1932.

FRANCO, M. Direct along wind dynamic analysis of tall structures. Boletim Técnico, São Paulo, EPUSP, BT/PEF/9303, 1993.

GEORGIOU, P.N. A study of the wind loads on building frames. London, 1979. 182p. These (Master degree). Faculty of Engineering Science, University of Western Ontario.

GEORGIOU, P.N.; VICKERY, B.J. Wind loads on building frames. In: International Conference, 5., Fort Collins, 1979. Proceedings. Oxford, Pergamon, 1980. v.1, p.421-33.

GOULD, R.W.F.; RAYMER, W.G. Measurements over a wide range of Reynolds numbers of the wind forces on models of lattice frameworks with tubular members. s.L., National Physical Laboratory, 1972. (NPL-Mar-Sci-5-72)

HARRIS, R.I. The nature of the wind: the modern design of wind-sensitive structures. In: SEMINAR AT INSTITUTION OF CIVIL ENGINEERS, London, 1970. Proceedings. London, ICE, 1970. Paper 3, p. 29-55.

HOLMES, J. D. Along-wind response of lattice towers: part I - derivation of expressions for gust response factors, Engineering Structures, v.16, n. 4, p287-292, 1994

HOLMES, J. D.; BANKS, R. W.; ROBERTS, G. Drag and aerodynamic interference on microwave dish antennas and their supporting towers, Journal of Wind Engineering, v.50, p.263-270, 1993.

LAWSON, T.V. Wind effects on buildings. London, Applied Science Pub., 1980. 2 v.

NATIONAL BUILDING CODE OF CANADA. Live loads due to wind. Ontario, NRCC/Canadian Commission on Buildings and Fire Codes, 1995.

RIERA, J. D.;BLESSMANN, J. Respuesta dinâmica de estructuras en dirección del viento, XX Jornadas Sulamericanas de Engenharia Estrutural, Cordoba, Argentina, V.2, p. B8-1 - B8-23, 1979. 
RIERA, J. D.; GALINDEZ E. E. Determinación de la acción dinâmica dél viento en Normas sobre cargas en las construcciones, XX Jornadas Sulamericanas de Engenharia Estrutural, Cordoba, Argentina, V.3,p. B20-1 - B20-25, 1979.

SIMIU, E.; SCANLAN, R.H. Wind effects on structures: fundamentals and applications to design. 3.ed. New York, John Wiley, 1996.

SMITH, B.W. Experience with the New British and European design codes for masts and towers. In: STRUCTURES CONGRESS, New Orleans, 1999. Structural engineering in the $\mathbf{2 1}^{\text {th }}$ century: proceedings. New Orleans, ASCE, 1999. p.958-961

STANDARDS ASSOCIATION OF AUSTRALIA. Minimum design loads on structures (known as the SSA loading code) - AS 1170.2-1989. Part 2: Wind loads. Sydney, 1989.

TAYLOR, A. The relevance to a constructor: the modern design of wind-sensitive structures. In: SEMINAR AT INSTITUTION OF CIVIL ENGINEERS, London, 1970. Proceedings. London, ICE, 1970. Paper1, p.11-5.

TELECOMMUNICATION INDUSTRY ASSOCIATION. Structural standards for steel antenna towers and antenna supporting structures TIA/EIA-222-F (revision of EIA/TIA-222-E). Arlington, 1996.

VICKERY, B.J; KAO, K.H. Drag or along-wind response of slender structures. Journal of Structural Division. American Society of Civil Engineers, n.p., Jan. 1972.

VICKERY, B.J. Wind loads \& design criteria for chimneys. In: US NATIONAL CONFERENCE ON WIND ENGINEERING, 8., Baltimore, 1997. Proceedings. s.L., s.ed., 1997. n.p.

WHITBREAD, R.E. The influence of shielding on the wind forces experienced by arrays of lattice frames. Teddington, National Maritime Institute, 1981. (NMI R113). 